ORPHEUS

Logic of

Experimentation

Rethinking Music Performance through Artistic Research

INSTITUTE 
Logic of Experimentation:

Rethinking Music Performance through Artistic Research 



\section{LOGIC OF EXPERIMENTATION: RETHINKING MUSIC PERFORMANCE THROUGH ARTISTIC RESEARCH}

Paulo de Assis 

11 Preface: A Transdisciplinary Conjuncture

19 Introduction: Experimentation versus Interpretation

\section{Part 1. Assemblage Theory for Music}

41 Chapter 1: Virtual Works-Actual Things Rasch - The limits of music philosophy and the role of artistic research - Music ontologies: some problems - Beyond transcendence: approaching a Deleuzian ontology — Virtual works, actual things: towards a new image of musical work Strata - Rasch ${ }^{25}$....vers la nuit

71 Chapter 2: Assemblage, Strata, Diagram

Musical orks as assemblages - Agencement, logic of assemblage, assemblage theory - Intermezzo: a note on translation From structure to assemblage - Strata — Diagram - Logic of assemblage

\section{Part 2: Experimental Systems in Music}

107 Chapter 3: Experimental Systems and Artistic Research An epistemology for artistic research? - A methodology for artistic research - Hans-Jörg Rheinberger's experimental systems - Thought collective and ensembles of experimental systems: MusicExperiment 21 - Series of experiments and modules of research

123 Chapter 4: Epistemic Complexity in Music Performance Complexity and epistemic complexity - Epistemic complexity in biology - Epistemic complexity in technology - Epistemic complexity in music - Experimentation in music performance: how to make the future? 


\section{Part 3. Beyond Interpretation: Bodies-in-Action}

137 Chapter 5: Transduction and the Body as a Transducer Transduction in music performance: relaying flows of intensities; - Gilbert Simondon's various definitions of transduction Discharge (potentiality); - Passage (time and temporality); - Energy (thermodynamics): potential, scales, entropy - Information theory: structural germs and singularities (structuration) - Haecceity: from haecceitas (Duns Scotus) to eccéité (Simondon) to heccéité (Deleuze and Guattari) to microhaecceity - Topology: in-formation - Corporeality: somatic transduction - Permanent transduction: being-in-the-world and fluctuatio animi; 11 . Conclusion

159 Chapter 6; $\operatorname{Rasch}^{26}$ : The Somatheme

The somatheme - Roland Barthes at the piano: musica practica The impact of Julia Kristeva: phenotext and genotext New musical concepts: geno-song, pheno-song, somatheme Intermezzo: fourteen somathemes - The impact of Jacques Lacan: signifier and jouissance - Lacan's desire - Situating the somatheme within Lacan's graphs of desire - Conclusion: artistic research and transdisciplinarity

\section{Part 4. A New Ethics of Performance}

189 Chapter 7: The Emancipated Performer: Musical Renderings and Power Relations

Music performance and power relations - The dominant image of work and the problem of interpretation - The tacit authorities: Deleuze's "Postscript on the Societies of Control" - Nietzsche's three modes of relation to history: monumental, antiquarian, critical - A new image of work - The emancipated performer

201 Chapter $8 \ldots$ at the borders of time that surround our presence...

What is the contemporary? - Agamben's contemporary: Barthes reading Nietzsche - Nietzsche's untimely: lost in translation ... at the border of time that surrounds our presence ...-Artistic research as the carrier of the contemporary 


\section{Appendices}

217 Appendix 1: Beyond Urtext: A Dynamic Conception of Musical Editing

On notation and time - The urtext era - Urtext editions: an epistemological obstacle - Critical editing of music and different types of editions - Music editing and performance practice: a dynamic conception

225 Appendix 2: The Conditions of Creation and the Haecceity of Musical Material:

Philosophical-Aesthetic Convergences between Helmut Lachenmann and Gilles Deleuze

Helmut Lachenmann and Gilles Deleuze: an unconnected connection - Helmut Lachenmann: toward an aestheticostructural methodology - Helmut Lachenmann's three "theses" on composing - Gilles Deleuze's diagnostic function of art, capture offorces, and body without organs: first convergences with Helmut Lachenmann - Helmut Lachenmann's four conditions of the musical material - Gilles Deleuze's opinion, corporeity, fold, and latitude: further convergences with Helmut Lachenmann - The conditions of creation and the haecceity of musical material: a philosophical-aesthetic Erewhon

\section{Acknowledgements}

249 Index 

I am an experimenter in the sense that I write in order to change myself and in order not to think the same thing as before.

Michel Foucault, 1978

Experimentation on oneself ... is our only identity, our single chance for all the combinations which inhabit us.

Gilles Deleuze, 1977 



\section{Preface}

\section{A Transdisciplinary Conjuncture}

This book was primarily composed in the second half of 2017 and during January 2018, in the final months of the five-year research programme Experimentation versus Interpretation: Exploring New Paths in Music Performance in the TwentyFirst Century (in short, MusicExperiment21), of which it is the last and final outcome. As one of MusicExperiment21's outputs among many others, this book focuses on the musical- and performance-related conceptual achievements of the project. Thus, it is not about the project. It is not its summary, nor is it intended as its theoretical explanation, justification, or foundation. It collects the most relevant conceptual inventions I have made in the last five years, which have a certain autonomy and independence from the various performances, compositions, and installations created, as well as from the other essays and articles generated within the project, which also included texts written by other team members. All those other outputs, which expose the concrete practice of MusicExperiment21, and most of its artistic realisations, are available on diverse media and multimedia formats, such as CD, DVD, LP, and on the web platform Research Catalogue. They exist in a different space of inscription and representation, often conveying fewer conceptual and more sensuous aspects of the project. They are accessible online at www.musicexperiment21.eu, where the interested reader will find connections to and resonances with the ideas presented in this volume.

Significantly, the concepts presented here would not have been articulated without the specific set-up of persons, institutions, and new configurations of systems of knowledge production that created the conditions for the five years of work that finally led to their formulation. Thus, to write about this book, its context, situatedness, and rationale, is to write about MusicExperiment21. This programme, funded by the European Research Council, hosted at the Orpheus Institute, Ghent, Belgium, and led by myself, developed foundational work in relation to the use of diverse notions of experimentation in music, aiming to advance innovative performance practices of Western notated art music. Concluded at the end of January 2018, MusicExperiment21 is being continued and even expanded under the acronym MusicExperimentX. In hindsight, MusicExperiment21 functioned as the first phase in a broader research endeavour bringing together diverse artistic, performative, historical, methodological, epistemological, and philosophical perspectives, contributing to a new attitude and discourse, crucially moving from interpretation towards experimentation. The notion of experimentation is not used in relation to measurable quantifiable phenomena, but rather to a critical willingness to constantly reshape 
thoughts and practices, to operate new distributions of the sensible, affording unpredictable reconfigurations of musical, artistic, social, and conceptual practices. More concretely, the project generated new modes of musical performance, and offered innovative channels for the presentation and dissemination of artistic research in music. It had a transdisciplinary structure, with specific research foci on music performance, composition, musicology, philosophy, and epistemology.

Seen from a bird's-eye perspective, both MusicExperiment21 and this book reflect a specific artistic and academic conjuncture, made of (at least) four components: (1) the emergence of artistic research in the European higher education area; (2) the renewed attention given to music performance within contemporary musicology, music philosophy, and performance studies; (3) recent developments in contemporary philosophy, particularly related to a reassessment of the experimental thought of Gilles Deleuze and post-Deleuzian discourses; and (4) the growing affirmation of practice-driven epistemologies, specifically in relation to experimental science as described by the historian of science Hans-Jörg Rheinberger (1997). Critically, MusicExperiment21 approached this conjuncture not from a purely theoretical point of view but from the perspective of music practitioners, all team members being performers, composers, or artists. Furthermore, this book also reflects the locus where it was conceived and written: the Orpheus Institute, Ghent, its research centre, and its international community of artist researchers.

\section{THE CONSOLIDATION OF ARTISTIC RESEARCH}

In terms of the conjuncture mentioned above, the perspective offered by MusicExperiment21 stresses the possibility of situating artistic practices beyond conventional disciplinary boundaries, making a case for the establishment of a vibrant relation to contemporary philosophical and epistemological debates. This implies a widening of horizons that is indebted primarily to artistic research, an alternative mode of making art and producing knowledge that has gained significant relevance in the last two decades. While there is no universally accepted definition of artistic research, there is some consensus that it describes a particular mode of artistic practice and of knowledge production in which scholarly research and artistic activity become inextricably intertwined. Questioning the boundaries between art, academia, philosophy, and science, artistic research enables the exploration and generation of new modes of thought and sensible experience. Crucially, artistic research is not to be confused with research on the arts, or research on aesthetic matters, or research about the arts. Artistic research is not a subdiscipline of musicology, art history, or philosophy. It is a specific field of activity where practitioners actively engage with and participate in discursive formations emanating from their concrete artistic practice. Artistic research is mostly conducted by artists; however, these artists have the capacity to infuse research with a particular kind of intensity, which comes from the intensive processes they know and daily use while making art. Fundamentally lateral to traditional disciplinary boundaries, artistic research enhances multiple 
ontologies, developing different epistemologies and creating varied modes of presentation. It does not necessarily present objects of conclusive knowledge but rather insists on unfinished thinking, on a permanent fluidity between thoughts and practices, triggering sensible processes as an interplay between conceptual and artistic thinking, between abstract thought and physical engagement with things, materialities, and institutions. Concurrent with the growing recognition of artistic research, recent developments in musicology, philosophy, and epistemology enabled the development of specific conceptual alliances of transdisciplinary nature, which proved to be highly stimulating for MusicExperiment21.

\section{EMERGENT DISCOURSES AND PRACTICES IN MUSIC PERFORMANCE}

The renewed focus on music performance recently observable within the music industry itself, but also in musicological and music philosophical debates since the last decade of the twentieth century, played an important role in the conjuncture that created the concrete operational conditions for MusicExperiment21. On the one hand, the growing availability of primary musical sources (sketches, historical editions, period instruments, recordings, etc.) and the continuous development of sophisticated multimedia tools enabled the emergence of extended performance practices. These practices might include conventional concert renderings as one component, but they crucially enable the creative composition of performances as complex arrangements of diverse and multiple components. On the other hand, music philosophers and musicologists like Lydia Goehr (1992), Richard Taruskin (1995), Carolyn Abbate (2004), and Nicholas Cook (1998) offered fundamental critiques of certain dominant concepts and practices, not only of the work concept and its regulative function but also of the dominance of text-based renderings of highly idealised musical works. A shift to the study of concrete practices of music performance took shape in the late 1990s, leading to the establishment of new fields of inquiry, which centred the discourse on elements of music that might be labelled as operating with, but beyond text. By thinking of music scores as scripts rather than texts, Nicholas Cook proposes a new understanding of performance, opening up perspectives that had been undervalued by text-oriented renderings: "The text-based orientation of traditional musicology and theory hampers thinking about music as a performance art. Music can be understood as both process and product, but it is the relationship between the two that defines 'performance' in the Western 'art' tradition" (Cook 2001, 1). All these developments and renewed attitudes towards musical works and their performances were beneficial for creating the conditions for MusicExperiment21 to emerge. However, it is absolutely crucial to stress the fundamental difference between MusicExperiment21 and all those theoretical constructions. MusicExperiment21 operates on a totally different level, aiming not at analysis or comparison of data (be it scores, recordings, or performances), but at the generation of new and unprecedented sonic events-events that are designed, composed, and performed by its team members, all of whom are highly trained and experienced performers and composers. While the perform- 
ance studies trend established itself as a subdiscipline of musicology (analysing already existing technical objects, ${ }^{1}$ such as scores, recordings, or performances), the endeavour articulated by MusicExperiment 21 is situated in the creative field of artistic research, aiming at the generation of new phenomena relevant to knowledge and artistic development. MusicExperiment21 team members write articles and essays, but regularly go onstage and doubly expose themselves: as bodies in action in a purely performative sense, and as highly informed performers proposing challenging readings of past musical works. Thus, MusicExperiment 21 effectively embodies the turn to the "making of art as research" in music. Its team members not only analyse works or performances done by others but also crucially make them themselves.

\section{EXPERIMENTAL THOUght AND POST-DELEUZIAN PHILOSOPHY}

In philosophy, the last decade observed a profound reassessment of the work of Gilles Deleuze, whose concepts and ideas seem to have productive implications for almost every conceivable field of knowledge and artistic practice. Indeed, the philosophies of Gilles Deleuze, Félix Guattari, Gilbert Simondon, and other authors who had an impact on Deleuze, and the wider field of more recent post-Deleuzian thinkers, have become increasingly relevant to artistic research, acting as a key reference for many artist-researchers, not the least of whom are those involved in MusicExperiment21. Gilles Deleuze's move from interpretation towards experimentation which happened around the composition of Logic of Sense (first published 1969), and his insistence on the creative powers of an experimental attitude towards thought, art, and life ("Experiment, never interpret!" [Deleuze and Parnet 1987, 48]), have been a major source of inspiration to us. But beyond that particular aspect, and on a more structural level, Deleuze's central claim that philosophy is the creation of concepts is probably even more relevant to the appropriations of his thought made by artist researchers. In fact, such a claim reverses a whole philosophical tradition that considers knowledge as the discovery, the recognition, or the rememberance of something prior to our enquiries. Contrary to this view, Deleuze understands concepts as being invented, constructed, and fabricated, as being the result of a process of thinking that generates an event. Considered in this creative mode, concepts become almost literary characters, having their specific history, moment of birth, development, inflections, and death. This dynamic notion of concepts is profoundly connected with the view that thought always starts with an encounter between something and something else exterior to it. To have a thought is to go outside oneself, outside a particular discipline, outside a given system of coordinates, outside socially constructed images of thought. While there is a definite discipline of philosophy and several definite disciplines in the arts, these disciplines can only productively operate by reaching out beyond themselves.

1 On the notion of technical objects, see Rheinberger (1997), and below, in this book, chapter 3, especially pages $113^{-14}$. 
For philosophy, this means an encounter with that which is not philosophy; for the arts, an encounter with that which is not art; for music, with that which is not music (see Somers-Hall 2012, 5). Moreover, as Deleuze and Guattari wrote "even science has a relation with a nonscience that echoes its effects" (1994, 218). This idea resonates with Nietzsche's famous remark that "the problem of science cannot be recognized within the territory of science" (Nietzsche 1999, 5), an observation to which artistic research might contribute with a renewed set of problems and unexpected territories for enquiry. Both MusicExperiment 21 and this book explore practical and conceptual encounters that go well beyond the confines of music, addressing issues that relate to the contemporary situation in performance and in the arts in general, as well as proposing new concepts for performance, such as those of virtual/actual, assemblage, strata, and diagram (Chapters 1 and 2), transduction and micro-haecceity (Chapter 5), somatheme (Chapter 6), the emancipated performer (Chapter 7), and the contemporary (Chapter 8).

\section{NeW EPISTEMOLOgIES-EXPERIMENTAL SYSTEMS}

Another key element for MusicExperiment21's strategic positioning at the crossroads of art, philosophy, and science came from post-Kuhnian epistemological discourses, such as those presented by Ian Hacking (1983), Bruno Latour and Steve Woolgar ([1979] 1992), Steven Shapin and Simon Schaffer (1985), and-most importantly-Hans-Jörg Rheinberger (1997). Beyond their differences, all these authors move away from the hegemony of theory, considering science to function not on a theory-driven basis but rather on a practice-driven one, an aspect that intimately resonates with practice-led modes of artistic research. For them, there is no science "in general," only concrete, ever-changing, and, to a certain extent, unpredictable reconfigurations of matters, connectors, and functions. Hans-Jörg Rheinberger, who is himself interested in the potential usefulness of his thinking for other disciplines, has twice visited the Orpheus Institute during the lifetime of MusicExperiment21 (in 2012 and 2017), including to present a keynote lecture at the Second International Conference on Deleuze and Artistic Research, held at the Orpheus Institute in November 2017, and has contributed an interview (Rheinberger and Schwab 2013) and an essay (Rheinberger 2018) to publications from the project (Schwab 2013, 2017). The appropriation of his findings from the history of science to recent developments in artistic research enabled the development of a creative notion of experimentation, based upon sequential series of research outcomes and performances, which became one of the hallmarks of MusicExperiment21 (see, for example, the series Rasch, which has had twenty-five instantiations so far, its twenty-sixth being Chapter 6 of this book). This effective hybridisation of research strategies (from life sciences to artistic research), and its intrinsic search for future possibilities of the materials at hand, seems to confirm Rheinberger's statement that "the minds of inventors and scientists, much like those of artists, are not oriented toward recognizing what exists; they 'turn more upon future possibilities, whose speculations and combinations obey an altogether different rule of order, described here as a 
linked progression of experiments composing a formal sequence" (Rheinberger 1997, 8o, interpolating quotation from Kubler 1962, 33).

\section{The Orpheus Institute}

Finally, some words about the place where this book was written. I have been associated with the Orpheus Institute since 2008 , first on a remote and sporadic basis, then, since 2013 , as a fully affiliated member of its faculty and research centre. The Orpheus Institute is a pioneer and leading centre for artistic research in music, providing postgraduate education for musicians since 1996, and operating a world-leading research centre since 2008. Its absolute commitment to innovative modes of musical practice and research, and more specifically its embracing of "music experimentation" as its core research focus for the period 2010-17, were fundamental triggers for the design, definition, and unfolding of MusicExperiment21. Without the Orpheus Institute and the invaluable discussions with its international community of artist researchers, MusicExperiment21 would not have happened and this book would not have been written. This book is not about abstract ideas or aprioristic concepts and definitions. On the contrary, it is the result of the most concrete work with the basic materials of music-making (scores, editions, instruments), and of a substantial series of debates, rehearsals, performances, recordings, and writings. While composing the chapters and organising their sequence, I frequently experienced two complementary sensations: that of writing about results and findings from the past five years, on the one hand, and that of laying the foundations for the future, of opening avenues for work to come, on the other. In this sense, this book functions as a pivotal achievement, summarising work already done and paving the way for upcoming research activities and even more challenging performance practices.

\section{REFERENCES}

Abbate, Carolyn. 2004. "Music-Drastic or Gnostic?" Critical Inquiry 30 (3): 505-36. Cook, Nicholas. 1998. Analysing Musical Multimedia. Oxford: Oxford University Press.

. 2001. "Between Process and Product: Music and/as Performance." Music Theory Online 7 (2). Accessed 18 December 2017. http://www.mtosmt.org/issues/ mto.01.7.2/mto.01.7.2.cook.pdf.

Deleuze, Gilles, and Félix Guattari. 1994. What Is Philosophy? Translated by Hugh Tomlinson and Graham Burchell. New York: Columbia University Press. First published 1991 as Qu'est-ce que la philosophie? (Paris: Minuit).

Deleuze, Gilles, and Claire Parnet. 1987. Dialogues. Translated by Hugh Tomlinson and Barbara Habberjam.
New York: Columbia University Press. First published 1977 as Dialogues (Paris: Flammarion).

Goehr, Lydia. 1992. The Imaginary Museum of Musical Works: An Essay in the Philosophy of Music. Oxford: Clarendon Press.

Hacking, Ian. 1983. Representing and Intervening: Introductory Topics in the Philosophy of Natural Science. Cambridge: Cambridge University Press.

Kubler, George. 1962. The Shape of Time: Remarks on the History of Things. New Haven, CT: Yale University Press.

Latour, Bruno, and Steve Woolgar. (1979) 1992. Laboratory Life: The Construction of Scientific Facts. Princeton, NJ: Princeton University Press. First published 1979 as Laboratory Life: The Social Construction of Scientific Facts (Beverly Hills, CA: Sage). 
Nietzsche, Friedrich. 1999. "The Birth of Tragedy." In The Birth of Tragedy and Other Writings, edited by Raymond Geuss and Ronald Speirs, translated by Ronald Speirs, 1-116. Cambridge: Cambridge University Press. First published 1872 as Die Geburt der Tragödie (Leipzig: Fritzsch).

Rheinberger, Hans-Jörg. 1997. Toward a History of Epistemic Things: Synthesizing Proteins in the Test Tube. Stanford, CA: Stanford University Press.

. 2018. "Transpositions: From Traces through Data to Models and Simulations." In Schwab 2018, 215-24. Rheinberger, Hans-Jörg, and Michael Schwab. 2013. "Forming and Being Informed: Hans-Jörg Rheinberger in Conversation with Michael Schwab." In Schwab 2013, 198-219.
Schwab, Michael, ed. 2013. Experimental Systems: Future Knowledge in Artistic Research. Orpheus Institute Series. Leuven: Leuven University Press. , ed. 2018. Transpositions: AestheticoEpistemic Operators in Artistic Research. Orpheus Institute Series. Leuven: Leuven University Press.

Shapin, Steven, and Simon Schaffer. 1985. Leviathan and the Air-Pump: Hobbes, Boyle, and the Experimental Life. Princeton, NJ: Princeton University Press.

Somers-Hall, Henry. 2012. Introduction to The Cambridge Companion to Deleuze, edited by Daniel W. Smith and Henry Somers-Hall, 1-12. Cambridge: Cambridge University Press.

Taruskin, Richard. 1995. Text and Act: Essays on Music and Performance. New York: Oxford University Press. 



\title{
Introduction
}

\section{Experimentation versus Interpretation}

\author{
BEYOND REPRESENTATION: PERFORMANCE AS \\ PROBLEMATISATION
}

The performance of Western notated art music is usually associated with the notions of execution, recitation, transmission, reproduction, or interpretation, relying on the existence of a commonly accepted, sedimented musical text, and on a set of stabilised conventions that regulate the communication between composer, performer, and audience. From this perspective, performance is the moment for the concrete sonic representation of an already known sound structure. This book challenges this view, proposing a different perspective, understanding performance first as a space of problematisation, not of representation. It proposes a critical stance on the diversity of the available musical sources and materials, stressing their epistemic complexity and their potential for productive reconfigurations, suggesting new modes of creatively operating with them. Moving beyond the work concept, the book presents a new image of musical works, based upon the notions of strata, assemblage, and diagram, and proposing innovative practice-based methodologies that integrate archival and musicological research into the creative process leading to a performance. This view is not primarily intended as a rejection of interpretation, but as a movement towards a space of problematisation that is situated beyond interpretation, and that might include interpretation as one component of its fabric. Thus, my effort is to push interpretation into post-interpretation. It is, however, important to make clear that post here is to be understood neither as an epochal category, nor simply as chronologically following interpretation, but rather as a rupture and a beyond that continue to entertain relationships with interpretation. It involves subjecting the traditional relationship between music and interpretation to a critical reconsideration. This critical deconstruction of interpretation creates a productive tension with representational models, which resist change, and it is a proposal for critical renderings infused by research and inventiveness. Musical practice becomes primarily a critical act, allowing performances to be critical studies of the works performed, significantly in, by, and through the means of performance itself. In this sense, performance gains a supplementary dimension, and can be thought of as an independent form of art: independent of works of music, of supposedly uncorrupted traditions, and of idealised reconstructions of past practices and instruments. Consequently, this view also argues for a new kind of performer, emancipated from authoritative texts and traditions, and open to 


\section{Introduction}

critical reconfigurations of past musical objects, which ought to be questioned rather than uncritically reproduced and consumed. More than an executant or an interpreter, the performer becomes an operator, ${ }^{1}$ activating unexpected assemblages of forces and materials, and overcoming the distinction between performer and composer. Beyond representational modes of performance- be it mainstream or historically informed performance practices-this book aims at creating an ontological, methodological, and ethical space for experimental performance practices, suggesting a new mode of performance that is sustained by thorough research and driven by inventive imagination. Music performance becomes both a critical and a constructive act: critical in the sense that it renegotiates the boundaries of pre-existing knowledges and practices, constructive in that, through practice, it creates anew its own conditions and materialities.

\section{EXPERIMENTATION}

Experimentation is the key concept to operate the intended shift from representation to problematisation. While representation in music is fundamentally tied to the notion of musical interpretation, to the permanent discovery or rediscovery of previously unnoticed qualities of a pregiven, well-defined musical work, an approach that fosters problematisation must remain open and flexible in terms of its starting objects of inquiry (which are not seen as pre-existing the inquiry itself, nor as well defined in advance), but also in terms of methods, outputs, and modes of communication - in a word, a problematising approach must remain experimental. To avoid any possible misunderstanding, I want to clarify straight away that this book is neither about experimental music nor about the realisation of measurable experiments, made with the purpose of supporting a given theory or hypothesis. What was known in the 1950s, 1960s, and 1970s as experimental music generically referred to compositional practices that consciously intended to be situated outside dominant modes of music production and reception. ${ }^{2}$ It was a term coined, and mostly used by composers and critics, who saw its potential to overcome academicism and any form of rigidity of thought. Its focus was the production of new, experimental compositions radically departing from mainstream compositional approaches, and of performances thereof. My research endeavour is completely different in that it focuses on performance, aiming at establishing an experimental regime for the performance of any past musical work, critically including pieces that have not been consciously composed to be "experimental." Only on a higher level of thought is there a common thread to these two positions: they both aim to criticise, challenge, and deconstruct prevailing practices and concepts through concrete musical practice: through the making of new pieces in the first case, of innovative performances in my case. On the other hand, the notion of experiment in music-understood as the realisation of tests in order to confirm or deny certain theories or hypotheses- has

1 For further substantial consideration of the notion of a musical operator, see D’Errico $\left(2018,125^{-27}\right)$.
2 For a short, yet thorough introduction to experimental music, see Gilmore (2014). 
gained visibility within the musicological subfields of performance science and performance studies, at least since the 1990s. In his essay "From Experimental Music to Musical Experiment," Frank X. Mauceri $(1997,193)$, distinguishing between the use of the word experiment as a historical or stylistic category and its use in science, states: "Experiment is a technique by which evidence is gathered in support of a theory. It is a method that tests hypotheses." This might be relevant for musicologists interested in data collection, measurement, and external observation of performances, potentially leading to new insights into performance practices, past and present. But again, this has nothing to do with the aim and topic of this book, which is centred on the constitution, definition, and critical presentation of an aesthetico-epistemic set of references, enabling the emergence of spaces of experimentation in and for performance.

\section{EXPERIMENTAL THOUGHT AND PRACTICE}

The notion of experimentation that lies at the origin of this book is one concerned with creating the conditions to overcome representation and interpretation in music performance. Crucially, it does this not through negativity, nor by criticising or overtly rejecting those notions, but positively, by proposing conceptual tools for open-endedness, for a research practice that, without knowing or foreseeing its precise outcome, still knows enough to want to embark on a process that has the potential to move practices and thoughts towards something different. Particularly in relation to artistic research, experimentation permits communication between heterogeneous systems, creating new couplings between diverse materials that are rigorous rather than accidental—even if they are indeterminate. An experimental method follows neither the arrangement of structures nor the transformation of structures into other structures, but makes transversal modes of communication thinkable and materially graspable. Such a notion enhances several experimental approaches, including experimental musical practices, experimental modes of writing, and an "experimental thought," going beyond disciplinary, methodological, and institutional boundaries, which are crossed transversally. Inter-, trans-, or anti-disciplinary strategies are embraced not to deny existing disciplines, but rather to redefine the starting discipline, and productively come back to it with new tools. At the core of this perspective lies a profound willingness to reshape thoughts and practices, to operate new distributions of the sensible, affording unpredictable reconfigurations of musical, artistic, and conceptual practices. This search is not primordially motivated by a quest for newness, or for unprecedented results, but first by a will to extend, enlarge, and, if possible, reconfigure the field of the visible, of the utterable, and of the audible. Such an endeavour implies a break, a suspension, and an overcoming of the given parameters of specific aesthetic and conceptual practices. In this sense, my own activity as a practitioner and as a researcher emerges within a field of aesthetico-epistemic experimentation. It is aesthetic because the kind of performances I propose must and can be assessed in aesthetic terms; epistemic because they claim to take part in a broader discourse that contributes to the production, discussion, and transmission of knowledge; and, finally, experimental 
because they are open to the creative exploration of inconsistencies in the materials and concepts of my own practice.

At the very foundation of this perspective, one arrives at the necessity of changing oneself, of becoming something different, of not being reducible to an imprisoning "I am" that undermines so many other possible selves. It is precisely in this sense that my research in general and this book in particular strongly relate and are deeply indebted to the philosophical work of Michel Foucault and Gilles Deleuze. The double epigraph at the front of this book makes it explicit, referring to the fundamental multiplicity of the $I$ as a source of inventiveness and creativity. In an interview from 1978, Foucault (2001, 240) affirms experimentation as a mode of writing and thinking that enables us "not to think the same thing as before"; while Deleuze, in 1977, directly addresses the infinite larval selves that populate our brain and body, which diverse systems of codes and rules try to repress and keep silent, and to which experimentation offers a liberating way out: "experimentation on oneself ... is our only identity, our single chance for all the combinations which inhabit us" (Deleuze and Parnet 2007, 11). In place of interpreting an idealised and uncorrupted $I$, both Foucault and Deleuze propose the notion and practice of experimentation, disclosing the positivity of the split ego as an opportunity for new modes of affect and rhizomic interconnection. This obviously relates to the notion of schizoanalysis developed by Deleuze and Guattari in Anti-Oedipus in 1972 (see [1977] 1983), which focuses on the concrete, material, and machinic operations of the unconscious, insisting on their creative power rather than on their unhealthy function, which Freud thought was a problem requiring therapy. Instead of therapy, schizoanalysis suggests infinite modes of experimentation, offering innumerable possibilities to understand how desire produces the real. Experimentation, thus, concerns the emergent fractality of the unconscious and the immanent plurality of the $I$. It is in this specific sense that experimentation is so crucial, so fundamental, and so promising for artistic research.

\section{LOGIC OF EXPERIMENTATION}

Experimentation fosters communication between systems that might be heterogeneous and full of inconsistencies. Nonetheless, when communication occurs - when the "dark precursor" (Deleuze 1994, 119) opens a productive path for energetic transfer-what emerges in the world as the result of artistic action does have some kind of "sense." It defines certain sorts of intensities, events, structures, and entities that can become objects of thought. What was factually unforeseeable a priori becomes somehow graspable a posteriori. There seems to be some kind of "logic" that enables the articulation of thought, creation, and events. Such logic cannot be prior to experimentation itself; it is only a secondary form that accounts for the links, connectors, and relationships at work within the experimental field. This logic is neither exterior nor prior to the experimental system; it is not a formal logic. It relates to the network of distributed structures and encounters generated by concrete clashes between things, actions, and concepts. Even if one cannot be sure of the outcomes of such clashes, one 
can describe where and how they have reverberated. It is not about revealing a closed logical consistency, but about challenging thought through problematic conjunctures, bifurcations, hybridisations, contradictions, and paradoxes that, despite everything, still "make sense." The logic behind this sense is not necessarily rational; it can actually include irrational and aberrant components, as long as they are not arbitrary. When something anomalous appears in a given system, it enables the formation of a new synthesis, of new conjunctures, thus, of new sense. Critically, for artistic research, any productive practice can only make sense if it also generates sensations, if it directly addresses the nervous system, overflowing and traversing it before cognition happens and before meaning is discerned. Sensation is the immediate encounter of a force with a body exterior to it. Sensation affects bodies, effectively impinging on them and moving them into new configurations. In art, sensation shifts attention from formal aspects of the artwork to the nature of its encounter with other bodies. In short, sensation concerns a vital movement of matter upon matter, taking place before the brain captures it. Yet, here too, there is a logic at play. It might be a logic of the non-discursive, a logic of intensive (thus, non-verbal) forces; nevertheless, it is a logic. Experimentation also constructs its own logic, a logic of experimentation, which is precisely situated between a logic of sense and a logic of sensation. It creates new sense and new sensations, productively including sense and nonsense, under-sense and paradoxes, defined and dividual bodies, discursive and non-discursive signs, rationality and irrationality, precise calculation and unpredictable results. A logic of experimentation is the contrary of a system designed to replicate experiments and tests; it is more like an "apparatus of capture" employed to capture colours, sounds, vibrations, forces, and intensities. It deals with matter and materialities, always starting from concrete practices that are exerted upon concrete objects and things. It articulates thought and corporeality beyond interpretation, beyond linguistic games, and beyond hermeneutics. In it, the actual body of the practitioner (the artist researcher), with its constituted $I$, coexists with its virtual (yet really existing), dividual modes of existence. It is exactly in this tension between the formed body and its infinite compossible formations that lies the force and potential of experimentation in and for artistic research, positively stressing the Lacanian gap between the I and the I. Instead of closing the gap, or of healing the wounds it creates, this can be the locus for the emergence of unprecedented sensations and of unpredictable sense. In this gap, something happens. This is the place where a logic of experimentation starts unfolding.

A major reference in my work for the past ten years has been Gilles Deleuze, and the logic of experimentation proposed in this book implicitly refers to his two logics: a logic of sense, expressed in 1969 in the book of the same name (Deleuze 1990), in which Lewis Carroll and Antonin Artaud play a central role; and a logic of sensation, which is the subtitle of Deleuze's monograph from 1981 on the painter Francis Bacon (Deleuze 2003). These two logics define a space "in between" sense and sensation that is particularly well suited to experimentation. If understood as a practice, experimentation discloses a powerful logic of bodies in action and of actions leading to new thoughts, senses, and sensa- 


\section{Introduction}

tions. It enables experimental thought, which is a possible descriptor of the kind of thinking developed by Deleuze-alone or in conjunction with Félix Guattari-throughout the 1970 os and 1980 os, thought that would lead him away from his early focus on interpretation (with his books on Hume, Nietzsche, Proust, Kant, Bergson, and Sacher-Masoch) to a profound critique of interpretation (starting with Difference and Repetition and Logic of Sense), through a focus on schizoanalysis and politics (with Guattari, since 1970), up until a deep engagement with art and creativity (from Francis Bacon: The Logic of Sensation onwards, including the books on cinema, on the Baroque, and on literature). In the overarching architecture of Deleuze's complete oeuvre, the period between Logic of Sense and Logic of Sensation (1969-81) is the moment of significant conceptual inventions that find profound resonance in the present book. One of them, extremely characteristic of the interplay between sense and sensation, is the notion of body without organs $(\mathrm{BwO})$, which finds its first formulation in the thirteenth series of Logic of Sense (Deleuze 1990, 88), in direct relation to Artaud's original phrasing from 1947 of the corps sans organes (Artaud [1976] 1988, 571), and its very last appearance in the ninth chapter of Francis Bacon: The Logic of Sensation (Deleuze 2003, 72), after which it is subsumed in the notion of figure. The body without organs is the pivotal conceptual invention for the introduction of a visceral corporeal dimension that positively destabilises any linguistic, propositional, or rational logic. It enables a totally renewed relation between thought and body. It articulates the actual body of a person, the body that resulted from ontogenetical, social, and biographical pre-conditions, with its virtual body, the infinite possible and compossible manifestations of that body under precise stimulating conditions. Both bodies coexist in a productive tension that leads to the emergence of previously unforeseen forces and intensities. This is the body that allows art to pass from sense to production, enabling the abandonment of meaning, hermeneutics, analysis, historiography, and interpretation. Writings, paintings, sculptures, compositions, or performances are produced through concrete operations of the body. In the sharp formulation of Anne Sauvagnargues, "sense is an excremental element emitted by the voice and deposited by the hand, and is nothing more than an expelled, physical fragment" (2005, 96, my translation). There is no "superior" sense to achieve, or from which to deduce art objects. Deleuze's logic of sense bypasses any notion of truth, refusing to consider truth as a crucial factor of thought (see Bouaniche 2007, 120). This permits a new philosophical perspective that also rejects the heights of Platonic transcendental Ideas, in favour of a flattened exploration of topological surfaces. This new perspective combines sense and non-sense to express events that happen outside the domain of propositions. Thus, Deleuze's theory of sense is inseparable from a theory of the event (see Bouaniche 2007, 123), which again relates to continuous experimentation and to intensive unfoldings of energies and materialities. This, in turn, is precisely the link to Deleuze's theory of sensation. Sensation is understood materially "as a force that is exerted upon a body, but through modulation, rendering perceptible [those] heterogeneous forces that it captures in a previously unheard material" (Sauvagnargues 2005, 107, my translation). Materiality and the body's work with 
it are the crucial elements for connecting sense and sensation: sense understood as made of sense, non-sense, paradoxes, inconsistencies, and uncertainties; sensation understood as made of impacts, clashes, waves, and invisible/inaudible forces. Their encounter happens through continuous experimentation, and their effect is directly felt in the nervous system through a conjunction of two faces (Deleuze 2003, 34): "Sensation has one face turned toward the subject (the nervous system, vital movement, 'instinct'...) and one face turned toward the object (the 'fact,' the place, the event)." Thus, there is always a coupling of sense and sensation. In order to produce sense and sensation, it is necessary that a force exerts its intensity on a body. Sense and sensation, Lewis Carroll's paradoxes, Artaud's schizo-screamings, and Francis Bacon's hysterical postures are nothing more than renewed expressions of the Spinozan aphorism "no one knows what a body can do" (as translated in Baugh 2010, 36; see Spinoza [1994] 1996, 71). A logic of experimentation precisely addresses this doing, aiming at expanding what a body can do. As such, in its vitalist and reinvigorating dimension toward artistic and aesthetic practices, a logic of experimentation is another mode of affirming the "kind of declaration of faith in life" that Deleuze $(2003,61)$ identified in the paintings of Francis Bacon.

\section{STRUCTURE OF THE BOOK}

Four lines of research lie at the origin of this book. They emerged during the last five years as increasingly central to my own research and musical activities, defining fields of inquiry that broadly establish the starting conditions, the operative modes, and the wider horizon of possible results and consequences of my practice. They have been addressed on different occasions, including in diverse modes of presentation (oral communications, written essays, performances), and are here presented close to one another for the first time, defining the four parts of this book.

Part 1 concerns a fundamental redefinition of musical works, presenting a new image of the musical critically conceived as a fluid multiplicity, and not as a solid monument, thus questioning traditional ontological accounts and arguing for wider ontological perspectives. Moving away from the work concept, and grounded in the notions of strata, assemblage, and diagram, I propose to understand musical works as assemblages, as complex conglomerates of things and intensities, containing innumerable and potentially never-ending additional components, which are continuously rearranged and reassembled in their specific modes of appearance throughout history. More than refuting conven-

3 The proposed neologism is used in this book with a particular meaning. Work appears whenever I am referring to the notion of "work" as it is understood in the classical paradigm (Davies), which is grounded around the work concept (Goehr). To designate the kind of entities that I bring forward in this book-which have the potential to replace this classical notion of work-I propose the notions of assemblage and multiplicity. Thus, when thinking about my new image of "work," it is immediately obvious that it is a new image not of the classical work but of something different. Yet, this difference unavoidably recalls the classical notion, which is still active when conceiving its own dismantling. Thus, by mean the positive and constructive deconstruction of the old term; it is still there, but its foundations are being dismantled piece by piece. In this sense, it is a transient and provisory term. 


\section{Introduction}

tional theories, this notion of assemblage has the capacity to include conventional music ontological accounts as particular cases, as historically situated subsets, which take only a reduced number of parameters into consideration. Those simpler accounts are perfectly functional for musical practices that follow the mainstream notions of work concept, authenticity, interpretation, and textual fidelity, as well as for those other practices that focus on historically informed investigations. Only when one moves beyond historicity and beyond interpretation, entering the realm of more adventurous experimental performance practices, can there be an expanded perspective on musical entities that seems to me to be necessary and inescapable. Importantly, this new view was born out of my practice, resulting from daily work, from material activity and interaction with innumerable sources, documents, recordings, and performative options. All this work demonstrated that traditional ontological views have acted as repressive and limiting frameworks of reference, drastically reducing the accepted horizon of the possible and of the thinkable. Dominant images of musical works had - and still have-an enormous impact on what is performable and how it is concretely performed. They exert a policing control over artistic practices, allowing certain things to happen, and forbidding many others. When music philosophers talk about qualified and fully qualified performances of musical works, they are explicitly excluding several others as not qualified. And they do it based upon obscure syllogisms and highly complex propositions that are used as powerful guardians of an idealised temple of pure works. This is the world of the classical paradigm of music ontology, sharply described on many occasions by David Davies (see, for example Davies 2011, 24), within which the notion of the work concept perfectly operates. However, as long as the critique has not been carried to the heart of that image of work (and not only at the level of its regulative function, as Lydia Goehr importantly did in 1992 [see Goehr (1992) 2007]), it is difficult to conceive of compositions and performances that operate beyond the propositional mode. A new image of musical work, critically replacing work (noun) with work (verb), equals a liberation of practices and performance from those conventional images that imprison them.

Chapter 1, "Virtual Works, Actual Things," presents the basic ontological conditions, concepts, and definitions of this new image of musical Introducing one of my artistic projects- $\operatorname{Rasch}^{X}$, which will reappear at different moments throughout the book-this chapter critically reflects upon existing musical ontologies, exposing their limits and the way in which they impose specific modes of conceiving and performing past musical works. Next, after an introduction to Gilles Deleuze's basic ontological commitments, it describes musical orks as consisting of innumerable component parts, as a collection of heterogeneous elements, and, at the same time, as being full of intensive connectors that make those elements vibrate and develop an affective and effective relationship with one another. In this light, musical are fundamentally reconceived as having properties that are actual, and capacities that are real but not necessarily actual, even if they are not being exercised in a specific hereand-now of performance, listening, or reflection. Musical are then seen as having two main basic parts: actual things, which are to be found in the actual 
world (sketches, manuscripts, editions, theoretical essays, recordings, performances, etc.), and virtual diagrams, highly individual abstract constructions based upon particular singularities, which enable us to think about those

Chapter 2, "Assemblage, Strata, Diagram," introduces the notion of assemblage, which is situated within a complex ecology of several other concepts. It addresses the notions of agencement, strata, and diagram, revealing them as central conceptual operators for an understanding of musical as assemblages. I describe the path that led to the historical emergence of such concepts, placing them within a crucial move away from structuralism and phenomenology, and directed towards far-from-equilibrium complex systems. The chapter includes references to other disciplines-geology, paleo-anthropology, and linguistics-as well as a note on the problems of translating the word agencement.

Together, these two chapters define a new ontology of musical orks, an ontology that is better described as a "becomology," or as an "onto-genealogy, focusing on the ontogenetical properties of any given musical artefact.

Part 2 deals with epistemological questions, mainly related to a quest for innovative methodologies for artistic research in music. If Part 1 investigated what kind of objects we are willing to accept and to produce in artistic research, Part 2 moves the focus of attention toward the kind of epistemological operations we exert upon those objects: how can we know them? How can we reduce their epistemic complexity while keeping their full intensity? Which of their characteristic properties must we operationally retain, eliminate, or transform? What kind of daily praxis can we develop that is adequate to the new image of as assemblage? These questions imply a search for an allagmatics of artistic research. ${ }^{4}$ More than disclosing structural traits and properties of the objects under investigation, this new perspective enables an understanding of how those properties came into being: "a structure is the result of a construction, and an operation is that which makes a structure appear, or that which modifies a structure" (Simondon [1954-58] 2013, 529, my translation, my emphasis). Through this shift of focus from a theory of laws and axioms to a differentiated system of operative functions, an epistemology of the concrete takes shape. Simondon's doctoral thesis (from 1958) was not published until 1995 (partially) and 2005 (in full). Thus, most of his ideas and concepts had little influence for almost half a century; only in the last decade have they become relevant to philosophers and historians of science. Therefore, and even if Simondon appears to me today to be a central reference for contemporary discourses on science and technology, my starting references for an epistemological account that could suit artistic research came originally from a different source: first, from the work done by

4 Allagmatics is Gilbert Simondon's word for a "theory of operations" that critically moves beyond the search for the generic structures of conventional science and creatively looks for genetic operations. Simondon used the term as the title of the second supplement that was added to the edition of L'individuation à la lumière des notions de forme et d'information prepared by Jacques Garelli in 2005 (Simondon [1954-58] 2013, 529-36). Its original text was found among Simondon's draft manuscripts for his dissertation from 1958. See also Barthélémy (2012, 203). 


\section{Introduction}

the historian of science Hans-Jörg Rheinberger, particularly from his notion of experimental systems (Rheinberger 1997b). Such systems are extremely concrete, defining units of research that operate in a specific time and place, with specific individuals, and under specific social, institutional, technical, and instrumental arrangements. Through their radical concreteness, they indicate that there is no science "in general," only particular, ever-changing, and to a certain extent unpredictable reconfigurations of matters, functions, and operations. Within them, sequences or series of experimental activities take place, replicating and changing conditions, parameters, scales, and observations. Given a research problem, infinite experimental iterations of precisely calibrated experiments generate expected results (predictable), but crucially also generate unexpected ones (unknown). It is through this unexpected and unknown part of the results that science advances. An experimental system becomes a machine for making the future. This epistemology of the concrete was adopted and appropriated for music, functioning as a basic model for the daily practice and routines of my research team and me. This created a unique modus operandi, based upon a precise mapping of the research materials and components in terms of technical objects, epistemic things, space of representation, space of graphematicity, and machines for making the future (on these notions, see Rheinberger 1997b, especially $27-31$ and 223-29).

Chapter 3, "Experimental Systems and Artistic Research," describes these notions and explains how they have been appropriated for musical practice. It offers a compact overview of the notion of experimental systems, making some terminological clarifications, and suggesting modes of appropriating such systems for artistic research. Next, it presents MusicExperiment21 as a thought collective, as an ensemble of experimental systems, and as a proliferating machine, enhancing the generation of differential repetition and the establishment of links and connectors between different projects, both within the project and in terms of the project's integration within a wider research environment such as that of its host institution. In the last section of the chapter, the diversity of aesthetic and research practices is displayed, presenting selected examples from the project's use of series of aesthetico-epistemic experiments, and of specific modules of research, each resulting from a different research method or perspective.

Chapter 4, "Epistemic Complexity and Experimental Systems," discusses the notions of complexity and reduction of complexity, which are mentioned by Rheinberger but not really addressed in his writings. In fact, Rheinberger often reiterates the idea that "reduction of complexity is a prerequisite for experimental research" (Rheinberger 1997a, S245, my emphasis); however, he doesn't address the topic of complexity for the simple reason that his central concern is the concrete experimental situation. Even when he writes that "experimental systems are machines for reducing complexity" (ibid., S247) he does not enter a discussion on what makes and what characterises this complexity or how it can be reduced. Thus, further elaboration of the notions of complexity and of reduction of complexity became inescapable, and Chapter 4 includes extensions to biology, science and technology studies, and computer science. 
While the first two parts are devoted to material objects and things (Chapter 1), strata and assemblages (Chapter 2), and functions and operations (Chapters 3 and 4), Part 3 turns to the performing body, the body-in-action of the musician. This body is not only a measurable form or a quantifiable addition of functions (external or internal). More importantly, it is "a complex relation between differential velocities, between deceleration and acceleration of particles," as Deleuze $(1988,123)$ wrote about the concept of body in Spinoza. It possesses, primarily, the capacity for affecting and being affected by other bodies. It is a dynamic body, affectively and informationally charged. This body will be perceived with that which it makes perceptible in the world, as it proceeds in it at changing paces, step-by-step, point after point. The form or the functional mechanism of a body might be exactly described and minutely registered in a collection of data, but all these numbers and figures will not reveal anything about the effective mode of existence of that body in the world, of its energetic interaction with other bodies. The famous example offered by Deleuze is illuminating: "there are greater differences between a plow horse or draft horse and a racehorse than between an ox and a plow horse. This is because the racehorse and the plow horse do not have the same affects nor the same capacity for being affected; the plow horse has affects in common rather with the ox" (Deleuze 1988, 124). Thus, to think about bodies-in-action in a more stimulating way, one has to turn to their intensive modes of existence (their intensive properties) and to their immanent modes of expression in the world. Bodies certainly do have extensive properties (which are dividable, like weight, length, or volume), but it is their intensive properties (pressure, temperature, density, genetic information, or-crucial to the arts-their will, desire, drives, speeds, and directions) that enable their apprehensibility in the world. The less intense a body is, the less it acts, and the less it is acted upon in the world. The diversity of bodies that we can perceive in the world are, thus, entities bounded in extension but that are generated by invisible processes governed by differences of intensity. ${ }^{5}$ Crucially, intensities are not graspable entities, they are "virtual yet real events whose mode of existence is to actualise themselves in states of affairs" (Boundas 2005, 131). This actualisation, this concrete emergence of extension out of intensive processes, defines the expressivity of matter, things, stars and rocks, animals, individuals, landscapes, technical devices, and works of art. Every intensive process has and generates its own expression, but, critically, "that which is 'expressed' exists only by virtue of its expression" (Young 2014, 118). Contrary to the common-sense meaning of expression as the expression of something that exists prior to the expression itself (an interior world, a subjectivity, a feeling), expression gains a totally different force if understood as the unfolding of an action in the world. Expression, then, is the production of an affect that knows nothing about those producing it; it is the generation of something that didn't exist before its own expression. In this sense, expression always expresses something that could not be expressed in another way. It constitutes itself in that which is being expressed. Thus, we can 5 On the concepts of intensive and extensive properties of matter and organisms, see DeLanda (2010,
$\left.115^{-39}\right)$. 


\section{Introduction}

say with Spinoza and with Deleuze, "you do not know beforehand what a body or a mind can do, in a given encounter, a given arrangement, a given combination" (Deleuze 1988, 125). If one understands ethics not in its restrictive sense of a morality or a code of behaviour but instead as the study of the modes by which different bodies act and interact with each other in the world, then Part 3 of this book is about an ethics of performance focused on the body-in-action of the musician. It is about the performer's capacity to move, to change its speed of movement, to intensify energetic flows, and to establish connectors between fields of forces with different energetic potentials.

Chapter 5 scrutinises Gilbert Simondon's central notion of transduction as a possible way to overcome both subjectivity-based approaches and "scientific" analytical measurements of performance. Transduction refers to a dynamic operation by which energy is actualised, moving from one state to the next, in a process that individuates new materialities. It is Simondon's key concept for understanding processes of differentiation and of individuation in a number of fields, including scientific disciplines, social and human sciences, technological devices, and artistic domains. This chapter appropriates Simondon's concept for performance in general, and for musical practice in particular. It aims at establishing a foundational conceptual layer for a broader research effort that crucially includes performance and composition under the unifying notion of energetic transductive processes.

Chapter 6 is an in-depth exploration of the somatheme, an overlooked concept invented by Roland Barthes in 1975 in an essay on the music of Robert Schumann (see Barthes 1985). The somatheme (somatème), which is presented by Barthes in the plural (somathemes), is defined as describing "the figures of the body" (ibid., 307); it relates to a claimed "second semiology, that of the body in a state of music" (ibid., 312). This is one of the rare texts in which Barthes is quite explicitly opposed to structural, propositional semiology, clearly advocating "a second semiology" (semiotics) based upon intensive processes: "let the first semiology manage, if it can, with the system of notes, scales, tones, chords, and rhythms; what we want to perceive and to follow is the effervescence of the beats [the second semiology]" (ibid.). The first semiology aims to understand structures and propositions (intelligibility), the second to perceive and follow forces and intensities (drives and desire). Moreover, Chapter 6 discusses the relation of the somatheme to Jacques Lacan's graphs of desire, situating music performance beyond verbal articulation, in a territory situated between verbal and non-verbal modes of communication, whereby the unspeakable body-inaction of the performer gains absolute centrality.

Finally, Part 4 proposes a new artistic and social role for the performer of Western notated art music. More than an executant and more than an interpreter, this new kind of performer is understood as a critical and creative operator, exposing in unprecedented ways selected sources and materials related to a given musical piece. Instead of performances of musical works, this new mode of performance offers problematisations of such works, exposing some of the tensions and potential inconsistencies latent in them. Beyond representing a work, the performances 
made by an operator investigate how those works work, suggesting a fundamental move away from musical works (noun) toward the work (verb) of performance. Where an interpreter aims at reproducing the musical work (with more or less faithfulness to a score and more or less subjective expressivity), an operator aims at creating a performative situation that can be regarded as a critical study of that work through the means of performance itself. This implies a twofold displacement in relation to conventional practices. First, it requires an emancipation from the multiple authorities that regulate, control, and police the performance of Western notated art music: composers, musical texts, qualified or even "authorised" performers, teachers and music directors, performing traditions, musicological rectitude, musical structure, even common sense, which is invoked as soon as something slightly different than usual is proposed. ${ }^{6}$ Second, it demands profound knowledge of the existing sources and discourses around a musical work, as well as a sharp sense to detect "symptoms," to grasp in a given work its own immanent points of rupture, its lines of flight, its planes of vertigo, in short: all those inconsistencies point to what is outside the work, to other planes of consistency, planes whose loose structure the operator makes (somehow) perceptible. There is nothing obscure about the operations made, they are always very concrete: a given passage from a score enters into dialogue (or into tension) with a specific text, image, or yet another musical passage; it is not about "hidden" meanings, nor about inscrutable intentions: it is about immediate clashes between different materials, inducing affective responses in the nervous systems of the audience members. On some occasions, the operator might seem close to a composer, but he or she does not aim at producing new "compositions" but rather at problematising existing ones. Some might claim that the kind of performances offered by a musical operator as defined here might be seen as composed performances, similar to composed theatre. Nevertheless, this would reduce these performances to conventional paradigms of reception, restating once again the idea of a work. The specificity of the operator is that he or she works beyond conventional notions of performance, execution, interpretation, and composition, which all merge together in the operator's daily practice and in his or her presence onstage. This practice and presence constitute a critical act against the commonplace and the clichéd, and generate an aesthetico-epistemic space of experimentation, overcoming both interpretation and representation. Moreover, traditional musical interpretation presupposes and constitutes a kind of reality, both artistic and social, which is defined by pre-given images of musical works, and clearly distributed social partitions. The experimental performance practice of a musical operator permits the emergence of other realities, fostering an image of the musical work as a multiplicity, establishing a working methodology that brings together research and artistic skills, and arguing for a new ethics of performance and music reception.

Inspired by Jacques Rancière's The Emancipated Spectator (2011), by Deleuze's short essay from 1990 on societies of control (Deleuze 1995), and by Nietzsche's "On the Uses and Disadvantages of History for Life" (Nietzsche 1997), Chapter

6 For an overview of these tacit authorities, see Dreyfus (2007, 254). 


\section{Introduction}

7 introduces the notion of the emancipated performer, first disclosing the strong power relations implicit in conventional interpretative approaches, then comparing such relations with systems of policing, control, and punishment from the old feudal and disciplinary societies, finally arguing for a critical mode of relating to history and to historical artefacts, which is opposed to what Nietzsche called the monumental and the antiquarian modes of understanding the past.

Starting precisely from Nietzsche's notion of the untimely, Chapter 8 develops reflections on time, temporality, and the contemporary, extending Nietzsche's remarks on history to other concepts, such as Barthes's contemporary, Foucault's actual, Péguy's aternal, and Deleuze's haecceity. All these notions help define a new regime of temporality, a proto-theory of time in which the musical operator can most effectively operate and generate new problematisations of (and at) any given historical time. To live in a given time is to be contemporaneous with it, which is a piece of factual evidence and does not carry any critical stance over one's own presence in that particular time in which we live. Establishing a critique of one's own time is the role of the contemporary, and it is crucial for any single musical operator to develop a sense of it-otherwise the musical operator's contemporaneousness will condemn him or her to historicism. Critically, if distinguished from the contemporaneous of a given historically situated present, the contemporary becomes an ahistorical mode of relating to any given presence. It gains a critical function (on the identity of the present), enabling a clinical glance (symptomatology) at our own time. The present, and our presence within that present, is surrounded and over-layered by a multiplicity of temporalities, which are at work in every single thinkable and experienceable here-and-now, and which are perceptible as otherness or uncanniness. The present is not One, and it is not a stable entity. Like the inner eye of a hurricane, it is a complex arrangement of different temporalities moving at different paces (fast and slow), with different accelerations (strata and becomings), and different temperatures (hot and cold). Problematising the archive, Michel Foucault ([1972] 2002, 147) identified a "border of time that surrounds our presence," a particular zone in which human beings problematise what they are, what they do, and the world in which they live. But this differential critical temporality can also be explored and creatively expanded in relation to the future. The fundamental step is to grasp the extent to which those borders of time are out of phase with the zeitgeist of their present, which they surround and latently threaten. To be at the border of time is to resist the centre, to resist death, servitude, habits, clichés, intolerance, common sense, consensuality, that is, the present. Looking toward the future (and not to the archive), aiming at constructing futures (and not at idealising them), is simply the desire to actualise different configurations of materials, connectors, and affects in a new present, which exists in the present but remains concealed to itself. As the last chapter in the book, wider extra-musical reflections are offered, pushing the discourse towards what is outside disciplinary divisions with the aim of questioning our own presence and our responsibility within any given temporality. It does not aim to close the book; on the contrary, it aims to open it towards 
unknown regions, which are situated "at the border of time that surrounds our presence."

If read in this sequence, from Part 1 to 4 , this book roughly follows a typical philosophical itinerary, moving from ontology (1) to epistemology (2), and to two kinds of ethics, an ethics of the performing body (3) and an ethics of the performer in the world (4). If one adds to these four parts all the available documentation and audio and video recordings of the artistic activities of the MusicExperiment21 project (which is available at musicexperiment21.eu), one would have a "Part 5 " that presents aesthetic achievements and questionings. However, there is another way of reading this book, which is more experimental and more closely linked to the mode of working developed by the project itself.

\section{EVERY CHAPTER, A BOOK}

Every single chapter in this book is a particular instantiation and elaboration of a specific research topic that has been discussed, presented, and sometimes even published in other contexts and on other occasions. It is part of a longer series of outputs on the same theme. Thus, every chapter is like a shoot sharing a common subterranean root with other shoots based upon the same genetic material and pertaining to a common rhizomatic network. At the same time, every single chapter is also constructed as a draft for a future book, the possible start of a tree trunk capable of producing branches, forks, and leaves; or as a linking bough between distinct, yet related trees. In this sense, the highly varied topics presented in this book work simultaneously on a rhizomatic and on an arborescent plane of composition. Subterranean, disparate roots and connectors emerge at the surface as markers and signals of a specific territory and modes of coding. Beyond the opposition between rhizome and tree, this suggests a rhizomic-arborescent model. Trees are more rhizomatic and rhizomes more arborescent than we think. Figure 1 depicts what might normally escape the eye: the delicate inter-twinning of the roots of ten young Scots pine trees.

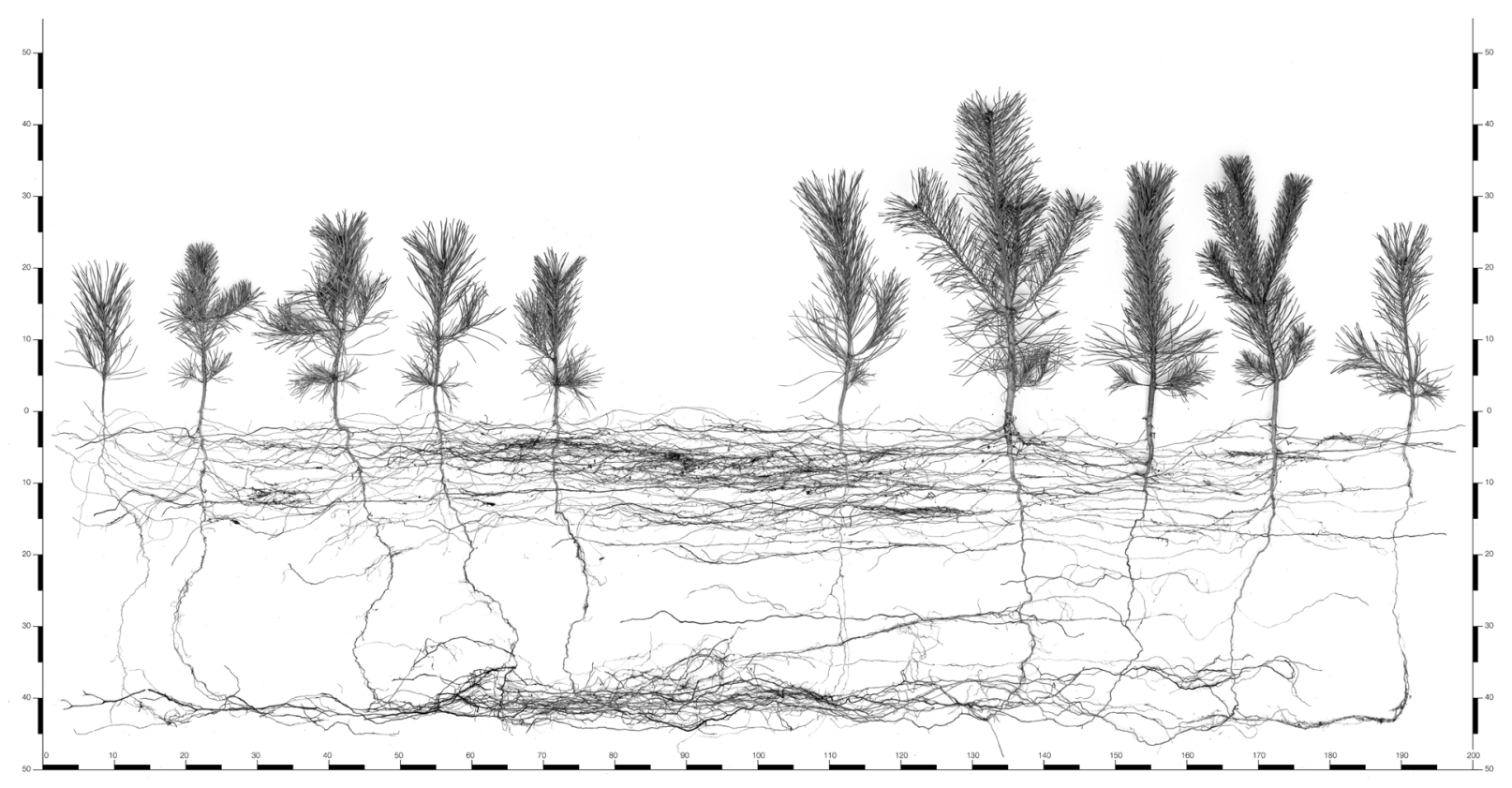




\section{Introduction}

This explains the chapter's highly condensed style of writing, which aims to contain the maximum possible amount of seminal information on its respective topic. In turn, this relates to my artistic practice, which is characterised by series of experiments that take a common set of materials as their starting objects of inquiry; these sets are constantly exposed to ever-changing arrangements, combinations, and reconfigurations. Contrary to conventional music interpretation, which despite admitting and even welcoming a certain degree of variability, rests on a "unique," highly idiosyncratic ideal of personal interpretation, my proposal for performance is to consciously and pro-actively produce differential repetition. To achieve this goal, the same starting materials are presented in a variety of formats and media, including live performances, recordings, CDs, DVDs, oral presentations, lectures, articles and essays, interviews, and web pages. From my point of view, and from my daily work, each of these different modes of expression pertains to the same path and trajectory. They all revolve around the same materials, putting the same questions in different formats and supports. They are like topological transformations of the same topological figure, appearing in ever-changing shapes while keeping the same fundamental questions. Each performance, presentation, installation, or publication coming from a case study defined one more instantiation in a long process of inquiry, being best seen as part of a potentially never-ending continuum. This modus operandi enables an always renewed attention to specific aesthetic and epistemic qualities of a given clash of materials, creating a process of experimentation that doesn't aim-in the first instance-at the generation of solely aesthetic or purely theoretical results. Every instantiation must be assessed locally, in terms of its concrete impact, and yet globally, as part of wider epistemic research. This methodology, which was first devised for work on musical pieces, is here expanded and applied also to conceptual constructions such as the main themes of each chapter in this book. A footnote at the beginning of every chapter provides further details on its positioning in these series of outputs.

\section{TwO APPENDICES}

Finally, this book is complemented with two appendices, which were written nine and seven years ago, respectively. They relate to seminal stages of the research that led to this book, manifesting early attempts to expand musical concepts and practices from dominant modes of thought toward exploratory and experimental perspectives on music editions (Appendix 1 ) and on the relations between a specific take on contemporary composition and selected concepts by Gilles Deleuze and Félix Guattari (Appendix 2). They can be seen as sort of "basic research," which was explored in more practical terms — and in more depth-in the last five years, leading to the kind of performances and the kind of musical thought reflected upon and expressed in this book.

The first appendix, "Beyond Urtext," was written in 2009 as a result of a research project developed at the Orpheus Institute on "the musician's relation to notation." That project followed a period of work on critical editions of contemporary music that allowed me to understand the ephemeral and tran- 
sient character of music editions in general. The essay places the notion of music editing in the realm of history, underlining its fundamental function as a meeting point between the fixed time of the composer and the movable time of the performer. Arguing that critical editions should generate critical users, this paper makes a claim for a new kind of editor and performer. The essay is clearly written from the perspective of a performer obeying the "classical paradigm," and it presents a line of argumentation (especially its conclusion) that has been superseded by my own later research (which moved away from such a paradigm). Nonetheless, it documents an important passage in my musical thought, which moved from forms of textual fixity to more flexible understandings of musical scores and inscriptions. Without this step, rooted in a critical assessment of music editorial practices, my broader subsequent critique of interpretation would probably not have been formulated.

The second appendix, "The Conditions of Creation and the Haecceity of Musical Material" (2011), explores connections between the compositional theories of the German composer Helmut Lachenmann and selected concepts by Gilles Deleuze. It was my first attempt at a Deleuzian perspective on music, looking for resonances between two bodies of work that had never been brought into communication before.

\section{REFERENCES}

Artaud, Antonin. (1976) 1988. “To Have Done with the Judgment of God." In Antonin Artaud: Selected Writings, edited by Susan Sontag, translated by Helen Weaver, 555-71. Berkeley, CA: University of California Press. Written as a radio play 1947-48. This edition first published 1976 (New York: Farrar, Strauss and Giroux).

Barthélémy, Jean-Hughes. 2012. "Glossary: Fifty Key Terms in the Works of Gilbert Simondon." Translated by Arne De Boever. In Gilbert Simondon: Being and Technology, edited by Arne De Boever, Alex Murray, Jon Roffe, and Ashley Woodward, 203-31. Edinburgh: Edinburgh University Press.

Barthes, Roland. 1985. "Rasch.” In The Responsibility of Forms: Critical Essays on Music, Art, and Representation, translated by Richard Howard, 299-312. Berkeley: University of California Press. Essay first published 1975 as "Rasch," in Langue, discours, société: Pour Émile Benveniste, edited by Julia Kristeva, Jean-Claude Milner, and Nicolas Ruwet (Paris: Seuil). Book first published 1982 as L'obvie et l'obtus: Essais critiques III (Paris: Seuil).
Baugh, Bruce. 2010. "Body.” In The Deleuze Dictionary, edited by Adrian Parr, rev. ed., 35-37. Edinburgh: Edinburgh University Press.

Bouaniche, Arnaud. 2007. Gilles Deleuze, une introduction. Paris: Pocket.

Boundas, Constantin V. 2005. "Intensity." In The Deleuze Dictionary, edited by Adrian Parr, 131-32. New York: Columbia University Press.

Davies, David. 2011. Philosophy of the Performing Arts. Oxford: Wiley-Blackwell.

DeLanda, Manuel. 2010. Deleuze: History and Science. New York: Atropos Press.

Deleuze, Gilles. 1988. Spinoza: Practical Philosophy. Translated by Robert Hurley. San Francisco: City Lights. First published 1970 as Spinoza (Paris: Presses universitaires de France), revised 1981 as Spinoza: Philosophie pratique (Paris: Minuit). . 1990. The Logic of Sense. Translated by Mark Lester with Charles Stivale. Edited by Constantin V. Boundas. New York: Columbia University Press. First published 1969 as Logique du sens (Paris: Minuit). 


\section{Introduction}

.1994. Difference and Repetition. Translated by Paul Patton. New York: Columbia University Press. First published 1968 as Différence et répétition (Paris: Presses universitaires de France). . 1995. "Postscript on Control Societies.” In Negotiations: 1972-1990, translated by Martin Joughin, $177^{-82}$. New York: Columbia University Press. Book first published 1990 as Pourparlers: 1972-1990 (Paris: Minuit).

-2003. Francis Bacon: The Logic of Sensation. Translated by Daniel W. Smith. London: Continuum. First published 1981 as Francis Bacon: Logique de la sensation (Paris: Éditions de la Différence).

Deleuze, Gilles, and Félix Guattari. (1977) 1983. Anti-Oedipus: Capitalism and Schizophrenia. Translated by Robert Hurley, Mark Seem, and Helen R. Lane. Minneapolis: University of Minnesota Press. First published 1972 as Capitalisme et schizophrénie: L'anti-Edipe (Paris: Minuit). Translation first published 1977 (New York: Viking Press).

Deleuze, Gilles, and Claire Parnet. 2007. Dialogues II. Translated by Hugh Tomlinson and Barbara Habberjam. Rev. ed. New York: Columbia University Press. First published 1977 as Dialogues (Paris: Flammarion).

D’Errico, Lucia. 2018. Powers of Divergence: An Experimental Approach to Music Performance. Orpheus Institute Series. Leuven: Leuven University Press.

Dreyfus, Laurence. 2007. "Beyond the Interpretation of Music." Dutch Journal of Music Theory 12 (3): 253-72.

Foucault, Michel. (1972) 2002. The Archaeology of Knowledge. Translated by A. M. Sheridan Smith. Abingdon, UK: Routledge. First published 1969 as L'archéologie du savoir (Paris: Gallimard). This translation first published 1972 (London: Tavistock).

. 2001. "Interview with Michel Foucault.” Translated by Robert Hurley. In Power: Essential Works of Foucault 1954-1984, Volume 3, edited by James D. Faubion, 239-97. London: Penguin. Interview conducted 1978 by $\mathrm{D}$. Trombadori and first published 1980 as "Conversazione con Michel Foucault" (Il Contributo 4 [1]: 23-84).
Gilmore, Bob. 2014. "Five Maps of the Experimental World.” In Artistic Experimentation in Music: An Anthology, edited by Darla Crispin and Bob Gilmore, 23-29. Orpheus Institute Series. Leuven: Leuven University Press.

Goehr, Lydia. (1992) 2007. The Imaginary Museum of Musical Works: An Essay in the Philosophy of Music. Rev. ed. Oxford: Oxford University Press.

Mauceri, Frank X. 1997. "From Experimental Music to Musical Experiment." Perspectives of New Music 35 (1): 187-204.

Nietzsche, Friedrich. 1997. "On the Uses and Disadvantages of History for Life." In Untimely Meditations, edited by Daniel Breazeale, translated by R. J. Hollingdale, 6o-123. Cambridge: Cambridge University Press. Essay first published 1874 as "Vom Nutzen und Nachteil der Historie für das Leben," 2nd part of Unzeitgemässe Betrachtungen (Leipzig: Fritzsch, 1873-76).

Rancière, Jacques. 2011. The Emancipated Spectator. Translated by Gregory Elliot. London: Verso. First published 2008 as Le Spectateur émancipé (Paris: La Fabrique).

Rheinberger, Hans-Jörg. 1997a.

"Experimental Complexity in Biology: Some Epistemological and Historical Remarks." In "Proceedings of the 1996 Biennial Meetings of the Philosophy of Science Association; Part II: Symposia Papers," edited by Lindsay Darden. Supplement, Philosophy of Science 64 (4): S245-54.

_.1997b. Toward a History of Epistemic Things: Synthesizing Proteins in the Test Tube. Stanford, CA: Stanford University Press. Sauvagnargues, Anne. 2005. Deleuze et l'art. Paris: Presses universitaires de France. Translated by Samantha Bankston as Deleuze and Art (London: Bloomsbury, 2013).

Simondon, Gilbert. (1954-58) 2013. L'individuation à la lumière des notions de forme et d'information [Individuation in light of the notions of form and information]. Grenoble: Jérôme Millon. Contains texts written $1954^{-5} 5^{8}$. This collection first published 2005 (Grenoble: Jérôme Millon).

Spinoza, Benedict de. (1994) 1996. Ethics. Edited and translated by Edwin Curley. London: Penguin. First published 1677 


\section{Experimentation versus Interpretation}

as Ethica in Opera posthuma (Amsterdam). Press).

This translation first published 1994 in A Young, Eugene B. 2014. "Expression.” In The Spinoza Reader: The Ethics and Other Works, Deleuze and Guattari Dictionary, by Eugene edited and translated by Edwin Curley $\quad$ B. Young with Gary Genosko and Janell (Princeton, NJ: Princeton University Watson, 118-21. London: Bloomsbury. 

Part 1

Assemblage Theory
for Music 



\section{Chapter 1 \\ Virtual Works Actual Things*}

\section{RASCH}

On the evening of 21 November 2017, during the second International Conference on Deleuze and Artistic Research, together with other musicians of the MusicExperiment21 Collective, I I performed a new iteration of $\operatorname{Rasch}^{X}$, an artistic research project around Robert Schumann's set of piano fantasies Kreisleriana $\left(1838,185^{\circ}\right) \cdot \operatorname{Rasch}^{X}$ is a series of mutational performances, lectures, and essays grounded in two fundamental materials: Robert Schumann's Kreisleriana, op. 16, and Roland Barthes's essays on the music of Schumann, written in 1970, 1975, and 1979 (see Barthes 1985a, 1985b, 1985c), particularly "Rasch," a text exclusively dedicated to Schumann's Kreisleriana. To these materials other components are added for each particular version: visual elements, other texts, or further aural elements. ${ }^{2}$ Under the title Rasch ${ }^{25}$. . . vers la nuit, the complete musical score of Schumann's piece was played on a modern grand piano and on an upright piano. Additionally, the performance included pre-recorded sounds and live electronics, as well as video projections of texts, images, and film fragments. The performance had no perceptible beginning: when the doors opened, a sonic and visual installation submersed the listener within a complex, multi-layered texture of film fragments, projected texts, fragments of other piano pieces, and audio extracts from different materials that would reappear throughout the performance. A

* Earlier and partial presentations of the ideas exposed here were made at two conferences and in one publication: (1) as a lecture at the Thirteenth International Orpheus Academy for Music and Theory, Orpheus Institute, Ghent, Belgium, 5 April 2016; (2) as a keynote speech at the interdisciplinary conference Music, Art and Philosophy in Dialogue, convened by Marcello Ruta, Zentrum Paul Klee, Bern, Switzerland, 20 May 2016; and (3) as a book chapter in the collected volume Virtual Works-Actual Things: Essays in Music Ontology (Assis 2018), edited by me, with contributions by Andreas Dorschel, David Davies, Gunnar Hindrichs, John Rink, and Lydia Goehr. I wish to express my gratitude to Lydia Goehr, David Davies, and Lucia D'Errico for their extensive and precise comments on earlier versions of this chapter.

1 The MusicExperiment21 Collective (in short, ME21 Collective) is composed of artistic researchers involved in or collaborating with the research project MusicExperiment21, and is the project's performative extension. It is made up of musicians, performers, composers, dancers, actors, and philosophers, and it has no stable formation. Its modes of communication include not only conventional formats such as concerts, performances, and installations, but also lectures, publications, and web expositions. It has performed in Argentina, Austria, Belgium, Brazil, Germany, Ireland, Portugal, and the United Kingdom. On this particular occasion, the performers were me (concept and piano), Lucia D'Errico (concept, guitars, video and sound projection), Juan Parra Cancino (live electronics and sound projection), and Marlene Monteiro Freitas (dance).

2 An overview of the complete instantiations of the Rasch series is available at Research Catalogue, https://www.researchcatalogue.net/view/64319/64320. A full-length video recording of Rasch ${ }^{11}:$ Loving $^{\circ}$ Barthes $_{[1]}$ can be watched online at https://www.researchcatalogue.net/view/99320/99321. 
recorded reading of Roland Barthes's 1979 essay “Loving Schumann” was diffused over four loudspeakers, and another essay by Barthes-"Rasch," from 1975functioned as a constant, recurrent conceptual layer throughout the complete performance, fragments of which were projected onto the walls or heard through the loudspeakers. At some points, the pianist (me), while scrupulously playing all the notes prescribed in the score, played them in extreme slow motion. At other times, I sustained a chord, or even stopped playing for more than a minute. Other pieces of music were played live or through the loudspeakers at specific moments of the performance: Beethoven's An die ferne Geliebte (especially number 6, "Nimm sie hin denn, diese Lieder"), Ignaz Moscheles's Etude caractéristique pour piano, op. 95, no. 1, Bach's Gigue from the second French Suite, BWV 813, and very short fragments of the Goldberg Variations, BWV 988, and also recordings of pianists like Yves Nat and Vladimir Horowitz playing Schumann's Kreisleriana. Instead of the customary thirty or so minutes of a rendering of Kreisleriana, this performance lasted fifty-five minutes.

Clearly, this was not a performance "of" Kreisleriana, though all its pitches, rhythms, dynamics, and formal proportions were played and faithfully respected. It was also not a performance "about" Kreisleriana, as it had no pedagogical intention of revealing to the audience anything it didn't know before (even if that happened as a side effect). And it was also not a performance "after" Kreisleriana, for the simple reason that the full score was played in an intended mainstream, modern mode of musical interpretation. Significantly, all materials external to Schumann's score, all the various layers that were brought into dialogue with it, were not chosen incidentally or associatively, but rather following a precise and rigorous research process. Every single component of the performance had a close relation to Schumann's piece, whether prior to the composition, as a fertile humus that had an impact on the compositional process, or a posteriori, as reflective exercises directly inspired by the piece. ${ }^{3}$

Kreisleriana, an iconic piece of the mainstream pianistic repertoire, is regarded as well known; thus, normally, there would be many fully qualified ${ }^{4}$ performances and recordings of it. However, as we now know, this is not the case. 5 Not only are there two versions of the score (the first from 1838 , the second from 1850), but also four different editions were printed in the nineteenth century, two prepared by Schumann, the other two by Clara Schumann (see Rostagno 2007,

3 As examples of such materials, one can mention the following: Roland Barthes's essay "Rasch," which is exclusively dedicated to Kreisleriana (see Barthes 1985b); his text "Loving Schumann," which is devoted to more than the German composer as it was first published as the introduction to Marcel Beaufils's monograph on Schumann's piano music (see Barthes 1985a; Beaufils 1979); Beethoven's An die ferne Geliebte, which is literally quoted in Schumann's Fantasie, op. 17 (composed immediately before Kreisleriana), in a passage with close melodic resemblance to the end of Kreisleriana no. 2; Moscheles's piano study Zorn [Anger] that served as direct inspiration for Kreisleriana no. 5 (see Rostagno 2007, 98-102); and Bach's Gigue from the second French Suite, whose rhythmical pattern is exactly the same as the rhythm of the main theme of Kreisleriana no. 8.

4 On the notion of fully qualified performances, see David Davies $(2018,47)$, where he states that "something is fully qualified to play the experiential role in the appreciation of a given artwork $X$ at a time $t$ just in case at $t$ it possesses all those experienceable properties that are necessary, according to the practices of the art form in question, to fully play this role."

5 For details on the two versions of the score, see Antonio Rostagno's (2007) detailed account of the compositional and editorial history of this piece. 
205-8). In the twentieth century, attempts were made to offer the reader a combination of all these disparate bits of information. The result was that, with the exception of Charles Rosen, every single pianist plays the version of 1850 , but does not really play everything as it was notated by Schumann-some possible alternative passages from the 1838 version "infiltrate" these renderings, so that most performances we hear today are of a musical object that was not exactly designed in that manner by the composer. So much for fully qualified illusions. ${ }^{6}$

But, beyond the specific problem of "the score," the question that the performance made by the ME21 Collective raises is of a different nature: what kind of relation is there between all these things-which were part of the performance and have an umbilical relation with the piece-and Schumann's work? What are these things in relation to this piece? In an orthodox ontological account, they have nothing to do with Kreisleriana. Yet, they obviously do have something to do with it. ${ }^{7}$ Ontological questions were not part of the original research plan of MusicExperiment21, and I did not turn to them out of a philosophical will to clarify the nature of my objects of daily work. Nor did I aim at developing a new aesthetic model for the reception of past musical works. More simply, but-I suspect-with deeper consequences, I found myself in a situation where my own practice could not be aesthetically assessed on the basis of existing ontological accounts, and where our ways of working with the materials started suggesting new and alternative views of what a musical work is, which component parts it might have, and how its material constitutive parts allow for the individual and collective construction of an image of work.

Crucially, my mode of operating clearly considers the performative moment as a place for representation not of already known sound structures but of a critical problematisation of the musical objects under consideration. With the project $\operatorname{Rasch}^{X}$, a major breakthrough happened: it seemed to me and my team members that musical works could be considered from a completely new perspective, moving beyond currently available music ontologies, which are based on a representational mode of thinking about musical works. ${ }^{8}$ Is it possible to

6 I am referring here to those ontological accounts that determine a work's qualification solely on the basis of a score or a plurality of scores, per se. This view must be differentiated from other accounts (such as the one mentioned in footnote 4 ), which are less essentialist and that take into account the modalities through which a given musical community frames and receives performance practices.

7 David Davies has pointed out that this statement depends on which particular ontological account I am referring to. As he wrote to me (pers. comm., 15 January 2018): "For a contextualist like Levinson or myself, at least some of the things included in the performance do enter into the work. To cite the most obvious example, the Beethoven passage quoted by Schumann in the earlier piece [Fantasie, op. 17] would be, for the contextualist, partly constitutive of the earlier piece, in the sense that the passage features in Schumann's work as a quotation, and a failure to grasp this is a flaw in a listener's grasp of that piece. Whether this also extends to Kreisleriana will depend, for the contextualist, on how she takes this to itself relate to the earlier piece." In any case, Davies agrees with me in that "even for such a contextualist, most of the things incorporated in to the performance of Rasch would not enter into the appreciation of Kreisleriana as a work.” As an example of relative openness to the inclusion of heterogeneous components into a work, Davies mentions Jerrold Levinson, who "thinks that the ways in which future composers or performers take up elements in a given piece do enter into a full engagement with the latter." I thank David for this precise and important comment.

8 By representation, I refer to the performance of something, or, more precisely, the performance of something as something, which implies the existence of something original, prior to the performance, something that is then rendered perceptible through some sort of representation in the moment of the performance. In this sense, the performance functions as a representation of something exterior to it. Thus, 


\section{Chapter 1}

think about those entities that we usually call "musical works" in another way? Is there another way of conceiving musical renderings of past musical objects? Is it possible to move beyond the classical paradigm of music performance and reception? How could all those materials that are not supposed to be played in a performance, but which obviously relate to a given musical work, be considered as being part of that work? What kind of image of work would that imply? It seemed to me that there are multiple ways of conceiving musical works, and that every specific image of work has implications for its renderings in concerts, recordings, performances, or installations. Thus, to my own surprise, I found myself in the middle of ontological questions, as new views on ontological issues seemed to be necessary. ${ }^{9}$

\section{ThE Limits OF MUSIC PHILOSOPHY AND THE ROLE OF ARTISTIC RESEARCH}

Lydia Goehr's The Imaginary Museum of Musical Works ([1992] 2007), with its profound analysis of the regulative force of the work concept, its historically situated emergence, and its powerful impact on the legitimation of certain musical practices, was a major attempt to break down dominant modes of thinking, particularly in the face of several musical practices that were demolishing concepts and conventions, forcing people to revisit their mental categories, in a period (the late 1980s) where musicians and aestheticians seemed to have no hold on their concepts. Later, David Davies (2011) developed the notion of the classical paradigm, an important construction that aimed at defining the best possible ontological account that could accommodate Goehr's notion of the work concept. Today, almost entering the third decade of the twenty-first century, musical practices are demolishing the ontological establishment even more than in the late 1980s; however, the most recent analytic philosophy tries to make things and musical "works" more transparent, grasping or explaining them better, mapping their position in an overall transcendentally defined territory. Some of the contemporary defenders of music ontologies, such as Andrew Kania (2012) or Julian Dodd (2007), for example, reaffirm the authority of the work, "improving" propositional judgements, but not challenging concepts or practices. Music ontology seems to be caught within dominant conservative views on music, and even conservative views on the world beyond music. Because of this state of affairs, most music practitioners, whether performers or composers, are extremely sceptical of music ontologies, which appear to them to be profoundly

I am not referring to the old aesthetic question of music's "resistance to representation," related to the absence of the signified in musical pitches, rhythms, or formal structures. In any case, music theory and music philosophy have a long tradition of thinking about musical entities in representational terms. As Christopher Hasty $(2010,4)$ has put it, "[even] if music seems to defy representation and has occasionally challenged the claims of representation, music theory has embraced representation as a way of fixing the musical object."

9 This was actually the trigger for the organisation of the Thirteenth International Orpheus Academy for Music and Theory (2016), to which the Orpheus Institute invited Andreas Dorschel, David Davies, Gunnar Hindrichs, John Rink, and Lydia Goehr. A volume containing expanded and revised versions of their contributions has been recently edited by myself and published by Leuven University Press (see Assis 2018). 
sterile and unrelated to their practices. However, practical musicians should be aware that currently existing ontologies have a tremendous influence on what they play and how they are supposed to play it. The argument that ontological judgements have no aesthetic consequences (as claimed for example by James O. Young $[2014-15,1])$ is unashamedly ideological because it aims to reinforce musical practices subsumed under the strong work concept, tamed by authoritative texts and sources, whose production is the property of a caste of privileged musicologists and music philosophers. The way one defines what counts as a work establishes profound constraints on what is considered as acceptable and unacceptable, as possible and impossible, what is allowed and what is forbidden, thus providing the musical market with precise instruments of survey and control. Therefore, ontological judgements, which are a priori judgements, do have empirical consequences-at least in the empirical world of music performance.

According to Lydia Goehr (2001, 601), most philosophical engagement with music has been done by three different kinds of thinkers: (1) by philosophers developing metaphysical systems "in which each subject and type of phenomenon, including music, is assigned its proper place" (ibid.); (2) by "philosophers treating music as one of the arts within their different philosophical systems of aesthetics" (ibid.); and (3) by "musicians-composers, performers, theorists and critics-drawing on and thus contributing to explain the foundations, rationale and more esoteric aspects of their theories, practices and products" (ibid.). ${ }^{10}$ At the same time, several contemporary performance practices, of which those developed by myself and MusicExperiment21 are one example among others, suggest renewed ontological accounts-accounts that come from a fourth group, namely that of performers working in the context of Western art music who are working within a creative and research-based mode of performance. These are artist-researchers, who are proactively contributing to a redefinition of our mental categories, namely in respect of ontological definitions of those entities usually called musical works. I am not saying that our practice "needs" an ontological rooting, nor am I saying that performers long for music ontologies; I am simply saying that the concrete, creative practice of music generates philosophical insights that "pure" philosophy or applied musicology are not delivering. In this sense, it seems to me that the necessary renewal of the ontological discourse will not come from music philosophers, nor from musicologists, but precisely from this new kind of performer, trained and oriented towards artistic research. Through our critical apparatus and creative mode of making music, new images of thought and new images of the musical work are emerging.

In my particular case, and resulting from my work within MusicExperiment21, my ideas developed into music ontological thought, ${ }^{11}$ which is significantly

10 These three kinds of positions are clearly observable in the volume Virtual Works-Actual Things (Assis 2018): Gunnar Hindrichs presents his own metaphysical system and David Davies his own system of aesthetics, while John Rink and Andreas Dorschel centre the discourse on performative issues.

11 I presented draft versions of this proposed ontological perspective in several venues over the last three years. Particularly in 2016, I had the opportunity to discuss these perspectives with many music ontologists, including those present at the Orpheus Academy in Ghent, as well as those participating at the 


\section{Chapter 1}

inspired by the differential ontology of Gilles Deleuze, and which I present in the next sections of this chapter. I proceed in three steps: First (section 3), I point out some of the problems with currently available music ontologies, as they have been discussed in recent years (mostly) by analytic philosophers. Next (section 4), I present some basic components of a Deleuzian ontology as it has been extracted from his writings by post-Deleuzian philosophers. Finally (section 5), I present a novel way of thinking about musical entities, suggesting a new image of work, and, consequently, an alternative music ontology. I would like to emphasise that I do not claim to offer a complete and perfectly finished ontological account, as this would actually be contrary to its fundamental claims.

\section{Music ontologies: SOME PROblems}

To start with, one has to register that currently existing music ontologies are in an impasse, not to say in a deep crisis. In a recent collective volume on the appeal to abstract objects in art ontology generally, edited by Christy Mag Uidhir (2012), Guy Rohrbaugh (2012) enthusiastically opens his chapter (the first in the collection) by stating "we surely live in a golden age for the ontology of art" (29). However, throughout the chapter, he presents us with a series of burning issues that seem to condemn music ontology to irrelevance, even concluding that "an ontology ultimately driven by a description of what it is we already do, as it must if it is to be an ontology of art at all, looks like it will be unable to turn around and informatively explain or justify any of those doings we described.... One might say that there is no such endeavor as the ontology of art" (37). Along the way, Rohrbaugh addresses several problems around pragmatist and deflationist views, comparing various positions, authors, and recent debates, not hesitating to openly discuss critical problems that might endanger the field of music ontology itself. First, he observes that ontologists are motivated to preserve the appearances of dominant practices (32), which remain by and large unquestioned. Second, he identifies a serious problem in the fact that music ontologists are squeezed between traditional metaphysics and traditional musical practices (33), not taking into account alternative or innovative approaches. Third, expressing a dilemma he shares with Jerrold Levinson, Rohrbaugh confesses that "We describe objects that fit our practices to a tee and then proceed to claim that there are such objects. Unfortunately, they are not there. Any number of critics, myself included, have pointed out that the idea of an indicated type does not really make much sense" (33). Fourth, he acknowledges that music ontology often ends up with two discourses: one is obvious, and thus unnecessary; the other is of a hermetic character, and thus highly elitist: "At the object-level, our practices may be recognized as going on just as they do, while our deflationary attitude at the meta-level need only be known to the philosophical elite for whom it matters.

conference "Music, Art, and Philosophy in Dialogue,", organised by Marcello Ruta, which took place at the Paul Klee Zentrum, Bern, Switzerland, 20-21 May 2016. Among the invited speakers were Peter Kivy, Ulrich Mosch, Alessandro Arbo, and myself. 
... But instead of ending up with a picture on which our practices give rise to the very objects of their own concern, we instead end up with, quite literally, nothing" $(34-35) \cdot{ }^{12}$ Thus, what had been announced as living in a "golden age" seems to be more pertinently described as a discipline fading away in a sombre corner of the humanities.

A summary of all existing ontological positions would go beyond the scope of this chapter, ${ }^{13}$ but a very important observation-one that cannot be overlooked-is that the vast majority of music ontologists are philosophers attached to analytic philosophy, focusing on and presenting their arguments principally in logical propositions, to which they claim most forms of human knowledge are reducible. ${ }^{14}$ In the last decade a significant number of philosophers, such as Ross P. Cameron, Ben Caplan, Carl Matheson, David Davies, Julian Dodd, Andrew Kania, Chris Tillman, and Guy Rohrbaugh (among others), have contributed major essays on art and musical ontology, renewing an analytic discourse initiated in the 1960 and continued until the 198 os by music philosophers and theoreticians such as Nelson Goodman, Richard Wollheim, Nicholas Wolterstorff, Jerrold Levinson, Stanley Cavell, Peter Kivy, and Stephen Davies (among others). Despite some considerable differences within this analytic tradition, its problem is that the basic structure of its arguments-so fundamentally concerned with the conditions of identity-is incompatible with the objects it pretends to define and explain (see Butt 2002, 62). Analytic philosophers define the identity of things by the necessary conditions that enable such things to belong to a general category, that is to say, they must have an essence. ${ }^{15}$ It was this kind of analytical landscape that Lydia Goehr, back in 1992, managed to call into question. Her critical perspective primarily addressed not whether musical "works" exist but the particular moment in history when a specific way of conceiving musical works became the regulative force for musical practices. Goehr first and foremost disclosed the regulative function of the work concept, showing its profound historicity. Consequently, and in a second (though

12 Guy Rohrbaugh's ontological arguments have been of personal interest to me, especially his notions of continuants and historical individuals (that he vaguely retrieves from biology and from processes of speciation), which makes his position-among all other currently available accounts- the one that comes closest to my own practice and perspective (even if still with substantial differences). Furthermore, I also share with him his declared scepticism about music ontologies, a scepticism related to the widespread use of philosophical terminology that has lost its connection to the modes of existence of musical works and practices of our day.

13 For a precise and concise description of Platonism, nominalism, fictionalism, perdurantism, endurantism, and eliminativism, see Davies (2018). Another excellent overview of ongoing positions and discussions, including viewpoints from several authors, is the volume Art and Abstract Objects, edited by Christy Mag Uidhir (2012), particularly Andrew Kania's essay “Platonism vs. Nominalism in Contemporary Musical Ontology" (2012). A further recent edited volume on music ontology is Alessandro Arbo and Marcello Ruta's Ontologie Musicale: Perspectives et débats (2014).

14 As David Davies mentioned to me (pers. comm.), analytic philosophers do acknowledge the existence of some practical "knowledge [of] how [to do things], "and many would recognize that some knowledge is irreducibly embodied." For a detailed account of the complex field of analytic philosophy in relation to music, see David Davies's forthcoming essay "Analytic Philosophy of Music," which will be part of the Oxford Handbook on Western Music and Philosophy.

15 In this respect, David Davies (pers. comm.) reminded me that that both Goodman's and Wolheim's writings "explicitly reject the project of defining art, any of the arts, and limit themselves to the more modest task of providing necessary conditions" for the existence of an artwork. 
critical) moment, the work concept itself appears as dependent on a historical point of view. As John Butt (2002, 62-63) expressed it, "In Goehr's account, no analytic theory adequately accounts for the historical boundary of the music that it concerns. ${ }^{16}$... According to Goehr [the work concept] is an 'open concept, allowing for the subtraction or addition of defining characteristics provided that its continuity is assured and that it is consistently recognisable over its period of operation." Goehr was simply trying to get hold of the innumerable musical practices that were obviously incompatible with analytic constructions deprived of any sense of historical situatedness and ideally placed in a world without time and imperfections. As Goehr ([1992] 2007, 86) put it, "The lurking danger remains that the [analytic] theories will probably become forever divorced from the phenomena and practices they purportedly seek to explain.... The problem with the search for identity conditions resides in the incompatibility between the theoretical demands of identity conditions and the phenomena to be accounted for." Moreover, the theoretical abstraction of analytic philosophies is not only divorced from musical practice, it is also completely removed from philological studies, from research on sketches, music editorial practices, changes in execution and interpretation paradigms-in a nutshell, from the complexities of history, and from the concrete, processual, and immanent fabrication of all those documents that enable us to think about "musical works" in the first place.

A second problem with contemporary ontologies has to do with the problem of representation. Despite their profound differences and quarrels, the three main existing umbrella theories-Platonism, nominalism, fictionalism-share a common trait: they are all sustained by a representational model of thought and by representational musical practices. There is always the performance or the listening to of something as something, or the performance of something. Whatever one perceives in any specific here-and-now (a performance, a recording, a description), it is a representation of something else. Platonists insist on the primacy of an original idea and of perfectly encapsulated sound structures (Wollheim's types) that can be represented through performances (Wollheim's tokens, which can be qualified or fully qualified). Nominalists focus on the material entities internal to musical practice, rejecting abstracta but keeping the central assumption of performance as based upon the repeatability and variablity of an immanently generated but clearly well-articulated work, which crucially pre-exists the performance and to which the performance is

16 If one takes into account recent developments in analytic philosophy, a more nuanced formulation could probably be presented. But the point is that such recent developments will take many years until they reach the vast majority of music practitioners and musicologists. And even "nuanced" the core problem remains the same, namely that most analytic philosophers think in eternal qualities and categories, not taking history and historicity as the starting point of the investigations. As David Davies expressed to me (pers. comm.), "I think this is the important criticism of much of the analytic work on music (e.g., Kivy), although it is not true of all the writers you cite [in this chapter]. Levinson, for example, restricts his account of 'what a musical work is' to musical works of a certain period, and recent work by analytic philosophers has been much more sensitive to differences between musical practices. But it is also true that when Lydia Goehr wrote her book [late 1980s], analytic philosophy of music was, for the most part, guilty of the things she charged." 
compared, thus reintroducing a transcendental entity into the picture. For fictionalists there are no works as such, but through their construction of works "as if they existed" they commit-in practical terms-to the same model of performance as presenting (or representing) a pre-given musical entity (even if phantasmatic). They all agree that there are musical works (the exception being the eliminativists), and they all look for "what kind of things they are." However, despite their considerable differences, these three main currents of music ontology further share a common set of fundamental questions that relate to the conditions of identity of musical works: What exactly is a musical work? Are musical works abstract ideas or concrete things? How can a musical work be identified as this musical work? How can an instantiation of a work be considered as adequate, legitimate, or, to use the language of ontologists, fully qualified? In addition to the conditions of identity, these questions also relate to the criteria of judgement of any given appearance of a musical work, thus doubly pertaining to a representational mode of thinking, a mode that is actually of Aristotelian imprint, more than Platonic.

In this double sense, the vast majority of current music ontologies could be seen as actually relying on the Aristotelian world of representation. But this world is umbilically related to Plato's theory of ideas. The very notion of representation implies something prior to it that has the capacity to be represented. As Gilles Deleuze argued in a long section of Difference and Repetition (1994, 262304), the Aristotelian world of representation is enabled first by Plato's theory of ideas, and crucially by its intrinsic moral motivation.

\begin{abstract}
Plato inaugurates and initiates because he evolves within a theory of Ideas which will allow the deployment of representation. In his case, however, a moral motivation in all its purity is avowed: the will to eliminate simulacra or phantasms has no motivation apart from the moral.... Later, the world of representation will more or less forget its moral origin and presuppositions. These will nevertheless continue to act in the distinction between the originary and the derived, the original and the sequel, the ground and the grounded, which animates the hierarchies of a representative theology by extending the complementarity between model and copy. Representation[, thus,] is a site of transcendental illusion. (Deleuze 1994, 265 , my emphasis)
\end{abstract}

While discussing and critically challenging Plato's notions of copy and simulacrum, Deleuze observes - in the conclusion to Difference and Repetition - that from a Platonist perspective the copy can always be systematically distinguished from the simulacrum by subordinating its own difference to a fourfold principle: of the Same, the Similar, the Analogous, and the Opposed (ibid.). According to Deleuze, these strict verifiable correspondences do not per se imply a system based upon representation: "with Plato these instances are not yet distributed as they will be in the deployed world of representation (from Aristotle onwards)" (ibid.). It is in the transition from the Platonic world to the world of representation that "a slippage occurs" (ibid.). As Miguel de Beistegui (analysing and paraphrasing Deleuze's reversal of Platonism) makes clear: 


\title{
Chapter 1
}

\begin{abstract}
It is only superficially that the Platonic method involves dividing something according to its natural articulations, that is, according to genus and species. In other words, the operation of specification, from genus to species and all the way to what Aristotle calls “differences," with which Plato's work is sometimes associated, is only a preliminary step towards a more significant goal. Or, to put it differently, the Aristotelian operation of division and specification is itself an effect of, and a response to, the image of thought that Plato had identified for philosophy. (Beistegui 2012, 59-60)
\end{abstract}

Thus, it was actually after Plato that "the sameness of the Platonic Idea ... gives way to the identity of the concept, oriented towards the form of identity in the object, and grounded in a self-identical thinking subject" (ibid., 61). A "thinking subject" that "brings to the concept its subjective concomitants: memory, recognition and self-consciousness" (Deleuze 1994, 266). In this new representational model, both objects and subjects are taken as being perfectly defined, transparent, and uncorrupted. This is what permits analytical investigations (of the objects, but also of their coded, i.e., linguistic articulations), on the one side, and for phenomenological considerations (of and by the subjects), on the other. The main operation for knowing the world becomes recognition, and difference in thought disappears because, as Beistegui $(2012,61)$ observes, "the image of thought as recognition ... requires the concordance and collaboration of all faculties (perception, memory, reason, imagination, judgment, etc.) in the presentation of the same object, or the object in the form of self-identity. Far from breaking with the doxa, and becoming paradoxical, the dominant image of thought inherited from Platonism solidifies into an orthodoxy, all the more difficult to shake off in that its hidden, underlying presupposition is moral through and through.”

In this light, and strictly in this particular sense, one can appropriate for musical ontology the Deleuzian qualifications regarding the problem of representation in Plato and Aristotle. Surprisingly, the major existing musical ontologies (even those not officially labelled Platonic) can be traced back to Plato's theory of Ideas. The fundamental questions of the diverse music ontologies assume the existence of identifiable and stabilised musical works (be it abstracta or concreta), of uncorrupted subjects capable of immaculately apprehending them, and of a transparent link between a work's written codification and its sonic manifestation in performance. They do not take into account the energetic, intensive conditions and processes of their coming into being, nor the intricacies of their transmission throughout time and history. They rely on a foundational model based upon the notions of original, copy, and simulacra, even if they disagree in the concrete definitions of these notions. And they agree on an ontological partition of the world in genera, species, and individuals, fully adhering to an Aristotelian conception of categories and hierarchies. The danger of falling into scholastic "great chains of being" is lurking at the door. ${ }^{17}$ The difficulty is to overcome rigidly entrenched beliefs, which keep many

17 In this respect, Gunnar Hindrichs writes that "Every ontology manifests a conceptual scheme that articulates the great chain of being" (see Hindrichs 2018, 67, my emphasis). 
positions jailed in the sterile prisons of analytical logic and language games. As philosopher Manuel DeLanda (2012, 223) has put it, "For many analytical philosophers abandoning the categories of the general and the particular is a difficult step because many of them were trained to believe that all of mathematics had been reduced to $\log _{i{ }^{18}} \ldots$.. It is not surprising, therefore, that realist analytical philosophers tend to speak like Aristotle, defining the identity of things by the necessary and sufficient conditions to belong to a general category. In other words, defining identity by the possession of an essence."

This Aristotelian influence is manifest in some music ontological accounts, which explicitly refer to Aristotelian categories to ground their arguments. Curiously, this is particularly observable among the so-called Platonists. Julian Dodd, for example, when discussing norm-types, directly uses arguments from the field of biological species and individuals-his example being the domestic $\operatorname{dog}$ (Canis familiaris), about which he observes that even a dog missing an ear or a leg is still a token of the species (type) dog: "There can certainly be improperly formed tokens of The Domestic Dog (Canis familiaris): albino dogs and dogs missing an ear or a leg are nevertheless tokens of the type. And it is a truism that, just as long as an inscription is sufficiently close to being correctly formed, it counts as an inscription of a certain word, albeit one of which its author should not feel particularly proud" (Dodd 2007, 33). Jerrold Levinson defends a softer version of Platonism, accepting that composers are the "creators" of their own compositions (something that pure Platonists do not accept, instead claiming that musical works exist even prior to being written down, thus being merely "discovered" by composers); in turn, he recurs to the hedgehog as his example: "The creatures we call 'hedgehogs' possess a certain structure and stand in certain causal relations to some particular creatures that came into existence at a given past date ... Musical works ... are indicated structures too, and thus types that do not already exist but must instead be initiated. The same is true of poems, plays, and novels-each of these is an entity more individual and temporally bound than the pure verbal structure embodied in it" (Levinson 1990, 81-82, my emphasis).

Music ontologists, thus, talk about species, claiming them as means to further support their own art theories. As Rohrbaugh $(2012,36)$ wrote, "Orthodox views hold that species membership is a part-whole relation and that species are scattered individuals, perhaps four-dimensional sums." Critically, the problem with these views is that they don't allow, and they actually repress, any thought that could lead to the consideration of concrete and historical individuals as fundamental constitutive parts of musical works. ${ }^{19}$ On the contrary, works become fixed, petrified, and highly reified generalities. Unfortunately,

18 Against DeLanda, David Davies (pers. comm.) claims that he is describing something closer to logicism, a view of mathematics to which "very few analytic philosophers [would] subscribe."

19 In my view, this is the point where Rohrbaugh could have found a way out of the analytic tradition, making a critique of what he just so precisely described. Unfortunately, he continues alluding to the Aristotelian kind of way of thinking about species as scattered individuals whose constitutive parts are individual creatures (his constituants, which have been strongly criticised by music Platonists). Within the ontological account that I propose further down, Rohrbaugh's continuants can find a new mode of existence, independent of transcendent systems and from hierarchical categorisations. 


\section{Chapter 1}

as Rohrbaugh (ibid., 37) puts it, "when one asks, 'What sort of thing is a symphony?' what one really gets in response is just an expression of the speaker's own aesthetic views about what is and is not important about symphonies, in short, ideology." Attempts to emphasise, or simply to propose the centrality of historical individuals, of elements that appear in a precise moment in time, that undergo changes throughout historical time, that disappear or that reappear in another century, are boldly excluded and rejected. This was the case with Guy Rohrbaugh's concept of the continuants, which found resistances so strong that he himself (in a kind of externally induced self-critique) was forced to admit several shortcomings of his own (in my view interesting) formulations. ${ }^{20}$

Thus, if one is aiming at a renewal of ontological discourses, if one wishes to propose and sustain a new image of work, one has to look farther away from the field of available music ontologies. One has to search for something capable of replacing Aristotelian metaphysics, for some sort of "image of thought" that doesn't operate under the rules of the three Aristotelian categories of entities: genus, species, and individual. Moreover, such an image of thought must also overturn Platonism, in the strict sense of readdressing the fundamental distinction between icons and phantasms, between images and simulacra. In a nutshell, it must exclude both categorical hierarchies and idealist transcendence.

\section{Beyond transcendence: approaching a Deleuzian ONTOLOGY}

The poisoned gift of Platonism is to have introduced transcendence into philosophy, to have given transcendence a plausible philosophical meaning. (Deleuze 1998, 137)

If one is looking for some kind of ally in the search for a novel, nonhierarchical, and fully immanent ontology, Gilles Deleuze seems to be one of the best placed philosophers to help us. As is well known, the overturning of Platonism (in the wake of Nietzsche's famous claim) and the overcoming of representation were two of Deleuze's life-long projects, and they are at the very core of his primary thesis for his Doctorat d'État, his famous book from 1968, Différence et répétition (see Deleuze 1994). Deleuze himself did not "officially" write texts specifically devoted to ontological issues, but, as Constantin V. Boundas (2005b, 191) has written, "For Deleuze, philosophy is ontology," and one could even claim that his books (also those co-authored with Félix Guattari) make significant contributions, not to one ontology but to several, multiple ontologies. Crucially, Deleuze's philosophy is one of difference, a difference that remains unsubordinated to identity and to being, rejecting hierarchical categories, and insisting on the profound reality (and realism) of his concepts of the virtual, the intensive, and the actual, which manifest themselves in various assemblages of energies, forces, and tendencies, making the world in which humans and non-humans live.

20 P. D. Magnus $(2012,108)$ even writes that Julian Dodd pronounced an “accusation” against Rohrbaugh's idea that "historical individuals are familiar parts of the world." 
Among other philosophies of difference (such as Derrida's), one must stress the point that while rejecting laws and axioms, Deleuze "offers us principles and methods ... whereas Derrida offers us an ethos and style of writing about difference explicitly resistant to the emergence of principles or methods" (Williams 2013, 27). For someone operating in the creative field of artistic research, which is by definition a constructivist field of activity (as it generates objects or events of artistic nature), a permanent resistance to principles and methods would be counterproductive, if not simply sterile. That's why philosophers like Michel Foucault, Gilles Deleuze, or Félix Guattari are so relevant to artistic research: they offer a possibility for thought and practice outside laws and axiomatic principles, but they also enable the positive fabrication of materialities issuing from intensive processes. "Deleuze's ontology," as Constantin V. Boundas $(2005 \mathrm{~b}, 191)$ makes clear, "is a rigorous attempt to think of process and metamorphosis-becoming- not as a transition or transformation from one substance to another or a movement from one point to another, but rather as an attempt to think of the real as a process" (my emphasis). If the real is thought of as a process, its processuality simultaneously is fed by and generates a continuous flux of forces and intensities, which reveal themselves only in the very moment of their transductive actualisation. These forces and intensities generate forms and matter, but it would be a mistake to think of them exclusively in terms of things and their qualities. Extension and extended magnitudes are only the result of the intensive genesis of the extended. Becoming is not becomingBeing, but a much more complex and elaborated process of permanent actualisation, of endlessly becoming-something-different. Instead of a linear process from one actual state to another, becoming is better conceived as an intensive movement from an actual state of affairs, through a dynamic field of virtual tendencies, to the actualisation of this field in a new state of affairs. ${ }^{21}$

In what follows, I will briefly introduce five key notions that enable us to grasp the ontology of Gilles Deleuze, including the couple actual-virtual, intensity, individual and universal singularities, topological unfoldings, and multiplicities. ${ }^{22}$

\section{Actual/virtual}

The terminological doublet virtual-actual is central to the ontology of Gilles Deleuze, being present in his books and essays since his first published texts on Henri Bergson in 1956. Actual and virtual describe the fundamental domains of Deleuze's differential ontology. According to Anne Sauvagnargues (2003, 22, my translation), "the actual designates the present and material state of things, while the virtual refers to everything that is not currently/presently here (including incorporeal, past, or ideal events)." It is the exchange and communication between the actual and the virtual that enable a dynamics of becoming as

21 For a thorough discussion of the relations between the couple virtual-real and the notion of becoming, see Boundas (2007, 489-91).

22 Other concepts, such as the couple molar-molecular, the dark precursor, the quasi-cause, transduction, or the event are not addressed here for the sake of space, though they are also central to Deleuze's ontological construction. 


\section{Chapter 1}

different/ciation and creation. Primary differences of energy and energetic potentials generate "differentiation" (virtual structure) and "differenciation" (the genesis of actuality). Such dynamics always happen in the form of an event-an event being the individuation of differentiation, and the actualisation of differenciation. One cannot overstress that for Deleuze, both the virtual and the actual are real. As Deleuze $(1994,208-9)$ himself has put it: "The virtual is opposed not to the real but to the actual. The virtual is fully real.... Indeed, the virtual must be defined as strictly a part of the real object - as though the object had one part of itself in the virtual into which it plunged as though into an objective dimension. $\ldots$ The reality of the virtual consists of the differential elements and relations along with the singular points which correspond to them."

Importantly, Deleuze's virtual is by no means to be understood in terms of virtual reality, but, on the contrary, as something absolutely real, that is even actually perceived as tension or inconsistencies in/of the actual, as a diagrammatic reservoir of effectively potential actualisations (some of which will affect the world, some of which not), but that exist in a topological space of possibilities. ${ }^{23}$ Moreover, the distinction between the virtual and the actual is not unilateral, nor is it ontologically black-boxed. This distinction is processual and differential, making the "a priori and the a posteriori ... a product of individuating processes rather than their condition" (Toscano 2009, 389). The virtual-real might lead (under precise, yet unforeseeable transductive conditions) to an actual-real, which in turn (as soon as it emerges-in-the-world) fabricates a new virtual-real. Without resembling the actual, the virtual nonetheless has the capacity to bring about actualisation, and yet the virtual never coincides or can be identified with its actualisation. The virtual is the whole set of forces, energies, potentials, and intensities that exist, that are real, yet that are not actualised in the here-and-now of the present. The actual are all the forces, energies, potentials, and intensities that are currently happening in the here-and-now of our presence. There is no actual without virtual, and no virtual that cannot be actualised.

\section{Intensity}

Both the virtual and the actual appear, then, as the result of concrete energetic processes, involving the passage, the relay, or the transformation of one type of energy into another, crucially establishing a connection between two or more series with different energetic potentials. The virtual does not exist a priori to the intensive processes that generate it; it does not pre-deterministically define the processes of its actualisation (which would imply a kind of neo-Platonism). At the same time, the actual is not an image (a copy) of a pre-existing model, but it emerges progressively as the result of concrete intensive processes of onto- and morphogenesis. Before the definition of any ontological category, there

23 It is in this sense that Deleuze, directly inspired by Bergson, could talk of a past that has never been present (the virtual as immemorial past), and of a future that will never be present (the virtual as a never-attainable messianic future). This link between the couple virtual-real and past-future temporalities prevents any reification of the past (as in Plato's recollection), or of the future (as in some teleological ideologies) as it presupposes non-determining and non-deterministic tendencies. 
are several constantly ongoing ontological processes, which are summarisedin Deleuze's terminology - under the notion of the intensive. Intensive processes generate singularities in the two sides of the real: individual singularities in the actual-real, and universal singularities in the virtual-real. Thus, Deleuze's notion of intensity, the pre-individual relationship between two or more fields with different potentials, gains centrality within his ontological scheme. Intensities are not ontological entities or categories (as the virtual and the actual can be considered to be), they are real events "whose mode of existence is to actualise themselves in states of affairs" (Boundas 2005a, 131).

A thorough discussion of the complex relations between the virtual, the actual, and the intensive would lie outside the scope of this chapter, especially as there have been several attempts to clarify this topic, each leading to significantly different understandings. ${ }^{24}$ Be that as it may, what seems clear from all these different understandings of Deleuze's ontology is that "intensity holds the true key for Deleuze's metaphysical system," as Clisby $(2017,251)$ pointedly summarises. Critically, Deleuze's ontology is an ontology of forces and of actualisations, not an ontology of actualised phenomena. As its object, it takes not the completed form (be it ideal or nominal) but formation itself. In the words of James Williams $(2013,42)$, "Deleuze's view is that no object is fully accounted for through its actual properties since the changes that it has undergone and will undergo, and the differences implied in those changes, must be considered to be part of the object." In this sense, as long as we insist on the existence of well-defined things, Deleuze's position will not be grasped, and his case to overturn Plato and Aristotle will not prevail. With Williams (ibid., 69), one can say that "to be is not to be a well-defined thing with recognisable limits [but] on the contrary, it is to be a pure movement or variation in relation to well-defined things." The process of actualisation does not occur in a vacuum: "at every moment there exists a field of intensity implicated in the explicated objects of experience" (Clisby 2017, 254).

Within a dynamic system, any process of individuation starts from intensity, leading to the emergence of singularities: be it actual singularities, or virtual ones. In the fifth chapter of Difference and Repetition, Deleuze $(1994,247)$ clearly states that individuation precedes and gives rise to actualisation: "Individuation does not presuppose any differenciation; it gives rise to it." Thus, "every differenciation presupposes a prior intense field of individuation" (ibid.). Critically, this "prior intense field of individuation" is a problematic field. There is no transparent nor straightforward correspondence between the prior field of individuation, the field of individuation itself, and the individuated singularity

24 In fact, there is no consensus about the precise placement of these three notions within Deleuze's ontological system. Dale Clisby's recent essay "Intensity in Context: Thermodynamics and Transcendental Philosophy" (2017, especially 250-55) offers a short, yet precise, overview of the three main currently available positions: (1) those that align the intensive with the virtual, which is the (critical) position of Peter Hallward (2006) and Alain Badiou (2000); (2) those that think the intensive as a third ontological domain, as has been convincingly proposed by Manuel DeLanda (2002) and John Protevi (2013), who excavated the precise scientific influences in the writings of Deleuze; and (3) those who consider the intensive as being part of the actual, or as "the being of the actual" as Jon Roffe (2012, as quoted in Clisby 2017, 253) has suggested. 


\section{Chapter 1}

it affords. In all phases and at all moments of the individuating process there are multiple and incommensurable forces playing a complex game of intensive tendencies and unfoldings. Any intensive process is a metastable flux of energetic discharges, potentials, and tendencies. And whereas this differentiation establishes a problematisation, the concrete actualisations of that virtual field express differenciations as the constitution of solutions (by local integrations), leading to the formation of actual things. Such things are formed by different sets of specific individual singularities that are actualised in the here-and-now, in the present. The process of differenciation happens through transduction, changing one type of energy into another, critically leading to the formation of new and unexpected individuations, which contain emergent properties that were not predetermined in advance. These actualisations result in individual singularities, which can be things, objects, or documents, all with two parts: an extensive part (quantitatively measurable and divisible) and an intensive part (qualitatively active and non-divisible). The actual things in the world are thus not just the result of an intensive genesis, as they remain processual, even within their physical constraints. They are never (or only very rarely) petrified in a final state of zero energy. Intensive processes never stop and never come to an end.

\section{Singularities}

From the working together of the notions virtual-actual, intensity, and transduction (or modulation as Anne Sauvagnargues prefers to call it), ${ }^{25}$ one starts grasping the virtual diagrams and the actual things that populate Deleuze's materialist world-a world that radically departs and is totally different from the Aristotelian system of categories. ${ }^{26}$ With the couple virtual-actual and with intensity, we have the ontological domains of Deleuze's system. I will now turn to those entities that Deleuze acknowledges as existing in the world. ${ }^{27}$ For Deleuze, the actual world is populated only by individual singularities that often appear as populations of individual singularities, which exist in different spatio-temporal scales and in different modes of interaction among individual components. The actual world is the world of actual things, and all these things have the same ontological status-thus, no hierarchies, but a flat ontology to start with. As DeLanda (2010, 83) makes clear: "In [Deleuze's] approach all actual entities are considered to be individual singularities, that is, all belong to the lowest level of Aristotle's

25 See Sauvagnargues (2016, especially chapter 4, "The Concept of Modulation in Deleuze, and the Importance of Simondon to the Deleuzian Aesthetic," 61-84).

26 Deleuze's extremely dense critique of Aristotle-which essentially focuses on his concept of difference, and which aims at showing that Aristotle's definition of difference is problematic and misses a deeper understanding of the term-is to be found in paragraphs three to five of the second section of the first chapter ("Difference in Itself") of Difference and Repetition (Deleuze 1994, 38-44). On this difficult passage, see also Williams (2013, 64-68), Somers-Hall (2013, 23-30), and Hughes (2009, 40-42).

27 As this is a notoriously difficult task, I support my inquiry with reference to authors who have already dealt with this topic in great depth. In addition to Constantin V. Boundas, I am deeply indebted to Man uel DeLanda's several accounts of Deleuzian ontology, to Anne Sauvagnargues on its implications for art, and to Arkady Plotnitsky for his invaluable clarifications in relation to mathematics (see Boundas 2005b, 2005c, 2007; DeLanda 2002, 2006, 2010, 2012; Sauvagnargues 2003, 2005, 2013, 2016; Plotnitsky 2006, 2009). 
ontological hierarchy, while the roles of the two upper levels are performed by universal singularities."

Every individual singularity emerges as the outcome of a historical process, it is the concrete result of intensive processes that occur in the world. Every singularity is produced or fabricated in a specific point in time and space. So, for example, atoms of hydrogen are fabricated inside stars; there is no "hydrogen in general," but a concrete population of materially existing hydrogen atoms (DeLanda 2010, 85). Likewise, there is no canis familiaris in general, but rather a population of single dogs, each of which is an individual singularity, unique and unrepeatable (as a simple DNA test can prove). As every individual singularity is unique, special, and remarkable, what deserves attention are not the species but the moment of speciation, that particular moment when something changes state or phase, when a mutation occurs, when a cosmic phenomenon happens. Larger populations of singular individuals define larger individuals, and what matters are those moments when a new species appears, and when it disappears. Species are historical entities that depend on the concrete evolution, transformation, and mutations of all the individual singularities that define them-one individual at a time, one by one. The focus on such ontogenetic processes, on intensive individuations, enables Deleuze to populate reality exclusively with immanent entities, eliminating transcendent ones, such as the essences of Aristotle's two upper categories, genus and species. For Aristotle the world is already divided by general and specific categories that are eternal, unchangeable, and not subject to corruption and decay. For Deleuze, on the other hand, the world of discrete things emerges constantly, as solutions to problems that are defined by conditions that do not determine a result, nor impose consistency. Finally, as DeLanda writes, "as these ontological problems undergo a process of actualization they become progressively differentiated into a multiplicity of actual solutions. This differentiation proceeds in a fully historical way, and may only reveal a portion of the possibility space at a time" (2012, 236, my emphasis). Thus, the Aristotelian categories of the general and the particular (in musical Platonism: the types and the tokens) can be replaced in a Deleuzian ontology by two radically immanent entities: the universal singular and the individual singular.

\section{Topological unfoldings}

Influenced by theories from mathematics and embryology, Deleuze thinks of the actualisations that lead to the individuation of singularities as happening through a sequence of topological unfoldings. In very simple mathematical terms, a topological entity is one that can be folded into another form without losing its identity. As philosopher and mathematician Arkady Plotnitsky (2006, 191) defined it, "Geometry has to do with measurements, while topology disregards measurement, and deals only with the structure of space qua space and with the essential shapes and figures." Differently than in Euclidian geometry, in topological geometry a circle, for example, can be stretched into an ellipse or into a quasi-square without losing its topological identity. A sphere can be compressed into a cylinder, a cone, or a pear-like shape, its topological identity 


\section{Chapter 1}

remaining untouched. In an essay on mathematician Bernhard Riemann (who, together with his teacher Gauss, was one of the inventors of topology), Plotnitsky $(2009,201)$ is very precise about this identity: "Insofar as one deforms a given figure continuously (that is, insofar as one does not separate points previously connected and, conversely, does not connect points previously separated) the resulting figure is considered the same.” However, spheres are topologically different from tori, and they cannot be converted into each other without disjoining their connected points. If one extends these mathematical notions to biology, genetics, and embryology, one can think of the unfolding of an embryo as a matter of topological transformations, or of a vertebrate animal as the result of topological changes and developments. French naturalist Geoffroy Saint-Hilaire thought (at the beginning of the nineteenth century, i.e., before Darwin) that species could be conceived without genera, as transformation (transmutation was his word) from one into the other. This leads to the perspective that the world can be conceived primarily as a continuum of intensity that becomes segmented into species only as certain tendencies are manifested and certain capacities exercised (see DeLanda 2010, 91). These remarks are extremely relevant as we attempt to eliminate transcendent entities from the world. Every single animal or embryo is the result of concrete, immanent, intensive processes, and is absolutely not an "instantiation" of an idea, of a "genus," or of a "species." We need to think of an animal as a topological animal (ibid., 96), which can be folded and stretched into the multitude of different animal species that exist on Earth. Of course, this is only physically possible at the level of the embryos, which are flexible enough to endure these transformations. Moreover, every topological or "virtual" animal must have the capacity to be divergently actualised (leading to concrete divergent individual singularities), and each actualisation must be inheritable with a slight degree of unpredictability. We come close to describing DNA structures, and it is indeed "the structure of the space of possible body plans that replaces the genus 'Animal”' (ibid., 97). The relevant causal agents (chromosomes, genes, genes marking axes of longitude and latitude, cellular populations, etc.) do not operate and act as formal causes, but as efficient causes. As DeLanda highlights, "Aristotelian species like 'Horse' and 'Human' should be replaced by historically constituted species that have the same ontological status as the organisms that compose them, that is, that are individual singularities; and the genus 'Animal' should be replaced by a space of possibilities in which the different body plans are universal singularities, capable of being divergently actualized into a large number of sub-phyla and classes" (DeLanda 2010, 102, my emphasis).

On a higher scale, biological populations of individuals (what we use to call species in common language) are "as singular, as unique, and as historically contingent as individual organisms: species are born when their gene pool is closed to external flows of genetic materials through reproductive isolation, and they die through extinction" (ibid., 93-94). As is widely accepted today, no species is sempiternal, they are all historically contingent and ephemeral. Even stars are ephemeral: they exist for a limited amount of time, even if this is beyond our human capacity to imagine. Everything is ephemeral, everything is contingent, everything is part of a continuous relay of intensive energies from one actual- 
isation to the next, without being predetermined and without being predictable. The diversity of entities that populate the world are bounded in extension, but they are generated by invisible and temporal processes set in motion by immanent differences of intensity — not by any transcendental "substance" or "essence," which are no more than unreal reified generalities.

\section{Multiplicities}

In addition to the singularities and topological intensive transductive processes, the concept of multiplicity is absolutely crucial for a Deleuzian ontology. It is one of the most recurrent concepts in Deleuze's works-alone or in collaboration with Félix Guattari-and it finds its roots not in philosophy or linguistics, but in mathematics, particularly in the subfields of differential geometry, group theory, and dynamical systems theory. ${ }^{28}$ Deleuze mentioned it early on, in his 1966 book Bergsonism, where the subtitle of the second chapter is precisely "Théorie des multiplicités"29 (Deleuze 1991, 37-49). Although originally derived from Bernhard Riemann's differential mathematics, Deleuze first uses it in relation to time (duration) and space, particularly focusing on the notion that time is the condition for change or becoming. As Eugene B. Young (2013, 210) observed, this has profound consequences: "If [time] is taken as the foundation for conceiving space, then space (or objects and subjects within it) is not subjected to transcendent criteria but must be conceived in terms of difference and intensity."

For Deleuze, an important part of the role played by the concept of multiplicity is to further enable a replacement of the Aristotelian concept of essence. The essence of a thing is what explains its identity, and consequently how many different objects resemble each other by the fact that they share such an essence. However, in a Deleuzian ontology, "a species ... is not defined by its essential traits but rather by the morphogenetic process that gave rise to it" (DeLanda 2002, 9-10). As we have seen before, species are historically and contingently constituted entities, not the representatives of timeless categories. While an essentialist worldview sees species as static, a morphogenetic account, such as the one offered by Deleuze, is inherently dynamic. As Boundas (2007, 489-90) has put it: "Deleuze's ontology is an ontology of forces attempting to correct the mistake we make whenever we think exclusively in terms of things and their qualities: in privileging extension and extended magnitudes, we overlook the intensive genesis of the extended."

Critically, Deleuze's notion of space, surfaces, and points on a surface is directly indebted to the mathematical constructions of Gauss and Riemann, particularly to their surfaces, which are spaces in themselves and thus do not need to have an additional $(\mathrm{n}+1)$ dimension perceived. These are purely immanent surfaces; they are not placed within a transcendent space. In such surfaces, which build a dynamical system, each point in the surface becomes a possible state for the system-be it in an actual or virtual mode of existence in the

28 This has been exhaustively disclosed and explained by DeLanda (2002, 2010). A very different perspective, critical of DeLanda's assumptions and interpretation, has been offered by Mary Beth Mader (2017).

29 A subtitle that, unfortunately, is not rendered in the 1991 English translation of the book. 


\section{Chapter 1}

present moment. The complete space is a collection of all possible states that the system can have. Crucially, Riemann also discovered that some points more probably occur than others - these are called topological singularities. As there are too many possible points in a system (all its universal singularities), we cannot map them all. Instead, we can map the topological singularities (also called attractors). This is what permits a replacement of hierarchical categories and of the necessary and sufficient conditions for those categories: a topological space of possibilities, where individual singularities are actualised entities, and universal singularities are virtual points. ${ }^{30}$ It is the virtual network of connectors between those topological singularities that makes the structure (the diagram) of a dynamic system. As Deleuze famously stated, "the reality of the virtual is structure" (Deleuze 1994, 209, my emphasis).

To avoid any possible misunderstanding over Deleuze's use of this term, one has to stress right away that structure is understood by Deleuze in its mathematical and anthropological sense, not in the conventional musicological sense of the "fixed system of relations" or "infra-structure" of a given piece. As Christopher Hasty (2010, 10n23) has put it, "Deleuze's understanding of structure is quite different from that of musicology or linguistics, in which structure is regarded as a fixed form, a substance underlying the accidents of performance. Structure for Deleuze points to the differentiated multiplicity of Idea." ${ }^{1}$ James Williams $(2013,160)$ expressed a similar remark, clarifying that "structure as multiplicity is in movement and does not give priority to fixed structures." Multiplicities specify the structure of spaces of possibilities, which, in turn, offer an explanation for the regularities and inconsistencies in the morphogenetic processes, and in the concrete, material actualisations of the individual singularities. "The reality of the virtual consists of the differential elements and relations along with the singular points which correspond to them. The reality of the virtual is structure. We must avoid giving the elements and relations which form a structure an actuality which they do not have, and withdrawing from them a reality which they have" (Deleuze 1994, 209).

In the last sentence of this quotation we find crucial arguments against the two dominant schools of music ontology. Nominalists should not insist in defending at all costs the actuality of all singularities that are part of a musical work ("we must avoid giving the elements and relations which form a structure an actuality which they do not have" [ibid., my emphasis]), and Platonists should not axiomatically deny the material and real existence of singularities that are part of a musical work ("we must avoid... withdrawing from them a reality which they have" [ibid., my emphasis]). As multiplicities, what we usually call "musical

30 I insist on the crucial aspect that these universal singularities are by no means to be confused with Platonic ideas. They are real and effective parts of a dynamic system, and they can be actualised instantly at any given time of the system's lifespan. They are not the result of predeterminations, nor do they point towards necessary or unidirectional solutions.

31 Deleuze's use of the term Idea would also require some further explanations, which unfortunately I cannot undertake here. In short, I simply stress that Deleuze's Idea is mobile and changeable, thus very different from the reified Ideas of traditional idealisms and from the Kantian concepts of the understanding, which Deleuze discusses in chapter 4 of Difference and Repetition, in relation to Salomon Maïmon's reading of Kant (see Deleuze 1994, 168-76). 
works" are diagrams of the virtual, that is, they are real but not actual, and they are capable of divergent actualisations in several different media, times, and modes of appearance.

To conclude this section, one can summarise Deleuze's ontological proposal as defining a world view made of three separate, but intrinsically interrelated domains. One is the domain of actual individual singularities, of materially existing and observable products of natural and human invention, which can be defined by their extensive properties, by their length, area, volume, weight, number of components, and so on. Next there is a domain of intensive processes (transduction), defined by differences of potential, flows of energy, phase shifts, and critical thresholds, which change quantity into quality, and quality into quantity. They link the individual singularities to the universal singularities that remain virtual, some of which are more likely to be actualised than others (topological singularities). Finally, there is the domain of virtual structure, the topological space of possibilities, which diagrammatically maps the universal singularities, and that accounts in a purely immanent way for the regularities (but also for the inconsistencies) in the processes and in the individuations. The virtual diagram cannot exist without the actual and virtual singularities that build it. Nothing would happen in the world without the continuous relay of intensities from the virtual to the actual, and vice versa.

This leads to an ontology that is processual, immanentist, and based upon difference (different/ciation), a difference that is conceived not negatively, as lack of resemblance, but productively, as that which drives dynamic processes. Epistemologically, it defines a problematic epistemology (or an epistemology of problems and problematisations), one that gets rid of the general laws of axiomatic epistemologies without denying the objectivity of physical knowledge, which is now investigated by immanent distributions of the singular. The notion of truth is also devalued, as the dynamic processes are not predetermined, nor are they predictable. Ethically, the world emerges as profoundly transformed: a closed, finished, and authoritative world pervaded by transcendental ideas and categories gives place to an open world of immanent events and singularities, "full of divergent processes yielding novel and unexpected entities, the kind of world that would not sit still long enough for us to take a snapshot of it and present it as the final truth" (DeLanda 2002, 6).

\section{VirTUAL WORKS, ACTUAL THINGS: TOWARDS A NEW IMAGE OF MUSICAL WORK}

At this point, the choice of the title of this chapter should be clear to the reader. What traditionally, or at least for the last two hundred years, have been called "musical works" are specific zones, or partial elements of something that can be more aptly described and thought about in terms of musical multiplicities, which are fabricated by intensive processes that generate virtual structures and actual things. Music Platonists focus only on the structures, the reality of which they deny and which they conceive as purely abstract, fixed, immobile, and eternal. For their part, nominalists rely only on extensive individual singularities, his- 


\section{Chapter 1}

torically contingent, but also fixed and totally defined, to which they deny a virtual (intensive) component. For a Deleuzian-inspired music ontology, musical multiplicities must be grounded in the actual, even as some of the forces that the actual summons might remain virtual. Both-abstract structures and petrified strata - have to be overcome. Structures are mobile and fluid, while strata are constantly being dismantled and reshaped. As Michael Gallope stated, in his attempt to define "a Deleuzian musical work,"

\footnotetext{
Deleuze offers a glimpse of something different: music for him is certainly based in a materiality of sound, but is not reducible to any social or perceptual situation. It has a strange kind of autonomy, one that is oriented towards the absolute, but not as a vehicle for the actual work's content. Incredibly, he tries to think a musical work that is once more ideal and more empirical than the common perspectives. A Deleuzian musical work would be more ideal than a Platonist view since the logic of sensation has no "fallen" or exterior moment like performance external to itself. And it would be more empirical than a historicist perspective since it takes no recourse to the regulative norms of any historical moment. (Gallope 2008, 117-18)
}

Michael Gallope's essay “Is There a Deleuzian Musical Work?" (2008) is, to my knowledge, the only serious attempt so far to think about music ontology from a Deleuzian perspective. However, he places his inquiry within currently available ontologies, using Peter Kivy and Lydia Goehr as two examples of the polarisation of the debate between Platonism and historicising views. My take is different: I think it is indispensable to think outside existing music ontologies, to come up with a new image of work (which replaces the word work itself), and to appropriate for music ontology the basic features of Deleuze's ontology-and not so much what Deleuze said or wrote about music. So, I don't think there is "a Deleuzian musical work," which is Gallope's central concern. There cannot be a Deleuzian musical "work." There can only be a Deleuzian musical which is a multiplicity made of virtual topological singularities, actual individual singularities (containing a virtual component in themselves), and intensive transductive processes (generating the virtual and the actual).

Under this new image of work, every musical multiplicity has two halves: a virtual image and an actual image, resonating with Deleuze's statement that "every object is double without it being the case that the two halves resemble one another, one being a virtual image and the other an actual image" (1994, 209, my emphasis).

If we consider these two images in relation to musical works, one can think of the virtual image as the one relating to the flexible structure, to the diagram of a musical work, with all its topological singularities. It remains abstract without being ideal (because those singularities are real; that is, they exist), and is dependent on the quantity and quality of the concrete mapping of its universal singularities made by every single person. Thus, there are as many virtual images of a musical work as persons thinking of it. Every single person has his or her own and unique diagram of any given musical work. This diagram is always individual, and can only be thought about if one starts from the topological singularities that enable us to think of it in the first place. It is by no means some- 
thing prior to our mapping of the singularities; it is not an abstract or transcendental entity. On the contrary, it is the most extreme immanently generated construction, being dependent on an innumerable amount of concrete singularities working together in a specific assemblage of forces, intensities, and tendencies (remember that every singularity is the result of intensive energetic processes of individuation, thus, not sempiternal Platonic fictions). In order to emerge, this structural image requires a transcendental empiricism, an enormous (transcendental) amount of events, of individual and topological singularities, of intensive processes, of forces and tendencies empirically experienced by every single agent (performer, listener, reader, etc.). Thus, virtual images of $a$ musical work are potentially infinite-there are no "absolute" or universally intelligible musical works. Every musical is a space in itself, which has to be navigated internally by every single actant-it is not placed within an overarching $(\mathrm{n}+1)$ transcendental space containing it. Thus, a musical work is as many "works" as the people thinking of it. The virtual image, thus defines a problematic field, determining the virtual content of a musical arotk a problem, as an ideal (though not abstract) constellation of differential topological singularities.

Whereas this differentiation (with a $t$ ) establishes a problematisation, the concrete actualisations of that virtual field express differenciations (with a $c$ ) as the constitution of solutions, leading to the formation of actual images. Such images are formed by different sets of specific individual singularities that are actualised in the here-and-now, in the present (and in the presence) of a receiver, be it a reader of a score, a listener of a recording or concert, or an active performer of the music (or a non-human for non-human forms of expression). The process of differenciation happens through transduction, changing one type of energy into another, critically leading to the formation of new and unexpected individuations, which contain emergent properties that were not predetermined in advance.

As we have seen, current music ontologies primarily insist on the conditions of identity and recognition of a given musical work. Their common basic questions are of the type: what is a musical work? Are musical works abstract ideas or concrete things? How can a musical work be identified as this musical work? How can an instantiation of a work be considered as adequate, legitimate, or fully qualified? However, these questions take for granted precisely what needs to be explained: namely, the fact that those objects they label "musical works" emerged at a given historical time, were defined by innumerable sets of physical documents, were the result of intensive processes of generation, and continue to undergo constant redefinitions throughout time. Anyone with experience of editions of musical works (for print), or in research on sketches (in archives), just to give two simple examples, knows that any fixed "definition" of a work is highly problematic, open to criticism, and the object of change over time. Not only do traditions of musical practice and reception change, but the very definition of a musical text is constantly shifting. ${ }^{32}$ Musical works from the past have

32 I addressed this topic in detail in "Beyond Urtext: A Dynamic Conception of Musical Editing" (Assis 2009, 7-18; republished as Appendix 1 at the end of this volume). 


\section{Chapter 1}

been different entities throughout time. Think of a symphony by Beethoven and its many, varied, and literally different editions over the last two hundred years. There have been instruments added or changed, even pitches have not been totally indisputable. And the more one looks into its sketches, more problems arise and more options seem acceptable. Musical works don't possess a final, definitive, and sempiternal formal definition and unchangeable identity. If anything, they are mobile entities.

Traditional ontological accounts seem to ignore this, they treat musical works as perfectly defined entities, which are to be played by perfect performers, and which can be apprehended by perfectly intentionally oriented listeners. Instead of relying on such traditional ontologies (focused on Being), one needs to focus on the onto- and morphogenesis of musical works. The starting questions are, then, quite different: How are musical works effectively generated, constructed, formalised? Which intensive processes lead to their individuation? Which pre-individuating forces and materials create the humus where they will emerge? On which material basis are they transmitted throughout time? Which parts of them remain hidden and which ones are disclosed to a specific discipline, perspective, goal? What is the affective power of their extensive parts? Which concrete documents allow for their performance? How are they concretely performed? What other things influence their passive reception by an audience? Which things build their special topological singularities? Which are the modes of existence of such multiplicities? How can their diagrams/structures be thought? In the place of fundamental or higher order ontology, one urgently needs an ontogenesis, an account of the modes of individuation and continuous historical change of musical "works."

From this perspective, one cannot ignore the intensive energetic processes that lead to the emergence, that is to say, to the factual production of sketches, scores, editions, recordings, analyses, and theoretical reflections on a given "work." Critically, one cannot forget the innumerable material objects and things that enable the construction of any possible image of work in the first place. Before gaining their identity, their unmistakable modes of appearance, their enduring character, or their aura, musical works are constituted as energetic tendencies that generate complex conglomerates of things, such as sketches, drafts, manuscripts, scores, editions, recordings, transcriptions, treatises, manuals, instruments, depictions, contracts, commissions, letters, postcards, scribbles, diagrams, analytical charts, theoretical essays, articles, books, memories, and so on. These innumerable things are actual, they have been historically actualised at some precise point in time, and they persist existing, even if remaining modally and temporally flexible. Any single item from the list presented above can be differently read, interpreted, exposed, presented, or assembled as part of a book, an edition, a performance, a lecture, an installation, or whatever format. At this level, the individual singularities pertaining to a musical multiplicity function in a similar way to Guy Rohrbaugh's continuants, possessing three qualities that Platonic entities do not: they are modally flexible (they might have had different intensive properties than the ones they currently afford), they are temporally flexible (their intensive properties might 
differ over time), and they can come into and go out of exposure. Thus, they are not ideal and sempiternal, nor are they materially fixed once and for all. When Julian Dodd asks Rohrbaugh, "where are those historical individuals you claim to identify?" (quoted in Rohrbaugh 2012, 33), well, here they are! But they are not the full story, they are not "the work," they are transient, partial, and not always actualised components of the wider construction not of "works," but of works as multiplicities.

\section{Strata}

In very concrete terms, we have to be clear about which things we consider to be a legitimate part of the actual components of our musical multiplicities. In this sense, and as a useful tool for music practitioners creating innovative modes of performance, I have been proposing a terminology based upon strata and processes of stratification, which is vaguely inspired by Deleuze and Guattari's use of these terms in A Thousand Plateaus (1987, 39-74, 637-39).33 Appropriating their terminology, and remaining aware of the unavoidable anisomorphism between philosophy and art, one can divide all those musical materials that physically exist in the real world into diverse types of strata. Substrata are materials that already existed in the world before the first traits of instantiation of a new piece were produced; among them one finds other musical pieces, instruments, instrumental and compositional manuals, spoken and unspoken rules, codes of behaviour and practice, lists of personnel, payment sheets, and so on. Parastrata refer to documents produced while composing or preparing a performance, produced in view of the generation of a new piece, directly leading to the emergence of a new musical entity; they include sketches, drafts, first editions, letters, and writings or annotations by composers and performers. From that particular moment in time, when a piece has been first defined, many other future materials become thinkable and possible: new and renewed editions, all sorts of catalogues (of the sketches, of the variants, of the renderings), technical analysis of the piece or parts of it, reflexive texts about it, theoretical contextualisations, recordings, and so on-these are epistrata, they appear from the first materials that defined the piece and evolve from them in ever-growing circles. Next, there are metastrata, new materials generated at every future historical time, by practitioners aiming to present or, better, expose specific sets of materials from a given multiplicity in a new way; such strata include performances, recordings, transcriptions, expositions, or any other mode of critical reflection on the available sources. Furthermore, there are also interstrata, particular singularities that function in more

33 Deleuze and Guattari $(1987,522 \mathrm{n} 14)$ acknowledge their appropriation of these concepts from Italian paleoanthropologist Pia Laviosa Zambotti, more specifically from her book Les origines et la diffusion de la civilisation (1949), where she develops a whole theory on nomadic cultures and their progressive diffusion over the Earth's ecumene. Especially in chapter four, she addresses the topic of strata, substrata, and parastrata, illuminating the processes by which a nomadic culture interfered with, and was influenced by, the sedentary cultures it met. A set of substrata, which were part of the structures of a sedentary population or of its milieu, starts being challenged, while new configurations (parastrata) begin to emerge. The concrete planetary movements and migrations of human populations described by Zambotti proved to be wrong by the late 1950 os, but her descriptions of the kind of interactions between humans, and between humans and their milieu, still have validity and are worth reading. 


\section{Chapter 1}

than one register, being sometimes part of one strata, sometimes part of another. Finally, materials that have apparently nothing to do with a given piece, but that might under certain circumstances create relations to it are called allostrata. ${ }^{34}$ Significantly, all these different strata are not ontologically predefined, that is, their belonging to this or that stratum is more functional than existential. It all depends on the specific use made of them by the musical actants.

\section{RASCH ${ }^{25}$ : . VERS LA NUIT}

We can now understand some of the strata at work in my performance Rasch ${ }^{25}$ : ... Vers la nuit. Moscheles's piano étude Zorn, which Schumann notated in his sketchbook to Kreisleriana, acted as a substratum, a piece of music that existed in the world prior to the composition of Kreisleriana and that had an impact on it. The same applies to Beethoven's An die ferne Geliebte, which is literally quoted in Schumann's immediately preceding work (the Fantasie, op. 17) and evoked at the end of the second number of Kreisleriana. Roland Barthes's essays operated first as metastrata (when Barthes was writing them), and now as epistrata, adding new individual singularities to the multiplicity called "Robert Schumann's Kreisleriana." If one thinks of musical arks as multiplicities, their constitutive parts become not only innumerable but also unpredictable, an aspect that enables infinite differential and experimental reconfigurations of their connectors and relationships.

In fact, one of the goals of my $\operatorname{Rasch}^{X}$ series is to generate an intricate network of aesthetico-epistemic cross-references, through which the listener has the freedom to focus on different layers of perception: be it on the music, on the texts being projected or read, on the images, or on the voices. Situated beyond interpretation, hermeneutics, and aesthetics, the Rasch ${ }^{X}$ series is part of wider research on what might be labelled experimental performance practices. Such practices offer a tangible mode of exposing musical works as multiplicities. On the contrary, if one sticks to a traditional image of work based upon the One (or Idea), one has necessarily to stick also to notions of work concept, interpretation, authenticity, fidelity to the composer's intentions, and other highly prescriptive rules that originated in the nineteenth century. And if one sticks only to the historical situatedness of practices and codes of the time of the original compositions, then one is condemned to historicism, to the cultivation of relics and fetishes from other epochs (even if "historically informed practices" are a highly modern invention, as Richard Taruskin sharply demonstrated in several passages of his book Text and Act [1995]). What I mean is that every musical practice, every way of doing performance depends on, or is the direct result of, a specific ontological commitment. If one's goal is the passive reproduction of a particular edition of a musical piece from the early nineteenth century, one is indeed better advised to remain within the classical paradigm, with all its associated practices of survey, discipline, and control. But if one is willing to expose the richness of the available materials that irradiate from that piece,

34 A simple example of this is a concert situation where a piece by Schumann enters into an unexpected relation with a piece by Ligeti, or a work of Haydn with one by Schoenberg. 
one has to move towards new ontological accounts, such as the one proposed in this chapter.

Critically, different disciplines look at the different strata differently, each discipline constructing its own specific image of work. Robert Schumann's Kreisleriana is a different entity for a music sociologist, a music analyst, a clinical psychologist, or a pianist. They all take into account different actual things relating to that multiplicity, and they all build different virtual diagrams of it. And each individual person, even from the same discipline, sees different things and articulates them differently, thus constructing his or her own image of work. The (impossible to grasp) totality of materials pertaining to a work can only be considered as being virtual in the Deleuzian sense I explained above. Any actualisation of the virtual music singularities is a snapshot of wider images of work, the particular snapshot that a person, a group, or a community perceives for a certain duration of time. Brought together in specific configurations (historically, geographically, and disciplinarily situated), every imaginable individual stratum in its interaction with other strata enables the material, psychological, and sociocultural construction of diverse images of work, which have the potential to replace those reified generalities that we usually call "musical works."

Works appear then as multiplicities, as highly complex, historically constructed assemblages defined by virtual structures and actual things. While traditional musical ontologies remain attached to hermeneutic, analytical, and interpretative approaches, the new image of work enhances the emergence of creative, performative, and experimental events. Beyond transcendental typologies, beyond extreme or qualified versions of Platonism, beyond functional theories of operative concepts, and beyond aesthetic considerations coming from the ivory towers of academia, this new image of work offers a redefinition of musical works as highly flexible, mobile multiplicities with potentially infinite constitutive parts that can be exposed in different modes, to different audiences, and at different times. The shift from a work-centred perspective to a vision of an exploded continuum made of innumerable objects and things, in steady intensive interaction with one another, creates fields of discourse, practice, and perception based on pure difference, leading to processes of differential repetition. Every single performance then becomes different - not different from any original transcendental idea, but different from difference itself. It is only one ephemeral solution to the problematic field defined by a musical multiplicity.

When looking at those exploded things, a musician or a scholar has two options: one is analytical, remaining at a certain distance from the materials of musical practice, questioning things in terms of what they are, how they appear, which properties they have, and what relations they entertain with each other; the other option is one that decidedly dives into the materialities of music-making, focusing on what to do with these things, how to reactivate them, searching for the yet unseen virtual components that they possess, asking which potentialities they have, and how to express them anew. The first approach remains hopelessly imprisoned in the past; the second creatively and productively designs new futures for past musical objects and things. The first relates to conventional scholarly research and disciplines, the second-so 


\section{Chapter 1}

I claim - to new modes of research, primarily to artistic research, a mode in which the artistic dimension is quintessentially needed and requested. In the place of a reiteration of uncritically inherited performance practices, or patronising instances of survey and control, this perspective offers a methodology for unconventional, critical renderings that expose the variety and complexity of the musical materials available today. More than repeating what one already thinks one knows about a given work, it claims the pure unknown as the most productive field for artistic practices. Rather than accepting a reproductive tradition, it argues for an experimental, creative, and vitalist attitude.

\section{REFERENCES}

Arbo, Alessandro, and Marcello Ruta, eds. 2014. Ontologie Musicale: Perspectives et débats. Paris: Hermann.

Assis, Paulo de. 2009. "Beyond Urtext: A Dynamic Conception of Musical Editing." In Dynamics of Constraints: Essays on Notation, Editing, and Performance, edited by Paulo de Assis, 7-18. Leuven: Leuven University Press.

, ed. 2018. Virtual Works-Actual Things:

Essays in Music Ontology. Orpheus Institute Series. Leuven: Leuven University Press.

Badiou, Alain. 200o. Deleuze: The Clamor of Being. Translated by Louise Burchill. Minneapolis: University of Minnesota Press. First published 1997 as Deleuze: $L a$ clameur de l'Etre (Paris: Hachette).

Barthes, Roland. 1985a. "Loving Schumann." In Barthes 1985d, 293-98. First published 1979 as "Aimer Schumann," preface to Beaufils 1979, 9-16.

_.1985b. "Rasch." In Barthes 1985d, 299-312. First published 1975 as "Rasch," in Langue, discours, société: Pour Émile Benveniste, edited by Julia Kristeva, JeanClaude Milner, and Nicolas Ruwet (Paris: Seuil).

-1985c. "Musica Practica." In Barthes 1985d, 261-66. First published 1970 as "Musica Practica" (L'Arc 40). . 1985 d. The Responsibility of Forms: Critical Essays on Music, Art, and Representation. Translated by Richard Howard. Berkeley: University of California Press. First published 1982 as L'obvie et l'obtus: Essais critiques III, edited by F.W. (Paris: Seuil).

Beaufils, Marcel. 1979. La musique pour piano de Schumann. Paris: Phébus.
Beistegui, Miguel de. 2012. "The Deleuzian Reversal of Platonism.” In The Cambridge Companion to Deleuze, edited by Daniel W. Smith and Henry Somers-Hall, 55-81. Cambridge: Cambridge University Press.

Boundas, Constantin V. 2005a. "Intensity." In The Deleuze Dictionary, edited by Adrian Parr, 131-32. New York: Columbia University Press. - 2005b. "Ontology." In The Deleuze Dictionary, edited by Adrian Parr, 191-92. New York: Columbia University Press. - 2005c. "Les stratégies différentielles dans la pensée deleuzienne.” Translated by Alain Beaulieu. In Gilles Deleuze: Heritage philosophique, edited by Alain Beaulieu, 15-43. Paris: Presses universitaires de France.

_. 2007. "Different/ciations: The Case of Gilles Deleuze." In The Edinburgh Companion to Twentieth-Century Philosophies, edited by Constantin V. Boundas, 489-503. Edinburgh: Edinburgh University Press.

Butt, John. 2002. Playing with History. Cambridge: Cambridge University Press.

Clisby, Dale. 2017. "Intensity in Context: Thermodynamics and Transcendental Philosophy." Deleuze Studies 11 (2): $240-58$.

Davies, David. 2011. Philosophy of the Performing Arts. Oxford: Wiley-Blackwell. . 2018. "Locating the Performable Musical Work in Practice: A NonPlatonist Interpretation of the "Classical Paradigm."” In Assis 2018, 45-64. Orpheus Institute Series. Leuven: Leuven University Press.

DeLanda, Manuel. 2002. Intensive Science and Virtual Philosophy. London: Continuum. 
Assemblage Theory and Social Complexity. London: Bloomsbury.

. 2010. Deleuze: History and Science. New York: Atropos Press. 2012. "Deleuze, Mathematics, and Realist Ontology." In The Cambridge Companion to Deleuze, edited by Daniel W. Smith and Henry Somers-Hall, 220-38. Cambridge: Cambridge University Press.

Deleuze, Gilles. 1991. Bergsonism. Translated by Hugh Tomlinson and Barbara Habberjam. New York: Zone Books. First published 1966 as Le Bergsonisme (Paris: Presses universitaires de France).

-1994. Difference and Repetition. Translated by Paul Patton. New York: Columbia University Press. First published 1968 as Différence et répétition (Paris: Presses universitaires de France). .1998. Essays Critical and Clinical. Translated by Daniel W. Smith and Michael A. Greco. Minneapolis: University of Minnesota Press. First published 1993 as Critique et Clinique (Paris: Minuit).

Deleuze, Gilles, and Félix Guattari. 1987. A Thousand Plateaus: Capitalism and Schizophrenia. Translated by Brian Massumi. Minneapolis: University of Minnesota Press. First published 1980 as Mille plateaux (Paris: Minuit).

Dodd, Julian. 2007. Works of Music: An Essay in Ontology. Oxford: Oxford University Press.

Gallope, Michael. 2008. "Is There a Deleuzian Musical Work?” Perspectives of New Music 46 (2): 93-129.

Goehr, Lydia. (1992) 2007. The Imaginary Museum of Musical Works: An Essay in the Philosophy of Music. Rev. ed. Oxford: Oxford University Press.

. 2001. "Philosophy of Music: 1.

Introduction.” In The New Grove Dictionary of Music and Musicians, edited by Stanley Sadie, 2nd ed., 29 vols, 19:601-6. London: Macmillan.

Hallward, Peter. 2006. Out of this World: Deleuze and the Philosophy of Creation. London: Verso.

Hasty, Christopher. 2010. "The Image of Thought and Ideas of Music." In Sounding the Virtual: Gilles Deleuze and the Theory and Philosophy of Music, edited by Brian Hulse and Nick Nesbitt, 1-22. Farnham, UK: Ashgate.
Hindrichs, Gunnar. 2018. "Towards a General Theory of Musical Works and Musical Listening." In Assis 2018, 65-87.

Hughes, Joe. 2009. Deleuze's Difference and Repetition. London: Continuum.

Kania, Andrew. 2012. "Platonism vs. Nominalism in Contemporary Musical Ontology." In Mag Uidhir 2012, 197-219.

Laviosa Zambotti, Pia. 1949. Les origines et la diffusion de la civilisation: Introduction à l'histoire universelle. Translated by Jean Goillard. Paris: Payot. First published 1947 as Origini e diffusione della civiltà (Milan: C. Marzorati).

Levinson, Jerrold. 1990. Music, Art, and Metaphysics: Essays in Philosophical Aesthetics. Ithaca, NY: Cornell University Press.

Mader, Mary Beth. 2017. "Philosophical and Scientific Intensity in the Thought of Gilles Deleuze." Deleuze Studies 11 (2): 259-77.

Magnus, P. D. 2012. "Historical Individuals Like Anas platyrhynchos and 'Classical Gas.”' In Mag Uidhir 2012, 108-24.

Mag Uidhir, Christy, ed. 2012. Art and Abstract Objects. Oxford: Oxford University Press.

Plotnitsky, Arkady. 2006. "Manifolds: On the Concept of Space in Riemann and Deleuze." In Virtual Mathematics: The Logic of Difference, edited by Simon Duffy, 187-208. Manchester: Clinamen. . 2009. "Bernhard Riemann." In Deleuze's Philosophical Lineage, edited by Graham Jones and Jon Roffe, 190-208. Edinburgh: Edinburgh University Press.

Protevi, Jon. 2013. Life, War, Earth: Deleuze and the Sciences. Minneapolis: University of Minnesota Press.

Roffe, Jon. 2012. Badiou's Deleuze. Montreal: McGill-Queen's University Press.

Rohrbaugh, Guy. 2012. "Must Ontological Pragmatism be Self-Defeating?” In Mag Uidhir 2012, 29-48.

Rostagno, Antonio. 2007. Kreisleriana di Robert Schumann. Palermo: L'Epos.

Sauvagnargues, Anne. 2003. "Actuel/Virtuel." In Le vocabulaire de Gilles Deleuze, edited by Robert Sasso and Arnaud Villani, 22-29. Les Cahiers de Noesis 3. Paris: Vrin. . 2005. Deleuze et l'art. Paris: Presses universitaires de France. Translated by Samantha Bankston as Sauvagnargues 2013 . 


\section{Chapter 1}

2013. Deleuze and Art. Translated by Samantha Bankston. London: Bloomsbury. First published as Sauvagnargues 2005 .

- 2016. Artmachines: Deleuze, Guattari, Simondon. Translated by Suzanne Verderber with Eugene W. Holland. Edinburgh: Edinburgh University Press. Somers-Hall, Henry. 2013. Deleuze's Difference and Repetition: An Edinburgh Philosophical Guide. Edinburgh: Edinburgh University Press.

Taruskin, Richard. 1995. Text and Act: Essays on Music and Performance. New York: Oxford University Press.
Toscano, Alberto. 2009. "Gilbert Simondon." In Deleuze's Philosophical Lineage, edited by Graham Jones and Jon Roffe, 380-98. Edinburgh: Edinburgh University Press.

Williams, James. 2013. Gilles Deleuze's Difference and Repetition: A Critical Introduction and Guide. 2nd ed. Edinburgh: Edinburgh University Press.

Young, Eugene B. 2013. "Multiplicity.” In The Deleuze and Guattari Dictionary, by Eugene B. Young with Gary Genosko and Janell Watson, 210-13. London: Bloomsbury. Young, James O. 2014-15. "The Poverty of Musical Ontology." JMM: The Journal of Music and Meaning 13: 1-19. 


\section{Assemblage, Strata, Diagram $^{\star}$}

\section{Musical ORes as assemblages}

The new image of musical presented in Chapter 1 , with its actual and virtual components, implies a broader milieu of individuation, one in which its material, aesthetic, and social constitutive parts can be better situated, both in general terms, and in their relations to each other. If the dominant classical paradigm of the work concept implies a conceptual environment populated by the notions of the author's intentions, fidelity to the score, authenticity, urtext edition, interpretation, autonomy of the artwork, or its truth content, the new image of musical rork requires a totally renewed conceptual ecology. This is because "a tool or a machine ... should not be studied in isolation without taking into consideration the milieu of individuation that surrounds it and allows it to function. No machine or technical tool exists by itself ... they only function in an assembled milieu of individuation, which constitutes [their] conditions of possibility: there is no hammer without a nail, and thus the interaction between a multitude of technical objects makes the fabrication of hammers and nails possible, while also forming the conditions of their utilisation and the practices and habits associated with them" (Sauvagnargues 2016, 186).

In Chapter 1, I presented some important features of the "musical work as assemblage"; however, I mainly focused on the first part of the phrase- "the musical - the whole chapter being a critique of classical images of work and a proposal for a new mode of considering them. This was necessary, in order to expose the current state of affairs, and to emphasise the urgency of a new vision of musical entities. Yet, as a result, the second part of the phrase- "assemblage"-was only briefly mentioned, awaiting exploration. The concept of assemblage is absolutely central to my new image of because it is, in my view, the best currently available concept to explain the mutations, transformations, and reconfigurations of any far-from-equilibrium system (which I claim musical torks to be). Moreover, assemblages are made of

\footnotetext{
Earlier formulations of the ideas contained in this chapter, focusing on specific aspects of its topic, were presented in three editions of the Deleuze Studies Conferences: in Istanbul (2014), Stockholm (2016), and Rome (2017). I am grateful for the questions raised by audience members, and for the discussions issuing from them, particularly to Ian Buchanan's feedback after my presentation in Rome. Additionally, I had the opportunity to discuss this topic with Kamini Vellodi, Laura Cull, John Ó Maoilearca, and David Savat during three different study days at the Orpheus Institute (2016, 2017).
} 
actual and virtual components, an aspect that is central to my appropriation of the term for music, as my proposed new image of work is based precisely on the interplay between its actual and virtual parts by means of intensive processes of individuation. The actual things and the virtual diagrams described in Chapter 1 resonate with (and were inspired by) the notions of strata, concrete machine, diagram, and abstract machine, which are some of the basic components of the concept of assemblage as it has been described and applied in the last two decades in post-Deleuzian discourses.

Moving beyond the question of being and identity, and insisting on an approach to musical entities based on a perspective that privileges processes of permanent change and becoming, my new image of work poses the question not so much in terms of a conventional ontology, but rather in terms of ontogenesis and of productive operations with historically inherited materials. Thus, the problem shifts from ontology to epistemology, and to the modes by which musical carks be apprehended in the real world. They are perceived and known always through concrete performative operations that (re)construct them anew every single time one is confronted with them. Such operations bring to the fore well-known structures, but also, and crucially, zones of indeterminacy, grey spots, cracks in the structure that no identity-based ontology is able to explain. The component parts of a musical work are not perfectly packaged and well formed forever. They are fluid entities, which-more than having a clear shape-are in permanent processes of taking shape again and again. They have some sort of structure but are not totally defined. Thus, any productive musical practice constantly deals with the construction of the means precisely needed for that practice. If one deals with ready-made, ready-to-use tools, one may still be making music, but in a reproductive, repetitive, and not particularly exciting mode. In this sense, my new image of conveys a constructivist approach to musical practice and performance. ${ }^{1}$ Its basic posture is that musical entities can't be taken as given; they are rather seen as constantly becoming something else, without ever attaining a fixed state or definition, and they become this something else by means of concrete operations done by concrete individuals. Additionally, they can't appear in the world independently of their environment. On the contrary, they permanently come into the field of the visible and of the audible through new social, aesthetic, and cultural takes on them, which are also permanently changing and evolving from one state to the next. Thus, my proposed image of addresses ever-changing constitutions and perspectives of such musical entities, as well as their corresponding subject positions, from where they are perceived, received, or criticised. The object is changing, the environment where it is posited is changing, and the subjectreceiver is changing. This requires new forms of conceiving the overall ecological network around any possible formalisation of a musical work, forms that take into account its various components and that privilege the notion of permanent transformation.

1 By constructivism, I mean literally the sense of building or assembling from parts (see Hacking 1999, 103). 
For this purpose, I propose to appropriate for music the concept of assemblage, and the remainder of this chapter is an introduction to the concept, particularly focusing on its emergence and development in the work of Deleuze and Guattari, and on its relation to the notions of strata and diagram. Moreover, the chapter frames the concept in relation to some of its precursors (Hjelmslev, Laviosa Zambotti, Foucault) and some of its interpreters (DeLanda, Nail, Buchanan). Thus, it is a technical chapter, presenting basic components of the concept and their interaction at different levels and in different practices. It aims to establish the foundations for future work on the notion of assemblage applied to music. In this sense, and in relation to all this book's chapters being preliminary essays towards future books on their respective topics, this chapter offers seminal work towards a monograph on assemblage theory for music.

\section{AGENCEMENT, LOGiC OF ASSEMblage, ASSEMblage THEORY}

Since the end of the twentieth century, the concept of assemblage has emerged as a central concept for addressing problems of stability, instability, determination, and, most importantly, transformations regarding social, political, economic, philosophical, and aesthetic phenomena. As with previous concepts from philosophy and the social sciences, such as complexity, chaos, fractals, turbulence, flow, emergence, or multiplicity, it has been developed as a way to move beyond the notion of structure, which has dominated the human and social sciences (especially in the third quarter of the twentieth century). Structure and structuralism clearly obtained important results and were able to explain many problems and phenomena, but they seemed to fail in the face of complex systems, especially when rapid changes, mutations, and transformations led to unforeseen and unpredictable events. Instead of being fixed and resistant to change, complex systems operate in permanent processes of becoming and individuation, which contribute to their resilience. Thus, in a first moment, the notion of assemblage, with its interplay between structure and contingency, organisation and chance, "can be seen as a relay concept, linking the problematic of structure with that of change and far-from-equilibrium systems" (Venn 2006, 107). Even if this notion does not fully explain such systems, it provides basic tools to grasp some sort of logic, revealing some of those systems' tendencies and lines of development and the broad direction of their becomings.

What is currently called assemblage theory (see DeLanda 2006, 2010, 2016; Buchanan 2015, 2017) comprises diverse approaches in the human and social sciences, which more or less explicitly refer back to Deleuze and Guattari's foundational concept of agencement. Deleuze and Guattari invented this concept in 1975 in their joint book on Kafka (Deleuze and Guattari 1986), from which it emerged as a development of Deleuze's previous notion of disjunctive synthesis (1969 [see Deleuze 1990]) and Guattari's desiring machines (see Anti-Oedipus [Deleuze and Guattari (1977) 1983]). Crucially, and to clarify the ongoing debates around these notions, I think it is essential to distinguish between three different notions of the concept, which are often discussed 
without the necessary distinction: (1) the concept of agencement (from 1975) and (2) an extended logic of assemblage (from 1980), both of which are the work of Deleuze and Guattari; and (3) diverse assemblage theories that emerged after Deleuze and Guattari.

First, there is the original concept of agencement, which was substantially addressed and developed by Deleuze and Guattari in the Kafka book (first published 1975), but also in the 1976 first publication of "Rhizome" (see Deleuze and Guattari 1981), and in the Dialogues (1977 [see Deleuze and Parnet 2007]).

Second, in A Thousand Plateaus (1980 [see Deleuze and Guattari 1987]) there is a huge expansion of the original concept, which is used in relation to innumerable disciplines, fields of knowledge, problems, human practices, and nonhuman formations, including descriptions of geological formations, chemical compounds, biological organisms and cells, linguistic formations, paleoanthropological migrations, political organisations and states, cosmic constellations, war machines, and so on. The concept is extensively used and discussed throughout the book, defining a sort of general logic of assemblage, which is not intended as a fully fledged theory but as a sophisticated elaboration of descriptive and operative principles in order to deal with far-from-equilibrium systems. The impressive variety of perspectives offered by Deleuze and Guattaritogether and apart-seems to contradict Manuel DeLanda (2006, 3), when he writes that "the relatively few pages dedicated to assemblage theory" by Deleuze, alone or with Guattari, "hardly amount to a fully fledged theory." In my view, DeLanda is right in that Deleuze and Guattari didn't aim at producing "a theory"; nevertheless, he underestimates the copious amount of pages they dedicate to the notion of assemblage. Symmetrically to DeLanda, but on the other side, Thomas Nail $(2017,21)$ states that "contra DeLanda, Deleuze and Guattari do in fact have a fully fledged theory of assemblages," which he tries to convey in his essay "What Is an Assemblage?" (2017). Again, Nail is right in that Deleuze and Guattari wrote extensively on assemblages, but I don't think they ever aimed at defining a "fully fledged theory." I don't think, for example, that Deleuze's Logic of Sense is a "theory of sense," nor is his Logic of Sensation a "theory of sensation"; even A Thousand Plateaus, which is all about multiplicities, is not a "theory of multiplicities." What Deleuze (alone or with Guattari) was always interested in was the definition of operative principles and fluid logics that could pass through and cut across different concepts, practices, regimes of codings, and materialities.

Thus, I don't think there can be a "Deleuzian" assemblage theory. But there are (several) assemblage theories, and this is my third point: the construction and definition of assemblage theories happened after and as an outgrowth of Deleuze and Guattari's ideas. Such theories are autonomous and independent of Deleuze and Guattari, who serve only as a vague referent to their expansions. In this sense, I don't think we should validate them in purely Deleuzian terms. They might be considered more or less legitimate, according to one's willingness to accept twists in the original notions, but they strive for coherence and they can be very productive in a variety of fields. However, others are more critical towards them. 
In "Assemblage Theory and Its Discontents" Ian Buchanan (2015) summarises many of the ongoing debates around assemblage theory. He writes that "assemblage theory is rapidly gathering a significant following in the human and social sciences" (Buchanan 2015, 382). Situated within these disciplines, one could claim that the emerging field of artistic research is another area of practice where uses and appropriations of the concept of assemblage are currently observable. If the original Deleuzo-Guattarian notion of agencement is the common basic denominator of such appropriations, recent developments and disseminations of assemblage theory also seem to be derived from two other sources: Bruno Latour's and Michel Callon's actor-network theory (ANT), on the one hand, and Manuel DeLanda's (2006, 2010, 2016) analytical readings of Deleuze, on the other. According to Buchanan $(2015,383)$, these authors "cloud our understanding of Deleuze and Guattari and in that regard call for our critical attention." Buchanan identifies and analyses the "two kinds of error" (ibid.) which these theories, in his view, incur in appropriating Deleuze and Guattari: the focus "on the complex and undecidable" (ANT), and the focus "on the problem of emergence" (DeLanda) (ibid., 382). Although these "errors" are taken to derive from a wrong reading of Deleuze and Guattari, they might be considered as "providential errors," in so far as they open up new lines of thought in their own terms (ibid., $382-83$ ). More recent debates and essays (Nail 2017; Buchanan 2017) make an effort to clarify terms and definitions, in order to guarantee that a minimum relation to the original notions of Deleuze and Guattari remains, at least, plausible. Otherwise, assemblage theory risks becoming one of those reified generalities (like deconstruction and postmodernism) that have lost any authorial and referential source (see Buchanan $2017,458)$. At any rate, what the ongoing debate around assemblage theory demonstrates is that this concept has multiple sources, which can be separately identified but are not easy to disentangle from one another. And it also became apparent that there are diverse possible appropriations of the term that, even if "wrong," can be productive.

Thus, I insist, one has to separate, on the one hand, the concept of agencement and a logic of assemblage, both of which are the work of Deleuze and Guattari, and, on the other hand, a theory of assemblages, which departs and is autonomous from their work. In what follows, I will not try to summarise all existing views on assemblage (which is an important task, but one that would go beyond the scope of this chapter), nor will I make an attempt to bring Deleuze and Guattari's different definitions of assemblage together (which has been attempted by DeLanda [2016]). What I will do, is focus on yet another aspect: the intricate relations between Deleuze and Guattari's notions of agencement, strata, and diagram, as they define the basic constitutive parts of the concept of assemblage in the first place. After a quick intermezzo on the problem of the translation of the French word agencement into the English "assemblage," I will scrutinise the origins of the concept of agencement, trying to understand why in the mid 1970 os Deleuze and Guattari invented this concept. Thus, I will first focus on the logic of assemblage that Deleuze and Guattari deployed in their own writings. Next, I will refer to various authors who had an impact on Deleuze 
and Guattari's texts (Laviosa Zambotti, Hjelmslev, and Foucault, in relation to the notions of strata, content/expression, and diagram, respectively) and to other thinkers who developed original insights or who made relevant comments on their views (DeLanda, Buchanan, Nail, Sauvagnargues, Krtolica, Venn, Zdebik, and Zourabichvili).

\section{INTERMEZZO: A NOTE ON TRANSLATION}

For the sake of clarity, it is important to briefly address the issue of the English translation of the French word agencement as “assemblage." As is well known today, this translation is problematic in many respects, especially because most people use it in the regular understanding of the English word (see Buchanan 2017, 458; but also, Alliez and Goffey 2011a; Bogue 1989; Buchanan 2015; DeLanda 2006, 2016; Wise 2005; Nail 2017; Phillips 2006; et al.). However, the regular understanding creates the incorrect impression that the concept refers to a final product and not to a process. As Thomas Nail $(2017,22)$ and Manuel DeLanda $(2016,1)$ precisely explain, both words have completely different etymological roots, the French agencement comes from the verb agencer (the action of matching or fitting together a set of components, and the result of such action), while the English assemblage comes from the French assemblage (not from agencer), which in both languages means the joining of two or more things, thus pointing to a perfectly fixed final product. In his book on Deleuze from 1989, Ronald Bogue $(1989,174$ n1) remarked: "for agencement, translators of Deleuze and Guattari have suggested 'assemblage,' 'arrangement' and 'organization,' but no one of these is fully satisfactory." On the same note, but already adding a positive aspect to the translation, Éric Alliez and Andrew Goffey write: "although the French agencement is something that might be said of the way in which elements on the page of a magazine are put together, of a palette of colours or of the arrangement of furniture in a room, in the use that Deleuze and Guattari make of it, it also conveys an active sense of agency as being what some or other entity does, a precious indicator of the constructivist horizon within which it operates... The term 'assemblage' does not really convey this crucial nuance of agency, even while it does capture the function of synthesis of disparate elements rather well" (Alliez and Goffey 2011b, 10-11).

The first English translation of agencement was made by Paul Foss and Paul Patton in 1981 (see Deleuze and Guattari 1981). They opted for "assemblage," and Brian Massumi retained this word in his 1987 translation of $A$ Thousand Plateaus. Meanwhile, in 1984, the American edition of a collection of essays by Guattari (Guattari 1984a) included a glossary especially written by Guattari for this purpose. In it, agencement is translated as "arrangement" in a short glossary entry that is worth recalling here:

\footnotetext{
Arrangement (Agencement): This is a wider idea than those of structure, system, form, process, etc. An arrangement contains heterogeneous components, as well as biological, sociological, mechanical, gnoseological, imaginary. In the schizo-analytic theory of the unconscious, arrangement is conceived as replacing the Freudian “complex." (Guattari 1984b, 288)
} 
This means that the concept of agencement has an additional (and fundamental) dimension that roots it in psychoanalysis, an aspect that passed mainly unnoticed until Buchanan's 2015 essay, where he writes: "Despite the fact it is Guattari himself who defines the assemblage this way.... the connection between Freud's complex and the concept of the assemblage has been almost completely ignored" (Buchanan 2015, 383). Furthermore, Buchanan claims that agencement is Deleuze and Guattari's personal translation "or perhaps re-arrangement would be a better word, of the German word Komplex (as in the 'Oedipal complex' or the 'castration complex')" (ibid.). Crucially, Freud's Komplex does not necessarily require the consideration of a material object, thus moving the notion of agencement into the realm of a psychological construction. Two things are worth mentioning. On the one hand, it is obvious from Kafka: Toward a Minor Literature that the figure of Oedipus and Kafka's relationship to his father as it is expressed in the "Letter to the Father" play a central role in the definition of the concept of agencement. Chapter 2, "An Exaggerated Oedipus," makes that rather obvious. Additionally, and to complicate things a bit more, the psychoanalytical notion that Deleuze and Guattari explicitly mention is not complex but condensation: "The judges, commissioners, bureaucrats, and so on, are not substitutes for the father; rather, it is the father who is a condensation of all these forces" (Deleuze and Guattari 1986, 12). On the other hand, in his glossary entry, Guattari clearly states that "Arrangement [agencement] is conceived as replacing the Freudian 'complex"' (Guattari 1984, 288, my emphasis). Thus, agencement would not be a translation (or a rearrangement) of "complex" but its replacement, its overcoming. To complicate things even further on the psychoanalytical front, one could mention that Lacan used the French term assemblage in relation to set theory, and that in Seminar XX he did so in a sense that is not dissimilar to Deleuze and Guattari's agencement (session from 16 January 1973, see Lacan 1998, 47). Therefore, in order to avoid further complications, I think that it is wise to stick to "assemblage" as the translation of agencement, making clear the link to the original formulation whenever necessary.

\section{From structure to assemblage}

\section{Beyond structuralism}

Deleuze and Guattari's notions of strata, agencement/assemblage, concrete machine, abstract machine, machinic assemblage of bodies, collective assemblage of enunciation, and diagram are part of a dynamic philosophical system. They are not rigidly defined, and they can only be understood in continuous relation and interaction with one another (thus, not independently). Taken together, they have been integrated (crucially, after Deleuze and Guattari's lifetimes) in what has been called "assemblage theory." However, in Deleuze and Guattari's work a theory is not constituted; rather, they create a varied ecology of concepts and practices that enable new understandings of dynamic processes-without pinning them down to analytical definitions or constraints. In particular, the notions of strata, assemblage, and diagram - taken in their mutual interrelations-have been of the utmost relevance for them in enabling an alternative 
to structuralism and phenomenology, to those dehistoricised structures that structuralism often implied, and to those subjective phenomena that were the basis of phenomenological approaches.

In the late 1960s, Deleuze was looking for a perspective that could include the transformations and mutations of structures, mutations that were observable, but to which there were no adequate explanatory theories. Structuralism had achieved important results in linguistics (Jakobson), sociology and anthropology (Lévi-Strauss), epistemology (Foucault), semiology (Barthes), psychoanalysis (Lacan), and political theory (Althusser), offering innovative insights into every field of practice based upon linguistic models ("In fact, language is the only thing that can properly be said to have structure" [Deleuze 2004, 170]). But structuralism failed to account for dynamic systems, for the emergence of unexpected or paradoxical behaviours within a given structure. As Couze Venn writes $(2006,107)$ :

\begin{abstract}
Structure in the natural and social sciences grounds causal determination within a logic of stability and linear causality.... [Such logic,] which positivism and various forms of structuralism support, has clear pay-offs from the point of view of homogenizing and predicting social phenomena.... However, the limitations of approaches based on this notion of determination have been demonstrated in their failure to account adequately for change, resistance, agency and the event: that is, the irruption of the unexpected or unpredictable.... The problem for theory is that of thinking structure as well as multiplicity and indeterminacy within the same theoretical framework.
\end{abstract}

This is precisely what Deleuze, in response to Claire Parnet, expressed: "The difficult part is making all the elements of a non-homogeneous set converge, making them function together. Structures are linked to conditions of homogeneity, but assemblages are not" (Deleuze and Parnet 2007, 52).

In this sense, Deleuze's invention of a whole range of new concepts around the core concept of agencement can be seen to emerge from the shortcomings and limits of structuralism to explain far-from-equilibrium systems. Deleuze, in one of his most important texts, "How do We Recognize Structuralism?" (Deleuze 2004), manifests a deep concern for the need to include in structuralism an adequate theory of the mutations and transformations of structures: "Henceforth, a set of complex problems are posed for structuralism, concerning structural 'mutations' (Foucault) or 'forms of transition' from one structure to another (Althusser)" (ibid., 191). What structuralism tended to see as "accidents," as something happening to the structures from their outside, as something external to them, is seen by Deleuze as an interior and integral part of the structure, concerning not mental representations of a problem but the concrete and real individuation of each one of the problem's actualisations. In this very special moment of any structure, namely in its events, nothing can any longer be reduced to an essence. The closed system of the structure must give place to a continuous individuation, integrating the power of heterogeneity in its most inner fabric. The vectors of mutation become a real internal component of every single real entity. 


\section{Desiring machines}

In short, one can describe Deleuze's conceptual trajectory between 1967 ("How do We Recognize Structuralism?") and 1972 (Anti-Oedipus), as a move from interpretation and structuralism to machinism, ${ }^{2}$ experimentation, and desiring production, paving the way for a logic of assemblages that dominate his joint books with Guattari on Kafka (1975 [see Deleuze and Guattari 1986]), on the rhizome (1976 [see Deleuze and Guattari 1981]), and on multiplicities (1980 [see Deleuze and Guattari 1987]). Such books could only have been written after that fundamental paradigm shift from structure to machine, the latter being an operative (and not descriptive) concept in relation to structure. Each individual not only is more than simply the result of a process but also is a milieu of potentially infinite individuations. In his conceptual trajectory, and even before his meeting and collaboration with Guattari, Deleuze developed a philosophy of intensive differen ${ }^{\mathrm{t}}$ / iations (Difference and Repetition, 1968 [see Deleuze 1994]) ${ }^{3}$ and articulated a logic of sense and non-sense (Logic of Sense, 1969 [see Deleuze 1990]) $)^{4}$ that shows the limits of propositional knowledge, opening the horizon to the body and its powers of variation. His first collaboration with Guattari, "La synthèse disjonctive" (1970), offers a first solution to the problem of thinking about heterogeneity in terms of a theory of the body and a theory of thought, revealing the synthesis of the unconscious as operating through concrete inscriptions that generate a physical network of syntheses. Thus, the unconscious is no longer seen as being primarily psychological, but also, and inseparably, as being physical and noological-as an operating machine: "the unconscious does not mean anything. On the other hand, the unconscious constructs machines, which are machines of desire.... The unconscious does not speak, it engineers [il machine]. It is not expressive or representative, but productive" (Deleuze and Guattari [1977] 1983, 180). 5 This unconscious is the place par excellence of desiring-machines, a concept that replaced Deleuze's notion of the larval selves (which still play a central role in Difference and Repetition and Logic of Sense), and that would be replaced, in turn, in 1975 with the concept of agencement. With the concept of desiring-machine, Deleuze and Guattari moved beyond the Freudian concept of the $i d$, and beyond "the Lacanian conception of lack as the principal motor of desire" (Buchanan 2010, 125), affirming desire as a productive, positive, and creative operator, definitely setting aside the traditional negative notion of desire as lack or need.

According to Ian Buchanan's thorough analysis of Anti-Oedipus, "[the] 'insistence' of desire is ultimately what Deleuze and Guattari are trying to account for with the concept of the desiring-machine" (Buchanan 2008, 47). In the place of

In relation to the notion of machinism, see Lapoujade (2017, 152-54); Sauvagnargues $(2016,193)$.

3 A first sketch of this theory (in nuce) is presented in the section "The Differential and the Singular" of "How do We Recognize Structuralism?" (Deleuze 2004, 176-78).

4 Deleuze had already mentioned the relation between sense and non-sense in "How do We Recognize Structuralism?": "There is, profoundly, a nonsense of sense, from which sense itself results" $(2004,175)$.

5 "l'inconscient ne veut rien dire. En revanche, l'inconscient fait des machines, qui sont celles du désir. ... L'inconscient ne dit rien, il machine. Il n'est pas expressif ou représentatif, mais productif" (Deleuze and Guattari 1972, 248). 
an unconscious, working as a theatre of representation, Deleuze and Guattari propose an unconscious primarily busy with desire-production and continuously operating schizophrenic processes, which are seen as its basic matrix. Desire does not relate to something we miss, but it becomes a process, something we actively do, something that more than producing fantasies (which is a secondary operation) is occupied with the production of production itself (see Buchanan 2008, 49). Crucially, desiring-production cannot operate without simultaneously producing new desiring-machines and destroying old desiring-machines. In its restless schizoid machinations, it cannot afford to stop at any frustration or joy, its impetus being to ceaselessly continue feeding desire-production. Thus, "desire is not desire for an object.... [Nor is it] a drive in the Freudian sense, and it is not a structure ... in the Saussurian model adopted by Lacanians" (Massumi 1992, 82). The core idea of Deleuze and Guattari is that the basic function of desire is to produce, to assemble, and to render machinic, meaning that "they give desire the means to not merely express itself, but [to] form something constructive" (Buchanan 2010, 125). Desire becomes the production of singular states of intensity, including disjunctive processes (which in the abstract machine are traversed by a "desire for abolition" (), and conjunctive ones (that result from the tension between free connective synthesis and fixed disjunctive synthesis).

\section{Agencement}

Nevertheless, and despite its obvious relevance and its power to enable a fundamental rethinking of structures within dynamic systems, the concept of desiringmachines appears only in Anti-Oedipus (first published 1972), being completely dropped thereafter. Its core characteristics are passed to the "new" concepts of abstract machines and assemblages, which vastly populate Kafka: Toward a Minor Literature (first published 1975), the Dialogues with Claire Parnet (first published 1977), and A Thousand Plateaus (first published 1980). According to Massumi $(1992,82)$, "due to persistent subjectivist misunderstandings ... the word was changed to the more neutral 'assemblage," and Deleuze seems to confirm this in his dialogues with Claire Parnet (Deleuze and Parnet 2007, 101). The general tendency to immediately associate desire with sexuality created particularly difficult problems in order to move toward wider social, political, artistic, and philosophical phenomena. Deleuze observes, "We do not believe in general that sexuality has the role of an infrastructure in the assemblages of desire.... No assemblage [agencement] can be characterized by one flux exclusively." He concludes (with obvious regret), "So Félix's fine phrase 'desiring machines' ought to be given up for these reasons" (ibid.).

6 On the notion of desire for abolition, see Sauvagnargues (2016, 193), particularly her remark that "The desire for abolition only has mortifying connotations for those wedded to the schema of identity. But when the abstract machine functions, it fails, it always fails, it necessarily fails, because any functioning involves the provisional singularity and uncertain contingency of a force that becomes exhausted right at the moment it gets going." 
The concept of agencement makes it appearance in 1975, in two texts: one co-authored by Deleuze and Guattari (Kafka: Toward a Minor Literature), where it plays a fundamental role; the other by Deleuze alone, a review of Michel Foucault's Surveiller et punir (1975), where it is first mentioned in relation to repression and ideology, which "explain nothing but always assume an assemblage or dispositif within which they operate, but not vice versa" (Deleuze [1988] 2006, 25-26; my emphasis, translation modified 7 ). The opening paragraphs of Kafka: Toward a Minor Literature, immediately address the basic components of an agencement, namely its forms of content and expression; but, interestingly, it is the concept of rhizome that is invoked and not agencement (see Deleuze and Guattari 1986, 3, 4). The concept of agencement is progressively developed through the book, culminating in the final chapter ("What Is an Assemblage?") after other notions have been exposed (minor, desire, series, connectors, intensities). According to Sauvagnargues, "the concept of rhizome is a good introduction to the concept of agencement, because it pedagogically insists on the multiplicity understood as a package of lines" (2011, 176-77, my translation). Such lines are mainly triple: a line of differentiation (molecular particles), a line of organisation (molar units), and a line of escape (the interstices between content and expression, potentiating cracks in the assemblage). With such lines, the rhizome (or the assemblage, or the dispositif) gains a kinetic and dynamic definition that renders it fluid and flexible, able to manifest itself in highly coded and territorialised stratifications, as well as in decoded and deterritorialised arrangements. Like a topological figure it can be stretched and folded, enhancing one or the other components to come to the fore. In the place of fixed structures, this dynamic vision makes it possible to view complex systems in terms of permanent change and variation. In its origins, the concept of agencement is particularly indebted to the work of the Danish linguist Louis Hjelmslev (whose theories will be described in more detail below), who Deleuze and Guattari ([1977] 1983, 243) emphatically declared (already in Anti-Oedipus) was the maker of "the only modern-and not archaic-theory of language," a theory that "stands in profound opposition to the Saussurian and post-Saussurian undertaking" (242) and that operated a "concerted destruction of the signifier" (243).

\section{Assemblage}

After Kafka: Toward a Minor Literature two additional features were added to the concept of agencement; in my view, these features are crucial to the definition of a proper concept of assemblage that is wider in scope and that has more components than the original concept of agencement. Dialogues (first published 1977) adds to content and expression their respective coefficients of stabilisation and

7 In the original translation, unfortunately, both crucial terms in this sentence-agencement and dispositif-have been lost, and translated as "organization" and "system," respectively. This obfuscates the intended meaning of the original concepts, as it misses an opportunity to establish a link between agencement and Foucault's concept dispositif. The French original is as follows: "la répression et l'idéologie n'expliquent rien, mais supposent toujours un agencement ou 'dispositif' dans lequel elles opèrent, et non l'inverse" (Deleuze 1986, 36 ). 


\section{Chapter 2}

becoming, and $A$ Thousand Plateaus (first published 1980) introduces the notion of the tetravalence of the assemblage (Deleuze and Guattari 1987, 89), which already implies the parametrisation of the concept that DeLanda (2006, 2016) analytically describes, based upon which he constructs his social ontology. Deleuze and Guattari are quite explicit about this, when they write:

On a first, horizontal, axis, an assemblage comprises two segments, one of content, the other of expression. On the one hand it is a machinic assemblage of bodies, of actions and passions, an intermingling of bodies reacting to one another; on the other hand it is a collective assemblage of enunciation, of acts and statements, of incorporeal transformations attributed to bodies. Then on a vertical axis, the assemblage has both territorial sides, or reterritorialized sides, which stabilize it, and cutting edges of deterritorialization, which carry it away. No one is better than Kafka at differentiating the two axes of the assemblage and making them function together. (Deleuze and Guattari 1987, 88)

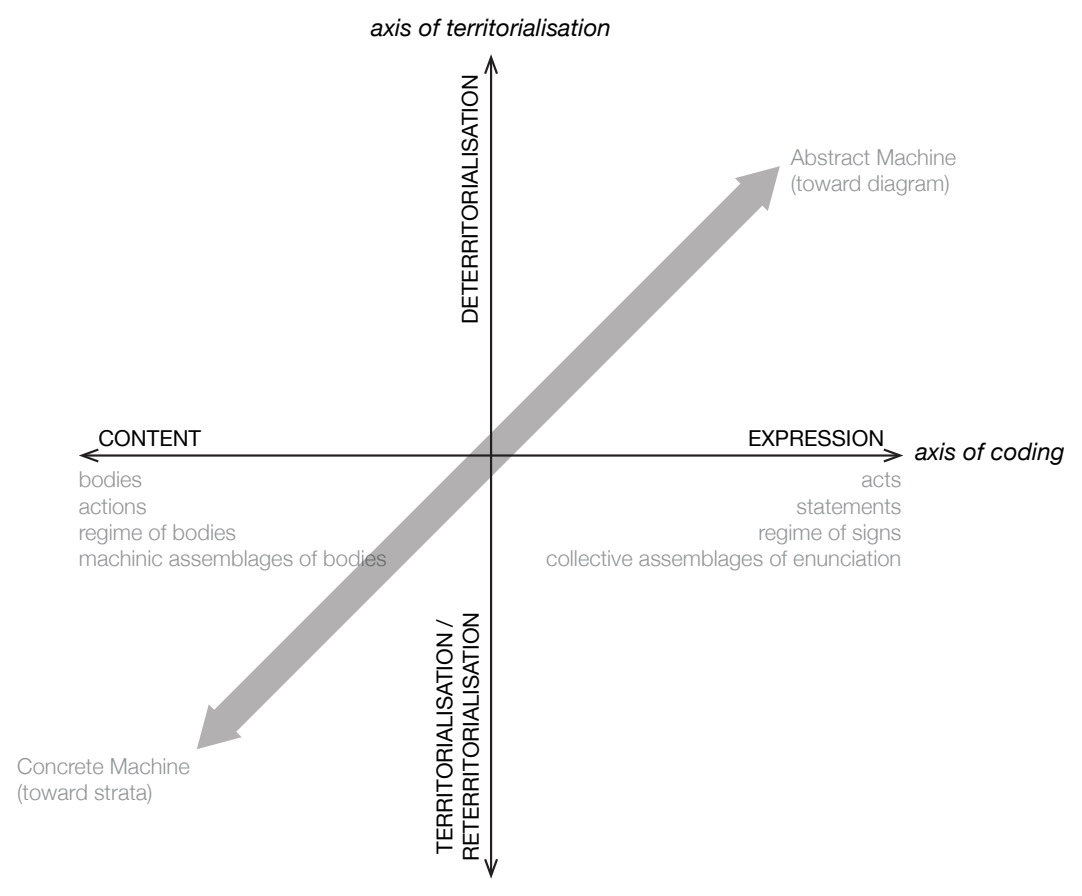

Figure 2.1.

Let us linger on this scheme, which offers a sort of map where the components and connectors of an assemblage can be situated. As a map, this scheme suggests the possibility of navigating any assemblage under scrutiny. As Deleuze and Guattari write, "the concrete machines are the two-form [content and expression] assemblages ..., whereas the abstract machine is the informal diagram. 
... It is as if the abstract [machine] and the concrete assemblages constituted two extremes, and we moved from one to the other imperceptibly" (Deleuze [1988] $2006,34^{-35}$, my emphasis). Importantly, let's keep in mind that an assemblage is primarily defined as a multiplicity, that is, it is not "a thing" but a complex arrangement of material, semiotic, and social flows (see Deleuze and Guattari $1987,22-23) .{ }^{8}$ Such flows have different degrees of coding and different degrees of territorialisation; they are more or less concrete, more or less abstract, more or less stratified, and they more or less escape the assemblage. A single semiotic flow doesn't produce an assemblage; it is always necessary to have several blocks, series, and segments of series to create a net of connections that finally enable the emergence of the assemblage. Thus, an assemblage is made of components (series of flows that will never stop proliferating) and connectors. Figure 2.2 schematically adds these components and connectors to Figure 2.1.

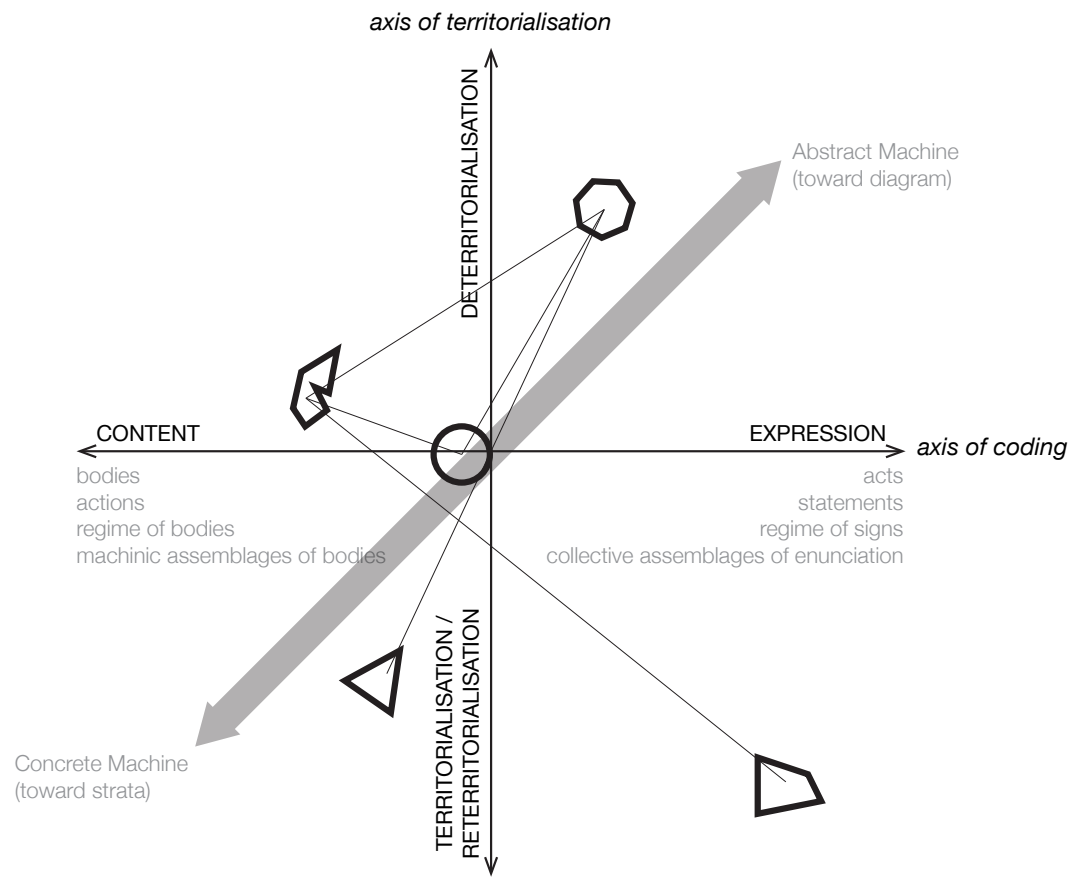

Figure 2.2.

The components are made of discursive and non-discursive forms, of forms pertaining to the visible and to the sayable, forms of content and forms of expression. The first example of an assemblage presented in Kafka is "the portrait of a porter with his head bent" (Deleuze and Guattari 1986, 3). In very simple terms, in this assemblage, the form of content is the bent head, and the form of expression is

8 "An assemblage, in its multiplicity, necessarily acts on semiotic flows, material flows, and social flows simultaneously." 
a portrait photo. In the case of Foucault's analysis of prisons and institutions of confinement, Deleuze identifies forms of expression in the physical building of the prison and in the penal code-the form of content being the prisoners. The same is true in relation to other forms of expression, such as schools, workshops, armies, and their respective contents: children, artisans, soldiers, and so on. Clearly, there is always a gap between the forms of the visible and the forms of the sayable: what we say is never what we do; what a code prescribes (or hopes to implement) is not what bodies do. As Deleuze has put it: "The concrete assemblages [being made of forms of content and forms of expression] are therefore opened up by a crack that determines how the abstract machine performs" (Deleuze [1988] 2006, 33).

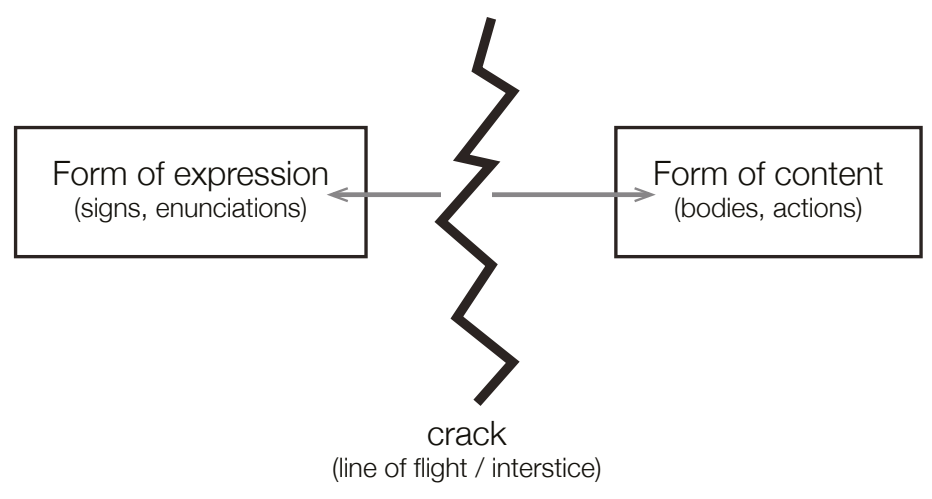

Figure 2.3.

Contrary to conventional perspectives based on the identity and endurance of entities, Deleuze and Guattari stress the positive power of such cracks within the system: "Expression must break forms, encourage ruptures and new sproutings. When a form is broken, one must reconstruct the content that will necessarily be part of a rupture in the order of things" $(1986,28)$. What would be a problem for structuralism and phenomenology (the discovery of a gap in the structure or of an inconsistency in the phenomena), becomes a source of creative possibilities, opening avenues for new arrangements of things.

On the other hand, the connectors that establish links between the forms of content and expression are also permanently changing and reconfiguring. They signal special points-singularities - that have the capacity to change state or phase within any given arrangement. They have the power to "augment the connections of desire in the field of immanence" (Deleuze and Guattari 1986, 63). These points are not subjective or aesthetic impressions that an assemblage may (or may not) induce in the bodies that come into contact with it; instead, they are markers of objects, characters, events, tendencies-they are by no means "impressions." As Deleuze and Guattari (ibid., 70) say in relation to Kafka: "This is why subjective impressions are systematically replaced by points of connection that function objectively as so many signals in a segmentation, so many special or singular points in a constitution of series.... The for- 
mula of the artist machine or of the machine of expression must be defined in a completely different way. ... Machinic definition, and not an aesthetic one."

Thus, as the scheme of the assemblage's tetravalence makes clear, an assemblage has two sides: on the one hand it is a collective assemblage of enunciation, on the other it is a machinic assemblage of bodies. But that's not all. An assemblage extends itself over several contiguous segments, which may be better described as pertaining to yet another assemblage, and any assemblage has points of deterritorialisation that may stop the assemblage from functioning altogether. Those cracks in the assemblage, its lines of escape, of flight, and of disarticulation, operate a continuous process of disassembly $y^{9}$ of the assemblage. Thus, assemblages include innumerable components and relate to various other concepts. Our only chance to grasp them, or to explain them, is to take them apart, in order "to examine both the elements that make [them] up and the nature of [their] linkages" (Deleuze and Guattari 1986, 53). In what follows, I will address the notions of strata and diagram, as they seem to configure the extreme cases of the concrete and the abstract machines, creating a wide field in which any given assemblage can take different forms and shapes, allowing its components and connectors to move "from one to the other imperceptibly" (Deleuze [1988] 2006, 34-35).

\section{STRATA}

The components of an assemblage that are characterised by a high degree of both coding and territorialisation, and that are concretely tied to a material fixation in the world, are called strata. They result from intensive processes of stratification, and they are made of formed matter and operative functions. As Eugene B. Young $(2013,298)$ has put it: "While structuralism emphasises interrelations that are often dehistoricized, the concept of strata permits an understanding of layers both in terms of space and time." Strata convey a specific, time-andspace-bound historical dimension that reveals them as historical formations; and history-according to Deleuze in "Michel Foucault's Main Concepts" (Deleuze 2007b) - is taken as an archive, or as a series of strata from which thinking draws its power and virtue. Strata are important not in themselves-not because of their historicity - but in so far as they give notice of intensive processes of individuation, processes that have the capacity to let us think their genesis in ever-changing arrangements and configurations: "[What is historical are] the formations which are stratified, made up of strata. But to think is to reach a non-stratified material, somewhere between the layers, in interstices" (ibid., 241). As Deleuze underlines, Foucault referred to part of his activity as "studies in history," but he insisted that these studies were not "the work of an historian" (ibid.). For the crucial point about the study of strata is to look at them not from a historical but from a philosophical and artistic perspective, checking them against the grain of common sense (which emphasises an idealised past against the present), and revealing them as (fragmentary) building blocks of a time to

9 The original word is démontage (see Deleuze and Guattari 1975, 146). 
come, thus contributing to their futurity. In this sense, the strata are "the affair of archaeology," but only because "archaeology does not necessarily refer back to the past. There is an archaeology of the present" (Deleuze [1988] 2006, 50). Instead of looking at the strata with a nostalgic, retrospective, and regressive gaze, one can confront them with their own future, fostering a productive tension between the sedimented and dynamic parts of a particular historical arrangement. As Deleuze writes ([1988] 2006, 98): "On the limit of the strata, the whole of the inside finds itself actively present on the outside. The inside condenses the past (a long period of time) in ways that are not at all continuous but instead confront it with a future that comes from outside, exchange it and re-create it. To think means to be embedded in the present-time stratum that serves as a limit: what can I see and what can I say today?"

But what are strata, concretely? According to Deleuze ([1988] 2006, 41), "strata are historical formations.... made from things and words, from seeing and speaking, from the visible and the sayable, from bands of visibility and fields of readability, from contents and expressions." They are the result of temporal and intensive processes that captured certain forces and singularities within a sedimentary bed, layers, or belts. Each stratum serves as the substratum for another stratum, thus generating history, or at least making historical sequences of things and events graspable. In simple terms, strata "consist of giving form to matters, of imprisoning intensities or locking singularities into systems of resonance and redundancy" (Deleuze and Guattari 1987, 40).

Strata proceed and take shape by means of two complementary operations, coding and territorialisation: "They operate by coding and territorialization upon the earth; they proceed simultaneously by code and by territoriality" (ibid.). According to Manuel DeLanda (2016, 22), who offers the most comprehensive and transparent analytical account of these concepts to date, "coding refers to the role played by expressive components in an assemblage in fixing the identity of a whole." Examples of such "expressive components" include chromosomes, languages, and viruses, all of which have very strict and resilient modes of transmitting and reproducing their deep inscriptional tools. Further examples include institutional organisations, corporate regulations, and the state apparatus, which all have highly coded modes of expressions and behaviour: "The more despotic a state apparatus, the more everything becomes coded: dress, food, manners, property, trade" (ibid., 23). Territorialisation refers to the degree of homogeneity and cohesion in the components of a specific arrangement of things - it indicates the sharpness of its boundaries (territorialisation), or of their destabilisation (deterritorialisation). Importantly, territorialisation also relates to non-spatial processes that increase the homogeneity of an arrangement, such as social, political, or racial segregation or discrimination, which increase the ethnic or racial homogeneity of a community. On the contrary "any process which either destabilizes spatial boundaries or increases internal heterogeneity is considered deterritorializing" (DeLanda 2006, 13). Thus, the notion of territorialisation doesn't directly relate to the physical borders or limits of a group, community, or state apparatus, but rather to "a mobile and shifting centre that is localisable as a specific point in space and time" (Message 
2005, 275). Accordingly, a territory is marked by the ways movement occurs over a space. The famous examples of such movement presented by Deleuze and Guattari are the refrain of a birdcall, which encapsulates a mode of expression that draws a territory and envelops into territorial motifs and landscapes, and the artist's signature, which resembles the placing of a flag on a piece of land and which creates a field of forces identifiable as "the author's effect." Processes of stratification happen, and concrete strata take shape, when these two parameters (coding and territorialisation) have high values.

\section{Geology (flysch)}

The concept of strata has an obvious geological origin and figure 2.4 provides a simple (and simplified) illustration of its basic processes and components. Deleuze and Guattari introduce this notion in the third plateau of $A$ Thousand Plateaus ("10,0oo BC: The Geology of Morals (Who Does the Earth Think It Is?)"), where Arthur Conan Doyle's fictional character Professor Challenger starts quoting sentences on strata taken from "a geology textbook" (Deleuze and Guattari 1987, 40). According to this (obviously unnamed) book, strata are the result of a double process, which they call double articulation. As Deleuze and Guattari explain (ibid., 40-41):

Each stratum exhibits phenomena constitutive of double articulation.... The first articulation chooses or deducts, from unstable particle-flows, metastable molecular or quasi-molecular units (substances) upon which it imposes a statistical order of connections and successions (forms). The second articulation establishes functional, compact, stable structures (forms), and constructs the molar compounds in which these structures are simultaneously actualized (substances). In a geological stratum, for example, the first articulation is the process of "sedimentation," which deposits units of cyclic sediment according to a statistical order: flysch, with its succession of sandstone and schist. The second articulation is the "folding" that sets up a stable functional structure and effects the passage from sediment to sedimentary rock.

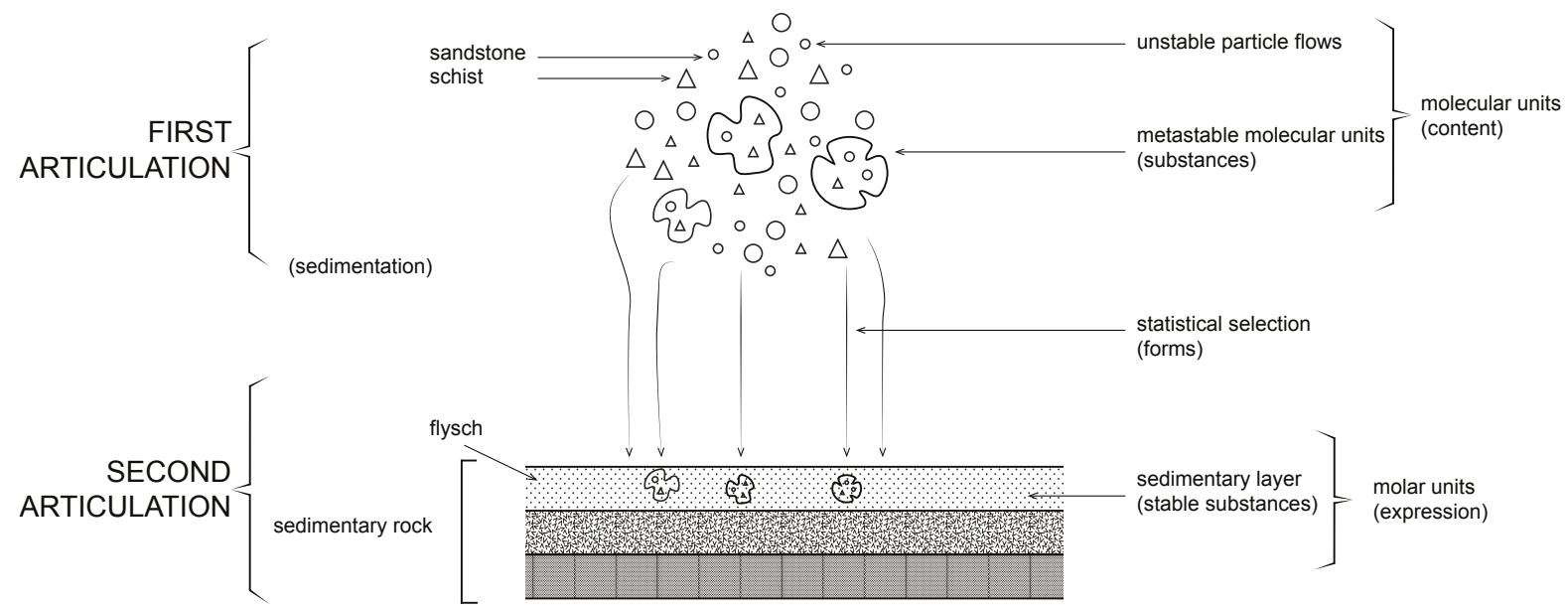

Figure 2.4. 
Thus, the first articulation concerns the materiality of the stratum, with the selection of the raw materials. The form and the substance of these materials is that of particle flows, of molecular entities in the process of being mainly (but not exclusively) territorialised (the sedimentary process). On the other hand, the second articulation concerns the expressivity of the stratum, with the folding of materials, and the manifestation of emergent properties (which are not present in the basic particle flows). The form and substance of these strata is that of sedimentary beds, of molar entities with a specific set of coding. The first articulation moves from molecular substances to molar forms; the second articulation moves from molecular forms to molar substances. Each articulation operates through form and substance: the first selects only some materials, out of a wider set of possibilities, and gives them a statistical form; the second gives these loosely ordered materials a more stable form and produces a new, larger-scale material entity.

This description of the processes of strata formation captures just one moment within a broader dynamic and temporal sequence of events. Deleuze and Guattari do not explicitly discuss the distinction between scales, but they do suggest it. First, in relation to the co-presence of coding and territoriality in each articulation, they write that "each articulation has a code and a territoriality; therefore each possesses both form and substance" (Deleuze and Guattari 1987, 41). And, they add, "substances are nothing other than formed matters" (ibid.), implying the existence of another double articulation, prior to the formation of the "metastable molecular units" of sandstone and schist. Not only those units but also those "unstable particles" (the single pebbles) are already forms with "a code, modes of coding and decoding" (ibid.). At the same time, Deleuze and Guattari also refer to (micro) "territorialities and degrees of territorialization and deterritorialization" (ibid.). Second, on a larger scale (figure 2.5), once the sedimentary rock is defined, it starts further processes of the accumulation of layers and tectonic foldings, leading to larger scale emergent entities: folded mountains like the Alps and the Pyrenees.

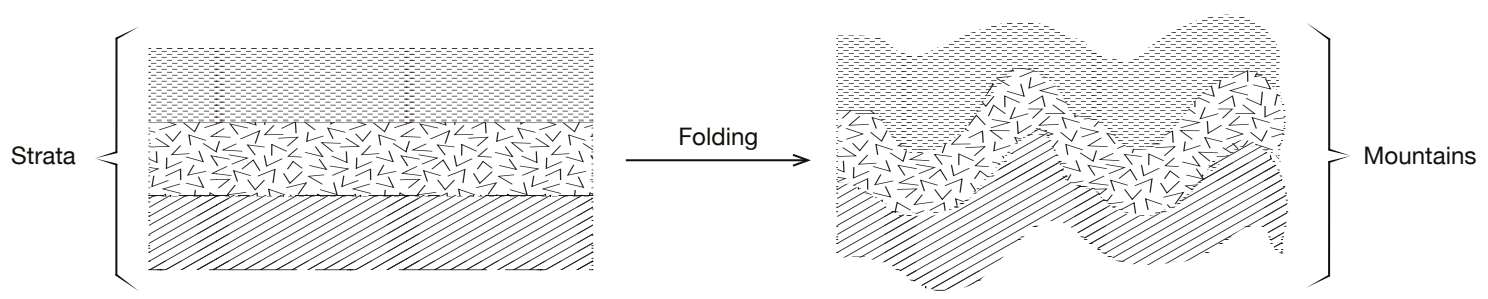

Thus, what has been regarded as being molecular becomes molar, and this new molar entity could become molecular in relation to wider processes of transformation: "Moreover, it cannot be taken for granted that the distinction between the two articulations is always that of the molecular and the molar" (Deleuze and 
Guattari 1987, 41). Now, it is the sedimented layer, which seemed stable at a certain scale, that becomes a metastable unit, lending itself to further processes of expression - a term that refers to the fact that something has acquired a performative function (see Buchanan 2017, 472). ${ }^{10}$ Contrary to the remark that "Deleuze and Guattari fail to make a distinction between different scales" (DeLanda 2016, 24), they explicitly write

\begin{abstract}
materials are not the same as the unformed matter of the plane of consistency; they are already stratified, and come from "substrata." But of course substrata should not be thought of only as substrata: in particular, their organization is no less complex than, nor is it inferior to, that of the strata... The materials furnished by a substratum are no doubt simpler than the compounds of a stratum, but their level of organization in the substratum is no lower than that of the stratum itself. The difference between materials and substantial elements is one of organization; there is a change in organization, not an augmentation. (Deleuze and Guattari 1987, 49)
\end{abstract}

\title{
Paleo-anthropology (Laviosa Zambotti)
}

After discussing other examples of double articulations in chemistry, linguistics, zoology, and biology, Professor Challenger's lecture secretly turns to paleoanthropology, making major references to the notions of strata, substrata, epistrata, and parastrata, which were coined in 1947 by the Italian paleoanthropologist Pia Laviosa Zambotti (see Laviosa Zambotti 1949). Deleuze and Guattari mention her work in two footnotes (Deleuze and Guattari 1987, 522n14, n16), acknowledging her first use of these notions and calling attention to "her conception of waves and flows from center to periphery, and of nomadism and migrations (nomadic flows)" (ibid., 522n16). Thus, the focus changes from strata as geological formations, to strata as cultural interaction between populations in movement, encountering each other at different speeds and levels of civilization. Laviosa Zambotti's main thesis is that the concept of civilisation results from a concentration and superimposition of cultures on top of one another, and that the expansion of civilisation throughout the Earth's ecumene originated in one single focal point. The originality of her thought (which is stressed by Mircea Eliade in the preface to the French translation of her book [see Eliade 1949, i-iv, my translation]), was to view culture as the result of "intensive and continuous collaboration between different human groups" (ibid., iii), which start and take shape from specific centres of diffusion, which crucially she studied in a planetary dimension that allowed a totally renewed and dynamic view of the dissemination of human cultures throughout the whole of the Earth's ecumene (Laviosa Zambotti 1949, 41).

10 Buchanan $(2017,472)$ writes: “for Deleuze and Guattari, expression, or better yet 'becoming expressive,' does not mean simply that something has acquired meaning(s) in the semiotic sense; rather, it refers to the fact it has acquired a performative function." 


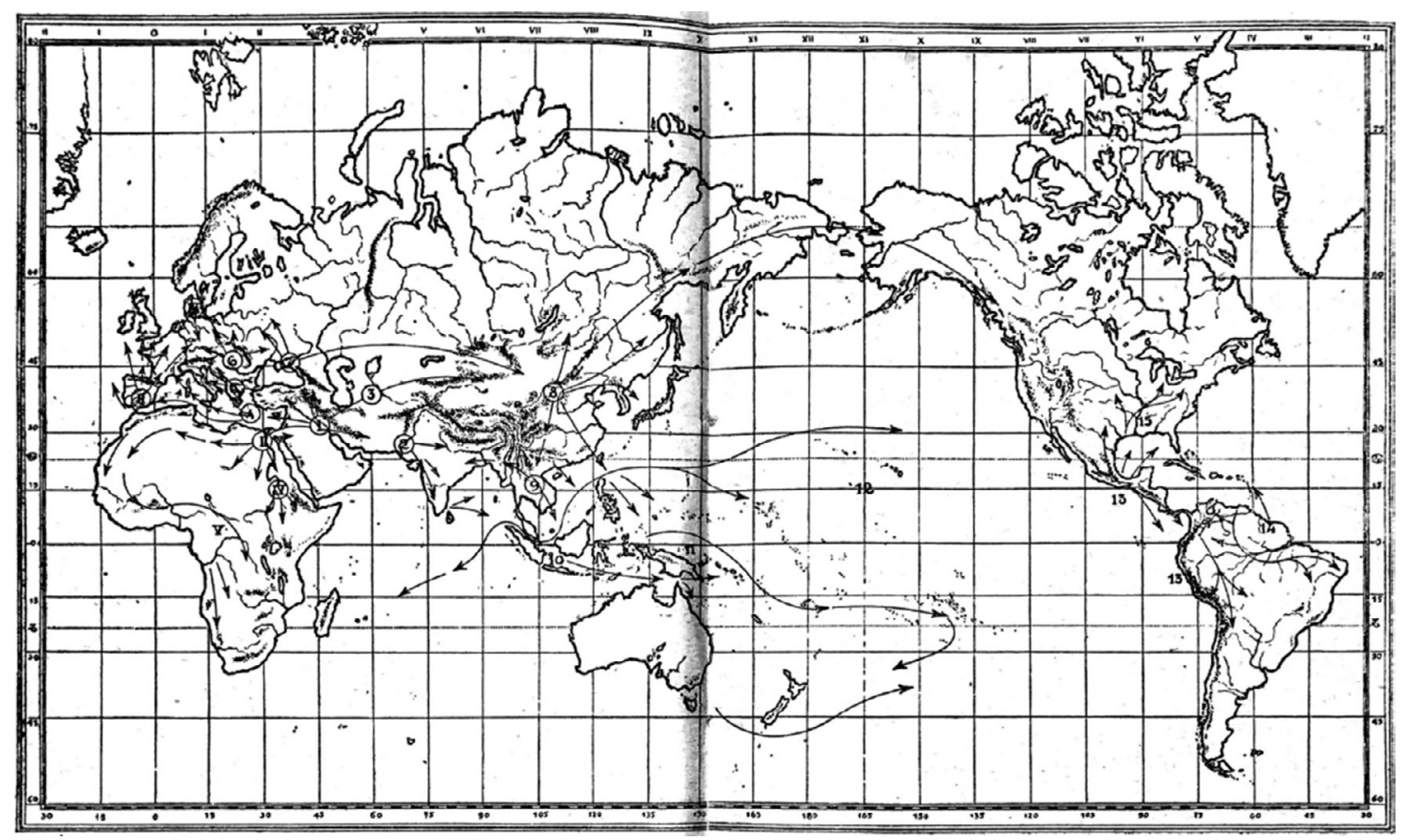

Figure 2.6.

Especially in chapter four of her book, Laviosa Zambotti describes how nomadic populations progressively moved, marked, and occupied territories along the ecumene (see figure 2.6). She focuses on the interaction between such nomadic populations and the stable groups they encountered in their trajectories. It is in the moment of the encounter that Laviosa Zambotti identifies the presence and effect of different strata: the substrate ${ }^{11}$ that (pre)existed in the territory and in the configurations designed by the stable groups, and the parastrata, which progressively emerge through the interaction of the two populations. Figure 2.7 schematically represents her view of the formation and interaction between the different strata. In the case of an encounter between a nomadic population and a territorially fixed community (see figure $2.7 \mathrm{a}$ ), there is a process of interaction between the substrata that configure the milieu of the fixed community and the parastrata brought by the nomadic group. This interaction results in the formation of (new) epistrata. None of the strata disappear; rather, they are laid one on top of the other, creating superimposed, multilayered arrangements of strata. The other process (figure $2.7 \mathrm{~b}$ ) relates to the expansion of a given community, moving

11 Laviosa Zambotti defines substrata as follows: "In the archaeological sense, we call a substrate the culture that, within the process of stratification, finds itself placed underneath another one" (Laviosa Zambotti 1949, 54, my translation). 
from a stable centre toward the periphery of their territory, where newly derived centres are founded. These new centres establish new connections, which result from the interactions between their own substrata and their newly configured milieu. This interaction produces parastrata, epistrata, and metastrata. ${ }^{12}$
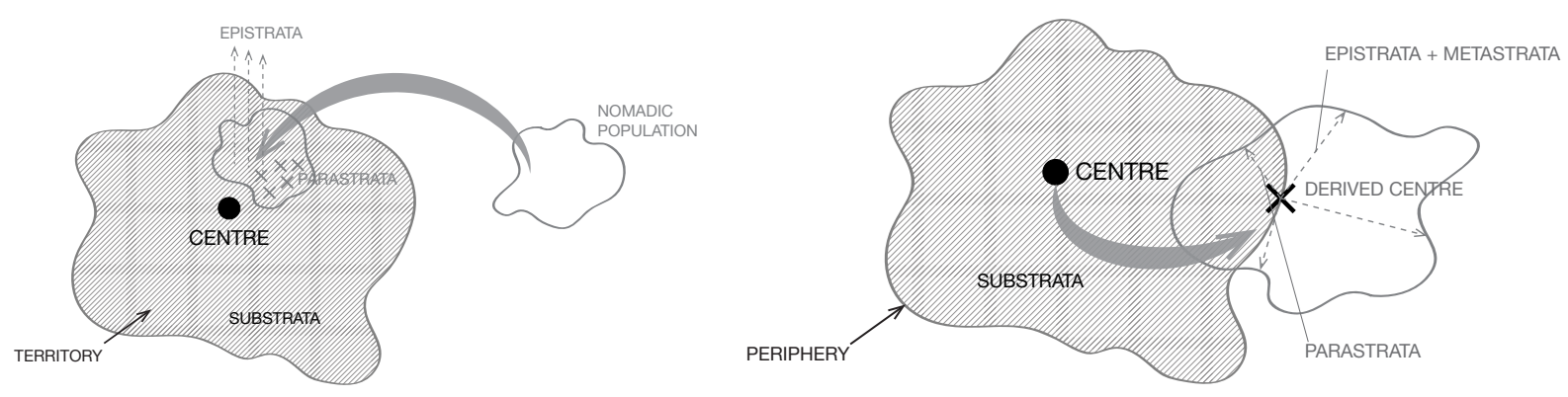

Laviosa Zambotti focuses on precise prehistorical and historical events (mostly from Europe and Asia), and the notions of strata remain actually underdeveloped in her book. It is thanks to Deleuze and Guattari that these ideas gained a wider importance and were applied to other realms and topics. They retain three fundamental ideas from Laviosa Zambotti: first, that human populations always move from one radiating centre to diverse peripheries, which become (new) centres under their own powers, creating a new milieu: "Nomadic waves or flows of deterritorialization go from the central layer to the periphery, then from the new center to the new periphery, falling back to the old center and launching forth to the new" (Deleuze and Guattari 1987, 53). Second, they preserve the idea that the diffusion of culture happens through phenomena of contagion-population A contaminating population B, and vice versa- "The central ring does not exist independently of a periphery that forms a new center, reacts back upon the first center, and in turn gives forth discontinuous epistrata" (ibid., 51). Last, and as a consequence, the diverse strata gain more specific functions: the substrata define the basic coding and territorial conditions of the encounter, the parastrata emphasise processes of decoding and overcoding, while the epistrata involve territorialisations, deterritorialisations, and reterritorialisations: "Forms relate to codes and processes of coding and decoding in the parastrata; substances, being formed matters, relate to territorialities and movements of deterritorialization and reterritorialization on the epistrata... The organization of the epistrata moves in the direction of increasing deterritorialization" (ibid., 53).

12 This last notion, metastrata, was coined by Deleuze and Guattari and is not mentioned by Laviosa Zambotti. 
With this last characterisation of strata, we are already moving towards a much more fluid notion of historical contingent formations, which consist of populations of interacting entities that might act as a source of limitations and affordances for its components. It is possible for strata (like assemblages in general) to undergo destabilising processes affecting their materiality or their expressivity, or both. Therefore, they may be subject to continuous or sudden processes of deterritorialisation and decoding. This is because, as Deleuze and Guattari $(1987,55)$ state: "the strata are continually being shaken by phenomena of cracking and rupture, either at the level of the substrata that furnish the materials (a prebiotic soup, a prechemical soup ...), at the level of the accumulating epistrata, or at the level of the abutting parastrata: everywhere there arise simultaneous accelerations and blockages, comparative speeds, differences in deterritorialization creating relative fields of reterritorialization.” Thus, strata are not perennial, and they might be opened up by a crack that determines how they function within a new arrangement of forces, discourses, and matters. This crack is real, it is part of any strata: it is the line of escape that is placed at the interstices of the strata's form of expression (signs and enunciations) and its form of content (bodies and actions).

\section{Linguistics (Hjelmslev)}

The terms content and expression, with their associated notions form of content, form of expression, substance of content, and substance of expression, were extracted by Deleuze and Guattari from the work of Danish linguist Louis Hjelmslev, particularly from his book Prolegomena to a Theory of Language from 1943 (Hjelmslev [1953] 1969). Guattari discovered his work in the 1970s, and he convinced Deleuze that Hjelmslev's linguistic theory offered a tool that would help overcome the structuralism that dominated French linguistics at the time: "I think it's with Hjelmslev, maybe Peirce ... on the one hand, and on the other with the founders of axiomatic theory, that we can find the key to 'clearing' out ... structuralism" (Guattari 2006, 38). It was particularly Lacan's "structuralisation” of psychoanalysis that Guattari posited as "the enemy" to attack and criticise. For Guattari-in contrast to Lacan's main assumption - the unconscious is not structured like a language: "Lacan was wrong to identify displacement and condensation with Jakobson's metaphor and metonymy on the level of the primary processes. He is turning everything into linguistics, and diachronizing, crushing, the unconscious" (Guattari 2006, 73).13 Lacan's structuralised psychoanalysis, which is one of the designated adversaries of Anti-Oedipus, leaned massively on Saussure and Jakobson. And this is the reason why Deleuze and Guattari made a violent critique of the Saussurian theory of the sign, which implied a definition of the linguistic field as transcendence turning around a master signifier. This linguistics of the signifier was to be replaced by a completely different linguistics of flux, and Guattari believed that Hjelmslev was the author who could provide the fundaments for such an alternative

13 Guattari is specifically referring to page 799 of Lacan's essay "Subversion du sujet et dialectique du désir dans l'inconscient freudien” (Lacan [1960] 1966, 793-827). 
linguistics. ${ }^{14}$ Thus, Hjelmslev was "enrolled" in Deleuze and Guattari's construction of a semiotic machine against structural semiology (see Dosse 2010, 232).

Of all the concepts and functions developed by Hjelmslev, Deleuze and Guattari specifically focused on his distinction between the reversible planes of expression and content (which they interpreted in their own way). For Hjelmslev there was only a single plane of consistency, which unfolded in multiple strata, thus overcoming Saussure's fundamental binarism between signifier and signified. This seemed to allow for a "purely immanent theory of language that shatters the double game of the voice-graphism domination, that causes form and substance, content and expression to flow according to the flows of desire; and that breaks these flows according to points-signs and figures-schizzes" (Deleuze and Guattari [1977] 1983, 242-43). In a highly laudatory tone, Deleuze and Guattari even describe Hjelmslev's linguistics as operating the destruction of the signifier: "Far from being an overdetermination of structuralism and of its fondness for the signifier, Hjelmslev's linguistics implies the concerted destruction of the signifier, and constitutes a decoded theory of language" (ibid., 243).

Hjelmslev did indeed intend to create a new theory of language, in which the positioning within linguistics of the subdisciplines of phonetics, morphology, syntax, lexicography, and semantics could be reconsidered, evolving the discipline toward a sort of algebra of language based on stratified layers of functions and contents. He called this new linguistics glossematics (see Hjelmslev [1953] 1969, 59-60). Instead of the arborescent system of language's network structures, Hjelmslev devised a stratified model, in which context (doings), semantics (meanings), lexicogrammar (sayings, wordings), and phonology (soundings) function as superimposed layers, defining a quasi-geological stratification of components. According to Guattari "the perspective opened by Hjelmslev ... consisted in admitting that semantic creativity can discover its origin in the concatenation of figures of expression and figures of contents" (Guattari 2011, 25 , my emphasis). In his critique of structural linguistics (especially what he calls "orthodox Chomskyans" [ibid., 24]), Guattari insists on the centrality of Hjelmslev's theories, exactly in relation to the notions of content and expression: "a return to Hjelmslev, or rather a detour through Hjelmslev, could be fruitful. It is by no means a question of renewing his project of the radical axiomatization of language, but of setting out from some of his categories that appear to be the only ones to come from a truly rigorous examination of the ensemble of semiotic problematics, while drawing, in particular, on all the consequences of his calling into question of the status of content and expression" (ibid., 41). It was the potential of these concepts to overcome the classical (Saussurian) opposition between signifier and signified that most interested Guattari: "In any event, at the most essential level of what the glossematicians call the 'semiotic

14 One should notice that Hjelmslev's system is actually even more formal than the systems of Saussure or Jakobson, but Deleuze and Guattari made a very personal interpretation of his work. As François Dosse observed (2010, 231-32): "In fact, Hjelmslev, the inventor of 'glossematics,' had initiated an even more formal linguistics than Saussure's, but Deleuze and Guattari had very little to do with glossematics and changed Hjelmslev's ideas slightly to serve their real purpose of using him against Saussurian thinking by creating a truly pragmatic linguistics." 
function,' the form of expression and form of content contract in order to constitute a 'solidarity' that radically relativizes the traditional opposition of the signifier and the signified" (ibid., 41-42). Importantly, Guattari clearly states the limits of Hjelmslev's own endeavour, which is seen as regrettably remaining within a Saussurian horizon of thought, ${ }^{15}$ and his claim is that his notions could be appropriated and expanded in his joint work with Deleuze towards Anti-Oedipus.

Hjelmslev develops the notions of content and expression in relation to his theory of signs, particularly to what he calls the "sign function" (Hjelmslev [1953] 1969, 47). Contrary to the traditional understanding according to which "a sign is first and foremost a sign for something" (ibid.), he tries to analyse the sign as a purely operative function, looking at its precise internal functioning, and not so much at its role as a mediator between a signifier and a signified. This sign function consists of two functives ${ }^{16}$ that contract the function in two different modes: one functive is called expression, the other, content. Expression and content (as functives) operate a fundamental contraction of the sign function itself: "There will never be a sign function without the simultaneous presence of both these functives; and an expression and its content, or a content and its expression, will never appear together without the sign function's also being present between them.... Thus, there is also solidarity between the sign function and its two functives, expression and content" (ibid., 48). An expression is expression only by virtue of being an expression of content, and content is content only by virtue of being the content of an expression. Therefore, there can be no content without an expression, nor can there be expressionless content; neither can there be an expression without content, or content-less expression (see ibid., 49). This leads Hjelmslev to conclude that "the distinction between expression and content and their interaction in the sign function is basic to the structure of any language" (ibid., 58).

Crucially, Guattari departs from language and linguistics, and discusses these functions, functives, and contractions in wider semiotic arrangements. In his 1979 book The Machinic Unconscious (see Guattari 2011), he addresses nonlinguistic and asignifying semiotic assemblages, looking at their molecular substances and molar units in terms of processes of coding and territorialisation precisely based upon the notions of content and expression that he appropriates from Hjelmslev. As Guattari writes $(2011,42)$ : "it is by semiotizing the most basic materials that [the] solidarity or this congruence of forms-

15 Guattari $(2011,41)$ writes: "One can certainly consider it regrettable that the Hjelmslevian double of expression and content in fact coincides with the Saussurian couple of the signifier and the signified, which causes the entirety of semiotics to fall under the dependence of linguistics."

16 On the notions of function and functive, Hjelmslev offers the following definitions: "A dependence that fulfils the conditions for an analysis we shall call a function. Thus we say that there is a function between a class and its components (a chain and its parts, or a paradigm and its members) and between the components (parts or members) mutually. The terminals of a function we shall call its functives, understanding by a functive an object that has function to other objects. A functive is said to contract its function. From the definitions it follows that functions can be functives since there can be a function between functions. Thus there is a function between the function contracted by the parts of a chain with each other and the function contracted by the chain with its parts. A functive that is not a function we shall call an entity" (Hjelmslev [1953] 1969, 33). 
which coincides here with the abstract machinism of language-constitutes the substances of expression and content." As the two basic components of any semiotic arrangement, they can only be defined and taken into account in relation to one another. With Hjelmslev's notions of expression plane and content plane ([1953] 1969, 59), Guattari (now with Deleuze) observes that "content and expression are two variables of a function of stratification" (Deleuze and Guattari 1987, 44). This happens, because content and expression vary from one stratum to another, intermingling, and infinitely multiplying and dividing within the same stratum.

In their reading of Hjelmslev, which is conveyed through Professor Challenger's eccentric lecture, Deleuze and Guattari insist upon the notion of stratification, which is central to Hjelmslev's glossematics (and which is part of the title of his collection of essays La stratification du langage), and which allows them to call him "a Danish geologist." Relating Hjelmslev's theory to their own geological and paleo-anthropological consideration of the notion of strata and its double articulation, its form of content and its form of expression, Deleuze and Guattari appropriate Hjelmslev's concepts in terms of processes of individuation and stratification of matter and flows of intensities, which temporally shape formed matters and functional structures. Figure 8 provides a simplified visualisation of the basic components of Hjelmslev's semiotic model of language (also called model of stratification) and its respective interpretation by Deleuze and Guattari, as it can be found in A Thousand Plateaus (Deleuze and Guattari 1987, particularly 43-44). I invite the reader to look at the scheme and to read Deleuze and Guattari's (1987) appropriation of Hjelmslev's terminology, which can be summarised in the following points:

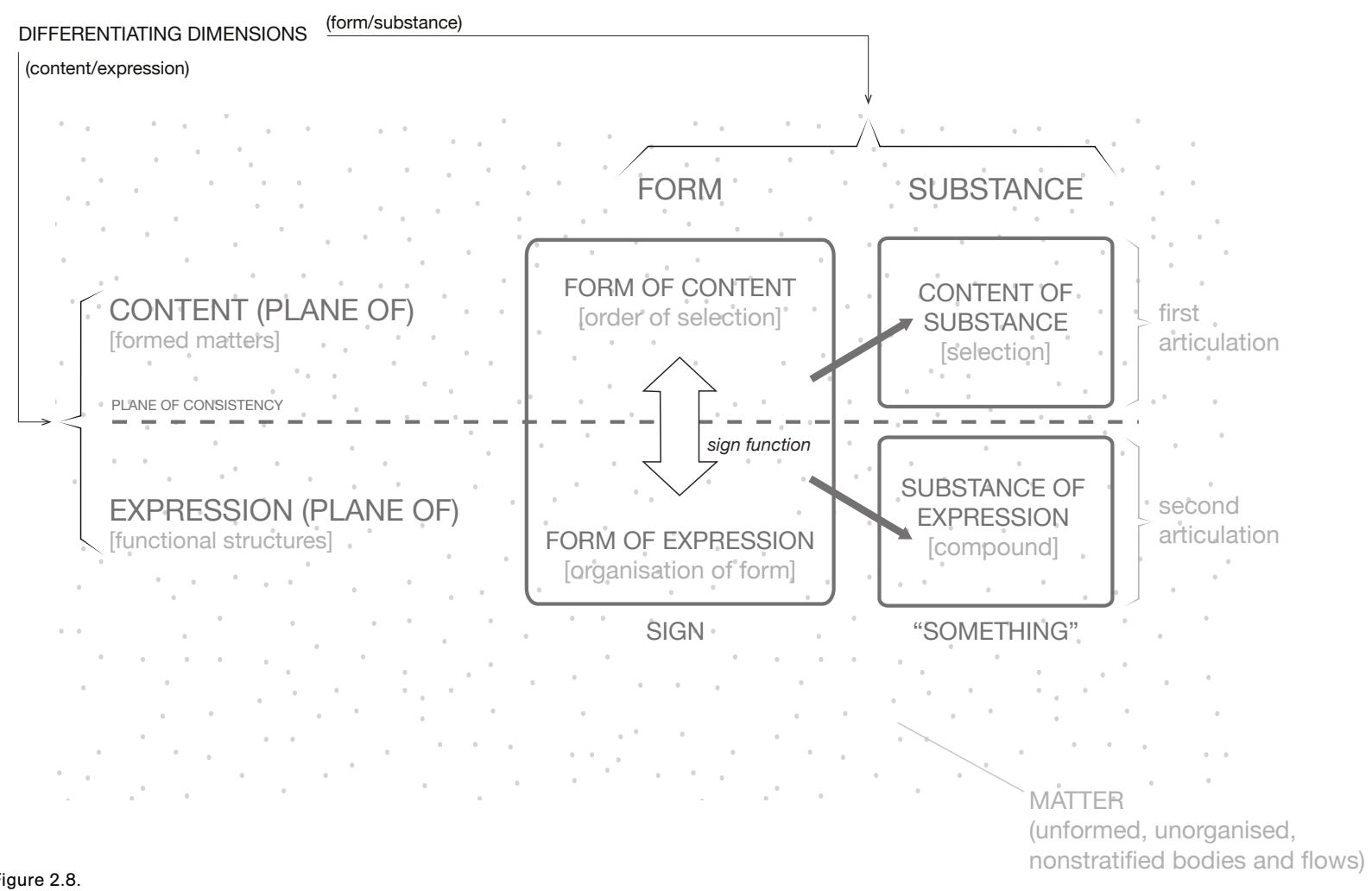


- "Content and expression are two variables of a function of stratification" (44).

- "[Hjelmslev] used the term matter for the plane of consistency ... the unformed, unorganized, nonstratified, or destratified body and all its flows: subatomic and submolecular particles, pure intensities, prevital and prephysical free singularities" (43).

- "He used the term content for formed matters, which [are] considered from two points of view: substance, insofar as these matters are 'chosen,' and form, insofar as they are chosen in a certain order (substance and form of content)" (43, my emphasis).

- "He used the term expression for functional structures, which would also have to be considered from two points of view: the organization of their own specific form, and substances insofar as they form compounds (form and content of expression)" (43, emphasis adjusted).

- The first articulation concerns content, the second articulation concerns expression. The distinction between the two articulations is not between forms and substances but between content and expression (41, my paraphrase).

- "The distinction between content and expression is always real, in various ways, but it cannot be said that the terms preexist their double articulation. ... On the other hand, there is no real distinction between form and substance, only a mental or modal distinction [scale]" (44, emphasis removed). In this particular reading of Hjelmslev's theories, Deleuze and Guattari's description of the function of stratification comes close to their descriptions of agencement and, by extension, of assemblage. As a function, an assemblage is not a thing in the world. On the contrary, as Buchanan $(2017,463)$ reminds us, "it is assemblages that explain the existence of things in the world, not the other way round." Things appear in the world as a result of individuating agency (human and nonhuman), and they contain formed matters and functional structures. Thus, assemblages are structured and structuring; they are not purely processual. Their material components must always be produced; they do not simply exist. The material of an assemblage is not the unformed matter of chaos; it is the formed and functionalised folding of matter on a plane of consistency or of composition. In this way, one can say that the assemblage has two faces: one looking at the state of things (particles/bodies, content), the other looking at a system of signs (functions, expression). The first gaze reveals a machinic assemblage of bodies, the second, a collective assemblage of enunciation. It is the interplay between the two gazes that defines an assemblage and that permits a productive solution of the problem of the relationship between content and expression. Contrary to what structuralism believed, it is not expression that produces content; and contrary to Marxism, it is not content (economic infrastructure) that produces expression (ideological superstructure). There is no infra- or superstructure, just as there is no archetypical matrix defining language and things "from above." There is only a flat plane of consistency, in which contents and expression are articulated. The question, then, is how and under what conditions does matter become material? How and under what conditions is a plan of articulation defined? Diagram is what Deleuze and Guattari call this plan upon which contents and expression are articulated. As Krtolica writes (2009, 106, my translation): "The 
diagram is the map of the balance of forces, which are incarnated in concrete assemblages by the means of a double differentiation: forms of content (visible) and forms of expression (sayable)." The concept of diagram is thus inseparable from the notions of strata and assemblage. Like the strata and the strata's lines of escape, it is an important component of an assemblage. The diagram is the assemblage's virtual part, which is real because the diagram maps functions and informal matters that effectively act upon the actual, and it remains virtual because the incarnations it implies are effectuated on the strata and not in the diagram itself, which remains non-representational. As a map of virtuality, the diagram points to all possibilities before they are actualised, it "charts the relation of forces that can be utilized or made manifest in various situations" (Zdebik 2012, 7).

\section{Diagram}

Deleuze found the concept of diagram in Foucault's Discipline and Punish, where it is used in relation to prisons and penal codes from the seventeenth and eighteenth centuries. In his review of that book, published in 1975 as "Écrivain non: Un nouveau cartographe" (Deleuze 1975), Deleuze precisely articulates the inseparable relation between the concept of assemblage (agencement) and diagram. Reflecting on the double meaning of an assemblage's form (form of content, form of expression), Deleuze states that there is a correspondence between the meanings, which can be explained by the fact that "we can conceive of pure matter and pure functions, abstracting the forms which embody them" (Deleuze [1988] 2006, 29). This allows us to think of an abstract machine that "passes through every articulable function," and that is "always concerned with unformed and unorganized matter and unformalized, unfinalized functions" (ibid.). It is this new informal dimension that Deleuze, following Foucault, calls "a diagram" (ibid., 30): a machine that functions "abstracted from any obstacle ... or friction [and which] must be detached from any specific use" (Foucault 1977, 205). ${ }^{17}$ The diagram is, thus, an abstract machine defined by its informal functions and matter. It does not make a distinction either between content and expression or between discursive and non-discursive formations. Highly unstable or fluid, the diagram is "continuously churning up matter and functions in a way likely to create change" (Deleuze [1988] 2006, 34). In this sense, it makes it possible to conceive the transformations that affect real entities, enabling a concrete effectivity of modulations and becomings. The diagram includes and encapsulates the vectors of mutation that affect any given strata and assemblage, directly relating to the futurity of an assemblage. As Zdebik $(2012,16)$ put it, "The diagram is an image of something to come rather than something that is already there." Or, as Deleuze and Guattari $(1987,142)$ formulated it, "The diagrammatic or abstract machine does not function to represent, even something real, but

17 Crucial for Deleuze's reception of this point is that Foucault stress that the panopticon would be unsatisfactorily defined as long as it was viewed only as an architectural system. It was the combination of the physical space with its associated penal code that constituted a dispositif, of which the whole structure of surveillance acted as a function called diagram. 
rather constructs a real that is yet to come, a new type of reality." Crucially, and contributing to Deleuze's move beyond structuralism, the diagram is not a structure; it traces the flows of forces that are part of an assemblage and that are in permanent change and transformation. Relating to a set of relations of forces, it "never exhausts force, which can enter into other relations and compositions" (Deleuze [1988] 2006, 74). Therefore, "a true abstract machine pertains to an assemblage in its entirety: it is defined as the diagram of that assemblage. It is not language based but diagrammatic and superlinear. Content is not a signified nor expression a signifier; rather, both are variables of the assemblage" (Deleuze and Guattari 1987, 91, my emphasis). Thus, the two-form mechanism of the assemblage (form of expression, form of content) affects and is in turn affected by the informal diagram, the concrete machine affects and is affected by the abstract machine, creating a continuity between the diagram and the event, between the virtual and the actual. Assemblages are in permanent becoming, partly because of this promise of constant reconfigurations implied by diagrams. Between assemblages and diagrams, a space opens up for the ever-changing continuous unfolding of flows of forces, in a movement that ceaselessly goes from the virtual to the actual to the virtual, perpetually moving between codings/uncodings and territorialisations/deterritorialisations.

At the limit, one reaches uncoded and deterritorialised abstract machines (the radical antipodal entities in relation to the strata, which are highly coded and territorialised). At this level, such machines have proper names or dates, which "of course designate not persons or subjects but matters and functions. The name of a musician or scientist is used in the same way as a painter's name designates a color, nuance, tone, or intensity: it is always a question of a conjunction of Matter and Function. The double deterritorialization of the voice and the instrument is marked by a Wagner abstract machine, a Webern abstract machine, etc." (Deleuze and Guattari 1987, 142). This is the sphere of the "Kafka effect," the "Webern effect," the "Mahler's Sixth Symphony effect," or the "Kreisleriana effect." In their abstraction such abstract machines do not specifically indicate any physical entity, while, at the same time, they do suggest a functioning and a materiality that is dependent on the concrete mapping of all (individually) known strata and arrangements that are part of the assemblage they refer to. Thus, when thinking about "Schumann's Kreisleriana" one is not thinking about bar number twenty-three of its third piece, nor is one thinking about the vinyl recording by Yves Nat. What instantly comes to one's mind is the abstract totality of all (personally) known strata that populate the assemblage that goes under the label "Kreisleriana, op. 16." The population of things (matters and functions) that make up such an assemblage operate both against the assemblage and in favour of it: on the one hand, all the strata with their innumerable and potentially never-ending particles operate a contrario a unified, identitary entity, which in music would be the well-defined work concept; on the other hand, all possible diagrams, with their ever-changing reconfiguration of forces and relations of forces, operate a posteriori, outlining cracks and paths of escape that could lead to a redistribution of forces and to 
a reconfiguration of the assemblage. ${ }^{18}$ In this way-and this is the last characteristic of the abstract machine that I want to mention here-the abstract machine is profoundly contrary to structure, for it is traversed by a "desire for abolition" (Sauvagnargues 2016, 193). In music, where the work concept and all its associated concepts and practices are fundamentally based upon an image of the musical work as being stable and unitary with a strong identity, the image of as assemblage reveals as metastable entities, whose constitutive parts (strata and diagram) actually work against an immaculate definition, pointing toward processes of destabilisation and dissolution of identity. This is not to be confused with deconstruction, with simple inconsistencies, or with any form of death drive. It is the result of a mode of thought that sees consistency as something always provisional and temporary. As Sauvagnargues $(2016,192)$ writes in relation to the thought of Guattari: "consistency proceeds through deterritorialization, not through an identificatory binding together: abstract machines operate within concrete assemblages through points of decoding and deterritorialization. It would be wrong to consider them an essence, a reason behind the assemblage, or a kind of structure that evaporates from the real: there is nothing eternal about them, as they are positioned precisely at the interstices of components that they deterritorialize by connecting. Presupposed by the assemblage as its condition of possibility, neither exterior, nor anterior, but strictly coextensive with its empirical existence.”

\section{LOGIC OF ASSEMBLAGE}

As the preceding sections have shown, the concepts of strata, agencement, assemblage, and diagram are inseparably linked to one another, defining component parts of what I would like to call not "assemblage theory" but more simply a logic of assemblage. On the one hand, it is now clear that it is not possible to take the concept of assemblage in isolation; on the other hand, the project of building a "theory" would put too much pressure on the concepts and force them to an over-definition that is contrary to the idea of assemblage as distributive power in the first place. "Logic of assemblage" points to a whole range of interrelated concepts, to their variable functioning, and to a mapping of loose operational principles that allow navigating an assemblage without the constraints of formalising its components too much. Additionally, it is relevant to note that Deleuze himself (in his interview with Catherine Clément from 1980) considered the idea of assemblage to constitute the unity of A Thousand Plateaus (Deleuze 2007a, 177), referring to it as "a general logic" of assemblages: "the analysis of assemblages, broken down into their component parts, opens up the way to a general logic: Guattari and I have only begun, and completing this logic will undoubtedly occupy us in the future. Guattari calls it "diagrammatism." Within this framework, the diverse notions presented so far build a complex, yet profoundly interrelated

18 Probably, it is the diagram's promise of a "real that is yet to come" that makes people wish to incarnate musical works again and again, through performing and listening to them. Every concrete instantiation or representation of a work immediately vanishes in the face of the potentiality offered by the diagram to re-enact it again in a different combination of matters and functions. 
ecology of concepts that enable a more vivid and productive understanding of dynamic systems.

To clarify my undertaking, it is important to insist once more that I am operating in the burgeoning field of artistic research in music, which is fostering new perspectives on the making of music and on the materials concretely used by musicians. As discussed in Chapter 1, traditional modes of doing and thinking about music (performance, composition, musicology, music analysis, music theory, etc.) normally insist on stable formations, entities, and structures. Artistic research can contribute to new modes of conceiving musical objects, moving beyond structural and phenomenological approaches. The notion of assemblage with its focus on the fluidity of matters, materials, signs, and functions appears to be extremely powerful in helping us experiment with new modes of conceiving musical objects and practices. Thus, my research on the notions of strata, assemblage, and diagram takes place in the framework of a new mode of conceiving musical which are seen as being made of complex arrangements of aesthetic-epistemic things, forces, intensities, and signs, which establish several superposed networks of historical, cultural, material, symbolic, and psychological dimensions. Musical certise to be conceived as a set of instructions or as an ontologically well-defined structure. They become reservoirs of forces and intensities, dynamic systems characterised by metastability, transductive powers, and unpredictable future reconfigurations. Not only have they been the object of changes in the past (as music history overwhelmingly demonstrates), they will continue to observe mutations and transformations in the future. With a logic of assemblage, music practitioners and theoreticians gain new tools to grasp these changes and take an active part in them. Crucially, the new image of work as assemblage has the capacity to include the old image of work within it, as a particular case of less complex combinations of codings and territorialisations.

A logic of assemblage has several consequences: the overcoming of unity in favour of multiplicity, of essence in favour of event, of being in favour of becoming, of elusive certainty in favour of informed inconsistency. As discussed above, one is in front of an assemblage whenever it is possible to identify a coupling made of an ensemble of material relations (content) and a specific regime of signs related to it (expression). Such couplings are not dialectically articulated, but they rather create two poles: a pole strata that is highly coded and territorialised, and a pole abstract machine (diagram) that is decoded and deterritorialised. Between these two poles there are infinite intermediate states and phases. The heterogeneity of the assemblage's components guarantees its functioning, even when some components are stopped, replaced, or eliminated. Thus, the assemblage is a fluid entity, moving from one state to another, from one phase to another. As Deleuze has put it: "It is as if the abstract [machine] and the concrete assemblages constituted two extremes, and we moved from one to the other imperceptibly" (Deleuze [1988] 2006, 34-35, my emphasis). To grasp the nature of these imperceptible movements, Deleuze and Guattari introduced the notion of the tetravalence of the assemblage (see figure 2.1, above), with its two axes based on two scales of coding/decoding and territorialisation/ 
deterritorialisation. They also insisted on the profound interconnection between all the concepts associated with these notions and axes: rhizome, strata, stratification, assemblage, plane of consistency, deterritorialisation, abstract machines, diagram, phylum, mechanosphere. Together, as they are presented in the last and conclusive plateau of $A$ Thousand Plateaus, they disclose a logic of multiplicities that is based upon the core concept of assemblage and that stresses the nomadic, fluid, and problematic nature of knowledge.

\section{REFERENCES}

Alliez, Éric, and Andrew Goffey, eds. 2011a. The Guattari Effect. London: Continuum. . 2011b. Introduction to Alliez and Goffey 2011a, 1-14.

Bogue, Ronald. 1989. Deleuze and Guattari. London: Routledge.

Buchanan, Ian. 2008. Deleuze and Guattari's Anti-Oedipus: A Reader's Guide. London: Continuum.

. 2010. Oxford Dictionary of Critical Theory. Oxford: Oxford University Press. . 2015. "Assemblage Theory and Its Discontents." Deleuze Studies 9 (3): 382-92. . 2017. "Assemblage Theory, or, the Future of an Illusion.” Deleuze Studies 11 (3): $457^{-74}$.

DeLanda, Manuel. 2006. A New Philosophy of Society: Assemblage Theory and Social Complexity. London: Bloomsbury. 2010. Deleuze: History and Science. New York: Atropos Press.

-2016. Assemblage Theory. Edinburgh: Edinburgh University Press.

Deleuze, Gilles. 1975. "Écrivain non: Un nouveau cartographe." Critique 343 (December): 1207-27. Translated by Seán Hand as "A New Cartographer" in Deleuze (1988) 2006, 21-38. 1986. Foucault. Paris: Minuit. . (1988) 2006. Foucault. Translated by Seán Hand. London: Continuum. First published as Deleuze 1986. Translation first published 1988 (London: Athlone Press).

-1990. The Logic of Sense. Translated by Mark Lester with Charles Stivale. Edited by Constantin V. Boundas. New York: Columbia University Press. First published 1969 as Logique du sens (Paris: Minuit).

-1994. Difference and Repetition. Translated by Paul Patton. New York: Columbia University Press. First published 1968 as Différence et répétition (Paris: Presses universitaires de France). . 2004. "How do We Recognize Structuralism?” Translated by Melissa McMahon and Charles J. Stivale. In Desert Islands and Other Texts: 1953-1974, edited by David Lapoujade, translated by Michael Taormina [et al.], 170-92. New York: Semiotext(e). Essay written 1967 and first published 1972 as "A quoi reconnaît-on le structuralisme?” in Histoire de la philosophie, vol. VIII: Le XXe Siecle, edited by François Chatelet (Paris: Hachette), 299-335. Book first published 2002 as L'île déserte: Textes et entretiens 1953-1974, edited by David Lapoujade (Paris: Minuit).

. 2007a. "Eight Years Later: 1980 Interview." Interview by Catherine Clément. In Two Regimes of Madness: Texts and Interviews 1975-1995, edited by David Lapoujade, translated by Ames Hodges and Mike Taormina, $175^{-80}$. New York: Semiotext(e). Chapter first published 1980 as " 8 ans après: Entretien 1980 " (L'Arc 49: 99-102). Book first published 2003 as Deux régimes de fous: Textes et entretiens 1975-1995, edited by David Lapoujade (Paris: Minuit).

. 2007b. "Michel Foucault's Main Concepts.” In Two Regimes of Madness: Texts and Interviews 1975-1995, edited by David Lapoujade, translated by Ames Hodges and Mike Taormina, 241-6o. New York: Semiotext(e). Chapter written 1984. Book first published 2001 as Deux régimes de fous: Textes et entretiens $1975^{-1995}$, edited by David Lapoujade (Paris: Minuit).

Deleuze, Gilles, and Félix Guattari. 1970. "La synthèse disjonctive." L'arc 43: 54-62. 1972. Capitalisme et schizophrénie: L'anti-CEdipe. Paris: Minuit. Translated by Robert Hurley, Mark Seem, and Helen R. 


\section{Chapter 2}

Lane as Deleuze and Guattari (1977) 1983. 1975. Kafka: Pour une littérature mineure. Paris: Minuit. Translated by Dana Polan as Deleuze and Guattari 1986.

- (1977) 1983. Anti-Oedipus: Capitalism and Schizophrenia. Translated by Robert Hurley, Mark Seem, and Helen R. Lane. Minneapolis: University of Minnesota Press. First published as Deleuze and Guattari 1972. Translation first published 1977 (New York: Viking Press).

- 1981. "Rhizome: Introduction."

Translated by Paul Foss and Paul Patton. I and C 8: 49-71. First published 1976 as Rhizome: Introduction (Paris: Minuit). . 1986. Kafka: Toward a Minor Literature. Translated by Dana Polan. Minneapolis: University of Minnesota Press. First published as Deleuze 1975.

1987. A Thousand Plateaus: Capitalism and Schizophrenia. Translated by Brian Massumi. Minneapolis: University of Minnesota Press. First published 1980 as Capitalisme et schizophrénie: Mille plateaux (Paris: Minuit).

Deleuze, Gilles, and Claire Parnet. 2007. Dialogues II. Translated by Hugh Tomlinson and Barbara Habberjam. Rev. ed. New York: Columbia University Press. First published 1977 as Dialogues (Paris: Flammarion).

Dosse, François. 2010. Gilles Deleuze and Félix Guattari: Intersecting Lives. Translated by Deborah Glassman. New York: Columbia University Press. First published 2007 as Gilles Deleuze et Félix Guattari: Biographie croisée (Paris: La Decouverte).

Eliade, Mircea. 1949. Preface to Laviosa Zambotti 1949, i-iv.

Foucault, Michel. 1975. Surveiller et Punir: Naissance de la prison. Paris: Gallimard. Translated by Alan Sheridan as Foucault 1977.

1977. Discipline and Punish: The Birth of the Prison. Translated by Alan Sheridan. New York: Pantheon. First published as Foucault 1975.

Guattari, Félix. 1984a. “Glossary.” In Guattari 1984b, 288-9o.

1984b. Molecular Revolution:

Psychiatry and Politics. Translated by Rosemary Sheed. New York: Penguin. Includes materials from Psychanalyse et transversalité: Essais d'analyse institutionelle (Paris: Maspero, 1972) and La révolution moléculaire (Fontenay-sous-Bois: Recherches, 1977), as well as one essay from Les années d'hiver, 1980-1985 (Paris: Barrault, 1986).

- 2006. The Anti-Oedipus Papers. Edited by Stéphane Nadaud. Translated by Kélina Gotman. New York: Semiotext(e). . 2011. The Machinic Unconscious: Essays in Schizoanalysis. Translated by Taylor Adkins. New York: Semiotext(e). First published 1979 as L'inconscient machinique: Essais de schizo-analyse (Paris: Recherches).

Hacking, Ian. 1999. The Social Construction of What? Cambridge, MA: Harvard University Press.

Hjelmslev, Louis. (1953) 1969. Prolegomena to a Theory of Language. Translated by Francis J. Whitfield. Rev. ed. Madison: University of Wisconsin Press. First published 1943 as Omkring sprogteoriens grundlaggelse (Copenhagen: Ejnar Munksgaard). Translation first published 1953 (Baltimore: Waverly Press). Rev. ed. of translation first published 1961 (Madison: University of Wisconsin Press).

Krtolica, Igor. 2009. "Diagramme et agencement chez Gilles Deleuze: Lélaboration du concept de diagramme au contact de Foucault." Filozofija $i$ društvo 3: 97-124. https://doi.org/10.2298/ FID0903097K.

Lacan, Jacques. (1960) 1966. "Subversion du sujet et dialectique du désir dans l'inconscient freudien." In Écrits, 793-827. Paris: Seuil. First delivered as a conference presentation, Royaumont, 19-23 September 1960. Translated by Bruce Fink as "The Subversion of the Subject and the Dialectic of Desire in the Freudian Unconscious," in Ecrits: The First Complete Edition in English (New York: Norton, 2006), 671-702. 1998. The Seminar of Jacques Lacan;

Book XX: Encore 1972-1973; On Feminine Sexuality, The Limits of Love and Knowledge. Edited by Jacques-Alain Miller. Translated by Bruce Fink. New York: W. W. Norton. First published 1975 as Le séminaire de Jacques Lacan: Livre XX, Encore 1972-1973 (Paris: Seuil).

Lapoujade, David. 2017. Aberrant Movements: The Philosophy of Gilles Deleuze. Translated by Joshua David Gordon. South Pasadena, CA: Semiotext(e). First published 2014 as Deleuze, les mouvements 
aberrants (Paris: Minuit).

Laviosa Zambotti, Pia. 1949. Les origines et la diffusion de la civilisation: Introduction à l'histoire universelle. Translated by Jean Goillard. Paris: Payot. First published 1947 as Origini e diffusione della civiltà (Milan: C. Marzorati).

Massumi, Brian. 1992. A User's Guide to Capitalism and Schizophrenia: Deviations from Deleuze and Guattari. Cambridge, MA: MIT Press.

Message, Kylie. 2005. “Territory.” In The Deleuze Dictionary, edited by Adrian Parr, 274-76. New York: Columbia University Press.

Nail, Thomas. 2017. "What Is an Assemblage?” SubStance 46 (1): 21-37.

Phillips, John. 2006. "Agencement/ Assemblage.” Theory, Culture E Society 23 (1-2): 108-9.

Sauvagnargues, Anne. 2011. "Deleuze: De l'animal à l'art." In La Philosophie de
Deleuze, by François Zourabichvili, Anne Sauvagnargues, and Paola Marrati, 2nd ed., 117-227. Paris: Presses universitaires de France.

. 2016. Artmachines: Deleuze, Guattari, Simondon. Translated by Suzanne Verderber with Eugene W. Holland. Edinburgh: Edinburgh University Press. Venn, Couze. 2006. "A Note on Assemblage." Theory, Culture E' Society 23 (2-3): 107-8.

Wise, J. Macgregor. 2005. "Assemblage." In Gilles Deleuze: Key Concepts, edited by Charles J. Stivale, 77-87. Montreal: McGill-Queen's University Press.

Young, Eugene B. 2013. "Strata." In The Deleuze and Guattari Dictionary, by Eugene B. Young with Gary Genosko and Janell Watson, 298-30o. London: Bloomsbury. Zdebik, Jakub. 2012. Deleuze and the Diagram: Aesthetic Threads in Visual Organization. London: Continuum. 



\section{Part 2 \\ Experimental \\ Systems in Music}





\section{Chapter 3}

\section{Experimental Systems and Artistic Research ${ }^{*}$}

\section{An ePistemology For ARTiSTiC RESEARCH?}

The preceding two chapters proposed a renewed mode of thinking about past musical entities, presenting a new image of the musical work, crucially questioning traditional ontological accounts, and arguing for wider, less essentialist, and more practice-based ontological perspectives. Moving away from the work concept, and grounded in the notions of strata, assemblage, and diagram, such a perspective views musical works as multiplicities, as complex conglomerates of things and intensities, containing innumerable and potentially never-ending components, which are continuously rearranged and reassembled in their specific modes of appearance throughout history. Chapters 1 and 2 are thus concerned with ontogenetic processes of constitution, formation, and transmission of musical entities throughout time. The next two chapters, starting with this one, have a more epistemological perspective: given the entities we accept are part of our world of music performance, how can we concretely operate with them? How can we reduce their epistemic complexity? Which of their characteristic properties must we operationally retain, eliminate, or transform? How is it possible to open them and make them contribute to the generation of new knowledge? How can such new knowledge be made accessible and discussable to others? What kind of daily praxis can we develop that is adequate to the new image of work as multiplicity? How can one claim that a performance, in addition to its intrinsic aesthetic value, has epistemic content?

One possible approach to start addressing these questions systematically is to appropriate for the arts (and for music in particular) those kinds of laboratory mindsets and set-ups well known from science, especially from the life sciences, that deal with ever changing organs, organisms, and forms of life. Situating my research project at the crossroads of music, philosophy, and science, I particularly looked to post-Kuhnian epistemological discourses, such as those presented by Ian Hacking (1983), Bruno Latour and Steve Woolgar ([1979] 1992), Steven Shapin and Simon Schaffer (1985), and Hans-Jörg Rheinberger (1997). Crucially, all these authors move away from the hegemony of theory and

* I first discussed the topics covered in this chapter at the annual conference of the Society for Artistic Research, Helsinki, 30 April 2017. Following the prescribed mode of presentation for that particular conference, a web-based exposition containing the texts of my presentation and hyperlinks to the cited publications and audio and video recordings was published on Research Catalogue. See https://www. researchcatalogue.net/view/351463/351464/o/2512. 
consider science to function on a practice-driven rather than theory-driven basis, an aspect that intimately resonates with practice-led modes of artistic research. For these theorists, there is no science "in general," only concrete, ever-changing, and unpredictable reconfigurations of matter, connectors, and functions. More than the context of justification so often addressed by scientists, they shift the focus towards contexts of invention and discovery. In the place of absolute rules and axioms, they try to clarify how knowledge is constituted in and through practices. Applied to art practice, with its inherently polysemic objects, such epistemologies allow for the questioning of their function as vehicles of research. How can artworks participate in the production of knowledge? As Borgdorff $(2012,187)$ has phrased it: "How can [artworks] function not just as objects of research, but as the entities in which, and through which, the research takes place-and in which and through which our knowledge, our understanding, and our experience grows."

My principal reference in this respect has been the work of the historian of science Hans-Jörg Rheinberger, particularly his notion of experimental systems (Rheinberger 1997). ${ }^{1}$ Such systems (which are described further below) are extremely concrete, defining units of research that operate in a specific time and place, with particular individuals, and under concrete social, institutional, technical, and instrumental arrangements. Within such systems, sequences or series of experimental activities take place, replicating and changing conditions, parameters, scales, and observations. Given a research problem, infinite experimental iterations of precisely calibrated experiments generate expected results (predictable), but crucially also generate unexpected ones (unknown). Experiments are, thus, not simple methodological events made to confirm or reject certain hypotheses (knowledge already theoretically formulated); instead, they function as the actual generators of knowledge, adding knowledge that the system had no knowledge of before. It is through this unexpected and unknown part of the results that science advances, not by confirming or rejecting pre-existing knowledge. Thus, experimental systems become literally "machines for making the future," as Rheinberger $(1997,28)$, quoting François Jacob $(1988,9)$, wrote. So conceived, science appears not as a distant set of laws and axioms, but as a very concrete operating system based upon daily experiences and unpredictable experiments conducted in the lab.

We appropriated this epistemology of the concrete for music, adopting it as the basic model for the daily practice of MusicExperiment21. This created a unique modus operandi, based upon a precise mapping of the research materials and components in terms of technical objects, epistemic things, the space

1 References to Rheinberger's experimental systems and to their potential for artistic research have been pioneered by Michael Schwab and Henk Borgdorff (see Borgdorff 2012, 184-98; Rheinberger and Schwab 2013; Schwab 2013a; 2013b; 2014a; 2014b; 2014c; 2015). I am especially indebted to Michael Schwab for having introduced me to Rheinberger's thought in the first place, and for having created the conditions for my personal acquaintance with him on the occasion of a working meeting organised at the Orpheus Institute (5-6 July 2012). In addition to reading his essays, I had further conversations with Rheinberger during the annual conference of the Society for Artistic Research (Helsinki, 28-30 April 2017), at the Summer School of the École Polytechnique Fédérale de Lausanne (Lausanne, 11-14 July 2017), and at the second international conference on Deleuze and Artistic Research (Ghent, 20-22 November 2017). 
of representation, the space of graphematicity, and machines for making the future (on these notions, see Rheinberger 1997, especially 27-31, 223-29). Furthermore, it enabled the development of a creative notion of experimentation in the arts, based upon sequential series of research outcomes and performances, which became one of the hallmarks of MusicExperiment21 (a selection of which will be presented at the end of this chapter). This effective hybridisation of research strategies (from life sciences to artistic research), and its intrinsic search for the future possibilities of the materials at hand, relates to the following statement by Rheinberger: "The minds of inventors and scientists, much like those of artists, are not oriented toward recognizing what exists; they 'turn more upon future possibilities, whose speculations and combinations obey an altogether different rule of order, described here as a linked progression of experiments composing a formal sequence"' (Rheinberger 1997, 8o, incorporating quotation from Kubler 1962, 85).

Before describing the basic characteristics of Rheinberger's experimental systems, I will introduce the specific working methodology I developed (in the framework of MusicExperiment21) for artistic research in music. This is crucial in order to understand the precise place for experimental systems in my overarching research construction. They have been used in a specific moment of the research trajectory, namely in what I call the problematisation of the available materials and their reconfiguration in new combinations and arrangements.

\section{A METHODOLOgY FOR ARTISTIC RESEARCH}

As thoroughly explained in Chapters 1 and 2, the new image of as a multiplicity made of actual and virtual components is crucially grounded upon the notion of strata and processes of stratification. In this respect, I have proposed a taxonomy of strata into six types, referring to musical materials that physically exist in the real (graspable) world: substrata (treatises, manuals, iconography, period instruments, descriptions of concerts, critics, archives, lists of personnel, payments, etc.), parastrata (sketches, drafts, first editions, letters, writings by composers and performers, annotations, etc.); epistrata (period editions, editions over time, analysis, reflexive texts, theoretical contextualisations, recordings, etc.); metastrata (future performances, expositions, recordings, transcriptions, etc.); interstrata (infiltrations and contaminations of different types of strata generating this hybrid type); and allostrata (materials that even if not directly relating to a given work can enter productive relationships with it). All these strata are manifest as individual singularities and can be seen as sources or documents in a more conventional historiographical sense. By focusing on these innumerable documents, musical works are considered as historically constructed conglomerates of things, ${ }^{2}$ a view that (quite straightforwardly) allows different

2 The notion of thing, which Rheinberger took from George Kubler's The Shape of Time: Remarks on the History of Things (1962), is central to conveying the "not yet determined" character of research results and materials under investigation. As Borgdorff $(2012,190)$ put it, "Rheinberger has deliberately chosen the term 'thing' rather than 'object,' in order to signify the indeterminate, not yet crystallised status of the knowledge object. Epistemic things are chronically underdetermined." 
modes of research to be productively integrated within the creative fabric of an artist.

Starting from conventional research on the available things that pertain to a given musical work (see figure 3.1, "Archaeology: sources, documents, things"), one selects and isolates some of the things, subjecting them to historiographical, analytical, and comparative research (figure 3.1, "Genealogy"), so that, finally, (figure 3.1, "Problematisation in and through practice"), they are exposed in unprecedented reconfigurations and arrangements. As soon as a new arrangement is presented, it inevitably becomes another document or thing, thus feeding the process circularly. This is, in its shortest formulation, the three-step methodology created and used by MusicExperiment 21 for the generation of all its research outcomes (see figure 3.1). First, the innumerable material traces and things are archaeologically identified and retrieved for further consideration; second, the relations and connectors they entertain with one another, as well as their transmission over time, are studied in terms of a genealogy, disclosing singularities (i.e., particular points of high energy or concentration of forces); and, finally, specific selections of things are brought together as arrangements, or, in Deleuzian language, as "concrete machinic assemblages" (Deleuze and Guattari 1987, 555) that problematise them anew.

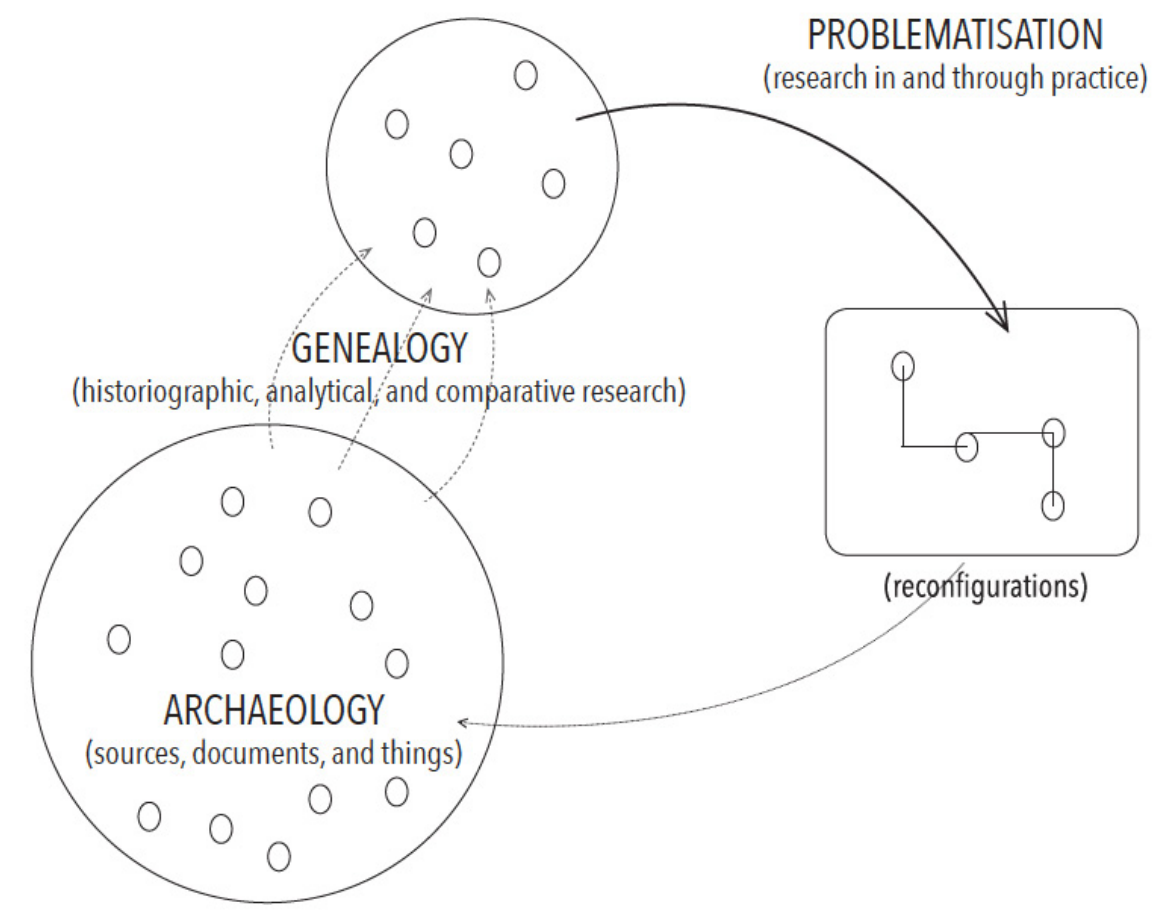

Figure 3.1. 
This methodology has several relevant features:

(1) It allows the integration into performance of diverse materials that go beyond the score (sketches, texts, images, and videos), offering a broader contextualisation of works within a transdisciplinary horizon.

(2) It fosters new modes of conducting research in music, overcoming traditional divisions and boundaries between music theory or musicology and creative practices; the practitioner becomes profoundly rooted in scholarly research, and in turn this research is a meaningful and integral part of the artistic results.

(3) It creates the conditions for a unifying approach to performance and composition, as the three steps and their respective operations are very similar for composers and performers.

(4) It makes graspable the potential of performance and composition to operate as knowledge-producing activities.

(5) Beyond the mere (re)creation or (re)production of a musical "work," it enables an understanding of musical things as objects for thought through performative or compositional devices.

(6) It overcomes traditional artistic and scholarly partitions between "success" and "failure," as any resulting reconfiguration results in a new finding being added to the system. ${ }^{3}$

The archaeological moment relates to conventional scholarly research, including archival and source studies; genealogy calls for interpretation, semiotics, and transtextuality; and problematisation happens by constructing new and experimental arrangements. With the latter, the artistic dimension becomes inescapable, requiring a kind of artist and researcher who can cohabit in the same body. It is in this phase of the research process that the notion of experimental system becomes particularly relevant and fruitful. In this moment, differential repetitions of combinations and reconfigurations of the objects under investigation take place. All the things taken into consideration to be used in the new arrangements (reconfigurations) must be precisely defined, calibrated, and evaluated from the point of view of their intrinsic energies, intensities, speeds of change, relation to the other components of the arrangement, and so on. This is the place for numerous new inscriptions, registering the unprecedented effects of the problematisation upon the objects under inquiry. In this sense, my appropriation of Rheinberger's notion of experimental systems for music is not arbitrary, nor is it vague or abstract. On the contrary, it is radically material, concrete, and precise. To make this clearer, the following section offers a compact overview of the notion of experimental system, clarifying some terminology and suggesting modes of appropriating such systems for artistic research.

3 Discussing the value of "results" in the sciences, Rheinberger notes the following: "What is a result? A-positive-result is a finding that, in principle, can be reintegrated as a component of the system and can thus enlarge or change the setup" (Rheinberger 1997, 135). 


\section{Hans-Jörg Rheinberger's experimental Systems}

On the first page of his book Toward a History of Epistemic Things, Rheinberger (1997, 1) states: "In a post-Kuhnian move away from the hegemony of theory, historians and philosophers of science have given experimentation more attention in recent years. This book is an attempt at an epistemology of contemporary experimentation based on the notion of 'experimental system." By situating scientific practices and research methodologies in their respective historical periods, Rheinberger closely addresses the problem of historicising epistemology, which so crucially contributed to a movement from science-as-a-system to science-as-a-process (see also Rheinberger 2010,1). This change happened in parallel with a profound shift of interest from a system of knowledge production based upon the finding and presenting of a "correct" scientific method to a more concrete interest "in what scientists actually do in pursuit of their specific research" (ibid., 3). Instead of testing theories, research happens on a daily basis, through the concrete (and still most often) manual manipulation of objects. Researchers appear as doers, not as illuminated academics delivering proof of a given theory. It was within these broader frameworks of interest (hybrid modes of research and materially based experimentation) that Rheinberger's notion of experimental systems became so central to the concrete practice of MusicExperiment21, providing a basic modus operandi to the team and to the design of the overarching research strategy.

Importantly, there have been two different yet complementary approaches to Rheinberger's theories within MusicExperiment21. On the one hand, Michael Schwab-an artistic researcher and philosopher, who has been in charge of the project's epistemological strand-investigated the wider epistemological consequences of such systems, particularly focusing on how to adapt experimental systems for contemporary art. While Rheinberger's experimental systems discuss the spaces of experimentation and the spaces of representation, Schwab situates contemporary art in the graphematic rather than representational space — as might still have been the case, arguably, for modern art (see Schwab 2015). In this line of thought, Schwab links Rheinberger's experimental systems to his own concept of expositionality (see Schwab 2014b). Notions such as the fragmentary, the untimely, or the contemporary are, therefore, central to his approach, which aims to look at transformations both in the work and in the system itself. 4

On the other hand, Rheinberger's experimental systems have been used to design artistic-research differential instantiations, leading to a large number of outputs. By "differential instantiations" I mean series of different performances and/or presentations made as part of a particular research project within MusicExperiment21. There were, for example, twenty-six different instantiations of the Rasch project, seven of Diabelli Machines, seven of Nietzsche $\mathrm{Z}$, and so on, each of which explored different materials and arrangements. This approach, which I have designed and developed since the beginning

4 This research focus, led by Michael Schwab, generated important events and outputs, such as a study day (Orpheus Institute, 5-6 July 2012), an interview with Rheinberger (Rheinberger and Schwab 2013), a research questionnaire (Schwab 2014a), and the collective volume Experimental Systems: Future Knowledge in Artistic Research (Schwab 2013a). 
of MusicExperiment21, has been focused on the concrete conditions of the experiments and on the generation of aesthetico-epistemic differential repetition. It looked at the distinction between technical objects and epistemic things and between the space of experimentation and the space of representation, and at the question of multimedia inscriptions resulting from and at the same time generating new modes of presenting artistic research.

Rheinberger developed his theory of experimental systems in relation to the empirical sciences, particularly to molecularbiology. However, it was Rheinberger himself who opened the door for other potential uses of this notion, specifically, for example, in relation to the activity of writing: "Writing is an experimental system in its own right" (Rheinberger 2007, my translation; Das Schreiben, so behaupte ich, ist selbst ein Experimentalsystem). That Rheinberger mentions "writing" [das Schreiben] as a potential field for applications of his theory certainly reflects his conception of the experimental space and of the scientific object itself as a complex "bundle of inscriptions" (Rheinberger 1997, 111). The idea of inscription might be traced back to Derrida, whose seminal book of Grammatology Rheinberger translated into German (with Hanns Zischler) in 1983. Taking Rheinberger's own suggestions further, I propose to extend the use of his theory also to the performance of past musical works.

Originally taken from the everyday practice and vernacular of mid-twentieth-century life scientists, the concept of an experimental system is frequently used to characterise the space and scope of the research activities conducted by researchers in the life sciences, particularly in biochemistry and molecular biology. Importantly, this is, in the first place, a practitioner's notion, not an observer's (see Rheinberger 1997, 19). This observation is of the utmost relevance for any attempt to appropriate experimental systems to artistic or musical activities: those operating the system must be music practitioners, that is to say, not music historians, music sociologists, or music theoreticians. Such musicologists can analyse a posteriori what the practitioners did, but the doing itself, the making of artistic research, remains in the first instance in the hands of those doing music not in those observing music from outside.

In his most succinct formulation, Rheinberger $(1997,23)$ states that "experimental systems are arrangements that allow us to create cognitive, spatiotemporal singularities." And in a later publication Rheinberger writes, "It is only at the beginning of the 1990 and in the context of an ongoing replacement of theory-dominated perspectives of scientific change by practice-driven views on research that the concept of experimental systems has found entrance into the historical and philosophical literature on science" (Rheinberger 2004, 2). Rheinberger, himself a molecular biologist and philosopher, developed "a framework in which experimentation takes meaning as a set of epistemic practices that constitute a specific kind of material culture" (Rheinberger 1997, 19).

More specifically, experimental systems are characterised by four main features, which Rheinberger thoroughly described on several occasions-notably in the prologue to Toward a History of Epistemic Things (1997) and in the essay "Experimental Systems: Entry Encyclopedia for the History of Life" (2004). In short, these features are as follows: 
(1) An experimental system is a specific working unit of contemporary research:

Experimental systems ... are the genuine working units of contemporary research in which the scientific objects and the technical conditions of their production are inextricably interconnected. They are, inseparably and at one and the same time, local, individual, social, institutional, technical, instrumental, and, above all, epistemic units. Experimental systems are thus impure, hybrid settings. (Rheinberger 1997, 2)

(2) Within such a system, mechanisms of reproduction and repetition aim at the generation of differences (differential repetition):

Experimental systems must be capable of differential reproduction ... in order to behave as devices for producing scientific novelties that are beyond our present knowledge, that is, to behave as "generator[s] of surprises." ... To be productive, experimental systems have to be organized in such a way that the generation of differences becomes the reproductive driving force of the whole experimental machinery. (Rheinberger 1997, 3)

(3) An experimental system is a space of representation where inscriptions are made in order to generate and preserve traces (graphematicity):

Experimental systems are the units within which the signifiers of science are generated. They display their meanings within spaces of representation ... in which graphemes, that is, material traces ... are produced, articulated, and disconnected and are placed, displaced, and replaced.... Scientists create spaces of representation through graphematic concatenations that represent their epistemic traces as engravings, that is, generalized forms of "writing." (Rheinberger 1997, 3)

(4) Finally, experimental systems can establish links to other experimental systems (conjunctures), be divided into several experimental systems (bifurcations), or merge with other experimental systems (hybridisation). At some point an articulation of ensembles of experimental systems might emerge, generating what Rheinberger calls experimental culture (see Rheinberger 1997, 3).

Terminologically, and to avoid conceptual misunderstandings, some explanation of terms is necessary here. First, Rheinberger's use of the term system does not relate to an enclosed, perfectly defined set of rules and axioms, but to "simply a kind of loose coherence both synchronically with respect to the technical and organic elements that enter into an experimental system and diachronically with respect to its persistence over time" (Rheinberger 2004, 3). Furthermore, the notions of technical objects and epistemic things reveal that technicity and epistemicity are not ontologically opposed to each other but form an intricate relation at the inner core of an experimental system. Epistemic things are the entities "whose unknown characteristics are the target of an experimental inquiry" (Rheinberger 1997, 238), paradoxically embodying what one does not yet know (see ibid., 28). Technical objects (sedimentations of earlier epistemic things) are scientific objects 
that "embody the knowledge of a given research field at a given time" (ibid., 245); they might be "instruments, apparatus, and devices which bound and confine the assessment of the epistemic things" (Rheinberger 2004, 4).

Epistemic things are necessarily underdetermined, while technical objects are characteristically determined. Technical objects and epistemic things coexist simultaneously within the experimental system; "whether an object functions as an epistemic or a technical entity depends on the place or 'node' it occupies in the experimental context" (Rheinberger 1997, 30); "within a particular research process, epistemic things can eventually be turned into technical things and become incorporated into the technical conditions of the system" (Rheinberger 2004, 4). Between these two extremes, there is room for a gradient scale, for diverse degrees of hybrid things, and for vague material entities whose function in the experimental system changes. An example of such an entity, when applying these notions to music, is the score, the material inscription of a complex set of signs and symbols that might be considered as either an epistemic thing or a technical object depending on the role it plays at any particular point during the compositional process, the research moment, its performance, or its recording.

Critically, when appropriating experimental systems for the arts, what is at stake are the epistemic qualities of art, and not an understanding of art as science, or of art as an object for science. When using the term epistemic thing, Rheinberger clearly avoided using "scientific thing," denoting that these things are not independent of the resources and media that allow them to exist (see Rheinberger 2008, 13'30"-13'45”). For artistic research, the most important questions are related neither to quantifiable data nor to subjective phenomenological observations. In my view, artistic research in music should not be addressing (or, at least, not in the first place) measurable phenomena, which are the domain of performance science, performance studies, organology, philology, historiography, and applied musicology. The crucial questions of artistic research are of a different nature, involving the epistemic power of art and its transformation from an object of aesthetic appreciation to an object of and for thought. These are the concerns that have the potential to redefine artistic practices, to generate conjunctures, bifurcations, and hybridisations of forms and materials.

On the other hand, the four basic characteristics of experimental systems, taken together, enhance the constitution of "thought collectives" (Denkkollektiv), a term coined by Ludwik Fleck in 1935 to which Rheinberger often refers. Such thought collectives, each with a special "thought style" (Denkstil), are fundamental to the production of knowledge in artistic research, moving beyond the individual "genius" to more distributed modes of creativity and reflection, which liberate the production of knowledge from disciplinary compartmentations. They extend practice and reflection beyond disciplinary thinking, avoiding what Bachelard called the "cantonisation" of science-a danger of which artistic researchers from any discipline should be well aware. 


\section{Thought Collective And ensembles of experimental SYSTEMS: MUSICEXPERIMENT 21}

MusicExperiment21 (2013-18) was an operative thought collective, a group of artistic researchers, including music performers, composers, musicologists, philosophers, artists, dancers, choreographers, video-makers, and music ensembles working closely together, mainly within the spaces of the host institution, but also through web-based platforms such as Research Catalogue. To be sure, the project was conceived and designed by myself alone (back in 2011), but from its very beginning it became a collective endeavour, with almost all its outputs being the result of collaborative efforts in which every single researcher acted as a component part of complex artistic machinery. Thus, for example, when I commissioned six new compositions from six young composers for the project Diabelli Machines, the compositions were not meant to be completely autonomous musical works; rather, they served a specific function in a wider performance context. In this way, composition itself became simply one more parameter in the overall research trajectory - an aspect that was explained and fully accepted by the composers involved, who saw the potential of a working methodology based upon the notion of collective agency. Moreover, MusicExperiment 21 had a dozen projects running in parallel, including projects for performance in concert halls (on the musics of Schumann, Beethoven, Nietzsche, Schoenberg, Nono, Maderna, and Stockhausen), others of a more speculative nature (on music ontology, on the notion of the contemporary, on the politics of performance), and others that were part of doctoral programmes conducted by the students within the project. This extreme diversity of interests and focuses of their respective research transformed the idea of collective thinking into a felt necessity. Every team member could only work productively when situated in a complex network of connectors and links between the different projects. Instead of diluting responsibility, this had the opposite effect, making everyone feel the distributed ownership of every single subproject. Each subproject, with all its numerous constitutive parts and its complex set of internal relations, was an experimental system in its own right. But if we take all the projects as a whole, which together make up MusicExperiment21, one can talk of an ensemble of experimental systems. Their intricate interactions permit us to conceive the whole as "an articulated experimental network of objects and practices whose coherence, just as in the case of individual experimental systems, is a tinkered and patched-up coherence with a collateral constitution" (Rheinberger 1997, 137). What held all these subprojects together, and what became increasingly "easier" to control, was not some kind of hidden referent to all of them but its horizontal concatenation, which is based upon the circulation of "model compounds, technical subroutines, and tacit knowledge throughout the network" (ibid.). Despite being different from one another, all the subprojects of MusicExperiment21 shared the same infrastructure, the same operating people, the same technical devices, the same spaces, daily schedules, and so on. In this sense, MusicExperiment 21 conducted in artistic research in music exactly what experimental systems have done in biology and chemistry, enabling the "transition from the microdynamics of 
localized and situated experimental systems to the macrodynamics of broader fields of experimentation.... Within such ensembles, the systems interact and remain connected through the exchange of sufficiently stabilized procedures and epistemically attractive objects" (ibid.).

Finally, on an even wider level of consideration, "experimental systems come in populations of multiple variants inhabiting overlapping areas of investigation" (Rheinberger 1997, 133), and MusicExperiment21 didn't exist in a bubble disconnected from the world. It was placed within a research centre-the Orpheus Institute - and was thus a part of a wider research community and international endeavour that aims at grounding and developing the burgeoning field of artistic research in music. In this sense, MusicExperiment21 was part of a research culture, part of an ensemble of other research projects, each of which can be seen as experimental systems in their own right: "such ... systems tend to form ensembles that construe the experimental space, not of a single, localized group of scientists, but of a circumscribed scientific community" (ibid., 136). In this light, the whole of the Orpheus Institute functions as an articulated experimental network of objects, concepts, and practices. It can be seen as an ensemble of experimental systems operating "as clusters of materials and practices," which can "evolve through drift (conjunctures), fusion (hybrids), and divergence (bifurcations)" (ibid., 137-38). Ultimately, such complexification of interactions leads to what Rheinberger calls experimental culture: 5 clusters of ensembles of experimental systems, that "share a certain material style of research" (ibid., 138).

Thus, MusicExperiment21's application of Rheinberger's terminology has been part of a major attempt to establish a wider horizon of practice for artistic research in music. At the same time, it also emphasised the need to provide as many concrete examples of such application as possible, and it produced copious amounts of outputs, including lectures, performances, recordings, essays, seminars, conferences, and books. The tripartite methodology described above enabled the permanent generation of differential repetition and the constant production of results, in the sense given to this word by Rheinberger, leading to the proliferation of synchronic series of experiments and diachronic modules of research.

\section{Series of experiments and MOdules of Research}

In 2014, Michael Schwab (2014b, 31) noted that "over the last few years, HansJörg Rheinberger's theory of 'experimental systems' ... has gained currency in debates around art and research.... [However,] it is striking that, in the literature to date, no coherent picture has emerged as to how his theory may productively be employed in this context.... Authors who focus on epistemological implications may identify 'epistemic things' in general within artistic practice, while failing to account for the specificity of experimentation in this context." In the same text,

5 Critically, what Rheinberger calls experimental cultures is to be understood in the first place as an epistemological and not as a sociological concept (see Rheinberger 1997, 138). 
Schwab addresses the relation between Rheinberger's notion of experimental systems and his own concept of exposition, which is defined as "the exposition of practice as research" (ibid., 35), insisting on the link between Rheinberger's graphematic space of experimentation and the inherent graphematicity of any thinkable form of representation of the results of such experimentation. It was partly to address this question that MusicExperiment21 aimed to generate as many "results" as possible and to display them in as varied media as possible. I insist on the specific Rheinbergerian sense of the word results, which means "a finding that, in principle, can be reintegrated as a component of the system and can thus enlarge or change the setup" (Rheinberger 1997, 135). To keep things under control, a set of five simple basic rules was put in place:

(1) The choice of the objects of research (strata) for every single case study must be rigorous, taking into account their potential to act sometimes as a technical object and at other times as an epistemic thing.

(2) Every case study must systematically generate differential repetition of some kind.

(3) To enhance this differential repetition, every case study must be presented in a series of experiments (synchronically), which are to be numbered according to specific parameters (thus, not necessarily strictly chronologically).

(4) Every subproject is presented in as many and diverse modes as possible through different modules of research (diachronically), each resulting from a different research method or perspective.

(5) Research Catalogue is to be used (in addition to the performance stage) as one of the main channels for experimentation and public communication of processes and results.

Thus, by using Rheinberger's experimental systems as a reference, MusicExperiment 21 developed a sort of musical lab, sustained by a series of experimental performances that contributed to a substantial turn away from conventional performance practices and musicological methodologies. In all case studies, projects, and subprojects, MusicExperiment21 insisted on the precise definition of the technical objects and epistemic things at play. Considering these objects and things as parameters within an experimental set-up allowed for differential combinations, regulations, and calibrations of material things and affective forces. The spaces of experimentation and representation are often intermingled; however, as a starting position, the spaces of experimentation were considered to be the physical spaces of the host institution and the music halls and art galleries where MusicExperiment21 performed, while the spaces of representation were books, journals, recordings (CDs, LPs, DVDs), and websites. In this latter respect, Research Catalogue took a particular position, being at the same time a space of experimentation and a space of representation. It was used not only to store, archive, and document research but also as a working tool, a virtual space where research can be produced as at a researcher's desk. ${ }^{6}$

6 An example of such "working use" can be seen in Schwab (2014c). 
Unfolding Waves

A good example of the diachronic model of modules of research presented in parallel is MusicExperiment21's first official publication, an article published in the Journal for Artistic Research titled "Con Luigi Nono: Unfolding Waves" (Assis 2014). From an epistemological point of view, one of the journal article's goals is to contribute to the development of artistic research methodologies and innovative modes of communicating knowledge that include aesthetic components. Therefore, it is organised around a modular structure with a very simple idea: to show the fluidity, flexibility, and continuity of the borders between "academic" and "artistic" practices and outputs. The numerical sequence of the modules ( 1 to 7 , or left to right as they appear on the entry page) indicates a progressive displacement from factual historiographical and analytic data to creative/imaginative appropriations of the researched materials. Thus, Module 1 is mainly historiographical, Module 2 archaeological, Modules 3 and 4 analytical, Module 5 interpretative, and Modules 6 and 7 creative and exploratory. On the one hand, the modules move from "more scholarly" towards "more artistic." On the other hand, each module enacts a different balance between these polarities, stressing that there can be neither a "pure" scholarly approach (without any creativity) nor any "pure" artistic practice (without any contextualisation and references). Additionally, the writing within the exposition is also experimental. Different modules have different types of writing, including conventional musicological discourse (Modules 1 and 6), spoken presentation (Module 2), diagrammatic inscriptions (Modules 3 and 4 ), and absence of text altogether (Modules 5 and 7 ). In respect to modes of writing, it is worth mentioning another MusicExperiment21 project, Nietzsche 5: The Fragmentary (Schwab and Assis 2015): the writing is also experimental in this exposition, yet a completely different approach is taken that enhances the fragmentary character of the research object. Thus, MusicExperiment21 experimented with context-situated solutions, looking for suitable formats and not aiming to develop a single solution that could fit all case studies.

\section{Rasch}

As for the principles of synchronic series of experiments, seriality, and differential repetition, the best example from MusicExperiment 21 is the project Rasch (see Assis 2017), which consists of a potentially infinite series of mutational performances based upon two basic materials: Robert Schumann's Kreisleriana, op. 16 (1838, 1850), and Roland Barthes's 1979 essay “Rasch," which is exclusively dedicated to Kreisleriana (see Barthes 1985). To these materials other components may (or not) be added for each particular version: visual elements (pictures, videos), other texts (such as Barthes's further essays on music, on Beethoven, and on Schumann), or further aural elements (recordings, live electronics, etc.). The main goal is to generate an intricate network of aesthetico-epistemic cross-references, through which the listener has the freedom to focus on different layers of perception: be it on the music, on the texts being projected or read, on the images, on the voices, and so on. Situated beyond interpretation, hermeneutics, and aesthetics, the twenty-five instantiations (so far) of Rasch have been emblematic of what might be labelled experimental performance practices. These practices productively deviate 
from conventional (repetitive) performative strategies transforming familiar artistic objects into objects for thought. For an overview of all instantiations of this project, including video recordings of the majority of them, see "Rasch" (Assis 2017).

\section{Powers of Divergence}

Powers of Divergence constitutes a particularly interesting case in as much as it is a substantial research project that was conceived, designed, and realised by the doctoral student Lucia D'Errico, working within MusicExperiment21. While all the other projects were essentially conceived before MusicExperiment21's official starting date, Powers of Divergence was made afterwards, benefiting from but also challenging the notions and practices MusicExperiment21 had already put in place. In its nine subprojects-dedicated to music ranging from Nicola Vicentino's Madonna il poco dolce (1555) to Schumann's Kreisleriana no. 4 (1838)-Powers of Divergence "consists [of] a series of performances, each of which takes as [its] departure point a given piece of notated music from the Western tradition (the 'primary work')," which functions more as a "generator of affects, of vectorial forces that impinge upon the here-and-now of the performer," than it does "something to be literally mirrored in performance" (D'Errico 2018). In her work with past musical objects, D'Errico (a classically trained guitarist and composer) does not aim to reproduce already known configurations of those objects. She is interested in performance "as a way to reflect, through practice, on the commonsensical limits of the interpretational approach to scores, in order to move beyond them" (ibid.). Embracing the notion of simulacra - as theorised by Gilles Deleuze in the first two appendices of The Logic of Sense (1990) - D'Errico radically departs from the scores of the pieces she performs, cutting the link with any illusion of an "original" sound and focusing on the concrete materiality of sound and of the performative gesture, which happens in the radical here and now of the performative event. This creates a state of suspension of accepted aesthetical codes and rules, enabling a glimpse into infinite other com-possible configurations of sounds and matter, generating an "encounter that exceeds both the (supposed) objectivity of the sign and the (supposedly existent) subjectivity of the performer," pointing to modes of "resemblance through non-resembling means" (D’Errico 2018).

Further examples from MusicExperiment21 are available online through a "portal" entry, from where it is possible to find all instantiations of the diverse projects, including audio and video recordings of most of them. ${ }^{7}$ These projects are the results of series of experiments conducted in light of the notion of experimental systems as explained above. However, one critical notion for the functioning of experimental systems has not yet been discussed in detailthe notion of complexity and its derived notion of reduction of complexity, without which no experimental set-up could possibly function, since the existing data related to any musical piece vastly exceeds what can be exposed within a performance or within an essay. Thus, the reduction of complexity, especially the

7 See https://www.researchcatalogue.net/view/470651/470652/3203/428. 
reduction of epistemic complexity while keeping the ontic and systemic complexity of a given system intact, is of paramount relevance for the productive generation of results and new insights into the objects under investigation. The next chapter addresses these concepts, making links to similar processes in biology and computer science.

\section{REFERENCES}

Assis, Paulo de. 2014. "Con Luigi Nono: Unfolding Waves.” Journal for Artistic Research 6. Accessed 5 April 2018. https://www.researchcatalogue.net/ view/51263/51264. . 2017. "Rasch": Schumann's Somathemes.” Research Catalogue. Accessed 5 April 2018. https://www. researchcatalogue.net/view/64319/64320.

Barthes, Roland. 1985. "Rasch.” In The Responsibility of Forms: Critical Essays on Music, Art, and Representation, translated by Richard Howard, 299-312. Berkeley: University of California Press. Essay first published 1975 as "Rasch," in Langue, discours, société: Pour Émile Benveniste, edited by Julia Kristeva, Jean-Claude Milner, and Nicolas Ruwet (Paris: Seuil). Book first published 1982 as L'obvie et l'obtus: Essais critiques III (Paris: Seuil).

Borgdorff, Henk. 2012. The Conflict of the Faculties: Perspectives on Artistic Research and Academia. Leiden: Leiden University Press.

Deleuze, Gilles. 1990. The Logic of Sense. Translated by Mark Lester with Charles Stivale. Edited by Constantin V. Boundas. New York: Columbia University Press. First published 1969 as Logique du sens (Paris: Minuit).

Deleuze, Gilles, and Félix Guattari. 1987. A Thousand Plateaus: Capitalism and Schizophrenia. Translated by Brian Massumi. Minneapolis: University of Minnesota Press. First published 1980 as Mille plateaux (Paris: Minuit).

D’Errico, Lucia. 2018. "Powers of Divergence: An Artistic Research Project.” Research Catalogue. Accessed 1 June 2018. https://www.researchcatalogue.net/ view/351522/351523/1202/o.

Hacking, Ian. 1983. Representing and Intervening: Introductory Topics in the Philosophy of Natural Science. Cambridge: Cambridge University Press.
Jacob, François. 1988. The Statue Within: An Autobiography. Translated by Franklin Phillip. New York: Basic Books.

Kubler, George. 1962. The Shape of Time: Remarks on the History of Things. New Haven, CT: Yale University Press.

Latour, Bruno, and Steve Woolgar. (1979) 1992. Laboratory Life: The Construction of Scientific Facts. Princeton, NJ: Princeton University Press. First published 1979 as Laboratory Life: The Social Construction of Scientific Facts (Beverly Hills, CA: Sage).

Rheinberger, Hans-Jörg. 1997. Toward a History of Epistemic Things: Synthesizing Proteins in the Test Tube. Stanford, CA: Stanford University Press.

—. 2004. "Experimental Systems: Entry Encyclopedia for the History of the Life Sciences.” The Virtual Laboratory: Essays and Resources on the Experimentalization of Life. Accessed 31 March 2017. http:// vlp.mpiwg-berlin.mpg.de/essays/data/ enc19? $\mathrm{p}=1$.

_.2007. "Man Weiss nicht genau, was man nicht Weiss.” Neue Zürcher Zeitung, 5 May. Accessed 4 June 2018. https://www. nzz.ch/articleELG88-1.354487. . 2008. "Rheinberger: Epistemische Dinge-Technische Dinge.” Recording made at Bochum Media Science Colloquium, 2 July. Vimeo video, 58:57, posted by “bkm," 26 November. Accessed 31 March 2017. https://vimeo. $\mathrm{com} / 2351486$. . 2010. On Historicizing Epistemology: An Essay. Translated by David Fernbach. Stanford, CA: Stanford University Press. First published 2007 as Historische Epistemologie zur Einführung (Hamburg: Junius).

Rheinberger, Hans-Jörg, and Michael Schwab. 2013. "Forming and Being Informed: Hans-Jörg Rheinberger in Conversation with Michael Schwab.” In Schwab 2013a, 198-219. Published 


\section{Chapter 3}

in German as "Experimenteller Geist: Epistemische Dinge, Technische Objekte, Infrastrukturen der Forschung; HansJörg Rheinberger spricht mit Michael Schwab" (Lette International 112 [Spring 2016]: 114-21).

Schwab, Michael, ed. 2013a. Experimental Systems: Future Knowledge in Artistic Research. Orpheus Institute Series. Leuven: Leuven University Press. . 2013b. Introduction to Schwab 2013a, 5-14.

. 2014a. "Artistic Research and Experimental Systems: The Rheinberger Questionnaire and Study Day; A Report." In Artistic Experimentation in Music: An Anthology, edited by Darla Crispin and Bob Gilmore, 111-23. Orpheus Institute Series. Leuven: Leuven University Press. - 2014b. "The Exposition of Practice as Research as Experimental System." In Artistic Experimentation in Music: An
Anthology, edited by Darla Crispin and Bob Gilmore, 31-40. Orpheus Institute Series. Leuven: Leuven University Press. . 2014c. "The Exposition of Practice as Research: Talks, Conferences, Workshops.” Research Catalogue. Accessed 4 April 2017. https:// www.researchcatalogue.net/ view/95500/217581/o/o.

_. 2015. "Experiment! Towards an Artistic Epistemology." Journal of Visual Art Practice 14 (2): 120-31. https://doi.org.1 0.1080/14702029.2015.1041719.

Schwab, Michael, and Paulo de Assis. 2016. "Nietzsche 5: The Fragmentary." Ruukku 5. Accessed 5 April 2018. https://www.researchcatalogue.net/ view/145982/145983/o/-25.

Shapin, Steven, and Simon Schaffer. 1985. Leviathan and the Air-Pump: Hobbes, Boyle, and the Experimental Life. Princeton, NJ: Princeton University Press. 


\section{Epistemic Complexity in Music Performance}

\section{Complexity And ePistemic COMPleXity}

In his essay "Experimental Complexity in Biology: Some Epistemological and Historical Remarks," Rheinberger (1997a, S245) states that the "reduction of complexity is a prerequisite for experimental research." In other words, the overall context of research is characterised by complex configurations and arrangements of complex things that must be filtered and precisely selected to become part of the experimental set-up. A vast quantity of components, interactions, behaviours, and embedded knowledge precede the experimental research itself. In order to do research and arrive at some kind of result, the ontic and the systemic complexities of the research object have to be reduced, while retaining its fundamental and specific epistemic complexity. Despite the title of his article, Rheinberger does not really address the topic of complexity, since his central concern is with the experimental situation itself. Even when Rheinberger (1997a, S247) writes that "experimental systems are machines for reducing complexity," he does not enter into a discussion of exactly what characterises this complexity, a characterisation that would inform the epistemic horizon that enables the research in the first place. Further elaboration of the notion of complexity, and particularly of epistemic complexity, seems thus pertinent.

Biologist Ladislav Kováč and philosopher Subrata Dasgupta-working separately and in different disciplines-have produced stimulating reflections on the topic of epistemic complexity. This chapter explores their different yet complementary understandings of this topic, relating and applying their understandings to music performance. According to Kováč (2007, 65), "biological evolution is a progressing process of knowledge acquisition (cognition) and, correspondingly, of growth of complexity. The acquired knowledge represents epistemic complexity." Dasgupta (addressing technology and complexity) uses the same term in relation to artificial (i.e., human-made) things, defining complexity as "the richness of the knowledge that is embedded in an artifact" (Dasgupta 1997, 116). Upon closer reading, their understandings, definitions, and characterisations of epistemic complexity share an astonishingly large number of common traits. In the next two sections, I briefly present Kováč's and Dasgupta's theories in order to introduce the possible translation of those theories into music and music performance.

\footnotetext{
* A previous version of this chapter was published as Assis (2013, 151-65).
} 


\section{EPISTEMiC COMPLEXITY IN Biology}

Inspired by Hans Kuhn's $(1972,1988)$ understanding of life as an unceasing process of accumulation of knowledge that starts with self-copying nucleic acids, Ladislav Kováć (1986) developed a bottom-up approach to epistemological problems-an approach that may be associated with cognitive biology ${ }^{1}$ and that conceives life as "epistemic unfolding of the universe" (Kováč [2000] 2018, 1). Biological evolution, which is based on a logic of self-replicating entities, is a continual growth of knowledge that involves the "creation of subjects with ever greater embodied knowledge" (ibid., 19, emphasis added). This principle presupposes that "there are levels of complexity in the living world and that, in the course of biological evolution, there has been a continuous growth of complexity" (ibid., 15). This tendency toward the epistemic unfolding of the universe constitutes what Kovác calls the epistemic principle (ibid., 14-20). According to this view, there is a general tendency toward ever more complex organisms. However-and importantly rejecting any positivist notion of progress - there is no teleology and no guiding principle with a clear end. What are observable are several teleonomic processes that simply produce complex products without any guiding foresight. The simplest teleonomic system (a self-copying molecule, for example) is already a subject facing the world as an object. A system (in this case a biological species) is situated in a given environment with (1) surroundings (the part of the environment that interacts with the system and has a detectable influence on it), and (2) an Umwelt (the specific part of the surroundings that interacts with the sensors of the system). ${ }^{2}$ However, only that part of the Umwelt that is experienced by the subject (Husserl's Lebenswelt) is effectively internalised as the basis for construction(s) and operationally used as the initial input for solving problems (see Kováč 2007, 66). As Kováč says: "At all levels, from the simplest to the most complex, the overall construction of the subject, the embodiment of the achieved knowledge, represents its epistemic complexity. It is the epistemic complexity which continually increases in biological evolution, and also in cultural evolution, and gives the evolution its direction" (Kováč [200o] 2018, 18). (One must remember that direction here is not meant to have any teleological character.)

1 According to Boden and Zaw (1980, 25), "a cognitive biology would be one in which biological phenomena were conceptualized for theoretical purposes in terms of categories whose primary application is in the domain of knowledge." Moreover, to quote Kováč ([2000] 2018,1), "knowledge is embodied in constructions of organisms, and the structural complexity of those constructions which carry embodied knowledge corresponds to their epistemic complexity."

2 The subtle differentiation between surroundings and Umwelt goes back to the work of Jakob von Uexküll (see Uexküll 1982). Jesper Hoffmeyer (2012) describes this difference as follows: "In everyday German, Umwelt means simply 'surroundings' or 'environment,' but through the work of the German biologist Jakob von Uexküll (1864-1944) the term, at least in scientific literature has acquired more specific semiotic meanings as the ecological niche as an animal perceives it; the experienced world, phenomenal world, or subjective universe; and the cognitive map or mind-set.” 


\section{Epistemic complexity in technology}

Coming from a completely different field of inquiry, with a background in computer science, artificial intelligence, and cognitive sciences, Subrata Dasgupta's theories on systemic and epistemic complexity open up new avenues for understanding human creativity and its tendency to continuously generate new artefacts. Whereas Kováć focuses on biological species and entities, Dasgupta's interests revolve around human-made artefacts and their origins, evolution, and epistemic content. According to Dasgupta, artefacts are "useful things that are produced or consciously conceived in response to some practical need, want or desire" (Dasgupta 1996, 9). But artefacts possess another fundamental and interesting property, one that relates to Kovác: "like organisms, they manifest evolution" (Dasgupta 1997, 114). The production of things and their evolution over time are, therefore, central topics of his reflections. In approaching these topics, Dasgupta distinguishes systemic complexity from epistemic complexity. Referring to Herbert Simon's (1962) article "The Architecture of Complexity," Dasgupta $(1997,113)$ argues that "a system ... is said to be complex if it is composed of a large number of parts or components that interact in nontrivial ways." Complexity depends, then, on quantitative characteristics and on intricate operational behaviours-aspects that tell us what the nature of an artefact is. Dasgupta calls this kind of complexity systemic complexity. It does not tell us how that artefact assumed the form it did, nor does it give us any clues about what it might produce in the future. Dasgupta's crucial claim is that beyond systemic complexity there is another, deeper kind of complexity in the universe of human-made things: "the richness of the knowledge that is embedded in an artifact. I shall call this epistemic complexity. It consists of the knowledge that both contributes to, and is generated by, the creation of an artifact" (Dasgupta 1997, 116). Any artefact is, therefore, surrounded by knowledge that is prior to its emergence and knowledge that appears only after the artefact was made. In addition to these ex-ante and ex-post moments, the specific moment of invention or design is itself a knowledge-rich, cognitive process. Furthermore, artefacts themselves are also knowledge: a design embodies and encapsulates one or more operational principles, to start with. "And, in the case of true invention, when the artifactual form is original in some significant sense, the operational principles it encodes constitute genuinely new knowledge" (ibid., 117). Whereas the systemic complexity of an artefact requires it to be made up of a large number of parts or components that interact in complicated, non-trivial ways, epistemic complexity adds to it two wholly new dimensions: the artefact's capacity for producing unexpected behaviour; and the amount, variety, and novelty of the knowledge embedded in it. It is this embedded knowledge that Dasgupta calls "the epistemic complexity of an artefact" (ibid., 118).

Epistemic complexity, in the sense exposed by Dasgupta, is also linked to creativity and original thinking. Even if systemic and epistemic complexity are not necessarily coupled, "epistemic complexity is entirely related to the originality of artifacts and, hence, to the creativity of the artificer" (Dasgupta 1997, 130). Someone doing "normal design" or working within a "mature technology" is certainly creating artefacts of potentially considerable systemic complexity; but if that system is an exercise in normal design, it will not be original 
but will be simple, epistemically speaking. Epistemic complexity is also avoided when the designer takes recourse in well-established styles or when a chosen style is adapted to the specific needs of the technological problem at hand. On the other hand, when the designer rejects several traditional solutions, striving for truly original configurations, knowledge may emerge in wholly surprising contexts. In such cases, "epistemic complexity is, then, a measure of the maker's creativity" (ibid., 131). However, the question of how such complexity can be assessed is not sufficiently addressed.

Dasgupta $(1997,135)$ proposes the identification and enumeration of the "significant knowledge "tokens" that constitute an artefact as a first step toward an evaluation of its epistemic complexity. However, the risk is that such an enumeration will stay within the limits of the artefact's systemic complexity, conveying "nothing of the intricacy of the interactions of these knowledge tokens, nor the manner in which they came to participate in the cognitive act, nor (in the case of old knowledge) why they were invoked at all" (ibid., 136). Here is where my proposed new image of work, with its associated notions of strata, assemblage, and diagram (see Chapter 2) seems to be extremely useful, as it allows us to better identify and situate the "significant knowledge tokens" at hand. At the same time, the practical use of Rheinberger's notion of experimental systems in its appropriation for music performance (as explained in Chapter 3) permits a precise calibration of the diverse objects/things involved in the experimental set-up, leading to the generation of graphematic outputs that enable the traceability and the constitution of new things, thus involving epistemic gain. Rheinberger's experimental systems have been described in the previous chapter, but to fully grasp their use in music performance it is necessary to address the question of what epistemic complexity might mean in music.

\section{EPistemic COMPleXity IN MUSiC}

Borrowing the notion of epistemic complexity from the sciences (Dasgupta 1997; Kováč [2000] 2018, 2007), and considering musical works as highly complex artefacts, this section explores different elements involved in music performance in terms of epistemic complexity. During the twentieth century, and especially since the 1990s, the performance of musical "works" became an increasingly complex articulation of different types of data, information, and knowledgeretraceable in diverse material sources (including a growing quantity of available sketches, instruments, editions, and recordings), in reflective discourses (in, on, and about music), and in multifarious performance styles (historically informed, Romantic-modernist, or Classical-modernist, actualising-mode, experimental, etc.). The continuous accumulation and sedimentation of these kinds of knowledge translates into an exponential growth of complexity that involves technical, artistic, aesthetic, and epistemic components. By breaking down musical works into their constitutive strata (see Part 1 of this book), the tokens of their respective and variable complexity emerge as boundary objects (Star and Griesemer 1989), 
objects that change their ontological and epistemological nature depending on the context in which they are used. ${ }^{3}$ Consequently, musical works no longer have an indisputable ontological character (Goehr [1992] 2007; Kramer 2011; Chapters 1-2, above), which is now seen as transient and dependent on their epistemic complexity, contextualisation, and use.

If we conceive musical works in terms of the characteristics of epistemic complexity described by Kováč and Dasgupta, one can observe that musical works are highly elaborated, complex semiotic artefacts with intricate operational functions. Additionally, they are made of a variable and normally large number of constitutive parts that interact in non-trivial ways. This gives them, in the first place, systemic complexity. But they are also the products of invention and embed a rich array of interconnected knowledge encapsulating one or more operational principles. Their conception, creation, and concrete making (and/or performing) inherently involve pre- and post-knowledge, as well as a vast combination of refined cognitive processes. Like organisms, they also manifest evolution (which doesn't necessarily imply "progress"), doing this in three ways: (1) in terms of "pure" creation, that is, new, original compositions; (2) in terms of re-creation, that is, the performance of past musical works; and (3) in the sophisticated process of their preservation over time (editions, recordings, theoretical reflections, etc.). Taking a closer look at the history of musical things (without adhering to traditional visions of music history, compartmentalised in styles and periods) and adapting George Kubler's statement regarding a history of things, a history of musical things would include both material artefacts and aesthetic positions, both replicas and unique examples, both tools and expressions-in short all materials worked by human hands under the guidance of connected ideas developed in temporal sequence (see Kubler [1962] 2008, 8). New pieces are a combination of old knowledge with new cognitive extensions, and-in the most interesting cases - with unexpected and surprising elements. In addition to their systemic complexity, musical things aim at producing unprecedented events embodying new knowledge. In this sense, through the amount, variety, newness, and richness of the knowledge that they embed, they have a considerable epistemic complexity, being artistic examples of what Rheinberger (talking about experimentation and following François Jacob) designates "a machine to make the future" (Rheinberger 1997b, 33). As Dasgupta writes: "Paintings, sculptures, novels, poems and plays, symphonies, fugues and ragas are all infused with epistemic complexity, especially in the intricate ways their creators summon the past and integrate it into their works" (Dasgupta 1997, 137). Just like technological artefacts, musical artefacts are characterised by systemic and epistemic complexity.

3 On the concept of boundary objects in the context of artistic research, see Henk Borgdorff's interview with Michael Schwab (Borgdorff 2012, 174-83, particularly 177). Borgdorff attributes the concept of boundary object to Thomas F. Gieryn. However, Gieryn's concept is that of boundary work, which has a different meaning, referring to instances in which frontiers, boundaries, limits, and demarcations between fields of knowledge are created, established, advocated, or reinforced (see Gieryn 1983). Borgdorff's use of the notion appears to be situated somewhere between boundary work and boundary object in the way I use the term here, which follows Star and Griesemer (1989). 
Musical works are surrounded by and encapsulated in specific epistemic settings, which are made of elaborated collections of historically produced (and inherited) things, such as sketches, drafts, first editions, recordings, or essays concerning a given musical work. After two centuries in which the work concept dominated (see, among others, Goehr [1992] 2007), in recent decades attention has turned to what may be called an extended work concept that takes into consideration the deconstruction of musical works into their graspable constitutive elements, revealing them as complex accumulations of singularities and as multi-layered conglomerates of things with the utmost diversity (see Kramer 2011, chapters 11 and 14). The closer one gets to such constitutive things, the clearer the epistemic complexity of musical works and performances becomes.

From the perspective of a performer dealing with a musical work from the past (which might also be a very recent past), types of relevant objects loaded with variable degrees of epistemic complexity include:

- Materials generated by the composer (sketches, drafts, manuscripts, first prints, revisions of prints, etc.) - Editions of a "piece" throughout time

- Recordings of works

- The reflective and conceptual (musicological, philosophical, analytical, etc.) apparatus around musical works (including theses, articles, books, etc.)

- The organological diversity; that is, the instruments in use (for example, historical versus contemporary)

- The performative/aesthetic orientation of the performer (historically informed practice, "Romantic interpretation," "new objectivity," "modernising approach," etc.)

- Arrangements of works

- The practitioner's own body, which is biologically, technically, and culturally organised

One important observation is that until quite recently many of the items in this list were not generally available since they were the "property" of an exclusive group of experts. In today's increasingly democratised knowledge society, more and more people have access to them. The items on the list are just the main tokens of a musical work's epistemic complexity and may be extended by potentially infinite further sub-tokens. They build a complicated network of things with embedded knowledge. At some point, they have all been reifications or sedimentation of a specific creative or reflective situation. Now, they might function as (1) objects of inquiry (What are they? How many parts do they have? How do they function?) or as (2) things for further inquiries (How can they become productive again? How can they build reconfigurations of the work they belong to? What futures do they enhance?). The first approach concerns a work's systemic complexity, the second, its epistemic complexity. Moreover, making explicit the epistemic complexity of musical works allows us to understand works as being made up of myriad boundary objects (see also Star and Griesemer 1989). To make performances using selections of such boundary objects is an act that discloses open-ended possibilities for new assemblages. Crucial to these new assemblagesand necessary to enhancing their epistemic complexity-is the inclusion of a 
productive not-yet-knowing, the creation of room for what is yet unthought and unexpected. In this light, processes of becoming appear as more productive than statements of being. Works, just like objects of knowledge, remain essentially open. The fundamental incompleteness of any attempt to "close" or narrow down a human-made invention becomes the starting point for epistemic games. As Knorr Cetina (2001, 181) states: "I want to characterize objects of knowledge ('epistemic objects') in terms of a lack in completeness of being that takes away much of the wholeness, solidity, and the thing-like character they have in our everyday conception." In the place of a clear-cut ontology of the artwork, we find an unfolding becoming, where experimentation and the concrete production of new incomplete arrangements become the central artistic activity.

\section{EXPERIMENTATION IN MUSiC PERFORMANCE: HOW TO MAKE THE FUTURE?}

As shown in Chapter 3, by applying Rheinberger's terminology and architecture of research (from biology) to music performance we are attempting to establish a wider common ground for artistic research in music performance. This application is not obvious, nor is it straightforward. Rheinberger developed his theories in a very specific field of inquiry. In transferring these theories to other fields (especially to artistic and creative areas), one must proceed cautiously. This said, however, there are several musical entities that might be considered as technical objects and/or epistemic things, depending on the specific use and context of their presentation. Accepting the risk of applying Rheinberger's theories to music, one might say that scores, instruments, or tuning systems, for instance, may be seen as technical objects that are brought into particular constellations (such as a concert or a CD recording), to produce art. The same entities may, however, operate as epistemic things, whose qualities can be divided into two main groups: those already known and those still to be known (discovered). Musical works participate, therefore, in two different worlds: one related to their past (what constitutes them as recognisable objects), another related to their future (what they might become). If we require performance to be an idealised act of interpretation (be it hermeneutic or performative ${ }^{4}$ ) and if we reduce it to the repetition of the score (understood as an instrumental technical object), we take away the possibility for epistemic things to emerge or to unfold into unforeseen dimensions. We would be dealing mainly with the work's past. If we want to give credibility to performance as an instance, among others, of epistemic activity, we need a concept such as experimentation that creates space in relation to the score (which would otherwise overdetermine and close down the epistemic potential of performance practice), allowing unpredictable futures to happen. And we also need Rheinberger's experimental systems as a basic methodological tool to frame our artistic experimental approach.

From this perspective, experimentation, methodologically conducted

4 For the distinction between hermeneutic and performative interpretation see Hermann Danuser's entry "Interpretation" in the German encyclopaedia MGG (Danuser 1994-2007). 
through experimental systems, might allow for making the future of past musical works, something of which interpretation is far less capable. Moreover, artistic experimentation has the potential to bring together the past and the future of things, enabling and concretely building (constructing) new assemblages-of which non-artistic modes of knowledge production are less capable.

But how can such new assemblages appear? Under what conditions and responding to which criteria? How can we evaluate their quality? How can we assess their constitutive parts and define them as contributions to knowledge? To suggest possible lines of answer to these questions, a brief summary of the concepts and practices exposed so far in this chapter-as well as a reference to the Foucauldian concepts of archaeology and problematisation-will help better situate and explain not only the concept of experimentation in use in this chapter but also my own conception of artistic research and its role in our knowledge society.

The first fundamental concept presented in this chapter was that of epistemic complexity as defined and developed by Kováč and Dasgupta. For Kováč epistemic complexity is the result of the epistemic unfolding of the universe (epistemic principle), while for Dasgupta it concerns the richness of the knowledge that is embedded in an artefact. If we think in terms of simple time coordinates, such as past-present-future, these two perspectives share one characteristic: both scrutinise things (biological organisms or human-made artefacts), looking at and analysing their respective pasts. What things are in the present is understood to be an accumulation of epistemic features throughout time, from the past until the present. Even if this approach might inform us how an organism or an artefact might behave in the near future, these two authors' main concern is not with the future but with identifying, articulating, and evaluating the (past) evolution of such things.

The second central topic developed in this chapter was the concept of things as developed by Rheinberger, who was inspired by Kubler. This concept allowed me to consider the epistemic complexity of the natural and human worlds as a potentially infinite galaxy of things, entities that escape closed definitions and that might have different functions according to the context in which they are temporarily immersed. Next, I mentioned some graspable examples of things that constitute musical works, things that I defined as tokens of a musical work's epistemic complexity. This breakdown of the epistemic complexity of musical works into its manifold constitutive elements (things) is crucial because it enables open-ended possibilities for new arrangements.

In this constellation of potentially infinite things the concept of archaeology, as elaborated by Michel Foucault, becomes a helpful methodological tool. According to Clare O'Farrell (2007), “'Archaeology' is the term Foucault used during the 1960 s to describe his approach to writing history. Archaeology is about examining the discursive traces and orders left by the past in order to write a 'history of the present.' In other words archaeology is about looking at history as a way of understanding the processes that have led to what we are today." In this sense, archaeology is a way to look at the past from the present, with the goal of better situating/understanding the present (and, crucially, not 
the past). It describes a boomerang-like route: from the present to the past, and back from the past to the present. It does not aim at disclosing "how things really were" but rather "why things are what they are" today. In Foucault's words:

\begin{abstract}
Archaeology does not try to restore what has been thought, wished, aimed at, experienced, desired by men in the very moment at which they expressed it in discourse.... It does not try to repeat what has been said by reaching it in its very identity. It does not claim to efface itself in the ambiguous modesty of a reading that would bring back, in all its purity, the distant, precarious, almost effaced light of the origin. It is nothing more than a rewriting: that is, in the preserved form of exteriority, a regulated transformation of what has already been written. It is not a return to the innermost secret of the origin; it is the systematic description of a discourse-object. (Foucault 1972, 139-40)
\end{abstract}

The link to Michel Foucault is explicit in Rheinberger's writings and is very important to his theories of experimental systems in several regards, particularly to the definition of epistemic thing: "[Foucault's] 'discourse-object' is what I call an epistemic thing" (Rheinberger $1997 \mathrm{~b}, 8$ ). For Rheinberger, epistemic things are "things embodying concepts" that "deserve as much attention as generations of historians have bestowed on disembodied ideas" (ibid.). To give epistemic things the attention they deserve is (1) to extract them out of the chaos of systemic complexity, and (2) to allow them to contribute to the formation of new entities, new epistemic things that, in turn, will add new things to the archaeology of epistemic things, that is, to epistemic complexity. From this perspective, archaeology appears almost as a necessary consequence of epistemic complexity.

But Foucault's discourse-object not only is to be described but also must be productively resituated, involving problematisation, another Foucauldian concept that gained increased relevance in Foucault's late works: "The notion common to all the work that I have done since Histoire de la Folie is that of problematization" (Foucault 1998, 257). With this concept Foucault refers to the work one does to direct one's thought toward present practices that were once seen as stable but which the researcher shows to be problematic in some crucial sense. "Problematization doesn't mean the representation of a pre-existent object, nor the creation through discourse of an object that doesn't exist. It is the totality of discursive or non-discursive practices that introduces something into the play of the true and false and constitutes it as an object for thought" (Foucault 1998, 257).

Problematisation, therefore, concerns objects, things that are archaeologically retraced and transmuted from neutral objects into objects for thought. In the context of the present chapter, archaeology and problematisation go hand in hand, and they both work as problematisation of the aesthetico-epistemic complexity described above. Epistemic complexity, things, archaeology, and problematisation are notions that relate to concrete material practices that scrutinise things (biological organisms, human-made artefacts, concepts) by enquiring into their past. The notion of problematisation can be understood in two ways: (1) as a highly elaborated form of interpretation of historical data, and (2) as a critical act of experimentation upon such data. In the first sense, it looks backwards, toward 
the past. Applied to music, it is perfectly recognisable in disciplines such as music history, music analysis, music theory, historical organology, music philology, and biographical studies - in fact, in the majority of all musicological sub-disciplines. In the second sense, however, it opens up new modes of problematising things, modes that, rather than aiming to retrieve what things are or were, search for new ways of productively exposing them within a contemporary situation. These are modes of acting upon the available materials, which instead of critically looking into the past, creatively project things into their possible futures.

Such is the final proposal of this chapter: to reverse the perspective from looking into the past to creatively designing the future of past musical works. In my view this is precisely what artistic research could be about-a creative mode that brings together the past and the future of things in ways that non-artistic modes cannot do. In doing this, artistic research must be able to include archaeology, problematisation, and experimentation in its inner fabric. The making of artistic experimentation through Rheinberger's experimental systems becomes a creative form of problematisation, whereby through differential repetition new arrangements of things are materially handcrafted and constructed.

In a deeper sense, experimentation is not the act of conducting experiments (and even less of testing). Aesthetic experimentation relates primarily to a completely new orientation of the senses and of reason, aiming to reconfigure the sensible. As phrased by Ludger Schwarte (2012, 187, my translation): "Aesthetic experimentation starts when the parameters of a given aesthetic praxis are broken, suspended, or transcended, in order to work out a particular mode of appearance that reconfigures the field of the visible and of the utterable."

That such reconfigurations are only possible after a profound consideration of the epistemic complexity of aesthetic things is the inevitable and necessary condition for creative problematisation - that is to say, for artistic research. From this perspective, artistic research therefore happens when: (1) the epistemic complexity of a given object of inquiry is scrutinised; (2) the constitutive things of such objects of inquiry are identified and isolated; (3) an archaeology of such things is explored; (4) the results of this exploration are problematised with the purpose of enabling their projection into the future; $(5)$ the problematisation happens in precisely calibrated frameworks (experimental systems); (6) inside an experimental system differential repetition is stimulated, enhanced, and achieved; (7) new arrangements of things emerge as the result of a constructive (and not only theoretical) endeavour; (8) this construction of new arrangements is made by bodies-in-action, involving a renewed perspective on the kind and mode of energies at play in those actions. Such energies, as well as their processes of transmission are the object of the next chapter, dedicated to Gilbert Simondon's notion of transduction. 


\section{REFERENCES}

Assis, Paulo de. 2013. "Epistemic Complexity and Experimental Systems in Music Performance." In Experimental Systems: Future Knowledge in Artistic Research, edited by Michael Schwab, 151-65. Orpheus Institute Series. Leuven: Leuven University Press.

Boden, Margaret A., and Susan Khin Zaw. 1980. "The Case for a Cognitive Biology." Proceedings of the Aristotelian Society, Supplementary Volume 54 (1): 25-72.

Borgdorff, Henk. 2012. The Conflict of the Faculties: Perspectives on Artistic Research and Academia. Leiden: Leiden University Press.

Danuser, Hermann. 1994-2007. "Interpretation." In Musik in der Geschichte und Gegenwart: Allgemeine Enzyklopädie der Musik, edited by Friedrich Blume and Ludwig Finscher, 2nd ed., 21 vols., 3:1053-69. Kassel: Bärenreiter; Stuttgart: Metzler.

Dasgupta, Subrata. 1996. Technology and Creativity. New York: Oxford University Press.

_. 1997. "Technology and Complexity." Philosophica 59: 113-39.

Foucault, Michel. 1972. The Archaeology of Knowledge. Translated by A. M. Sheridan Smith. New York: Pantheon Books. First published 1969 as L'archéologie du savoir (Paris: Gallimard).

-1998. Politics, Philosophy, Culture: Interviews and Other Writings, 1977-1984. Edited by Lawrence D. Kritzman. Translated by Alan Sheridan et al. London: Routledge.

Gieryn, Thomas F. 1983. "Boundary-Work and the Demarcation of Science from Non-Science: Strains and Interests in Professional Ideologies of Scientists.” American Sociological Review 48 (6): 781-95.

Goehr, Lydia. (1992) 2007. The Imaginary Museum of Musical Works: An Essay in the Philosophy of Music. Rev. ed. New York: Oxford University Press.

Hoffmeyer, Jesper. 2007. “Umwelt.” In Encyclopedia of Semiotics, edited by Paul Bouissac. Oxford University Press. Accessed 12 April 2018. http://www. oxfordreference.com/view/10.1093/ acref/9780195120905.001.0001/ acref-9780195120905-e-
290? rskey $=\mathrm{DbH}_{3}$ VO\& result $=290 \& \mathrm{q}=$.

Knorr Cetina, Karin. 2001. "Objectual Practice.” In The Practice Turn in Contemporary Theory, edited by Theodore R. Schatzki, Karin Knorr Cetina, and Eike von Savigny, 175-88. London: Routledge

Kováč, Ladislav. 1986. "Úvod do kognitívnej biológie" [Introduction to cognitive biology]. Biologické listy 51: 172-90; includes an abstract in English. . (2000) 2018. "Fundamental Principles of Cognitive Biology." Evolution and Cognition 6: 51-69. Republished online by Department of Applied Informatics, Comenius University, Bratislava, no date. Accessed 12 April 2018. http://dai.fmph.uniba.sk/courses/ CSCTR/materials/CSCTR_Ozsem_ Kovac_20oo.pdf. Page references are to the Department of Applied Informatics edition.

-2007. "Information and Knowledge in Biology: Time for Reappraisal.” Plant Signaling \& Behavior 2 (2): 65-73.

Kramer, Lawrence. 2011. Interpreting Music. Berkeley: University of California Press.

Kubler, George. (1962) 2008. The Shape of Time: Remarks on the History of Things. New Haven, CT: Yale University Press. First published 1962 (New Haven, CT: Yale University Press).

Kuhn, Hans. 1972. "Selbstorganisation molekularer Systeme und die Evolution des genetischen Apparats." Angewandte Chemie 84 (18): 838-62. . 1988. "Origin of Life and Physics: Diversified Microstructure-Inducement to Form Information-Carrying and Knowledge-Accumulating Systems.” Journal of Research and Development 32 (1): 37-46.

O’Farrell, Clare. 2007. "Key Concepts." Michel-Foucault.com. Accessed 14 April 2018. http://www.michel-foucault.com/ concepts/.

Rheinberger, Hans-Jörg. 1997a. "Experimental Complexity in Biology: Some Epistemological and Historical Remarks." In "Proceedings of the 1996 Biennial Meetings of the Philosophy of Science Association; Part II: Symposia Papers," edited by Lindsay Darden. Supplement, Philosophy of Science 64 (4): 


\section{Chapter 4}

S245-54.

1997 b. Toward a History of Epistemic Things: Synthesizing Proteins in the Test Tube. Stanford, CA: Stanford University Press.

Schwarte, Ludger. 2012. "Experimentelle Ästhetik: Arbeit an den Grenzen des Sinns." Zeitschrift fur Ästhetik und Allgemeine Kunstwissenschaft 57 (2): 185-95. Simon, Herbert A. 1962. "The Architecture of Complexity." Proceedings of the American Philosophical Society 106 (6): 467-82.

Reprinted in Herbert A. Simon, The Sciences of the Artificial, 3rd ed., 183-216
(Cambridge, MA: MIT Press, 1996). Star, Susan Leigh, and James Griesemer. 1989. "Institutional Ecology, 'Translations' and Boundary Objects: Amateurs and Professionals in Berkeley's Museum of Vertebrate Zoology, 1907-39." Social Studies of Science 19 (3): $387-420$.

Uexküll, Jakob von. 1982. "The Theory of Meaning." In an untitled special issue, edited by Thure von Uexküll, translated by Barry Stone and Herbert Weiner, Semiotica 42 (1): 25-82. 


$$
\begin{gathered}
\text { Part } 3 \\
\text { Beyond } \\
\text { Interpretation: } \\
\text { Bodies-in-Action }
\end{gathered}
$$





\section{Chapter 5}

\section{Transduction and the Body as a Transducer}

Transduction is Gilbert Simondon's key concept for understanding processes of differenciation and of individuation in several fields, including scientific disciplines, social and human sciences, technological devices, and artistic domains. Originating in the sciences and critically developed in its philosophical implications by Simondon, transduction refers to a dynamic operation by which energy is actualised, moving from one state to the next, in a process that individuates new materialities. This chapter appropriates this concept for musical practice, seeking to establish a foundational conceptual layer for a broader research effort that crucially includes artistic practice-both composition and performance-as its starting and end points. After an introductory depiction of what transduction might mean for a music performer, this chapter focuses on the presentation of different definitions of transduction, mainly stemming from Simondon himself, but including two further extensions: one to Deleuze's concept of haecceity (and via Deleuze, to my own micro-haecceity), and the other to Brian Massumi's notion of corporeality. Keeping in mind the potential of these definitions for music-making, this chapter explores eight different, yet complementary, ways of thinking through notions of transduction, which are presented in a growing scale of complexity from the incandescent light bulb (3) to the intricacies of decision-making in living organisms (10), passing by the question of time and temporality (4), thermodynamics (5), information theory (6), a redesigned theory of haecceities (7), Riemannian topology (8), and corporeality (9). All these topics are presented here, in short, as opening gates to wider fields of inquiry, suggesting future avenues of research, rather than claiming to offer finished thought.

\footnotetext{
This chapter is the fifth instantiation of a series of presentations and communications on the subject of the relation between Simondon's concept of transduction and performative musical practices. Each of these instantiations have in common a set of references and an overall approach to transduction; however, they differ from one another in their particular medium (oral communication, written essay, performance) and specific focus (respectively: musical flows of intensities, immanence, modulation, action-bodies). "Transduction 1" was a spoken presentation held in Vienna (Assis 2016); "Transduction 2 " is a journal article (Assis 2017); "Transduction 3" is a book chapter in a collected volume on the notion of transposition (Assis 2018); and "Transduction 4" was a set of seven performances, Rasch 15-22, made in collaboration with Lucia D'Errico and performed on 7 May 2016 at Angewandte Innovation Laboratory (AIL), University of Applied Arts Vienna, as part of the exhibition DA-TA, curated by Gerhard Eckel, Michael Schwab, and David Pirrò (see Assis and D'Errico 2017).
} 


\section{TRANSDUCTION IN MUSIC PERFORMANCE: RELAYING FLOWS OF INTENSITIES}

Imagine a young pianist just about to go onstage to perform Robert Schumann's piano fantasy Kreisleriana, op. $16(1838,1850)$. The performance will start in a few minutes, the piano is perfectly tuned, and the audience members are already seated, ready to listen; a stage manager will soon provide a sign to go onstage, and our soloist's mind is probably fully concentrated on the first two pages of the score, on the electrifying agitation of the piece's very beginning with its daunting restless triplets on the right hand. In this particular moment, in the very last seconds before going onstage, the whole piece-its overall form and all its pitches, rhythms, instrumental colours, dynamic ranges, tempi, pedalling, fingerings, gestures - is vividly present in the pianist's body and mind, being concretely felt as a huge virtual diagram. This virtuality relates to a virtual that is not to be understood as a kind of virtual reality, but, on the contrary, as something absolutely real, something that exists and that is perceived in this very momentjust before starting the performance-as tension, as an infinite reservoir of topological singularities, some of which will happen, and which will start happening as soon as the pianist's second finger of the right hand touches the middle A of the keyboard. For a musician, this is one of the best situations in which to feel, to grasp, and to understand the complex relations between the Deleuzian concepts of the virtual and the actual. ${ }^{1}$ Everything a musician knows and feels about a given musical work is viscerally present in such moments as highly energetic clouds of potentialities. As soon as the pianist starts performing-physically touching the keyboard, attentively listening to the acoustic result in the here-and-now of the performance-all those potentialities go through a process of synthesis, leading to the radical here-and-now of every single fraction of a second, which one by one, one after the other, in closest vicinity and rapid pace, produce concrete actualisations of forces and materials. Once the concert officially starts, what our young pianist and the listeners experience in real time is the passage from a "just already" constituted assemblage of forces, intensities, and energies to another one, still in the process of being constituted. Something-a force, a signal - is being transmitted from one instant to the next, at light speed, without any break or loss of energy. A continuous process of differenciation happens and takes place in front of our eyes and ears. This process happens operationally: something is at work, something is emerging from a vast field of pre-individual and impersonal tensions, which constitute the metastable horizon of the piece and of the performers, an operation that leads to the emergence of new tensions, which are generated in the radical here-and-now of the performance, without univocal determinism or absolute predictability. At the interstices between what the performer intends to do, what really occurs, and what is intended immediately afterwards, an impulse of virtuality runs from one actualisation to another. Flows of intensities unfold throughout time in the specific here-and-now, in the highly accelerated and hyper-energised Erewhons of music performance. It

1 On the terminological couple virtual-actual, see chapter 1, especially, pp. 49-50. 
is this particular process of music-making, communication, transmission, and emergence of intensities that I propose to call performative transduction-appropriating for musical practice the term introduced by the French philosopher of science Gilbert Simondon in the 1950s. ${ }^{2}$

Simondon's overarching goal was the development of a dynamic theory of technology, replacing ontology with ontogenesis and structure with embryogenesis. His effort resonates with and has been inspirational for my own ongoing work towards a dynamic theory of musical works and their performance. Simondon's concept of transduction is extremely promising for musicians because it seems to have the potential to afford new ways of conceiving, problematising, and doing artistic activities on the basis of intense temporal processes, such as music performances and compositions. Both in the moment of composing or in the act of performing, but also while simply reading a score or studying a sketch, several transducers and transductive processes can be identified. The main transducer (interface), however, is a human body (notating a score, playing an instrument, vibrating vocal cords), a complex living organism inhabited by diverse layers of information and by innumerable drives, which, working together, shape the actual rendering of musical events. Considering bodies, instruments, body-instruments, scores, recordings, concert halls, and audiences as different types of transducers, this chapter aims to lay the foundations for a novel approach to music-making, defining an experimental regime characterised by ensembles of transducers and their respective relaying of affects and intensities. Such an approach enables and enhances a decisive shift from the static opposition between work and performance, between score and expected image of work, between archetypal generalities (the work) and contingent particulars (a performance), to a zone that is energetic and molecular.

The appropriation for music of Simondon's concepts and terminology further enables an urgently needed move away from historically situated, but problematically still operative, formalistic and subjectivity-based approaches to music. On the one hand, music theory is dominated by formalism, dialectically separating form from matter (hylemorphism), focusing on fixed structures (res extensa, which remains the preferred field for analysis and historiography) while underestimating energetic potentials (res intensa, which constitutes the working habitat of composers and performers), and ignoring the energetic conditions and entropic processes that lead to the shaping of any given musical form and expression. Formalism relies more on moulding- "an abstract conception that opposes matter to form" (Sauvagnargues 2016, 70) - than on modulation-"a continuous assumption of form between properties of material and the concrete action of form" (ibid.). In this sense, it is important to stress that this chapter is part of a larger effort to investigate genetic operations, the processes of individuation of musical works, and a new image of musical objects based upon

2 The concept of transduction is so central to Simondon's thought that it is present in innumerable passages of his writings. Its first official appearance in a text is probably in the introduction to Simondon's doctoral thesis, "L'individuation à la lumière des notions de forme et d'information" (see Simondon $[1954-58] 2013,32)$. 
the notion of multiplicity, an effort that ultimately criticises generic structures or archetypal images of musical works.

On the other hand, questions about subjectivity have a propensity to ignore or exclude the non-human component of any transductive process. Studies of subjectivity tend therefore to be human, all too human. Any individual involved in a performance is modulating through a complex set of disparate elements, solving and resolving on the spot diverse disparate inconsistencies of the materials, operating instant syntheses (actualisations) out of a cloud of preindividual singularities (the virtual) that really exist. As Anne Sauvagnargues $(2016,63)$ reading Simondon demonstrates, the individual, "whether it concerns a subject or a being of any kind, is never given substantially, but is produced through a process of individuation.” Transduction permits a perspective in which musical objects and music performers are individuated at the same time, liberating the works from structural fixedness and the performers from psychological subjectification. Instead of operating out of a centralised, controlling consciousness, the performer appears as the (human and non-human) link between the impersonal and pre-individual diversity of the virtual components of any given work and its actualisation in sound and gesture. Beyond subjectivity, the notion of transduction enables the inclusion of a non-human perspective on the processes of relaying flows of intensities in music.

\section{Gilbert Simondon's VARIOUS DEFinitions of TRANSDUCTION}

Simondon defined transduction in several ways; but, in short, transduction is a process whereby a disparity is topologically and temporally restructured across some interface or ensembles of interfaces. Thus it contrasts with the Aristotelian, hylemorphic scheme, which is based upon the dualism form-matter and upon the pre-existence of pre-formed individuated terms, Simondon radically focuses on processes of in-formation, claiming that any event or any individual is not just a result, but a milieu of individuation.

Transduction is Simondon's key concept for understanding processes of individuation in a variety of fields: scientific disciplines such as physics, biology, histology, ethology, crystallography, psychology; technological devices such as motors, electric tubes, lamps, telephones, mills, turbines, and cars; and artistic domains - an aesthetic extension of his system, which Simondon sketches in the third section of his 1958 thesis, "On the Mode of Existence of Technical Objects" (see Michaud 2012, 121). The reasons for such impressive versatility are certainly many, and of different natures. First, Simondon's project is radically oriented towards a logic of creation: things and subjects are never considered as pre-constituted, and the "good form" is never stabilised (see Garelli 2013, 16), remaining suspended between structure and energy in a metastable balance. Second, the very notion of transduction thematises the event, insisting on the emergence of the new, on those components of any agency or assemblage that have the potential to change, to disrupt habits, stratifications, or any other forms of rigidity. Third, by focusing on energetic 
processes, transduction carries a vitalist dimension, generating sequences of becoming, a becoming-intensity, whereby intensity itself can be defined as the creative vector of the dissolution of individuation: becoming-something is not becoming-this, but always becoming-something-else. All these aspects reinforce a modal perspective on the world, opposed to rigid essentialist or substantialist accounts, making the notion of transduction easily applicable in any given field of inquiry.

Every philosophical concept has its own precursors, predecessors, lineages of formation, and different definitions. Concepts are operative in specific contexts, and they may go out of use, disappear for a while, and reappear later on, in a different context, relating to different sets of problems. Like cells, organisms, and machines, concepts also have their own embryogenesis, being the modal and temporary result of an individuating process. Furthermore, they partake in the virtual-actual couple, and also participate in transductive operations. On 10 November 1981, during the first session of his seminar on cinema, held at the University Paris VIII, in Vincennes, Gilles Deleuze made an important observation about the thickness of concepts:" "A philosophical idea is always an idea with diverse layers and levels. It is like an idea and its projections. I mean, it has many levels of expression, of manifestations. It has a thickness. A philosophical idea, a philosophical concept, is always a thickness, a volume. One can take it at one level, then at another, and still at another one; that is not contradictory. But the levels are very different from one another" (Deleuze 1981, o' $55^{\prime \prime}-1 ' 26$ ", my translation). ${ }^{4}$

Simondon's concept of transduction is a good example of a thick concept. Simondon himself offered diverse definitions of transduction, each time illuminating a particular perspective or addressing discipline-specific examples and problems. In what follows, I present, briefly, some of the different definitions of transduction provided by Simondon. Additionally, I present two further extensions: one to Deleuze's concept of haecceity (and via Deleuze, to my own micro-haecceity), the other to Brian Massumi's notion of corporeality.

\section{Discharge (potentiality)}

On the simplest technical level, Simondon defined a transducer as a continuous electric relay that operates as a modulable resistance between a potential energy and its concrete place of actualisation (see Simondon [1954-58] 2013, 82). In this simple and eminently technological definition, transduction is presented as a discharge of energy from a field of potentialities toward a particular emergence of an event. Significantly, in this definition, the transducer doesn't belong to

3 Deleuze was about to present Bergson's concept of intuition, and the sentence I am quoting here was a kind of spoken footnote that prepared the audience for the density and thickness of Bergson's concept.

4 "Une idée philosophique, il me semble, c'est toujours une idée à niveaux et à paliers. C'est comme une idée qui a ses projections. Je veux dire, elle a plusieurs niveaux d'expression, de manifestation. Elle a une épaisseur. Une idée philosophique, un concept philosophique, c'est toujours une épaisseur, un volume. Vous pouvez les prendre à tel niveau, et puis à un autre niveau, et à un autre niveau, ça [ne] se contredit pas. Mais c'est des niveaux assez différents." 
the domain of either the potential or the actual energy: it works as the mediator between these two domains, as the fringe of indeterminacy between them; and the indeterminacy results from information, which is a condition for actualisation to happen (see Simondon [1958] 2012,143). It is in this sense that Brian Massumi could conclude that "transduction [is] the transmission of an impulse of virtuality from one actualization to another and across them all.... Transduction is the transmission of a force of potential that cannot but be felt, simultaneously doubling, enabling, and ultimately counteracting the limitative selections of apparatuses of actualization and implantation" (Massumi 2002, 42-43). With the expression "a force of potential that cannot but be felt," Massumi refers to the absolute reality of that "potential": all forces that constitute Simondon's potential energy are real and do exist "in this world." Sometimes they are perceived as tension, at other times they remain hidden from our senses, but they are measurable with technical apparatuses.

The incandescent lamp is probably the simplest example of a transducer as a continuous electric relay. Electric current is available in the electric circuit as potential energy; the moment one switches the lamp on, a part of that potential energy is discharged into the bulb, which converts only 5 per cent of the total energy into visible light (the rest is dispersed as heat). The goal of the incandescent light bulb is to produce light, but the concrete transductive process generates light and heat, counteracting the material limitations of the tungsten filament and eventually destroying it by burning it. It is the modulable resistance-the complete set of filaments, materials, sustainers, and gases inside the bulb - that changes, generates, and varies the actual rendering of energy as light. All those materials are not "electric current," nor are they "light"; they are just the transducers, mediating between electricity and luminosity.

\section{Passage (time and temporality)}

A more general and broader definition of transduction is to be found in Simondon's collected essays Sur la Technique (2014), where-in the context of discussing notions of technical progress - transduction is presented as "the passage from a constituted ensemble towards another one in the process of being constituted" (Simondon 2014, 452, my translation). 5 What is striking in this definition is the fundamental inclusion of time and temporality as integral to the transductive operation. Transduction happens in time: it is a process, an operation with a temporal and energetic direction (even if not precisely determinable). And this temporal dimension unfolds from one point to the next, very close to one another, but not in a full continuum: "In this sense transduction is something transmitted little by little, something that propagates, eventually, in amplified form" (ibid., 452, my translation and emphasis). Simondon writes "de proche en proche," translated here as "little by little" but meaning also "gradually," "slowly," "progressively," or “step by step." Simondon couldn't be clearer about

5 This sentence was part of Simondon's reply to a question posed by Anita Kéchickian in a 1981 interview, published in a reduced version in the journal Esprit (1983) and as "Sauver l'objet technique" in Simondon (2014, 447-54). 
the essential feature of transduction: namely, its processuality. This reflection lies at the heart of Simondon's project: more important than discussing what things are is to consider how they come to be what they are, and what futures they entail. Every present, every here-and-now, every event-but also every material construction-is infinitely divided into past and future.

These two first definitions of transduction - the intensive discharge of discrete units of potential energy, and the temporal passage from one state to anotherreveal the underlying presence of different kinds of tensions, of different fields of problematicity. On the one hand-energetically-not all the potential energy is actualised in the here-and-now of the event; there are always ample amounts of potential energy that remain possibilities, which, even though real (as possibilities) are not concretised. ${ }^{6}$ On the other hand-temporally-not all the innumerable constituents of the pre-life of a thing or event can be actualised in their concretisations. The transductive process leads to ever-changing states that are, at the same time and without contradiction, more and less than their past or future potentials: less, because they cannot contain all virtual possibilities; more, because they generate new and not precisely foreseeable tensions, new potentials that require further processes towards equilibrium. If transduction involves a reduction of the potential(s) in the service of an ongoing actualisation, it also comprises a future increase of tensions (unpredictability), which will reinforce the field of the virtual.

\section{Energy (Thermodynamics): potential, scales, ENTROPY}

In contrast to classical theories of form such as the Gestalttheorie, which relates to stabilised forms, or the hylemorphic scheme, with its clearly distinguishable pair of form and matter, Simondon proposes a view of forms and matters that fundamentally includes the energetic dimension, fully loaded with transductions yet to take place. From the very first pages of his introduction to L'individuation (Simondon [1954-58] 2013), Simondon argues that the hylemorphic and the monist schemes fail to account for the energetic conditions of the constitution of form and matter themselves, which are inhabited by powerful energetic potentials and by shape-giving informational structures. A metastable system displays a complex balance between two major processes: degradation of energy (entropy) and generation of structural order (negentropy). In his consideration of individuation, both physic and psychic, Simondon regards being not as a substance, matter, or shape, but as a system in tension, oversaturated, something more than one single unity: "To think about individuation, one must consider Being not as a substance, or matter, or form, but as a system in tension, oversaturated, above the level of a unity, not constituted only in itself, and not satisfactorily grasped through the principle of the excluded third: the concrete being, or the whole

6 This is a point of contention that involves the notions of potential and real potential, which will be addressed in the next section. With his notion of potential, Simondon seems to exclude the Deleuzian virtual, but not so with his real potential, which comes closer to the Deleuzian understanding of the virtual. 
being - that is, a pre-individual being - is a being that is more than one unity" (Simondon [1954-58] 2013, 25, my translation).

Simondon's critique of modes of thought exclusively based upon stable forms of equilibrium, which impose being and exclude becoming, led him to a definition of metastability grounded upon three basic notions from thermodynamics: (1) the potential energy of a system; (2) the orders of magnitude of a system (including intensive and extensive variables, and the modulation from micro- to macro-scales); and (3) the growth of entropy (energetic degradation of the system). It is upon this tripartite set of references that Simondon bases his exploration of the notions of preindividual, metastable system, oversaturation, processes of differentiation, and individuation. A form considered totally stable, or finished, corresponds to the highest possible level of negentropy, defining an immovable stratum. Opposed to this, in any given metastable system there are flows of oversaturated potential energies of diverse orders that, at some point (structural germ), produce an over-voltage of the system, from where the energy deteriorates (entropy) leading to processes of differentiation and individuation (negentropy).

\subsection{Potential energy}

In the conventional usage of the term in physics, potential energy refers to the possible or the virtual (in the traditional sense of not being real, or remaining as pure possibility). Often, Simondon refers to this usage, and David Scott (2014) pointedly described the divergence of this conception from the Deleuzian notion of the virtual (where the potential possibilities are real, despite remaining non-actualised). Apparently, a crucial distinction between Simondon and Deleuze is implicit here, involving the concept of the virtual. On the one hand, "Simondon quite definitely rejects the notion of the virtual" (Scott 2014, 17); ; but, on the other, he introduces a crucial qualifier, namely the real potential, indicating that the potential "actually exists" (see Barthélémy 2012, 225). As Simondon writes: "The potential, conceived as potential energy, is real, because it expresses the reality of a metastable state, and its energetic situation" (Simondon [1954-58] 2013, 554n8, as translated in Barthélémy 2012, 225). The real potential is fundamental for the definition of a metastable system: it is the potential that gives such a system the possibility of a becoming, the possibility of shifting phases from one state to the next. An individuation starts with an imbalance between potentials of energy, from which an individual emerges progressively, as the solution to a problem that is itself of a different nature. As Beistegui writes ([2005] 2012, 170): "An organism ... is always 'more' than its organized and fully differentiated reality. This excess signals a virtual reality that can be observed at the embryonic stage."

7 Scott continues: "The taking of form is the passage from real metastability to a stable state. But this operation, for Simondon, has nothing to do with the notion of virtuality, which he argues is composed by an imagined ideal state ('Good Form'). In other words, completely opposite to Deleuze, who worries that one might confuse virtual and the possible [Deleuze 1994, 211-15], Simondon finds them to be synonymous" (Scott 2014, 17). 
5.2. Orders of magnitude (scales)

For Simondon any given portion of matter can only enter a process of new individuation if it is brought to a suitable energetic state. Against the hylemorphic scheme, which implies fixed forms and fixed matters, Simondon argues that "the coming-about of any entity equals the appearance of a metastable 'phase of being,' which constitutes its own, new 'magnitude" (Borum 2017, 99). The individuation process is thus based on singular events that establish a link between different orders of magnitude (today normally referred to as scales). For example, when DNA is transferred from one bacterium to another by a virus-a process in which, more generally, foreign DNA is introduced into another cell via a viral vector-the scale of the virus is passed to the scale of the bacterium, bringing the latter into a new form of individuation. Another example provided by Simondon ([1954-58] 2013) is the vegetative, which is presented as "an individual that puts in relation the order of the cosmic grandeur of sunlight - necessary for photosynthesis-and the molecular order of mineral salts that nourish the vegetative" (Barthélémy 2012, 220). The crucial point is that Simondon was looking for the effects of the relation between orders of magnitude. For him, the individual is relation and not simply in relation to something external. The individual that enables these relations is actually defined by them; it is the relation between different orders of magnitude that make the individual what it is. Thus, any given individual can only emerge in intrinsic articulation with an associated milieu. No individual is autonomous. There is no autonomy. Everything is relation between diverse orders of magnitude: "There is individuation, because there is an exchange between the microphysical and the macrophysical level" (Simondon [1964] 1995, 148 , my translation).

\subsection{Entropy}

A metastable system displays a complex balance between two major processes: degradation of energy (entropy) and generation of structural order (negentropy). Even if, according to the second law of thermodynamics, entropy can only increase, most of the existing systems are ruled by negentropy and by information. As Beistegui $(2012,171)$ has put it: "A metastable system is a system that, whilst not contradicting the second law of thermodynamics, which stipulates that, in the long term, all differences of energy will be cancelled, harbours within itself a sufficient amount of energy - of differences of potential, in other words- to create order... There is no form that presides over the organization of matter; there is simply a series of processes of in-formation through which matter organizes itself."

To distance himself from recent developments in cybernetics and in information theory, and from the debates about the notions of entropy and negentropy that involved Norbert Wiener and Claude E. Shannon, Simondon affirmed that "the differencing process can in no way be understood in quantitative terms, and is not susceptible to any kind of stable formalization" (Massumi et al. 2012, 32). For Simondon, even if photosynthesis does coincide with the discharge of a measurable amount of energy, it crucially coincides with passing a threshold to reach a qualitatively new level of individuation. The qualitative threshold 
is what most matters to Simondon. No doubt the system will degrade itself energetically, in the long run, but as long as the potential energy is not fully exhausted, information will counteract that dispersion, vibrantly opposing res intensa to res extensa. Traditional physics of substances and matter had ignored the problems posed by energetic distributions, focusing too much on res extensa (see Garelli 2013, 14). With thermodynamics, Simondon found a way to more adequately address the in-formation of events. An early draft of the introduction to L'individuation à la lumière des notions de forme et d'information reveals Simondon's precise positioning within cybernetic debates of the day: "In order to define metastability, it is necessary to include the notion of information of a system ... particularly the notion of information provided by modern physics and pure technology (information understood as negentropy), as well as the notion of potential energy, which gains a more precise meaning when linked to the notion of negentropy" (Simondon [1954-58] 2013, 26n3, my translation).

Along the same lines, on the occasion of a public lecture at the French Philosophical Society (27 February 1960), Simondon offered a complete definition of transduction, including the irreversibility of information at its very core. Once the potential energy starts being liberated, it appears as a new structure, "which is like a solution to the problem; from that moment, information is no longer reversible: information is the organiser of direction that arises a short distance from the structural germ and that conquers the field" (Simondon [1954$58]$ 2013, 538, my translation and emphasis). Entropy and negentropy define the fundamental coordinates of movement and directionality of the transductive operation.

\section{INFORMATION THEORY: STRUCTURAL GERMS AND SINGULARITIES (STRUCTURATION)}

The affirmation of the complex processes of differentiation/individuation described so far raises the question of knowing what causes, what initiates, what sets them in motion. A totally stable system no longer has any internal motion; it is a stratum with the highest level of negentropy. At the other extreme, a totally unstable, chaotic system is without the capability for structure, never concretising all its potentials. But what causes a metastable system to start the transductive process? Simondon is extremely precise in identifying the initiator of this process: it is what he calls a structural germ (see Simondon [1954-58] 2013, 77-84). Drawing on scientific studies of crystallisation, Simondon offers the example of allotropic crystals (crystals that exist in two or more different forms, though in the same physical state) in order to present transduction as "the name given to the ongoing actualization or structuring of the potentials of a metastable system whose constitutive, heterogeneous orders have been brought into communication by a singularity functioning as a 'structural germ"' (Bowden 2012, 141). ${ }^{8}$ This germ is the point of departure for the whole subsequent transductive

8 Bowden's synthetic formulation is based on Simondon ([1954-58] 2013, 78-82). 
process. It contains a singularity (Simondon [1954-58] 2013, 77); and this point has the capacity to break the metastable equilibrium of the system, enabling the propagation of a transformation that runs from point to point between the already transformed parts and those yet to be transformed. Every future point is, therefore, a sort of extension or prolongation of the initial germ with its intrinsic singularity. As Simondon puts it: "the individual results from a process of amplification that is triggered by a singularity within a hylomorphic situation, and it [the individual] prolongs this singularity" (Simondon [1954-58] 2013, 82, my translation).

Recapitulating: there is a starting germ, which contains a singularity. This singularity is then prolonged throughout time-that is, the singularity is set in motion for a certain length of time, defining a surface of intensities. The singularity cannot be described in itself, or abstractly, as Simondon consistently avoids any kind of essence. A singularity has only a local definition, given under precise conditions; and these conditions are exactly those that enable (or are enabled by) the rupture of the metastable equilibrium. The main point is that the starting germ is not a form or matter, but a structural constitutive potential; that is, it carries some sort of information, which sets the basic conditions for an event to happen, information that often comes from an external system (as, for example, the transfer of DNA from one bacterium to another described above). As Simondon writes: "The effective existence of an individuated being results from two conditions that are independent of one another and occur simultaneously: an energetic and material condition derived from the actual state of a system, and an 'evental' [from "event"] condition that most often includes a relation to other series of events, coming from other systems" (Simondon [1954-58] 2013, 80, my translation).

This quotation contains yet another crucial component of the transductive process. A metastable system is not only non-stable but also non-Unitarian. It is not One; there are always multiple series of events going through it. It is a system capable of expansion, and it is necessarily obliged to expand out of itself to interact with other systems. It is neither independent nor autonomous. It cannot survive or subsist in exclusive relation to itself. It is a contained system: tense, oversaturated, superposed over itself, heterogeneous with itself. Being cannot be reduced to what it is; being is at the same time structure and energy (see Simondon [1954-58] 1989, 284), sign and potency, longitude and latitude.

The structural germ functions therefore as a component in an assemblage that sets it in motion, that dramatises it. The distinction between the virtual and the actual is not unilateral, nor is it ontologically black-boxed. The distinction is processual and differential, making of the "a priori and the a posteriori ... a product of individuating processes rather than their condition" (Toscano 2009, 389 ). In this sense, individuation (with all its actualisations) can be thought of as dramatisation (in a Deleuzian sense): the sudden, unexpected, and effective formation and emergence of a percept. As Alberto Toscano (2009, 390) writes: "Simondon's theorisation of pre-individual singularities remains formative." The structural germ operates as the agitator, the excavator, or the explosive trigger of a spatio-temporal metastable system. It opens up new spaces and times, 
revealing not only unpredictable futures but also unsuspected pasts-things that had long been there but had never previously been seen or heard.

\section{Haecceity: from haecceitas (Duns Scotus) to eCCÉité (Simondon) to hecCéité (Deleuze and \\ GUATTARI) TO MICRO-HAECCEITY}

This dramatic opening of a new space-time of possibilities has strong resonances with Deleuze and Guattari's concept of haecceity, a concept that theorises the emergence of a singularity at any given scale and field-from molecular encounters, to geological clashes, landscapes, hours of the day, human thought, arts, and so on. Importantly, a haecceity refers not to a fully qualified space-time, but to an intensive spatio-temporal dynamism. As François Zourabichvili notes, "it does not combine two pre-existing space-times, rather it presides over their genesis. It is the putting-into-communication of heterogeneous dimensions of time from out of which space-times are derived" (Zourabichvili 2012, 128). Thus, a haecceity is a passage, a singular point in space-time that dramatises space-time itself, curving it, folding it, giving it transient form and temporal structure.

In "Memories of a Haecceity" Deleuze and Guattari (1987, 260-65) appropriated and remade the medieval concept of haecceitas to suggest a mode of individuation that is not confused with that of a thing or a subject (see Sauvagnargues 2016, 65). In response to a clarification requested by the translators of the American edition of Dialogues (Deleuze and Parnet 1987), Deleuze stated that "Haecceitas is a term frequently used in the school of Duns Scotus, in order to designate the individuation of beings. [I use it] in a more special sense: in the sense of an individuation which is not that of an object, nor of a person, but rather of an event (wind, river, day or even hour of the day)" (Deleuze and Parnet 1987, 151n9). The difference from Duns Scotus's usage is crucial and can only be perfectly understood in light of Simondon's (apparent) misspelling of hecceité as ecceité (without the $h$ ), which gives the term a modal (rather than essential) quality. ${ }^{9}$ In a famous footnote to A Thousand Plateaus, Deleuze and Guattari $\left(1987,540-41 n_{33}\right)$ explained precisely this crucial difference: "[Haecceity] is sometimes written 'ecceity,' deriving the word from ecce, 'here is. This is an error, since Duns Scotus created the word and the concept from haec, 'this thing.' But it is a fruitful error because it suggests a mode of individuation that is distinct from that of a thing or a subject" (my emphasis). And in the main text they explain further: "A season, a winter, a summer, an hour, a date have a perfect individuality lacking nothing, even though this individuality is different from that of a thing or a subject. They are haecceities in the sense that they consist entirely of relations of movement and rest between molecules or particles, capacities to affect and be affected" (ibid., 261).

9 Whereas Duns Scotus's haecceitas is "a non-qualitative property responsible for individuation and identity[,] ... [which is] supposed to explain individuality” (Cross 2014, \$1), Simondon's eccéité is modal, pointing to a never-finished process of emergence or appearance ("here is"). But Simondon keeps Duns Scotus's focus on the "thisness" (a haecceitas, from the Latin haec, meaning "this") as opposed to a "whatness" (a quidditas, from the Latin quid, meaning "what") (see Cross 2014, \$1). For a detailed introduction to Duns Scotus's theory of individuation, see Sondag ([1992] 2005). 
When appropriating this terminology for the performing arts (music, dance, theatre, or performance), and particularly when speaking of a particular type of haecceities that are set in motion through highly informed structural germs, I propose the introduction of the notion of micro-haecceity, a temporal radicalisation of the concept, collapsing it into an infinitesimal fraction of a second, into the radical here-and-now of the evolving performance. Such radical micro-haecceities would be characterised by intensive negentropic properties, by an almost instantaneous time of existence, and by following one after the other at very high speed. These kinds of haecceities do not suggest (stable) contemplation, but rather rash and metastable actions. Deleuze's characteristic example of haecceity-Lorca's "at five in the afternoon" (see Lorca 1997, 263, 265)-has a scenic quality: it evokes a particular landscape, time of the day, temperature, sunlight, inner memories, and so on. It implies that a certain amount of time (a thickness of the present) is required for it to be fully apprehended. Almost all the examples of haecceity advanced by Deleuze and Guattari describe situations of suspended temporality within long durations of chronometric physical time. But the young pianist performing Schumann's Kreisleriana-my starting example-is navigating high-speed successions of prolonged singularities. There is no time for contemplation; things must happen in the unavoidable urgency and imperative sequentially of the here-and-now. Micro-haecceities are highenergy-loaded and high-speed-moving singularities that carry a force of potential from one position to the next. They make up the visible or audible part of artistic transductive processes. In their functioning as radical becoming they never appear as stable beings, remaining an impulse of virtuality from one actualisation to the next. If one thinks, or does, or experiences artistic performances with these operations in mind, the Deleuzian notion of capture of forces becomes more graspable than ever: the virtual becomes actual in order to be instantly dissolved into the virtual again. The pianist playing Schumann perfectly exemplifies such a capture: he or she is not merely reproducing a stratified, pre-existing entity, but operating a capture of forces (from the virtual) that produces a new individuation (actual) as a highly intensive becoming, which immediately - as soon as it is generated-points forward to other virtual preand after-individualities. Micro-haecceities reveal, therefore, not so much the non-deterministic pasts of their individuated constitutive forces and energies, as their unpredictable futures. By so doing, micro-haecceities reveal that the making of art is a fundamentally problematic field-generating and enhancing heterogeneous tensions that produce the conditions of their own (transient) resolutions. Thus, micro-haecceities, like Deleuzian haecceities, thematise the event: the emergence of a singularity and the passage from one milieu to another.

\section{TOPOLOGY: IN-FORMATION}

With the definitions of transduction exposed so far, I have presented spatio-temporal energetic processes ranging from very simple electric discharges (the incandescent light bulb) to highly complex thermodynamic operations, including a link 
to Deleuze and Guattari's concept of haecceity. Thus, we have mainly remained within the realm of physical individuation, which corresponds, roughly, to one third of Simondon's overall project. In fact, Simondon proposed other ways of thinking transduction, including the individuation of biological organisms, and of psychic and collective agencies and assemblages. It is not possible to cover all those aspects here, but we shall mention one further essential aspect of transduction, namely its topological implications. As Jacques Garelli wrote in the introduction to L'individuation à la lumière des notions de forme et d'information: "Transduction, intimately linked to the discharge of the oversaturated potential energy of a metastable system, will emerge as the shaping of a form and, thus, in a double sense-topological and noetic - as in-formation" (Garelli 2013, 15, my translation and emphasis).

In the process of unfolding itself throughout time the transductive operation gives shape to a surface. Because this surface did not exist before the transductive operation itself, and because it came into existence only through the concrete, here-and-now inscriptions of the transductive process, one can label it as a surface of immanence, as opposed to any transcendental surface that would exist in advance (or at least as an idea of surface). ${ }^{10}$ Within the horizon of possibilities defined by their associated milieu and their multiple orders of magnitude, transductive processes generate a specific space that can be mapped without referring to external systems of coordinates. In parallel with the discharge of pre-individual potential energy, and with the interference between different scales, the transductive process in-forms a topological structure, generating a multi-dimensional shape. The information carried through the transductive movements is not to be conceived as the mere transmission of a coded message- perfectly sent by a sender to a receiver - but much more as a taking shape during the communication process itself. Information thus has two sides: a noetic side that carries the "structural germ," and a topological side that renders this structural germ visible, audible, touchable, or perceptible in some other way. In its double function - noetic and topological — transduction integrates thought and becoming in one single dimension that is not external to its own terms.

While deduction needs an external principle to solve a local problem in a given field, and while induction (by definition) makes generalisations by extracting the characteristics common to all terms in the field, transduction is the continuous creation of new dimensions within a system, establishing links and communication paths between its own disparate constitutive parts. Transduction engenders shapes and textures. It is in this sense that one can say that transduction points to a new concept of space based upon multiplicities, manifolds, vectors,

10 Mathematically, this discussion is indebted to the work of Carl Friedrich Gauss on curved surfaces. Gauss started by studying curved two-dimensional surfaces using the old Cartesian method, that is to say, by embedding the two-dimensional surface in a three-dimensional space with its set of axes. But later, as Manuel DeLanda writes: "Gauss realized that the calculus, focusing as it does on infinitesimal points on the surface itself (that is, operating entirely with local information), allowed the study of the surface without any reference to a global embedding space. ... 'Gauss advanced the totally new concept that a surface is a space in itself'" (DeLanda 2002, 12, emphasis original, incorporating quotation from Kline 1972, 882, DeLanda's emphasis). 
and potentialities. It is not a matter of curves in a flat space, but of the curvature of the space itself. In the place of a transcendental space of reference-with its system of coordinates and its external/extensive properties-transduction creates a Riemannian surface, an immanent space with intensive, internal, and intrinsic properties. The structural germ carries a powerful vector of transport, whose precise speed and direction are the relentless agents responsible for the unfolding form and structure. Where the hylemorphic scheme imposes a form on matter within a metric Euclidean space of coordinates, Simondon's transductive perspective enables multiplicities and differential manifolds to emerge within self-defined space-surfaces. Vectors and functions replace the traditional X-Y-Z system of coordinates. As Manuel DeLanda puts it, "while the points in a metric space are defined by a set $\mathrm{X}, \mathrm{Y}$, and $\mathrm{Z}$ values, presupposing a set of Cartesian coordinates and a transcendent global space in which the space being studied is inscribed, a differential manifold is a field of rapidities and slownesses, the rapidity or slowness with which curvature changes at each point" (DeLanda 2012, 227).

Topology becomes more relevant than geometry: the latter concerns measurements and locations in an external system of reference, while the former disregards measurement and deals only with the structure of space qua space. Figures and shapes are not placed in space; they constitute spaces in/of their own. As Arkady Plotnitsky argues (2009, 203), "this view radically transforms our philosophy of space and matter, and of their relationships, by leading to a horizontal rather than vertical (hierarchical) science of space as a 'typology and topology of manifolds', which Deleuze and Guattari associate with the end of dialectic and extend to spaces that are philosophical, aesthetic, cultural, or political."

Such can be the powerful consequences of a topological understanding of transduction, leading to a non-Euclidean mode of thought-enabling individuations to become space-surfaces of potentially infinite dimensions, and liberating relationships from any form of transcendental determination. The notion of a topological space of possibilities is what allowed Deleuze to overcome and replace the old dichotomy — which had dominated philosophy from Aristotle to Kant and Hegel-between the general and the particular, implying hierarchical (vertical) distributions of forms and matter. Deleuze replaces the general with a topological space of possibilities, a topological diagram that can be folded into another form without losing its identity (what Deleuze calls universal singularities). And, on the other side, the particular is considered only as actual populations of things (individual singularities). ${ }^{11}$ Beyond a system of categories, Deleuze's actual world is populated only by such individual singularities as result from transductive processes of individuation. The new topological spaces and their defining planes of reference or composition are deeply immanent and opposed to geometrical planes of transcendence, which always

11 For a thorough analysis and description of Deleuze's notions of universal singularities and individual singularities, see DeLanda (2006a [full lecture]; 2006b, 26-32; 2010, 81-113; 2011 [full lecture]; 2012). 
come from above, as if designed "in the mind of god ... [and involving the] formation of subjects" (Deleuze 1988, 128). In contrast, a plane of immanence has no supplementary dimension. Such a plane "will be perceived [only] with that which it makes perceptible to us, as we proceed" (ibid.). From a topological point of view, a plane of immanence and a plane of transcendence are fundamentally different- -we do not live or think or write in the same way on both [planes]" (ibid.).

\section{Corporeality: SOMATIC TRANSDUCTION}

A further extension of the concept of transduction has been proposed by Brian Massumi, who, focusing on the human body, defined it as a "transducer of the virtual": "In sensation the thinking-feeling body is operating as a transducer. If sensation is the analog processing by body-matter of ongoing transformative forces, then foremost among them are forces of appearing as such: of coming into being, registering as becoming. The body, sensor of change, is a transducer of the virtual" (Massumi 2002, 135).

It follows from this that the body-every single human body-is not only the individuated ongoing result of transductive process but also itself a transducer; it is itself part of diverse transductive chains of events. The human body is no longer the privileged place of an idealised subjective and uncorrupted $I$, but a conglomerate of molecules thorough which impersonal and pre-individual singularities have the chance to become actualised in specific events such as cell fecundation, embryonic stage, fluid- and organ-formation, nervous system, brain, heart, psychic and collective modes of individuation, noetic, cultural and artistic expressions, and so forth. This wide-ranging body is pre-human, human, non-human, and posthuman, all at the same time, through different processes of modulation and transduction. The crucial point is the death of the subject, which allows the body to embrace energetic processes that enable unpredictable events to happen: no one will ever know what a body can doespecially because this does not depend on any idealised will of the subject.

In music, whether in composing or performing, the main interface or transducer between the innumerable incompatible potentials and their effective, acoustic concretisation is precisely the human body: a body radically energised, activated by desire production, set in motion by diverse simultaneous impulses, attentively listening to its own ongoing manifestations, loving what it does, hating what it does, and continuing in the uncertainty of the future. It is a transducer within a metastable system, but it is itself another metastable system. With the human body we enter a realm of transducers of transducers, something like an ensemble of transducers. A performer's body is "a body that beats" (Barthes 1985, 299), an excited body just about to explode, just about to initiate an energetic discharge from the uncontainable tensions of music and somatic intensities to newly individuated tensions and sensations. Instead of a logic of sense (with clear forms and matters), the artist's body operates as a transducer within a logic of sensation (immersed in intensive, transductive processes). 
The body that notates a score, vibrates its vocal cords, plays an instrument, or conducts an orchestra is a complex organism, inhabited by diverse layers of information, which modulate and shape the actual rendering of musical events. As every musician knows, "no one knows what a body can do"; but beyond this Spinozan claim, one can affirm with Deleuze $(1988,124-25)$ that "no one knows ahead of time the affects one is capable of; it is a long affair of experimentation, requiring a lasting prudence-a Spinozan wisdom that implies the construction of a plane of immanence or consistency." It is the construction of such planes of composition, of unprecedented assemblages of forces and intensities, that moves the desiring body in the first place. Linguistic metaphors, structural analysis, or semiological studies cannot explain or interpret such productions of desire. Signs, forms, and forces are not to be "interpreted," but transduced and reassembled in a vital relation that allows the artist to become an experimenter, or, as Anne Sauvagnargues beautifully expressed it, an operator of forces: "A grouping of forces, an interpretation of forces, says Nietzsche; in other words, a mode of affection. A sign is a force as long as it is not interpreted, but it is felt in a living relation that allows the artist to be an experimenter, an operator of forces. This is where the invention of new forms takes place, which binds art to the exploration of margins about which it posits an intensive theory" (Sauvagnargues 2013, 33, my emphasis).

If we think with Simondon and use his terminology, such forces are to be captured from the tendentially inexhaustible reservoir of potential energy and from the negentropic loaded information of the structural germs. Once set in motion, the capture of forces prolongs itself, originating specific individuations of (new) forces and textures. More than for any other kind of individual, the human body reflects what Simondon expressed in general terms about universal individuals: "The individual, by its energetic conditions of existence, is not only inside its own limits; it constitutes itself at the limit of itself and exists at the limit of itself; it comes out of a singularity" (Simondon [1964] 1995, 6o, my translation and emphasis). This sentence comes close to Spinoza's famous definition from his Ethics: "By substance I mean that which is in itself and is conceived through itself" (Ethics I, 3 , as translated in Spinoza 2002, 217; Per substantiam intelligo id, quod in se est et per se concipitur), ${ }^{12}$ an affirmation that had the potential to exclude transcendence from the realm of things.

\section{Permanent TRANSDUCTION: BEING-IN-THE-WORLD AND FLUCTUATIO ANIMI}

The particular specificity of living organisms - that which differentiates them from purely technical objects-is that their transductive modes of individuation actually never stop (except with death, of course). While technical objects can cease their individuating processes, living organisms (for Simondon and Deleuze)

12 Reflecting on modes of performance of immanent expression, Arno Böhler $(2014,171)$ inspiringly interpreted this famous sentence by Spinoza as follows: "For Spinoza, substance does not exist in something else. It exists, rather, in itself such that it conceptualizes itself from within itself." 
are individualities that simply do not cease their individuation: they are in a state of permanent transduction (see Borum 2017, 114n12). An example taken from brick manufacture shows how the transduction happens "when the heat from burning and the pressure from the mould cause the clay molecules to simultaneously take on a collective individuality, held together by potential energy" (ibid.). Once moulded, transduction finishes, and the brick stops being individuated; and if the internal resonance is incomplete, the brick will crack in the burning process, never achieving an individuated state. With living organisms transduction never stops, due to their fundamental and necessary metastability as a complex system inhabited by a permanent structural germ: their DNA. In addition, another dimension comes into play: living organisms not only emerge as a solution to or resolution of pre-individual tensions or of impersonal structural germs, they also evolve with and within processes of decision-making - processes whereby the resolution "is not a solution, but a decision" (Stiegler 2012, 187). Within somatic transductions there is a special type of structural germ, which is motivated by decision and proactive action in the midst of doubt and uncertainty. Simondon referred to it as fluctuatio animi, a term of obviously Spinozan lineage: "This condition of the mind arising from two conflicting emotions is called 'vacillation,' [Lat. fluctuatio animi] which is therefore related to emotion as doubt is related to imagination, and there is no difference between vacillation and doubt except in respect of intensity" (Ethics III, Prop. XVII, Scholium, as translated in Spinoza 2002, 288).

Simondon invokes this Spinozan notion in relation to the innumerable ways of being-in-the-world. The notion of adaptation gains an important weight as a qualifier of living forms of individuation: "adaptation is a permanent ontogenesis" (Simondon [1954-58] 2013, 211, my translation). Being in a world that does not coincide with itself, which can only be but apprehended through a fundamental disparation, living organisms have to take decisions to survive, acting resolutely in the midst of chaos and uncertainty. Such actions do not happen on one single level or field of potentialities, but on many different levels and scales at the same time. As Simondon writes: "The fluctuatio animi that precedes any resolute action is not a hesitation between different objects or different paths, but rather between a changing collection of incompatible sets, nearly identical but still disparate. Before acting, the subject is suspended between diverse worlds, diverse orders; his action is a discovery of the meaning of this fundamental disparity, of the reason why the particles of every set join together in a richer, more far-reaching set, gaining a new dimension" (Simondon [1954-58] 2013, 210, my translation).

\section{Conclusion}

This chapter was conceived as a contribution to the establishment of a foundational ground for my ongoing theoretical and artistic work towards a dynamic theory of musical arks and their performance. Gilbert Simondon's concept of transduction plays a major role in this theory, offering a varied set of operational strategies, and suggesting new modes of conceptualising and doing musical performances (including composition). Crucially, it enables music studies to 
move beyond not only formalist, analytical, historiographic, organological, or philological approaches (which deal with res extensa), but also sociological, psychological, and subjectivity-based investigations (that are concerned with a human, all too human "I"). With transduction the energetic dimension and the non-human parts of intensive musical processes gain visibility and can be addressed. To compose or to perform a musical work is to enter transductive processes; and the human body implicated in such activities functions sometimes as a transducer and at other times as the individuated entity, both within the larger event of ongoing music-making.

Within Simondon's overall project to articulate a theory of individuation for physical matter, biological organisms, psychic and collective agencies, technology, and the arts, the latter gain a privileged position. Pre-individual clouds of potentiality are present in all modes of individuation, but the artistic ones make them experienceable, or at least almost experienceable. Individuation results from a potentially infinite set of topological possibilities that emerge in the finite actual world as an event; at the same time, this event disrupts the here-and-now of the empirical present, projecting it into new fields of future, infinite, topological singularities. As Deleuze and Guattari $(1994,197)$ proposed: "art wants to create the finite that restores the infinite: it lays out a plane of composition that, in turn, through the action of aesthetic figures, bears monuments or composite sensations."

Simondon's notion of transduction allows us to think of the plane of artistic creation as the material individuation of complex assemblages of forces, rather than as a deterministic or aleatoric stratification of the monist and hylemorphic conceptions. Between art and philosophy, "the role of art turns out to be crucial and paradoxical: it is from art, in so far as it is real experience, that philosophy awaits theoretical renewal, but this renewal is not produced conceptually: it is elaborated on the plane of artistic work" (Sauvagnargues 2016, 68). It is from here that I started, as a performer, and it is from here that I wish to continue: from the production of artistic works and events, and continuing through artistic means the intensive discourse developed in this essay. Even if this chapter is simply a transient individuation within a longer transductive process, it is a crucial moment, reinforcing the profound and necessary implications of making research in, through, and for artistic practice.

\section{REFERENCES}

Assis, Paulo de. 2016. "Transduction and Ensembles of Transducers: Relaying Flows of Intensities in Music." Presentation at the conference "The Concept of Immanence in Philosophy and the Arts," Angewandte Innovation Laboratory (AIL), University of Applied Arts Vienna, Vienna, 7 May 2016. . 2017. "Simondon's 'Transduction' as Radical Immanence in Performance.”
In "Philosophy On Stage: The Concept of Immanence in Contemporary Art and Philosophy," edited by Arno Böhler, Eva-Maria Aigner, and Elizabeth Schäfer, special issue, Performance Philosophy Journal $_{3}$ (3): 695-717.

. 2018. "Transduction and Ensembles of Transducers: Relaying Flows of Intensities." In Transpositions: AestheticoEpistemic Operators in Artistic Research, 
245-65. Orpheus Institute Series. Leuven: Leuven University Press.

Assis, Paulo de, and Lucia D’Errico. 2017. "Rasch ${ }^{15-22}$." Research Catalogue. Accessed 13 April 2018. https://www. researchcatalogue.net/view/285516/911.

Barthélémy, Jean-Huges. 2012. "Glossary: Fifty Key Terms in the Works of Gilbert Simondon." Translated by Arne De Boever. In De Boever et al. 2012, 203-31. Barthes, Roland. 1985. "Rasch.” In The Responsibility of Forms: Critical Essays on Music, Art, and Representation, translated by Richard Howard, 299-312. Berkeley: University of California Press. Book first published 1982 as L'obvie et l'obtus: Essais critiques III (Paris: Seuil).

Beistegui, Miguel de. (2005) 2012.

"Science and Ontology: From MerleauPonty's 'Reduction' to Simondon's 'Transduction.”' In De Boever et al. 2012, 154-75. First published 2005 (Angelaki 10 [2]: 109-22).

Böhler, Arno. 2014. "Staging Philosophy: Toward a Performance of Immanent Expression.” In Encounters in Performance Philosophy, edited by Laura Cull and Alice Lagaay, 171-96. London: Palgrave Macmillan.

Borum, Peter. 2017. "The Notion of 'Singularity' in the Work of Gilles Deleuze.” Deleuze Studies 11 (1): 95-120.

Bowden, Sean. 2012. "Gilles Deleuze, a Reader of Gilbert Simondon.” In De Boever et al. 2012, 135-53.

Cross, Richard. 2014. "Medieval Theories of Haecceity." In The Stanford Encyclopedia of Philosophy (Summer 2014 Edition), edited by Edward N. Zalta. Accessed 28 January 2017. https://plato.stanford.edu/ archives/sum2014/entries/medievalhaecceity/.

De Boever, Arne, Alex Murray, Jon Roffe, and Ashley Woodward, eds. 2012. Gilbert Simondon: Being and Technology. Edinburgh: Edinburgh University Press.

DeLanda, Manuel. 2002. Intensive Science and Virtual Philosophy. London: Continuum. . 2006a. "Deleuze and the History of Philosophy." YouTube video, 9:35, posted by European Graduate School Video Lectures, 10 April 2007. Accessed 3 April 2017. https://www.youtube.com/ watch? $\mathrm{v}=\mathrm{IKI}$ sA8yhP 58 .

- 2006b. A New Philosophy of Society:
Assemblage Theory and Social Complexity. London: Bloomsbury.

. 2010. Deleuze: History and Science. New York: Atropos Press.

. 2011. "Metaphysics as Ontology:

Aristotle and Deleuze's Realism."

YouTube video, 1:31:48, posted by

European Graduate School Video

Lectures, 13 October 2011. Accessed 3

April 2017. https://www.youtube.com/ watch? $=12 j M K G T Y f K_{4}$.

. 2012. "Deleuze, Mathematics, and

Realist Ontology." In The Cambridge

Companion to Deleuze, edited by Daniel W.

Smith and Henry Sommers-Hall, 220-38.

Cambridge: Cambridge University Press.

Deleuze, Gilles. 1981. "L'intuition de

Bergson,” November 10, 1981. CD 1 track 2 of Gilles Deleuze: Cinéma, audio recording of the course on cinema (Paris VIII), selected and edited by Claire Parnet and Richard Pinhas. Gallimard, A 77286, 2006, 6 compact discs. Also available online at http://www2.univ-paris8.fr/ deleuze/IMG/mp3/o1_10_11_81_502_1A. mp3 (14'40"-15'11"); transcribed by Fanny Douarche at http://www2.univ-paris8.fr/ deleuze/article.php3?id_article=17 (\$12). Accessed 30 September 2017. - 1988. Spinoza: Practical Philosophy. Translated by Robert Hurley. San Francisco: City Lights. First published 1970 as Spinoza (Paris: Presses universitaires de France), revised 1981 as Spinoza: Philosophie pratique (Paris: Minuit). -1994. Difference and Repetition.

Translated by Paul Patton. New York: Columbia University Press. First published 1968 as Différence et répétition (Paris: Presses universitaires de France).

Deleuze, Gilles, and Félix Guattari. 1987. A Thousand Plateaus: Capitalism and Schizophrenia. Translated by Brian Massumi. Minneapolis: University of Minnesota Press. First published 1980 as Mille plateaux (Paris: Minuit). . 1994. What Is Philosophy? Translated by Hugh Tomlinson and Graham Burchell. New York: Columbia University Press. First published 1991 as Qu'est-ce que la philosophie? (Paris: Minuit).

Deleuze, Gilles, and Claire Parnet. 1987. Dialogues. Translated by Hugh Tomlinson and Barbara Habberjam. New York: Columbia University Press. 
First published 1977 as Dialogues (Paris: Flammarion).

Garelli, Jacques. 2013. "Préface: Introduction à la problématique de Gilbert Simondon.” In Simondon [1954-58] 2013, 9-19.

Kline, Morris. 1972. Mathematical Thought from Ancient to Modern Times; Volume 3. New York: Oxford University Press.

Lorca, Federico García. 1997. Lament for Ignacio Sánchez Mejías. Translated by Alan S. Trueblood. In Federico García Lorca: Selected Poems, edited by Christopher Maurer, 260-73. London: Penguin.

Massumi, Brian. 2002. Parables for the Virtual: Movement, Affect, Sensation. Durham, NC: Duke University Press.

Massumi, Brian, Arne De Boever, Alex Murray, and Jon Roffe. 2012. "Technical Mentality Revisited: Brain Massumi on Gilbert Simondon.” In De Boever et al. 2012, 19-36.

Michaud, Yves. 2012. "The Aesthetics of Gilbert Simondon: Anticipation of the Contemporary Aesthetic Experience.” Translated by Justin Clemens. In De Boever et al. 2012, 121-32.

Plotnitsky, Arkady. 2009. "Bernhard Riemann.” In Deleuze's Philosophical Lineage, edited by Graham Jones and Jon Roffe, 190-208. Edinburgh: Edinburgh University Press.

Satoor, Christopher. 2017. "'A Part' of the World: Deleuze and the Logic of Creation." In Deleuze Studies 11 (1): 25-47.

Sauvagnargues, Anne. 2003. "Actuel/Virtuel." In Le vocabulaire de Gilles Deleuze, edited by Robert Sasso and Arnaud Villani, 22-29. Les Cahiers de Noesis 3. Paris: Vrin. . 2013. Deleuze and Art. Translated by Samantha Bankston. London: Bloomsbury. First published 2005 as Deleuze et l'art (Paris: Presses universitaires de France). . 2016. Artmachines: Deleuze, Guattari, Simondon. Translated by Suzanne Verderber with Eugene W. Holland. Edinburgh: Edinburgh University Press.

Scott, David. 2014. Gilbert Simondon's Psychic and Collective Individuation: A Critical Introduction and Guide. Edinburgh: Edinburgh University Press.

Simondon, Gilbert. (1954-58) 1989. Lindividuation psychique et collective
[Psychic and collective individuation]. Paris: Aubier. Written $1954-58$. - (1954-58) 2013. L'individuation à la lumière des notions de forme et d'information [Individuation in light of the notions of form and information]. Grenoble: Jérôme Millon. Contains texts written $1954^{-} 5^{8}$. This selection first published 2005 (Grenoble: Jérôme Millon).

- (1958) 2012. Du mode d'existence des objets techniques. Paris: Aubier. First published $195^{8}$ (Paris: Aubier). Translated by Cécile Malaspina as On the Mode of Existence of Technical Objects (Minneapolis: University of Minnesota Press, 2017). . (1964) 1995. L'individu et sa genèse physico-biologique [The individual and its physico-biological genesis]. Grenoble: Jérôme Millon. First published 1964 (Paris: Presses universitaires de France). . 2014. Sur la technique (1953-1983). Paris: Presses universitaires de France. Sondag, Gérard. (1992) 2005. Introduction to Duns Scot, Le principe d'inviduation, edited and translated by Gérard Sondag, 7-70. Paris: Vrin. First published 1992 (Paris: Vrin).

Spinoza, Baruch. 2002. Ethics. In Complete Works, translated by Samuel Shirley, edited by Michael L. Morgan, 213-382. Indianapolis: Hackett. Ethics first published 1677 as Ethica in Opera posthuma (Amsterdam).

Stiegler, Bernard. 2012. "The Theatre of Individuation: Phase-Shift and Resolution in Simondon and Heidegger." Translated by Kristina Lebedeva. In De Boever et al. 2012, 185-202.

Toscano, Alberto. 2009. “Gilbert Simondon.” In Deleuze's Philosophical Lineage, edited by Graham Jones and Jon Roffe, 380-98. Edinburgh: Edinburgh University Press. Zourabichvili, François. 2012. Deleuze: $A$ Philosophy of the Event, together with The Vocabulary of Deleuze. Translated by Kieran Aarons. Edited by Gregg Lambert and Daniel W. Smith. Edinburgh: Edinburgh University Press. First published 2011 as "Deleuze: Une philosophie de l'événement" in La philosophie de Deleuze, edited by François Zourabichvili, Anne Sauvagnargues, and Paola Marrati, 1-116 (Paris: Presses universitaires de France). 



\section{Chapter 6 \\ Rasch $^{26}$ : \\ The Somatheme ${ }^{*}$}

\section{The SOMATheme}

In 1975, in "Rasch"-an essay on Robert Schumann's Kreisleriana-Roland Barthes invented a new concept: the somatheme (somatème), which is presented in the plural (somathemes) and defined as "the figures of the body..., whose texture forms musical signifying" (Barthes 1985f, 307). "Rasch" was written for a collective volume dedicated to the French structural linguist Émile Benveniste (1902-76), a volume that included essays by other well-known linguists and semiologists of the day, such as Roman Jakobson, Julia Kristeva, Claude Lévi-Strauss, Nicolas Ruwet, and Tzvetan Todorov. Barthes's contribution is the only one relating to music; in it, Barthes argues for a "second semiology, that of the body in a state of music" (ibid., 312). Referring to Émile Benveniste's famous book Problèmes de linguistique générale (1974), Barthes particularly focused on the opposition presented there between two realms: the semiotic (articulated signs, each of which has a precise meaning), and the semantic (an order of discourse no unit of which signifies in itself, although the ensemble is given a capacity for signifying). Benveniste had posited that music belongs to semantics and not to semiotics, "since sounds are not signs (no sound, in itself, has meaning)" (Barthes 1985f, 311)-music here being defined as a language with a syntax but no semiotics. To that specific kind of (musical) signifying, Barthes added a radically new dimension, one steeped in desire ("pénétrée de désir"). It is this presence and continuous activity of desire and of desire production that enables a particular modality of signifying, "which destroys itself as it develops" (ibid., 312). This is the domain of Barthes's second semiology: "let the first semiology manage, if it can, with the system of notes, scales, tones, chords, and rhythms; what we want to perceive and to follow is the effervescence of the beats [the second semiology]" (ibid.). The first semiology aims to understand structures and propositions (intelligibility), the second to perceive and follow forces and intensities (drives and desire).

\footnotetext{
This chapter is the twenty-sixth instantiation of $\operatorname{Rasch}^{X}$, a series of artistic research outputs that explores Robert Schumann's Kreisleriana op. $16(1838,1850)$, and Roland Barthes's essays on music written between 1970 and 1979, particularly those focused on Schumann. In ever-changing configurations, these materials are reworked making use of different spaces of representation, including performances, lectures, essays (such as this one), and web-based expositions. For an overview of the Rasch ${ }^{X}$ series, see Assis (2016).
} 
It is within this theoretical framework, and through a close reading of selected passages from Schumann's Kreisleriana, that Roland Barthes identifies figures of the body, the somathemes, those musical figures that go beyond musical semiology and impose pulsional corporeal drives as the main referent for signifying. A "transgression” that "makes music a madness: not only Schumann's music, but all music" (Barthes 1985f, 308).

"Rasch" is written in a poetic, passionate, and sexualised style that perfectly captures the madness of music-making as defined by the uncontrolled, unconscious drives of its somathemes. As François Noudelmann $(2012,135)$ observed, Barthes's essay engages with "a whole complex of sensations, passions, and sexuality," aiming at the investigation of "the sexual power of the desire that nimbly leads both pianist and listener toward an unknown, disseminated jouissance" (ibid., 138; on jouissance see Lacan 1999, 64-77; Fink 2002). "Rasch" is one of the writings in which Barthes actively wants to escape from learned discourses, primarily from the imperialism of semiology, a recent discipline of which he had become one of the heralds. In music, Barthes did not trust the search for structural codes (analysis), nor all those interminable accounts and commentaries so characteristic of musicological studies. Bypassing any structural decrypting of music, Barthes-himself an amateur pianist-became alert and vigilant to the transformations of his own body while playing. "Rather than being attracted to the structures of music, he gave himself over to passions without language when playing the piano. He sought the imaginary excess of the body more than any measurement of sound-spaces" (Noudelmann 2012, 142).

The concept of the somatheme seems to have evolved from (at least) three different fields: (1) from Barthes himself, the amateur pianist who played Kreisleriana at home and was persistently disappointed by "professional" renderings of it in concert or in recordings; (2) from the overarching context of mid-1970s French linguistics, semiology, and semiotics-particularly in relation to the work of Julia Kristeva and her notions of chora, genotext, and phenotext; and (3) from early 1970 developments in psychoanalysis, especially related to Jacques Lacan's mathemes, the fundamental breaks of Lacanian algebra.

The remainder of this chapter will briefly address these three influences, first presenting Roland Barthes at the piano, then Julia Kristeva's impact on the musical thought of Barthes, and finally the relation of Barthes's concept of the somatheme to Jacques Lacan's mathemes and graphs of desire. Additionally, the specific fourteen somathemes that Barthes proposed in "Rasch" will be presented in an intermezzo.

\section{Roland Barthes at the piano: musica PRACTICA}

Roland Barthes was an amateur pianist who played the piano daily and who enjoyed sight-reading, freely wandering from one piece to the next. He did not memorise the music, nor did he play it in constant tempo; rather, he followed his limited playing ability. On the other hand, he was musicologically well informed and highly acquainted with the main pianistic repertoire. Piano playing accompanied him all his life, and it seems that it had an important function, enabling a 
particular openness to sonic and imaginary corporealities that exist before and after the production of articulated meaning. In François Noudelmann's (2012) view, "piano playing conjoins suspension and engagement. A refuge, a step to the side, an exclusive passion, the musical life of the body" (152). "Piano playing offered him [Barthes] a way out of codes, discourses, doxa, and the contemporary" (153).

A fundamental distinction between the activities of listening to music and of (corporeally) playing it became increasingly relevant to Barthes, culminating in his famous lines from 1970 (in "Musica Practica"): "There are two musics (or so I've always thought): one you listen to, one you play. They are two entirely different arts, each with its own history, sociology, aesthetics, erotics: the same composer can be minor when listened to, enormous when played ... - take Schumann" (Barthes 1985d, 261).

Even if the composer explicitly mentioned in this passage is RobertSchumann, the short essay where the passage appears was originally published in a special issue of the literary journal L'Arc $(40,1970)$ fully dedicated to Beethoven. In the essay, Barthes develops a notion of a certain mode of the inaudible inside the very fabric of the audible: "there is something inaudible in Beethoven's music (for which audition is not the exact mode)" (Barthes 1985 d, 264). The exact mode would be informed and defined by a "sensuous intelligibility" (264), an intelligibility somehow perceptible in, through, and to the senses. Such a perception (Baumgarten's sensuous knowledge?), would have been inconceivable "in terms of the old [pre-Kantian] aesthetics" (265). According to Barthes, it was Beethoven who inaugurated a new mode of musical intelligibility-one no longer based upon execution or hearing but on reading. In this mode, the body-in front of a keyboard, in front of a music stand-proposes, leads, coordinates: "the body itself must transcribe what it reads: it fabricates sound and sense: it is the scriptor, not the receiver; the decoder" (261). This means that there is a fundamentally practical approach to music, dependent not so much on an auditive as on a manual activity. At the same time, this is precisely what permits a new type of performer, "who can displace, regroup, combine, dispose, in a word [who] can structure" (265). To read Beethoven in this way, according to Barthes, consists of "traversing its writing by a new inscription ... to operate his music, to lure it... into an unknown praxis" (265).

This is the basic idea and rationale of a musica practica. With it, Barthes started a path suggesting a phenomenology of touch at the piano, or of the grain of the voice. This phenomenology is informed-in the first place-by Barthes's specular relation to his own playing body. He particularly recognises the power of the musics of Beethoven or Schumann when he himself plays them: "Schumann lets his music be fully heard only by someone who plays it.... I have always been struck by this paradox: that a certain piece of Schumann's delighted me when I played it (approximately), and rather disappointed me when I heard it on records: then it seemed mysteriously impoverished, incomplete" (Barthes 1985c, 294-95). For Barthes, music had to pass through the body in order to operate and to be operated by individual pulsions and drives: "Schumann's music goes much farther than the ear; it goes into the body, into the muscles by the beats of its rhythm, and somehow into the viscera by the voluptuous pleasure of its 
melos: as if on each occasion the piece was written only for one person, the one who plays it; the true Schumannian pianist—c'ést moi" (ibid., 295).

Further developed in short essays of fragmentary argumentation, such as "The Grain of the Voice" (1972 [see Barthes 1985a]), "Rasch" (1975 [see Barthes 1985f]), "Music, Voice, Language" (1977 [see Barthes 1985e]), and "Loving Schumann" (1979 [see Barthes 1985c]), this quasi-phenomenology of the touch, involves a continuous move between semiology and semiotics, between propositional language and pulsional drive, between signifier and signifying, between code and jouissance, between the subject of science and the subject of desire. Beyond the neutrality of musical language, with its codes, systems, and articulated rules, Barthes affirms in relation to the voice of Charles Panzéra that the singer's voice was animated by "a quasi-metallic strength of desire: it is a 'raised' voice—aufgeregt (a Schumannian word)—or even better: an erected voice-a voice which gets an erection" (Barthes 1985e, 283). Such allusions to sexualised modes of listening and playing are not infrequent in Barthes's essays on music, an aspect that has largely been ignored by those criticising the essays' poor musical analytical depth. Barthes's crucial point is, precisely, to move beyond the wise language of pitches, rhythms, harmony, phrasing, and formal construction, in order to expose a more essential beating body, which manifests itself through implosions and explosions of forces, different speeds, accelerations, and curvatures. Barthes was looking for these intensive qualities, principally within his own body, by means of inwardness, as if there were an outside to the inside. According to François Noudelmann (2012, 99), "Barthes's movement toward theoretical generality develops through the personal description of his tastes, his sensitivity, indeed his sexuality, all of which are linked to the piano. Besides listening to and reading music, there is also the inner playing of music, which carries with it a sensual understanding of the music. The piano player's ears and eyes cannot overshadow his hands or fingers; through them his body expresses and constructs the music."

Barthes's essays on music do not form a philosophical aesthetics or a philosophy of music, nor are they totally coherent. They extend Barthes's embodied experience of music into more speculative discourses, crucially animated by his vast knowledge of semiology and psychoanalysis. A famous semiologist himself, as well as an attentive reader of Lacan, Barthes's discourse on music comes close to Julia Kristeva's notion of semanalysis, a complex merging of linguistics and psychoanalysis, a cross-disciplinary approach that launched the bases for an important renewal of semiotics. When Félix Guattari, in L'inconscient machinique (1979 [see Guattari 2011]), insisted upon, and even reinforced the distinction between semiology and semiotics, he explicitly associated Barthes (negatively) with the former and Charles Sanders Pierce with the latter. Guattari's distinction between these supposedly opposed perspectives is as follows: semiology is understood as "a trans-linguistic discipline that examines sign systems in connection with the laws of language (Roland Barthes' perspective); and 'semiotics' as a discipline that proposes to study sign systems according to a method which does not depend on linguistics (Charles Sanders Pierce's perspective)" (Guattari 2011, 22). Guattari's project was to escape from language and from 
interpretative components in favour of symbolic (intensive) semiotics, and diagrammatic transformations "concerning asignifying semiotics that proceed through a deterritorialization relative both to the formalism of content and expression" (ibid., 20). On the one hand, this clear-cut division between semiology and semiotics was contested by the International Association of Semiotics (see ibid., 22); on the other hand, one can argue that Barthes's texts on music precisely try to address the perspective advocated by Guattari, namely the study of particular musical figures that escape the laws of language and linguistics.

In fact, what Barthes thoroughly explores in "Rasch" (Barthes 1985f) is the central idea that beyond the first text-generated in the wise language of pitches, rhythms, harmony, phrasing, and formal construction-there is a more essential beating body producing its own figures (somathemes) that directly communicate a second text. Barthes sometimes calls these two different layers first semiology and second semiology. This second semiology reveals the emergence of desire, the production of new agencies of musical signifying (forces, energy, power) that are situated both before and beyond linguistically determinable signification (analysis, harmony, themes, cells, phrases). In his definition of the somathemes, Barthes implicitly criticises semiology:

\footnotetext{
Such are the figures of the body (the "somathemes"), whose texture forms musical signifying (hence, no more grammar, no more musical semiology: issuing from professional analysis-identification and arrangement of "themes," "cells," "phrases"-it risks bypassing the body).... These figures of the body, which are musical figures, I do not always manage to name. For this operation requires a metaphorical power (how would I utter my body except in images?), and this power can occasionally fail me: "it" stirs in me, but I do not find the right metaphor. (Barthes 1985f, 307)
}

The kind of listening to which Barthes refers is not the advent of a signified, of an object of recognition or deciphering. No, it is a dispersion, what he poetically called the "shimmering of signifiers," "ceaselessly restored to a listening which ceaselessly produces new ones from them without ever arresting their meaning: this phenomenon of shimmering is called signifying ..., as distinct from signification" (Barthes 1985b, 259). Signification is grounded on deciphering, on recognition of patterns, themes, structures, on the identification of and obeisance to codes. Signifying requires listening to each sound one after the other, attentively, radically; it grants access to all forms of polysemy, of overdetermination, of superimposition, disintegrating the law that prescribes direct, unique listening. Signification and signifying: these are the two Barthesian words for the signifier and for the pulsional drives and desire. They must be understood in the contexts of linguistics and psychoanalysis. 


\section{Chapter 6}

\section{The impact of Julia Kristeva: phenotext and GENOTEXT}

The epigraph to "Rasch" stems from Diderot's imaginary philosophical conversation Le neveu de Rameau (1762-64), which contains a mysterious Latin quotation that Diderot is supposed to have "read somewhere": "musices seminarium accentus" (Barthes 1985f, 299) - "accent is the seed-bed of music" (translation based on Atkinson 2009, 58). Without ever telling the reader, Diderot is quoting a fragment from Martianus Capella's (c.420-c.490) De nuptiis Philologiae et Mercurii (On the Marriage of Philology and Mercury): "And just as there is no utterance without a vowel, so, too, there is none without an accent. As some assert, accent is the soul of utterance and the seed-bed of music, because every melody is composed of elevation or depression of the voice. Thus accentus is called 'ad-cantus'- 'for the purpose of song'-so to speak" (Martianus Capella, Book III, De arte grammatica, section 268, original and translation from Atkinson 2009, 58-59). ${ }^{1}$

Voice is presented as having two necessary components: vowels, abstract signs that give it structure, and accents, the elevations and depressions of the intonation, the plastic modulators of voice. Fifteen centuries before the invention of semiotics, Martianus Capella's text suggests the existence of two layers: a coded linguistic structure that is written down, and a potentially destabilising pulsional utterance. Remotely, in a different context, and through the mediation of Barthes (via Diderot), Martianus's sentence can be read in relation to twentieth-century semiology and semiotics, particularly to Julia Kristeva's notions of phenotext and genotext, which were particularly relevant to Barthes's writings on music.

Barthes had applied Kristeva's terms to music by 1972 , in his famous essay "The Grain of the Voice" (see Barthes 1985a). According to Barthes, some singers only perform phenotext, understood as the cultural, the aesthetic, the stylistic; whereas other singers emphasise the genotext, that is, the entire body functioning as a vehicle for drive energies. In Barthes's view, when listening to a song, one should hear the lungs expand and contract, the heartbeat, the muscles grow taut and relax, and so on (see Tarasti 2002, 23). Borrowing from Kristeva's genotext and phenotext, Barthes created the concepts of genosong and phenosong. Genosong refers to the physiological aspect of singing, the corporeal vocal technique that engages the whole body, while phenosong relies on the primacy of language, text, and civilisation, the sublimation of the physical level to that of high culture (see Tarasti 2002, 169).

The notions of phenotext and genotext are thoroughly presented and explained in La révolution du language poétique (1974), Julia Kristeva's state doctorate defended in Paris in July 1973, for which Barthes was one of the examiners. Inspired by the ideas of Lacan and the emphasis he gave to the role Freud had assigned to language, but crucially drawing upon Ferdinand de Saussure, Charles Sanders Peirce, and Émile Benveniste, Kristeva not only affirmed the

1 “... et ut nulla vox sine vocali est, ita sine accentu nulla. Et est accentus, ut quidam putaverunt, anima vocis et seminarium musices, quod omnis modulatio ex fastigiis vocum gravitateque componitur, ideoque accentus quasi adcantus dictus est.” 
necessity of taking into account the speaking subject within a social and historical field for a sound textual analysis, but also advocated a transdisciplinary discourse that could break down the barriers that isolated related disciplines from one another (see Roudiez 1984, 7). Between linguistics and psychoanalysis-sharing notions and methodologies from both of them-Kristeva invented a new "discipline," namely semanalysis. Analysing texts by Mallarmé and Lautréamont, Kristeva points to specific manifestations of the semiotic disposition, showing "how closely their writing practice parallels the logic of the unconscious, drive-ridden and dark as it might be; such a practice thus assumes the privilege of communicating regression and jouissance" (Roudiez 1984,3 ). Kristeva relegates aesthetic and formalistic considerations to the background, focusing on phonological rhythms and accents. What really matters to her is "to give an account of what went into a work, how it affects readers, and why" (ibid., 5).

In very simple terms, Kristeva differentiates two layers of a text: the phenotext that we have in front of us (notated through universal signs and symbols) and the genotext, a non-linguistic, process-driven field of drive energies (from the unconscious) that precedes and originates the phenotext. Those threads that are spun by drives and are fabricated within the semiotic disposition define the genotext; those issuing from societal, cultural, or grammatical constraints constitute the phenotext. In Leon S. Roudiez's $\left(1984,5^{-6}\right)$ expressive formulation: "A mathematical demonstration is perhaps a pure phenotext; there are writings by Antonin Artaud that come close to being unblended genotext, those, in Susan Sontag's [1981, 25] words, 'in which language becomes partly unintelligible; that is, an unmediated physical presence.' For ... it is often the physical, material aspect of language (certain combinations of letters, certain sounds-regardless of the meaning of words in which they occur) that signals the presence of a genotext."

According to Kristeva $(1984,86)$, the genotext reveals transfers of drive energy that "can be detected in phonematic devices (such as the accumulation and repetition of phonemes or rhyme) and melodic devices (such as intonation and rhythm)." Crucially, the genotext organises a space in which "the subject will be generated as such by a process of facilitations and marks" (ibid.). Even if it can be retrieved in language (through its special markers), the genotext is not linguistic: "it is, rather, a process, which tends to articulate structures that are ephemeral ... and non-signifying (devices that do not have a double articulation)" (ibid.). In this sense, the genotext can be seen as the underlying foundation of language. Phenotext denotes language that serves communication, which can be dissected formally and quantitatively; it follows rules of communication and presupposes both a subject of enunciation and an addressee. The genotext is based on bodily drives; it is a non-linguistic, process-driven field of drive energies from the unconscious; and it displays an asignificant background of language. Obviously, as it is the articulation between the pure bodily and the linguistic levels of communication, the genotext must be disclosed and exposed, and it becomes perceptible through the phenotext. The signifying process includes, therefore, both the genotext and the phenotext. 


\section{Chapter 6}

The phenotext relates primarily to fixed positions (as represented in generative grammars), while the genotext is a process, something in permanent becoming: the movement of a serpent through leaves...

\section{New musical concepts: Geno-SONG, Pheno-SONG, SOMATHEME}

It is difficult, if not impossible, to underestimate the impact of Kristeva's ideas on Barthes's musical thought. We know from the newspaper Le Monde that Barthes, who was a member of the committee examining Kristeva's doctorate in July 1973, did not raise one single question. According to the reporter who covered the event, Barthes is quoted as having said, "Several times you have helped me to change, particularly in shifting away from a semiology of products to a semiotics of production" (Buleu 1973, 15, quoted in Roudiez 1984, 10). It seems that Barthes's overall attitude was one of praise, indebtedness, and gratitude, rather than the stereotyped academic opposition.

Reading Barthes's essay "Rasch," or "The Grain of the Voice," is illuminating in this respect, as one can see several Kristevean concepts being used at a deep level. As already mentioned above, in "The Grain of the Voice" Barthes transposes the concepts of phenotext and genotext to music, calling them pheno-song and geno-song (Barthes 1984a, 270). They will serve, in the first moment, to help better locate the grain, to disengage it theoretically. According to Barthes (ibid., 270-71):

\footnotetext{
The pheno-song ... covers all the phenomena, all the features which derive from the structure of the sung language, from the coded form of the melisma, the idiolect, the composer, the style of interpretation: in short, everything which, in the performance, is at the service of communication, of representation, of expression: what is usually spoken of, what forms the tissue of cultural values ..., what is directly articulated around the ideological alibis of a period (an artist's "subjectivity," "expressivity," "dramaticism," "personality"). The geno-song is the volume of the speaking and singing voice, the space in which the significations germinate "from within the language and in its very materiality"; this is a signifying function alien to communication, to representation (of feelings), to expression; it is that culmination (or depth) of production where melody actually works on language- not what it says but the voluptuous pleasure of its signifier-sounds, of its letters.
}

Between the voice as carrier of propositional statements and the voice as bodily utterances, a new space emerges that is characterised by the "friction between music and something else, which is the language (and not the message at all)" (Barthes 1984a, 273). First, one hears something, one is alert; hearing - with its indexing function - establishes a determined auditive background, a kind of territory to be defended (because it quickly becomes "familiar" and "domestic"). Second, one starts deciphering what one hears, trying to classify all the sounds in terms of signs and codes, entering an oriented hearing and a first mode of listening (intelligible listening, which belongs to the realm of phenosong). Third, true listening starts happening: our brains focus on the signifiers, the actual producers of the sound (the voice, the body, the instruments, which 
belong to the field of geno-song). This last mode of listening creates a friction with the second, because what is being said, sung, or played crucially depends upon how it is corporeally said, sung, or played. This is the grain. For Barthes, the grain is not timbre; it is the body as scriptor, as producer of frictions, of inscriptions (also in a psychoanalytical sense): “The 'grain' is the body in the singing voice, in the writing hand, in the performing limb" (Barthes 1984a, 276). Dramatically, as Barthes sharply observed as early as 1972, "aside from the voice, in instrumental music, the 'grain' or its lack persists" (ibid.). When listening to or judging performances, the dominant mode became the one based on the mainstream rules of interpretation, on the constraints of style and historically informed codes and systems of coding, "almost all of which belong to the phenosong" (ibid., 277). The "rigor," the "brilliance," the "respect for the score," the "authenticity," the "musicality," the "differentiated playing" are all clichés that cover the absence of pulsional drives, of a radical intensity of exposing oneself totally, without fears, and beyond safety. Back then, in 1972, Barthes complained about the absence of geno-text in music performance: "there is nothing left but pheno-text" (ibid.). Moreover, at the end of "The Grain of the Voice" Barthes goes even further, announcing "another history of music [different] than the one we know[,] which is purely pheno-textual" (ibid.), and appeals, instead, to an aesthetic of musical jouissance.

Barthes developed these thoughts further three years later in "Rasch," a piece of writing exclusively dedicated to one single musical work, Schumann's Kreisleriana-a work of such radical corporeality that it seems to be the perfect line of flight for Barthes's escape from classical semiology. Accompanied by several fragments extracted from the score of Kreisleriana, "Rasch" contains the embryonic cell of a complex geno-phenomenology of music still to be made. On the one hand, it returns to powerful semiotic concepts and tools, such as the Saussurean paragram, the anagram ${ }^{2}$ and the anagrammatic network, the screen of the signified, fields of signifying, signifier and referent, semantics, paragrammatical structure, Kristeva's chora, and Benveniste's notions of the semiotic and the semantic (Barthes 1984g, 302-11). On the other hand, it is traversed by a pulsional body, putting forward a strongly sexualised view of music and playing. ${ }^{3}$ When speech becomes musical, or its instrumental substitute, it "is no longer linguistic but corporeal” (Barthes 1984f, 299-309, quotation from 306 ). "Music, then, is what struggles with writing. When writing triumphs, it takes up where science, impotent to restore the body, leaves off: only the metaphor is exact; and it would suffice that we be writers for us to be able to account for

2 On Saussurean anagrams, see Starobinski (1964); Kristeva (1969).

3 Some of Barthes's wordings include the following: a body that stretches; a body that declares itself to someone; a body that rises; a pulsional body; a body that pushes itself back and forth; a body that turns to something else; a stunned body (intoxicated, distracted, ardent); a body that undergoes interruptions; a body that explodes; a body that beats inside itself, against the temple, in the sex, in the belly, against the skin from inside, in the heart-a hallucinated body; the body as a histological fabric; a body that is lifted up, stretched out, erected; a body that progresses in revulsions and through incisions, entering the sudden wave of the swallowing throat; a body that curls itself up into a ball in order to stretch itself out all the better later on. Schumann's body strikes, collects itself, explodes, divides, it pricks, it weaves, it becomes arachnean, it speaks, it declaims, it doubles its voice, it leaves in breathlessness, haste, desire, anguish, it approaches orgasm, and it speaks but says nothing. 
these musical beings, these corporeal chimeras, in a perfectly scientific fashion" (Barthes 1984f, 308). This is the point where classical music semiology reaches its limits. Previously uninterested in the referent (the body with all its pulsional dimensions), conventional music analysis and music theory remained tied to the safety of the signified, to everything rationally explainable and dividable. But when one looks at music as a field of signifying and not as a system of signs, than a new music history, a new image of work, and new performative practices become not only possible but also necessary. Expanding his previous considerations of geno-song and pheno-song, particularly focusing on the former, Barthes arrives at the concept of the somatheme (see Barthes 1985f, 307).

Somathemes are presented as being figures of the body, musical figures that do not simply relate to the metaphorical musical gesture but that fundamentally include the physical gesture as well. More than consciously perceivable cells, themes, or phrases (the traditional objects of music analysis), they generate complex interwoven textures grounded on "images": "How would I utter my body except in images?" (Barthes 1985f, 307). These images are not to be understood as visual images but very much in the sense of Freud's imago. ${ }^{4}$ They operate at a deep psychological level, addressing the unconscious more than the conscious. Generating musical "signifying," and going beyond propositional meaning or intelligibility, such images are fundamentally overdetermined. ${ }^{5}$ In this sense, Barthes stated that somathemes require a not-always successful metaphorical power, and that they are linked to the constitution of images. And in the constitution of images (always singular and individual, unconsciously produced by the receiver) lies a fundamental element in Schumann's musicthe episodic, the fragmentary succession of short musical entities-that John Daverio $(2007,71)$ (in a passage closely related to "Rasch") understood as the imagistic essence of his music, which unfolds like "the discontinuous succession of frames in a film."

Related to the motions and movements of the human body (and/or voice), the figures of the body convey corporeal meanings, which-particularly in extreme ritardandos, in frantic, forward-rushing rhythmic lines, or in syncopated pulses-relate to a body "which is about to speak" (quasi parlando) without saying anything. As Robert S. Hatten (2001) wrote, Barthes identified "significant categories that differ from the linguistic in being corporeal."

4 Imago is the word used by Freud to describe unconscious object-representations (Rycroft [1968] 1995, 78). The word was first presented by C. G. Jung in Wandlungen und Symbole der Libido (Psychology of the Unconscious) (1911), where it is an imaginary scheme (and not an "image"), a scheme through which the subject relates to the other; in this sense an imago can be an image, but also an emotion, a feeling, a behaviour (see Laplanche and Pontalis [1967] 2007, 196).

5 In psychoanalysis, overdetermination is "a symptom, dream-image, or any other item of behaviour... that has more than one meaning or expresses drives and conflicts derived from more than one level or aspect of personality" (Rycroft [1968] 1995, 123).

6 Referring to Barthes's "Rasch," Daverio quotes him ("Music, in short, is an image, not a language" [Barthes 1985f, 301-2]) in order to add, "Put another way, the discursive model for much of Schumann's music is less the continuous unfolding of events in a narrative than the discontinuous succession of frames in a film" (Daverio 2007, 70-71). 
Finally, somathemes reveal the emergence of desire, the production of new agencies of musical signifying (forces, energy) that are situated beyond linguistically determinable signification (analysis, harmony, themes, cells, phrases). The "possibility of delirium" (Barthes $1985 \mathrm{f}, 309$ ) and the centrality of desire production could become central functions and categories for music production and reception. Such openness to pulsional energies would carry a "revolutionary" potential, allowing for a completely different reading of music history, composition, and performance. Barthes's somatheme could act as the central concept for this revolution. Conceived as figures of the body, whose texture engenders musical signifying, they belong to the sphere of the geno-song, beyond meaning and metaphors, enabling a new musical semiotics strongly related to unconscious image formation, to deep psychic processes, and to some kind of artistic or dream work. Barthes drops this concept in the middle of "Rasch" without further elaboration or developments. Fundamentally, it is simply there, waiting for someone interested (and with the technical competence) to expand it and start working on a new musical semiotics. This new musical semiotics would need first to map a certain group of somathemes, then to engage with their specific overdeterminations, and finally to join their Lacanian vectors of desire in order to cut across the diachronic chains of signifying and of jouissance. Only if one is equipped with such tools can one ask, from an entirely new perspective, What can a body do?, or, more precisely, Body, what do you want? Che vuoi?

\section{INTERMEZZO: FOURTEEN SOMATHEMES}

This intermezzo presents the fourteen musical examples offered by Roland Barthes in "Rasch." They seem to function as prototypes of somathemes and suggest possible avenues for a geno-phenomenology of the musical body. Transcribed here in sequence, they are accompanied by the relevant text fragments that relate to them in "Rasch" (Barthes 1985 f, 3 O1-9, translation adjusted). In this manner, the methodological similarity between this kind of approach and the one proposed by Julia Kristeva in the second and third parts of La révolution $d u$ language poétique (1974) becomes apparent (even if Kristeva, operating in the field of poetry, is much more precise, detailed, and technically informed). As in the case of Kristeva's methodology, Barthes is also indebted to the anagrams of Saussure (via Jean Starobinski). ${ }^{7}$

7 Crucial to the topic of anagrams and anagrammatic modes of thought is the work done in the 1960 by Jean Starobinski, who presented Saussure's notebooks on anagrams in diverse articles, culminating in his book Les mots sous les mots (1971). See Starobinski (1964, 1967, 1969, 1971); Kristeva (1969, 113-46). 
Chapter 6

(a) The second $\mathrm{K}$. begins with a scene of stretching...

Sehr innig und nicht gu asch

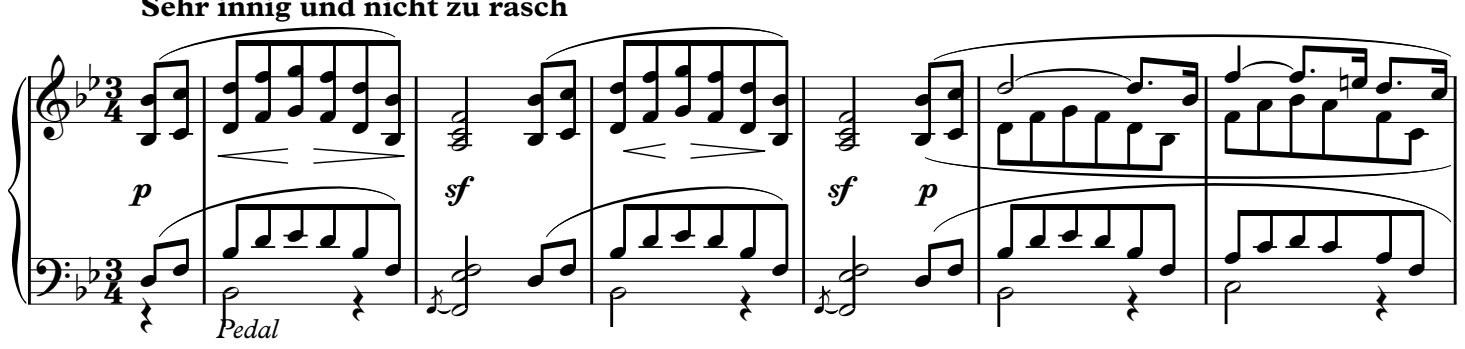

Figure 6.1a

(b) ... and then something (intermezzo I.) suddenly comes down the staircase of notes.

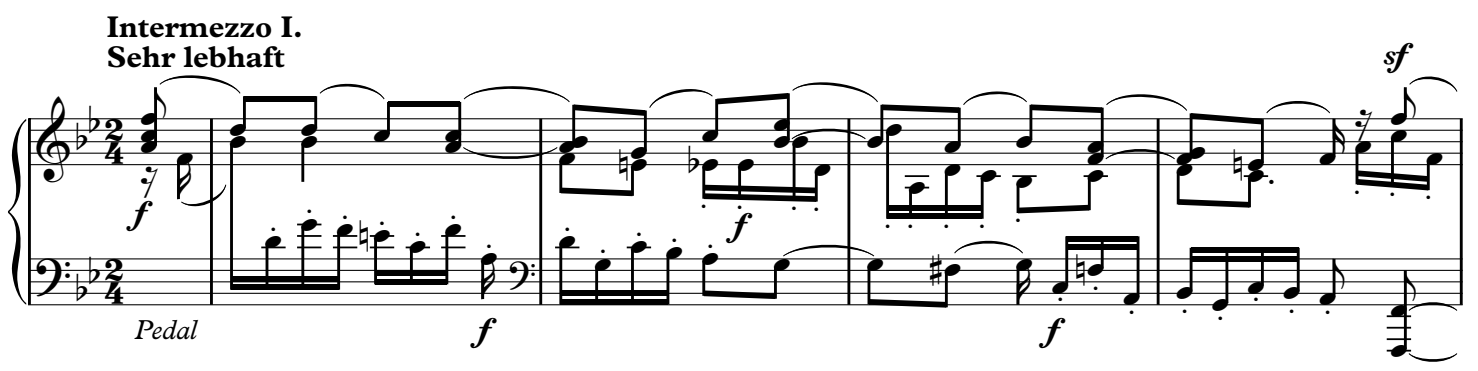

Figure 6.1b

(c) Schumannian beating is panic, but it is also coded (by rhythm and tonality); and it is because the panic of the blows apparently keeps within the limits of a docile language that it is ordinarily not perceived (judging by most interpretations of Schumann)... . It seems ... that only Yves Nat and I ... hear the formidable beating body of the seventh $\mathrm{K}$. [this body that beats].

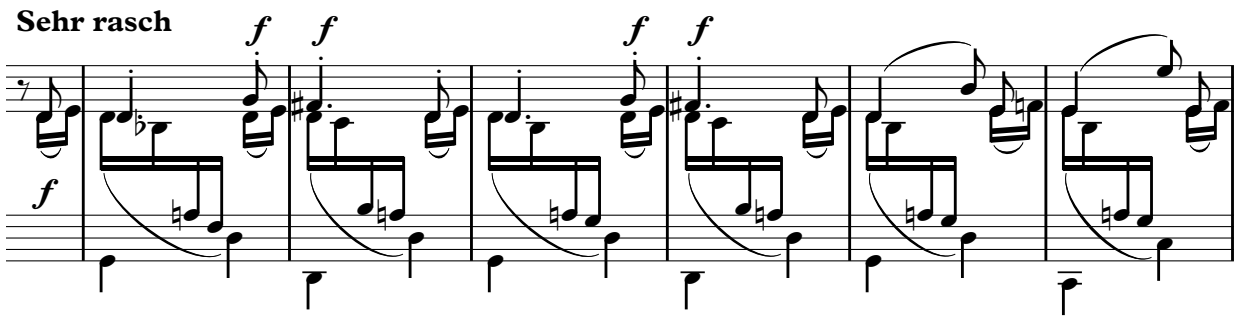

Figure 6.1c

170 
(d) The third K.... is not "animated" (molto animato): it is "raised" (aufgeregt), lifted up, stretched out, erected; one might also say ... that it progresses through a series of tiny revulsions, as if, at each incision, something were coming undone, were turning back, were being severed, as if all the music were entering the sudden wave of the swallowing throat.

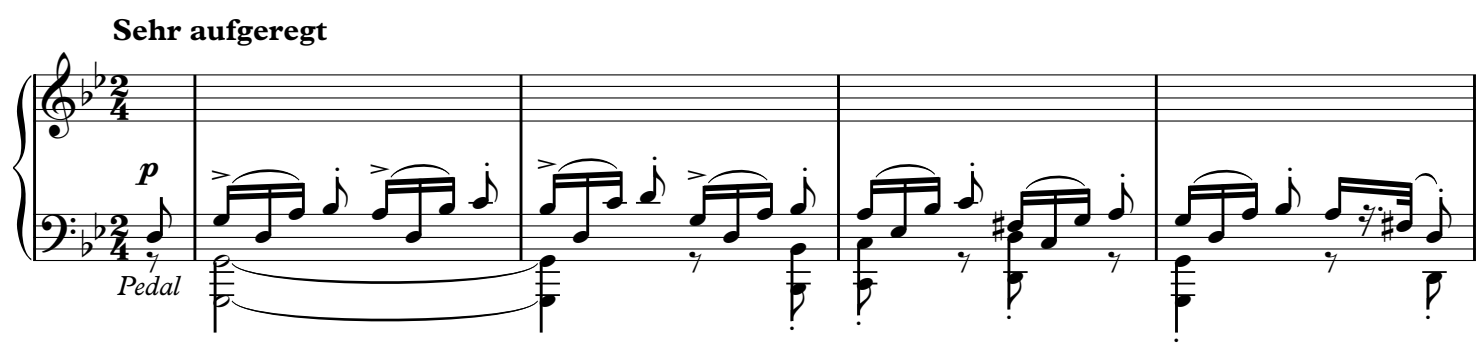

(e) Is there a better-dreamed-of stretching ... than that of the second K.?

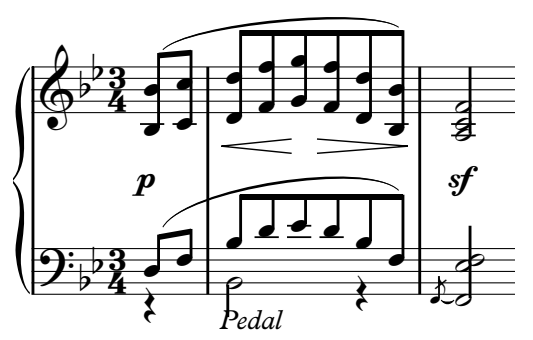

Figure 6.1e

(f) Here everything converges: the melodic form, the suspense harmony [by the stop on the dominant seventh].

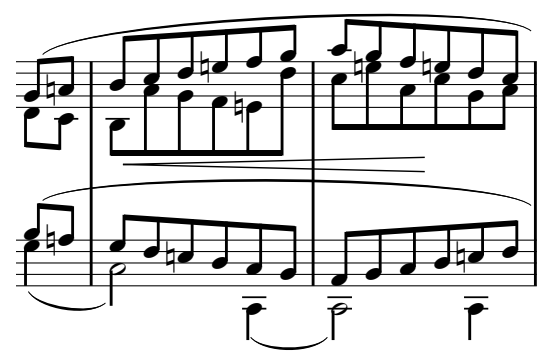




\section{Chapter 6}

(g) Sometimes the body even curls itself up into a ball in order to stretch itself out all the better later on: in the second $\mathrm{K} . .$.

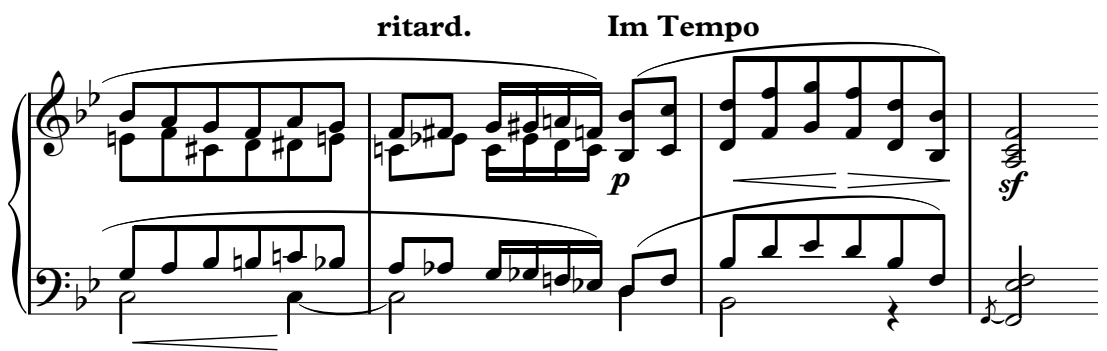

(h) ... or in the disguised intermezzo of the third, whose long stretching will varyby broadening or relaxing? - the pricked, swallowed, revulsed body of the beginning.

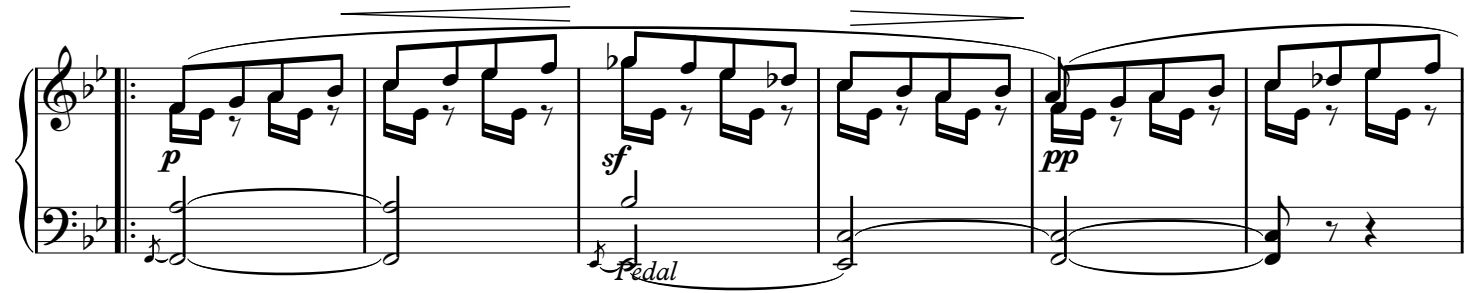

(i) What does the body do, when it enunciates (musically)? And Schumann answers: my body strikes, my body collects itself, it explodes, it divides, it pricks, or on the contrary and without warning ..., it stretches out, it weaves (like the Arachnean interlude of the first K.).

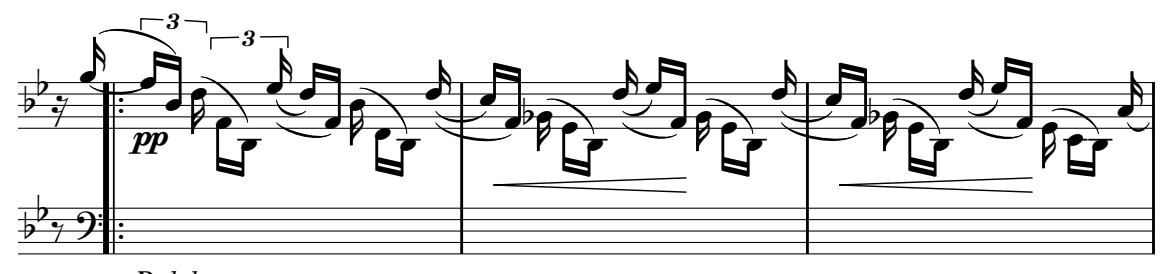


(j)... my body puts itself in a state of speech: quasi parlando.

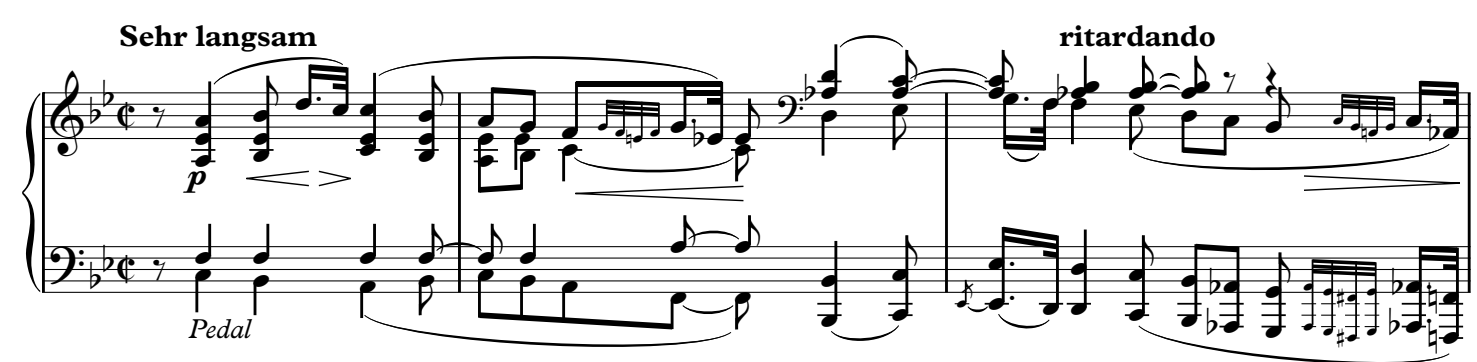

Figure 6.1j

(k) Quasi parlando ...: this is the movement of the body which is about to speak.

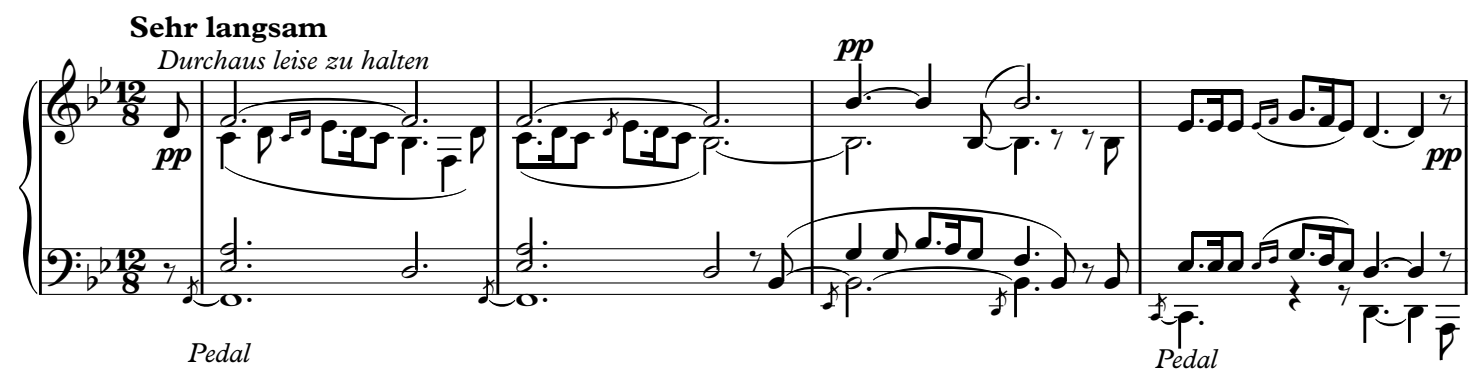

Figure 6.1k

(1) A certain episode (event, rather) of the fifth K. obsesses me, but whose corporeal secret I cannot transfix [transpercer]: “it" is inscribed within me, but I don't know where: in what part, in what region of the body and of language?

(Im Tempo)

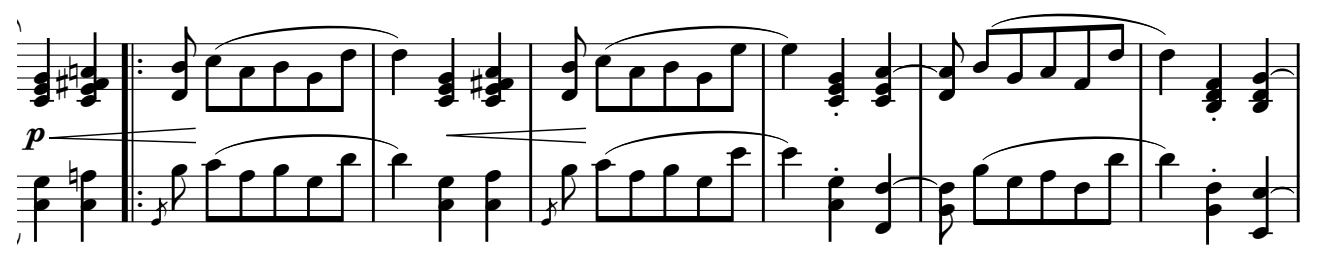

Figure 6.11 


\section{Chapter 6}

(m) Here are several of the "services" tonality performs for the body: by dissonance, it permits the beat, here and there, to "toll," to "tilt"; by modulation (and tonal return), it can complete the figure of the beat, give it its specific form; it curls up into a ball, says the first K.; but it curls up into a ball all the better if we return to the source after leaving it.

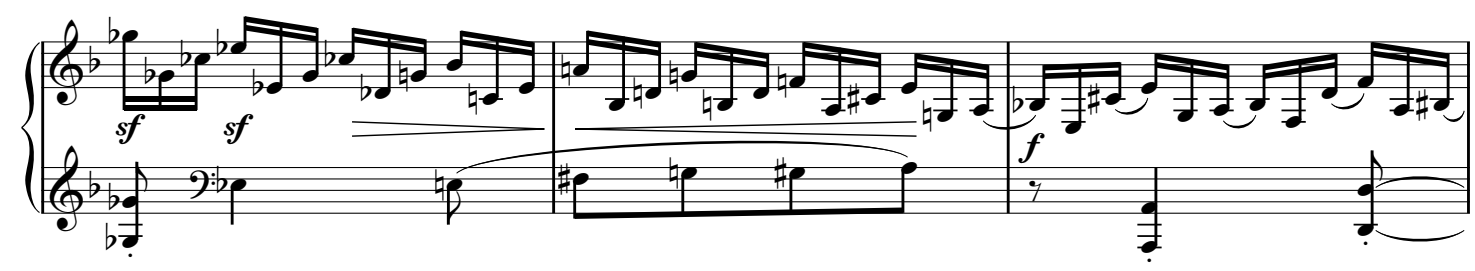

(n) Finally (to remain with the Schumannian text), tonality provides the body the strongest, the most constant of oneiric figures: the ascent (or the descent) of the stairs: there is, we know, a scale of tones, and by traversing this scale ... the body lives in breathlessness, haste, desire, anguish, the approach of orgasm.

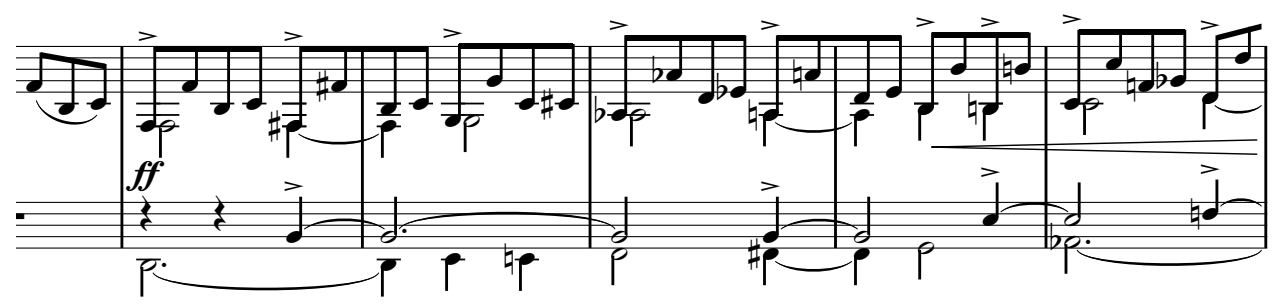

Figure $6.1 \mathrm{n}$ 


\section{The impact of Jacques LaCan: Signifier AND JOUISSANCE}

Roland Barthes doesn't provide a clearly articulated definition of somatheme, which remains vague and underspecified. Rather than try to come to a precise meaning of the term, it might be more productive to explore some of the reasons for such loose characterisation. The quick answer is that somathemes fundamentally belong to the world of pulsions, drives, and desire, being primarily related to unconscious processes that know nothing about signifiers, codes, and articulated speech. It is difficult logically to articulate a discourse on the somatheme because it does not really belong to the sphere of logically articulable discourses. Moreover, Barthes repeatedly uses words and expressions that point towards a jouissif body: ardent, erected, breathless, approaching orgasm. It is extremely difficult to capture this body within traditional, articulated knowledge. As Lacan wrote, "The unconscious is not a thinking being, but first and foremost an enjoying being who does not want to know anything of it" (1999, sec. 95, pp. 104-5). "Knowledge beyond articulation is literally and figuratively 'inter-dit,' in the double sense of the French, 'prohibited,' but also 'said, evoked between the sayings as such.' The question is, to which kind of Real does it give us access?" (Verhaeghe 2002, 121, quoting Lacan 1999, sec. 108). Interestingly, and in a parallel movement with Barthes, "Lacan associates this real more and more with the body, albeit not the body constructed through the Other... 'The real is the mystery of the speaking body, the mystery of the unconscious" (Verhaeghe 2002, 121, quoting Lacan 1999, sec. 118).

To this mystery, Barthes adds yet another dimension, namely the speaking body that does not speak, but that is about to speak, a body that outs itself in a state of speech (quasi parlando) without speaking or (at best) speaking but saying nothing (see Barthes $1985 \mathrm{f}, 306$ ). It is this speechless speech, this opening of the mouth into a vacuum of words that gives the somatheme its incredible force of communication. It communicates a special form of knowledge:

\footnotetext{
This knowledge is an enigma, demonstrated to us by the unconscious. Analytic discourse, on the contrary, teaches us that knowledge is something articulated. Through this articulation, knowledge is turned into sexualized knowledge ..., but the unconscious testifies especially to a knowledge that escapes the knowledge of the speaking being. This knowledge that we cannot grasp belongs to the order of experience. It is thus effected by llanguage, the motherly llanguage that presents us with enigmatic affects that go far beyond what the speaking being can articulate through his or her articulated knowledge. (Verhaeghe 2002, 121, paraphrasing Lacan 1999, sections $125^{-26}$ )
}

Lacan's two kinds of knowledge (analytic discourse and enigmatic language) can be read as a parallel to Barthes's pheno-song and geno-song, the former defined by the "wise" language of pitches, rhythms, harmony, phrasing, and formal construction, the latter by an intoxicated, distracted, ardent, and erected body. One belongs to the circle of knowledge/signifier, the other to the circle of jouissance/signifying. They imply a split subject- "divided between unconscious and conscious motivations, that is, between physiological processes and social constraints" (Roudiez 
1980, 6). This split subject, which operates as the fundamental background to Barthes's essays "Rasch" and "Musica Practica," was sharply discussed by Julia Kristeva in Revolution in Poetic Language. As Roudiez $(1986,6)$ put it, "The object of her investigations is no longer language (as in structuralism), or discourse (as phenomenology would have it), or even enunciation; rather, it is the discourse of a split subject-and this again involves her in psychoanalysis." Above, we already briefly sketched Kristeva's notions of phenotext and genotext, which are strongly related to this split subject; one could also discuss her concept of chora, which was important to Barthes, who mentions it in "Rasch." However, that would go far beyond the scope of this chapter. What is important is to note the centrality of the split subject to Lacan, Kristeva, and Barthes-each author focuses on different aspects and produces analytical variations on it. ${ }^{8}$ To situate somehow the somatheme in relation to this split subject, one can think of a schematic distribution of characteristics, following selected words by Barthes, Kristeva, and Lacan (see figure 6.2).

To start with, we consider the subject of signifier (figure 6.2, on the left) and the subject of jouissance (figure 6.2, on the right), which, very broadly, correspond to Freud's representation and affect, respectively. Kristeva's phenotext (and Barthes's pheno-song) belongs to the former, the genotext (and the geno-song) to the latter. The somatheme originates in, and goes back to the subject of jouissance; but, even if vaguely, and even if only for a fraction of a second, it must appear in the realm of the visible- that is, of the signifier, the oriented world of meaning. Therefore, we place it at the zone of intersection between signifier and jouissance. This is the crucial area in which artistic transfer (the paragrammatical structure of the musical text) starts happening-where codes begin to deterritorialise, where madness embryonically reterritorialises in and through a specific artistic medium.

Figure 6.2 synthesises many of the topics presented so far, broadly representing two poles: the linguistically articulated, written text (knowledge/signifier), and the enunciating body (drives/jouissance). This is not meant as a dualism, as both layers mutually need each other and can only be grasped in their reciprocal interaction. Two points must be stressed: first, according to Barthes and Kristeva, too much emphasis had been put on the layer of the signifier in much of the analytical work happening on that level, a situation that unproductively kept unconscious processes at bay; second, there is a continuous movement of the subject between one and the other, a movement that in figure 6.2 is represented by the light arrow of the vector of desire-a Lacanian notion that is constitutive of his theory of desire and that will be addressed in the next section, as it was obviously relevant to Barthes. 8 Lacan's Écrits, first published in 1966, seem to have had a catalytic effect, influencing a whole generation
of thinkers, particularly those associated with the editorial project Tel Quel. 
Signifier Jouissance

$\begin{aligned} \text { Phenotext (Kristeva) } & \text { Genotext (Kristeva) } \\ \text { Pheno-song (Barthes) } & \text { Geno-song (Barthes) } \\ \text { First semiology (Barthes) } & \text { Second semiology (Barthes) }\end{aligned}$

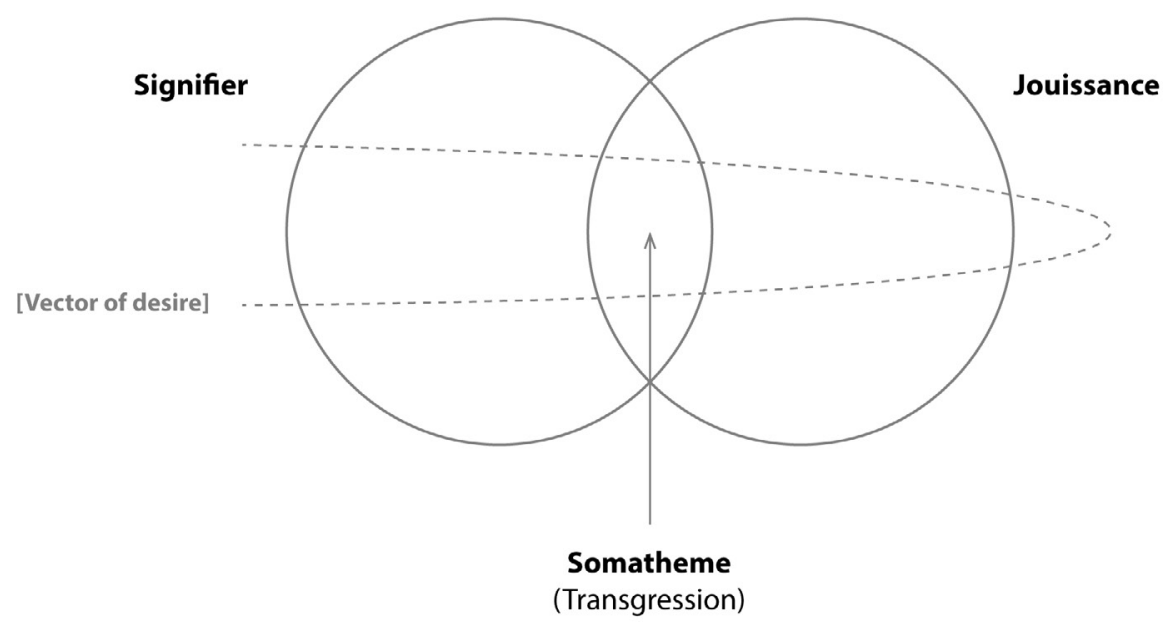

$\begin{aligned} \text { The subject of science } & \text { The subject of drives } \\ \text { Linguistics } & \text { Linguistricks (Lacan) } \\ \text { Semiology } & \text { Semiotics } \\ \text { Language } & \text { Libido } \\ \text { Representation (Freud) } & \text { Affect (Freud) } \\ \text { Grammar } & \text { Enunciations } \\ \text { Verbal } & \text { Non-verbal } \\ \text { Memory } & \text { Slips of tongue } \\ \text { Centrally organised body } & \text { Body without Organs } \\ \text { Organology } & \text { Histology } \\ \text { Knowledge } & \text { Ignorance } \\ \text { Rationality } & \text { Madness } \\ \text { Order } & \text { Delirium } \\ \text { Power } & \text { Desire }\end{aligned}$

\section{LACAN'S DESIRE}

Roland Barthes's 1976 essay “Listening” (see 1985b) is clearly, and in multiple ways, indebted to Jacques Lacan's psychoanalytical discourse. The beginning of its third section starts with a direct paraphrase of Lacan's most famous formula: "The unconscious, structured like a language, is the object of a special and ... exemplary listening: that of the psychoanalyst" (Barthes $1985 \mathrm{~b}, 252$, my emphasis). The point is that psychoanalytic listening functions from unconscious to unconscious, from a speaking unconscious to another one, which it is assumed can hear. A similar 
process can be said to happen with art in general, and with music in particular. If Barthes's somathemes exist, they emerge from the composer's and/or performer's unconscious, addressing (in a polysemic and overdetermined mode) the unconscious of the receiver. In "Listening," Barthes proposes three types of listening: (1) being alert, which relates to indexes and survival; (2) deciphering, which relates to consciously perceived signs and codes; and (3) understanding, which relates to the signifier and to the unconscious. Clearly, this typology emanates from the listening of the psychoanalyst. But it can be extended to musical listening, especially if taking into account the "promise of pleasure" to which Barthes $(1985 \mathrm{~b}, 248)$ refers: beyond the auditive background of the state of alert, beyond the signs and codes of articulated language, there might be a zone of suspended time where jouissance might reign. In that area (che vuoi?) one can become lost, and the great difficulty is to travel back from there to the prosaic auditive background where listening started.

Tracing the extent of the influence and impact of Lacan in the writings of Barthes would definitely go beyond the scope of this chapter, which will only focus on the relation between the central notion of désir in "Rasch," and Lacan's vectors of desire, as expressed in his famous "graphs of desire." The somatheme would remain vastly unintelligible without reference to this relation.

At first sight, there seems to be an overt etymological relation between Barthes's somatheme (from 1975) and Lacan's matheme (from 1971). Barthes does not mention it, and mid-1970s French academic jargon was full of similar terms, such as mytheme, grapheme, glosseme, phoneme, morpheme, lexeme, or semantheme..$^{10}$ Barthes only writes the word somatheme one single time, almost en passant, as if telling the reader not to give it too much importance, or as an indication of a certain point of humour, precisely playing with all the -emes so much en vogue. Lacan's matheme was intended as a highly formalised construction, which, by approaching mathematical language and precision, is certainly to be positioned on the field of the signifier, of scientifically articulable knowledge. By situating the somatheme in the field of drives and jouissance, Barthes

9 In the last paragraph of "Rasch," in a passage that reads like the culmination of the whole essay, Barthes states that "musical signifying, in a much clearer fashion than linguistic signification, is penetrated by desire" (Barthes 1985f, 312; translation changed because the original pénétrée does not mean "steeped in," as the translator wrote, but, precisely, "penetrated," with all its sexual connotations).

10 There follows various telegraphic notes on some of these terms: The matheme is a term that occurred for the first time in a lecture Lacan delivered on 4 November 1971; it was intended as a means to introduce some degree of technical rigour into philosophical and psychological writing; the choice of the word seems to have been inspired by Levi-Strauss's mytheme and the Greek word mathéma; in L'œuvre claire, J.C. Milner (1995) attempts to define the matheme on the basis of the definitions of phoneme (the linguist's phonetic unit) and mytheme (part of a myth). In structuralist studies of mythology (e.g., Levi-Strauss), a mytheme is the essential kernel of a myth, representing an irreducible, unchanging element, a minimal unit that is always found shared with other, related mythemes and reassembled in various ways or linked in more complicated relationships. Grapheme (a word coined in analogy with phoneme) is the smallest meaningful contrastive unit in a writing system, which became a central concept for Jacques Derrida. The glosseme (Hjelmslev) is defined as the smallest irreducible unit of both the content and expression of planes of language. A phoneme (linguistics) is one of the units of sound that distinguish one word from another in a particular language. A morpheme (linguistics) is the smallest grammatical unit in a language. A lexeme (linguistics) is a unit of lexical meaning that exists regardless of the number of inflectional endings it may have or the number of words it may contain. In this list, somathemes could be defined as the smallest units of bodily expression. 
proposes the opposite, an analytical tool for unconsciously produced artistic figures. Where the matheme reduces complex unconscious processes to a crystal-clear formula, the somatheme will generate infinite descriptions and narratives, because it is fundamentally overdetermined. Both Barthes and Lacan are willing to depart from structural linguistics, but they do so in different ways and directions: Lacan towards a growing formalisation and mathematisation of language, ${ }^{11}$ Barthes towards a growing corporeality and "poetisation" of language (associations). In Lacan's seminar from 1972-73 "Encore," one reads (at section 108) that "Mathematical formalization is our goal, our ideal. Why? Because it alone is matheme, ... it alone is capable of being integrally transmitted" (Lacan 1999, 119). But immediately after this sentence, Lacan makes a crucial remark, one that comes closer to Barthes's views: "Mathematical formalization consists of what is written, but it only subsists if I employ, in presenting it, the language (langue) I make use of. Therein lies the objection: no formalization of language is transmissible without the use of language itself. It is in the very act of speaking that I make this formalization, this ideal metalanguage, ex-sist" (ibid.). ${ }^{12}$ This means that both concepts (matheme and somatheme) have a dynamic mode of existence, because, even if situated in opposite poles within the representational scheme, they share the same origin in unconscious processes that somehow ought to be grasped.

Barthes's position evolved from what might be called "classical semiology" in the 1960 s to his "second semiology" of the 1970s, a move that corresponds to a change of focus from the signifier to the signifying. As for Lacan, throughout the 1950 and 1960 s, more and more diagrams, graphs, and symbolisations appeared throughout his lectures and writings, testifying to a steadily intensifying trend toward formalisation. By the late 1960s and, especially, the 1970s, discussions of logic, topology, and knot theory were prominent features of Lacanian discourse. The 1970 os have been characterised as his decade of the matheme, a unit of formalisation ( $q u a$ a mathematical-style symbolisation) distilling and fixing the core significance of a specific Lacanian analytic concept term. With these and other topological constructions, Lacan was able to recast the unconscious as an ensemble of contortions, curvings, foldings, inflections, twists, and turns - very much like Barthes reformulated the body of the musician as conceived through the somatheme concept. Both addressed a fundamentally split subject, and both were trying to find devices to capture some of the immanent deep processes at stake. And since Barthes is a "Lacanian," both think of the unconscious as being "structured like a language" (Barthes $1985 \mathrm{~b}$, $25^{2}$ ), therefore affording some kind of "structure of the paragram" (Barthes

11 For Gilles Deleuze and Félix Guattari's profound critique of these developments in Lacan's thought, see François Dosse (2010, 183-92). On the origins of the term, Dosse (ibid., 191) writes: "As Deleuze and Guattari began working on Anti-Oedipus [c.1970], Lacan was drawing away from structural linguistics and increasingly formalizing his thinking, using topological figures and mathemes. Lacan created a symbiosis between Lévi-Strauss's notion of the matheme, the Greek word mathema (knowledge), and the world of mathematics."

12 In this respect the following remark by Andrew Cutrofello $(2002,143)$ is interesting: "Lacan says that a matheme must be written; it has the form of an écrit, but it only 'subsists' as matheme through a motivating discourse that has the character of spoken language ('mon dire')." 
1985f, 302) or "anagrammatic network" (ibid., 303), which can be identified and interpreted. ${ }^{13}$

According to Barthes, the musician's body is in permanent movement, it never stays in one place, where one could catch it and calmly analyse it. This movement is a first transgression of the code, of the signifier, and it signals the beginning of a trajectory from the signifier towards the signifying: "the Schumannian body does not stay in place (a major rhetorical transgression). It is not a meditative body. It sometimes makes a meditative gesture, but does not assume meditation's bearing, infinite persistence, and faint posture of subsidence. This is a pulsional body, one which pushes itself back and forth, turns to something else ... (intoxicated, distracted, and at the same time ardent)" (Barthes 1985f, 300). An intoxicated body (by what?), distracted (from what?), and ardent (which objet $a$ ?) manifests itself, and emerges on the visible surface of music-in its phenotext-through "symptoms" that are identified within the genotext. Therefore, Barthes's beating body is not a paranoiac body, nor is it (at least immediately) a schizophrenic body, a body acting without rules and constraints. No, it is a body beating inside itself, drawing specific inner gestures that are idiosyncratically unique and unrepeatable - figures that urge permanent repetition and infinite variation (difference):

\begin{abstract}
It is not a matter of beating fists against the door, in the presumed manner of fate. What is required is that it beat inside the body, against the temple, in the sex, in the belly, against the skin from inside, at the level of that whole sensuous emotivity which we call ... the "heart." "To beat" is the very action of the heart (there is no "beating" except the heart's), which occurs at this paradoxical site of the body: central and decentered, liquid and contractile, pulsional and moral; but it is also the emblematic word of two languages: linguistics ... and psychoanalysis. (Barthes 1985f, 302)
\end{abstract}

The Barthesian body is "a body that beats." Therefore, it is a transgressive body, an interiorised, intimate, and solitary body. A body that refuses gregarious, collective, or massive expressions of the us (power) in favour of the $m e$ (desire). The beats produced by this body are censored by all those "who do not want to hear them, or are hallucinated by one man alone, who hears nothing but them" (Barthes 1985f, 302). People refuse to hear the second text, people refuse to travel beyond the chain of signifier and code-they remain in the safe terrain of the sayable, of the consciously oriented world, of statements and representations, of science, grammar, and linguistics. Barthes's somathemes present an offer to move beyond safety and move towards affect, libido, the unconscious-enhancing desire production and feeding pulsional drives. The price to pay is the permanent unfulfilment of desire and the cynical joy of the drives.

13 Thinking of the unconscious as being "structured like a language" is one of the major disagreements between Lacan (on one side) and Deleuze and Guattari (on the other). For Deleuze and Guattari the unconscious is material and by no means operates "like a language." They see the unconscious as a factory, ceaselessly producing desire; viewing it as a language (or structured as one) would mean repeating the Freudian model of the theatre, with all its interpretive work. It is in this sense that Deleuze and Guattari strongly advocate experimentation, claiming that there is nothing to be interpreted in the unconscious. 


\section{Situating the Somatheme Within Lacan's gRaphs of DESIRE}

Lacan's graphs of desire ${ }^{14}$ (see figure 6.3) help us better understand the trajectory suggested by Barthes between the two texts: the text of the signifier and the text of the pulsional body. Lacan originally developed these graphs in relation to the structure of witticism, which was his starting point (and where the distinction between what is propositionally said and how it is said has an obvious impact in the communicative process). The graphs deal with desire, but in a special way, because Lacan ([1977] 2001, 335) believed that "it is precisely because desire is articulated that it is not articulable." The graphs are topological, building a diagram that "also serves purposes other than the use [Lacan gave them], having been constructed and completed quite openly in order to map in its arrangement the most broadly practical structure of the data of our experience" (ibid.). Lacan created these graphs in order "to show where desire, in relation to a subject defined in his articulation by the signifier, is situated" (ibid.). In what follows, I discuss Lacan's completed graph in relation to Barthes's somatheme, more specifically how and where the somatheme can be located within the vector of desire.

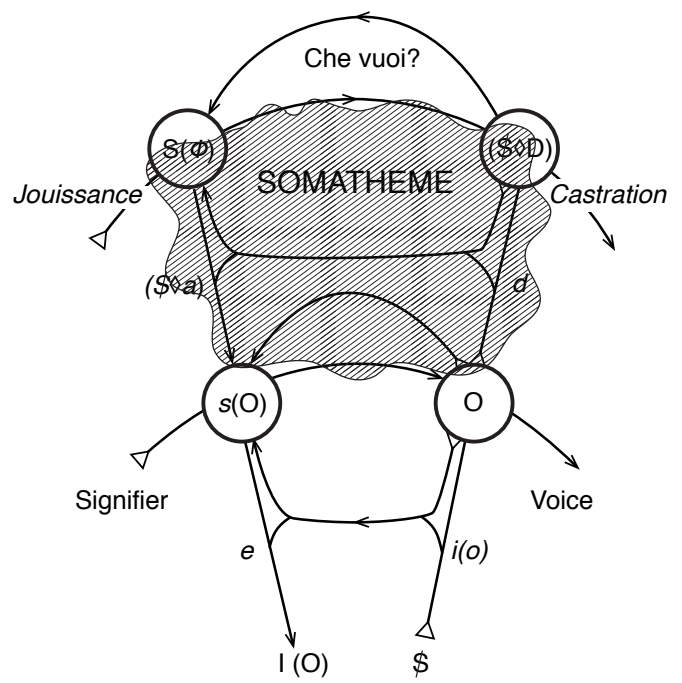

Topological space of the somatheme

Vector Jouissance-Castration

Roland Barthes's second language [Semiotics]

Vector Signifier-Voice

Roland Barthes's first language [Semiology]

Figure 6.3.

The core of Lacan's completed graph is the movement of the barred subject (\$), first towards the chain of signifier (supported by the vector S-S', also called in the completed graph Signifier-Voice), then to the chain of jouissance (the vector Jouissance-Castration), entering the Che vuoi? zone, and finally (with difficulty) coming back through the chains of signifiers to the starting level. This

14 Lacan's graphs of desire are fourfold-Graph 1, Graph 2, Graph 3 (Che vuoi?), and Graph 4 (Completed Graph)-growing in complexity from one to the next. Lacan started mentioning such graphs in 1957, in his seminar on the formations of the unconscious. They were published in 1966, as part of the Ecrits, in a chapter entitled "Subversion du sujet et dialectique du désir dans l'inconscient freudien" (Lacan 1966, 793-827; [1977] 2001, 321-60). 
movement-the vector of desire-defines a never-ending attempt of the One to assume the Other, but every attempt fails and keeps failing, thereby causing the insistence of the attempt as such (see Verhaeghe 2002, 131). The intersections of the vectors define precise points with specific functions in the overall economy of this diagrammatic representation. The crossing of the two pathways in the graph can be further understood to connote interference and constraint. Desire for the primordial object is not fulfilled except through the constraints of the signifying chain. The vector of desire is metaphorical, substituting various objects for the absolutely lost primordial one, and irrupting into language without regard for the passage of time. As Paul Verhaeghe $(2002,129)$ summed up, "The unconscious does not know time."

Importantly, Lacan distinguishes between desire and drive. An essential characteristic of desire is its restlessness, its ongoing agitated searching and futile striving. No object it gets its hands on is ever quite $i t$. Whereas desire is stuck with its dissatisfied drifting from object to object and ever onward, drive derives a perverse enjoyment from this desire-fuelled libidinal circling around the vanishing point of the impossible-qua-unattainable. Where desire is frustrated, drive is gratified. Drive gains its satisfaction through vampirically feeding off the dissatisfaction of desire. As Suzanne Barnard (2002, 173) puts it, "while desire is born of and sustained by a constitutive lack, drive emerges in relation to a constitutive surplus. This surplus is what Lacan calls the subject's 'anatomical complement,' an excessive, 'unreal' remainder that produces an ever-present jouissance."

As is now clear, Barthes's first language (the one producing the pheno-song) belongs to Lacan's first chain of signifiers, to the vector Signifier-Voice; this means that it is determined by the code of the Other, "since it is from this code that the subject is constituted, which means that it is from the Other that the subject receives even the message that he emits" (Lacan [1977] 2001, 337). To say it with Barthes, when he plays Schumann, what he calls "the first text" is the one notated by Schumann (the locus of Speech), not of Barthes, even if it is Barthes who is playing (addressing) Schumann. Barthes's "second language" (related to the geno-song) belongs to the second chain, that of the vector Jouissance-Castration. Passing the Other, through the Other, and with the Other, desire moves away from the signifier, hoping for some sort of fulfilment (Barthes's promesse du plaisir), which is always threatened by the fear of castration, of interruption or non-fulfilment of desire. From here, the jouissif body (che vuoi?) has to come back to its starting point, a difficult retroversion that unavoidably includes the signifier of a lack in the Other, which might stop the process (by reactions such as a state of shock, panic, tears, uncontrolled laughter, etc.) or bring it to the imaginary ego-ideal, from where the whole cycle will start again ... and again.

Barthes's somatheme must be situated between the two transversal chains, in the space defined by the intersections $\mathrm{O}, \$ \backslash \mathrm{D}, \mathrm{S}(\Phi), \mathrm{s}(\mathrm{O})$, including the segments of the vector of desire "d" (desire) and $\$ \backslash \mathrm{a}$ (fantasy). The somatheme functions in both directions: it is the scriptor, the transcriber of the unconscious into the coded language of the signifier. It is the disintegrating figure 
of the signifier, of its signs and symbols that lose consistency when activated by pulsions and drives. This space is at the same time ordered and unordered, deterritorialised and coded. As Julia Kristeva wrote in relation to Mallarmé's mystery in literature: "Mallarmé calls attention to the semiotic rhythm within language when he speaks of 'The Mystery in Literature'... . Indifferent to language, enigmatic and feminine, this space underlying the written is rhythmic, unfettered, irreducible to its intelligible verbal translation; it is musical, anterior to judgment, but restrained by a single guarantee: syntax" (Kristeva 1984, 29).

\section{CONCLUSION: ARTISTIC RESEARCH AND TRANSDISCIPLINARITY}

Focused on somathemes, this chapter presented a genealogy of the concept and discussed its broader implications for music, music analysis, linguistics, and psychoanalysis. Starting with Barthes at the piano, we suggested that this concept could only have been invented by someone who played an instrument. Next, we situated the concept in the larger context of semiology, semiotics, and linguistics, opening the door for a new geno-phenomenology of the body. Finally, the somatheme was placed inside Lacan's graph of desire, pointing to its potential relevance for a field outside music. The fourteen examples sporadically presented by Barthes in "Rasch" were presented here in proximity, allowing a more effective understanding of these musical passages as somathemes.

The reader might ask why a music practitioner such as myself turns his attention to semiotics, philosophy, and even psychoanalysis. The answer is that I was simply looking for one very specific concept (the somatheme), which I found in a text about a piece I was playing at the piano. In this sense, at the base of this research lies a bottom-up investigation, which starting from a single word expanded itself to wider and more complex terrains. In practice, the concept and all its contextualising references have been extremely relevant for a whole series of artistic and scholarly outputs generated by myself and by MusicExperiment21 in the last four years (see Assis 2014; Assis and D'Errico 2016). Of the type of presentation discussed in Chapter 3 (series of experimental performances), this kind of multiple-media presentation configures a unique approach to artistic research in music - an approach that does not oppose "scholarly research" (of the type presented in the present essay) to "artistic work" (which leads to concrete performances). In place of a dualistic opposition, I see "research" and "artistry" as two parameters, which can have different settings in different moments of the research procedure. They are always in relation to each other, defining an elaborated scale, which can be precisely calibrated and explored by artist-researchers. Artistic research is still in the process of affirming itself as a new "artistic" and "scholarly" perspective, and this process entails many dangers - the biggest of which is the temptation of science: the temptation of becoming a scientific discipline with specific methods, strategies, codes, laws, and hierarchies. As is well known from several examples from the past, when new disciplines were being born-such as 
sociology, psychology, musicology, psychoanalysis, or anthropology—all went through a process of purging themselves of unscientific elements. This may have been necessary for institutional implementation and to gain academic credibility. Nevertheless, if in those disciplines it could still make some sense, in artistic research it would be highly counterproductive; for, as Lacan once wrote, "It is not what is measured in science that is important, contrary to what people think" (Lacan 1999, 128). Artistic research can be much more interesting if it does not focus on "how things really were" or "how things really are" but, rather, on "what things can become." More than reconstructing or interpreting the past, artistic research can embrace a genuinely creative approach, understanding artistic practices and investigations as the result of intensive creative processes-whose mystery, according to Guattari $(2007,102)$ "resides in [their] function and not in their interpretation."

\section{REFERENCES}

Assis, Paulo de. 2014. "Rasch ${ }^{11}$ : Loving Barthes." Research Catalogue. Accessed 4 August 2016. https://www. researchcatalogue.net/view/99320/99321.

_. 2016. "Rasch ${ }^{\mathrm{X}}$." Research Catalogue. Accessed 9 October 2016. https://www. researchcatalogue.net/view/64319/64320.

Assis, Paulo de, and Lucia D'Errico. 2016. "Rasch ${ }^{22}$ : Transplosions." Research Catalogue. Accessed 4 August 2016. https://www.researchcatalogue.net/ profile/show-work?work=279021.

Atkinson, Charles M. 2009. The Critical Nexus: Tone-System, Mode, and Notation in Early Medieval Music. New York: Oxford University Press.

Barnard, Suzanne. 2002. "Tongues of Angels: Feminine Structure and Other Jouissance." In Barnard and Fink 2002, 171-85.

Barnard, Suzanne, and Bruce Fink, eds. 2002. Reading Seminar XX: Lacan's Major Work on Love, Knowledge, and Feminine Sexuality. Albany: State University of New York Press.

Barthes, Roland. 1985 a. "The Grain of the Voice." In Barthes 1985g, 267-77. First published 1972 as "Le grain de la voix" (Musique en jeu 9: 51-63). . 1985b. "Listening." In Barthes 1985g, 245-6o. First published 1976 as "Ascolto," co-authored with Roland Havas, in Enciclopedia I: Abaco-Astronomia (Turin: Einaudi), 982-91. - 1985c. "Loving Schumann." In Barthes 1985g, 293-98. First published
1979 as "Aimer Schumann," preface to Musique pour piano de Schumann by Marcel Beaufils (Paris: Phébus), 9-16. 1985 d. "Musica Practica." In Barthes 1985g, 261-66. First published 1970 as "Musica Practica" (L'Arc 40). -1985e. "Music, Voice, Language." In Barthes 1985g, 278-85. Delivered as a public lecture in Rome, 20 May 1977. First published 1978 as "La musica, la voce, il linguaggio" (Nuova Rivista musicale italiana $12[3]: 362-66)$. . 1985f. "Rasch." In Barthes 1985g, 299-312. First published 1975 as "Rasch," in Langue, discours, société: Pour Émile Benveniste, edited by Julia Kristeva, JeanClaude Milner, and Nicolas Ruwet (Paris: Seuil).

-1985g. The Responsibility of Forms: Critical Essays on Music, Art, and Representation. Translated by Richard Howard. Berkeley: University of California Press. First published 1982 as L'obvie et l'obtus: Essais critiques III, edited by F.W. (Paris: Seuil).

Benveniste, Émile. 1974. Problèmes de linguistíque générale, II. Paris: Gallimard.

Buleu, François-René. 1973. "Tel quel à l'Amphi." Le Monde, July 5, 15 .

Cutrofello, Andrew. 2002. "The Ontological Status of Lacan's Mathematical Paradigms.” In Barnard and Fink 2002, 141-70.

Daverio, John. 2007. "Piano Works I: A World of Images.” In The Cambridge Companion to Schumann, edited by Beate Perrey, 65-85. 
Cambridge: Cambridge University Press. Dosse, François. 2010. Gilles Deleuze and Félix Guattari: Intersecting Lives. Translated by Deborah Glassman. New York: Columbia University Press. First published 2007 as Gilles Deleuze et Félix Guattari: Biographie croisée (Paris: La Découverte).

Fink, Bruce. 2002. "Knowledge and Jouissance.” In Barnard and Fink 2002, 21-45.

Guattari, Félix. 2007. "Balance-Sheet for 'Desiring-Machines.” Translated by Robert Hurley. In Chaosophy: Texts and Interviews 1972-1977, by Félix Guattari, edited by Sylvère Lotringer, translated by David L. Sweet, Jarred Becker, and Taylor Adkins [et al.], 90-115. Los Angeles, CA: Semiotext(e). Chapter first published 1973 as "Bilan-programme pour machines désirantes," Minuit 2 (January): 1-25. - 2011. The Machinic Unconscious: Essays in Schizoanalysis. Translated by Taylor Adkins. Los Angeles: Semiotext(e). First published 1979 as L'inconscient machinique: Essais de Schizo-analyse (Paris: Éditions Recherches).

Hatten, Robert S. 2001. "Musical Gesture, Lecture 2: Embodying Sound: The Role of Semiotics." Semiotics Institute Online. Accessed 5 October 2018. http://projects. chass.utoronto.ca/semiotics/cyber/hat2. html.

Kristeva, Julia. 1969. Séméiôtiké: Recherches pour une sémanalyse. Paris: Seuil. Excerpts translated by Thomas Gora, Alice Jardin and Leon S. Roudiez in Kristeva 1980.

1974. La révolution du language poétique: L'avant-garde à la fin du XIXe siècle: Lautréamont et Mallarmé. Paris: Seuil. Abridged translation by Margaret Waller published as Kristeva 1984.

. 1980. Desire in Language: A Semiotic Approach to Literature and Art. Edited by Leon S. Roudiez. Translated by Thomas Gora, Alice Jardine, and Leon S. Roudiez. New York: Columbia University Press. Essays first published in Kristeva 1969 and in Polylogue (Paris: Seuil, 1977).

- 1984. Revolution in Poetic Language.

Translated by Margaret Waller. New York: Columbia University Press. Translation and abridgment of Kristeva 1974.

Lacan, Jacques. 1966. Écrits. Paris: Seuil. Translated by Alan Sheridan as Lacan 2001. Translated by Bruce Fink as Écrits:
The First Complete Edition in English (New York: W. W. Norton, 2007).

- (1977) 2001. Écrits: A Selection.

Translated by Alan Sheridan. London:

Routledge. First published as Lacan 1966.

This translation first published 1977

(London: Tavistock).

. 1999. The Seminar of Jacques Lacan;

BookXX: Encore 1972-1973; On Feminine

Sexuality, the Limits of Love and Knowledge.

Edited by Jacques-Alain Miller. Translated by Bruce Fink. New York: W. W. Norton. First published 1975 as Le séminaire de Jacques Lacan: Livre XX, Encore 1972-1973 (Paris: Seuil).

Laplanche, Jean, and Jean-Bertrand Pontalis. (1967) 2007. Vocabulaire de la psychanalyse. Paris: Presses universitaires de France. Translated by Donald Nicholson-Smith as The Language of Psycho-analysis (London: Hogarth Press, 1973).

Milner, Jean-Claude. 1995. L'œuvre Claire: Lacan, la science, la philosophie. Paris: Seuil. Noudelmann, François. 2012. The Philosopher's Touch: Sartre, Nietzsche, and Barthes at the Piano. Translated by Brian J. Reilly. New York: Columbia University Press. First published 2008 as Le Toucher des philosophes: Sartre, Nietzsche et Barthes au piano (Paris: Gallimard).

Roudiez, Leon S. 1980. Introduction to Kristeva 1980, 1-20.

-1984. Introduction to Kristeva 1984, 1-10.

Rycroft, Charles. (1968) 1995. A Critical Dictionary of Psychoanalysis. London: Penguin Books. First published 1968 (New York: Basic Books).

Sontag, Susan. 1981. Under the Sign of Saturn. New York: Vintage.

Starobinski, Jean. 1964. "Les anagrammes de Ferdinand de Saussure." Mercure de France (February), 243-62.

- 1967. "Les mots sous les mots." In

To Honour Roman Jakobson: Essays on the Occasion of His Seventieth Birthday, 906-17. The Hague: Mouton.

_.1969. "Le texte dans le texte." Tel Quel 37: 3-33

1971. Les mots sous les mots: Les anagrammes de Ferdinand de Saussure. Paris: Gallimard.

Tarasti, Eero. 2002. Signs of Music: A Guide to Musical Semiotics. Berlin: Mouton de Gruyter. 


\section{Chapter 6}

Verhaeghe, Paul. 2002. "Lacan's Answer to the Classical Mind/Body Deadlock:

Retracing Freud's Beyond.” In Barnard and

Fink 2002, 109-39. 


\section{Part 4 \\ A New Ethics \\ of Performance}





\section{The Emancipated Performer: Musical Renderings and Power Relations}

\section{Music Performance AND POWER Relations}

Beyond spectacular buildings that host spectacular ensembles and soloists who play spectacular pieces in front of mesmerised audiences; beyond historically constructed notions of execution, recitation, interpretation, transmission, rendering, or reproduction; beyond theoretical, analytical, historiographical, or sociological modes of scrutiny; beyond transcendental instrumental virtuosity; beyond ivory-towered musicological discourses; beyond all that: musical performances of past musical works have been fundamentally determined by power relations, by accommodating themselves to strong hierarchies, and by obeying highly prescriptive rules and authorities. This chapter aims to problematise such power relations, and to scrutinise their impact on performance. I will insist on the relevance of becoming aware of and liberated from them and I will propose an alternative model for performance-one that has the potential to change the performer from a well-domesticated reproducer to a critically engaged, emancipated operator. This chapter is organised in five sections: a first, introductory section on the prevailing image of work and the dangers of "interpreting" music; a second section on the tacit authorities that survey and control musical performances; a third section on modes of relating to history and historical materials; a fourth section, where a new image of work will be briefly presented; and, finally, a fifth section on the main topic of this presentation, namely, the emancipated performer.

\section{THE DOMINANT IMAgE OF WORK AND THE PROBLEM OF INTERPRETATION}

While music analysis, music theory, music editions, or music philology are seen as fields of activity that have the right to problematise musical works from the past, "performance" is not thought to do so; or, in the best cases, to do so only

\footnotetext{
* The first instantiation of this text was written for the international conference "Performance Analysis: A Bridge Between Theory and Interpretation," convened by Madalena Soveral and held at Casa da Música in Oporto, 4-6 October 2016. Further versions, with minor adaptations, were made for my lecture on "Music Performance and Politics" for the Honours Class at the University of Leiden (invited by Hafez Ismaili m'Hamdi), 1 November 2016, and for a group discussion at the Orpheus Research Centre's General Assembly, 7 December 2016. On all these occasions, the text was intended as a positive thought provocation for those audiences, giving it a polemic gesture, which is retained in this chapter.
} 
tangentially. The activity of performing music has been considered as a possibly neutral rendering of sound structures that pre-exist performance and that will endure it. A particular image of work has been formed historically, based upon the assumption that musical works - at least for the performer and from the performer's point of view - are stabilised entities that have been achieved by a composer, that can be apprehended on "one single occasion," that are encapsulated in one score, that are commonly sanctioned by specific communities of people, and whose potentially infinite reproductions are recognisable as "the same again." As part of this image of work, the repressor's role has been played by disciplines or activities such as music history, music editing, or music criticism, and also by music educators and concert organisers, all of which have exerted different forms of intimidation and corporative legitimation (even when they are not perceived as such) to ensure that nothing outside the conventional image of work can be offered onstage as a performance of a particular musical work. This image of work - which derives from what I call the strong work concept, which I deconstructed in Chapter 1-not only was prevalent in performance but also effectively managed to stop performers from being creative, mobilising their energies toward physical endurance and resistance, machine-like technical dexterity, harsh competition, and finally the well-tamed domestication of their creative powers. Recent trends in music pedagogy and research that focuses on studying performances from the past or resituates analysis from the perspective of the performer have significantly contributed to the arrival of more informed performers, offering a wider understanding of what a performer does. Such trends are, therefore, welcome. Nevertheless, at their core lies the idea that these better understandings will actually help performers perform better within the traditional image of work, which remains essentially unquestioned.

On the other hand, performers are generally supposed "to interpret" the works they play. As they are not the composers of the works they play, and thus are prevented by their discipline from improvising, so-called mainstream performers found in "interpretation" a last refuge through which to express some kind of individual subjectivity. Two aspects are often unnoticed: first, that the notion and concrete practices of "musical interpretation" only appeared in the nineteenth century (see Danuser 2016; Dreyfus 2007), in a parallel wave to the emergence of the work concept, the growing quantity of published music, and the increasing number of public concerts, concert halls, and music critics; (2) second, that "interpretation" depends on and is limited by the conventional image of work mentioned above, and is therefore epochal — which makes it possible that its own specific epoch will end.

In the twentieth century, the concept and practice of "musical interpretation" became normative for performers, listeners, and scholars (see Danuser 1994-2007). The concept is predicated on the existence of a source text (the score), which preserves an idealised concept of the authorised "musical work," and on a performer who brings the musical experience itself into renewed existence. The fact that various performances of the same piece by the same performer could (and to a certain extent "should") differ from one another is 
acknowledged within these conventions; but, at the same time, such differences are generally considered to be the result of occasional circumstances, not deeply affecting the constitution of a singular, consistent personal "interpretation." The idea that there is something "hidden," something "deeper," something below or beyond the apparent surface of the score, something that must be "interpreted," implies a centripetal approach from the performer towards the supposed "essence" of the artwork (its proclaimed "truth content"). Further, this idea is strongly related to other time-bound concepts, such as Werktreue, authenticity, composer's intention, and, crucially, to certain editorial practices, such as the urtext, or more recently the critical edition - all of which are expressions that sustain and enhance particular forms of exerting power, and of determining, controlling, and policing both the performer and the listener.

"Musical interpretation" has become a powerful weapon in the ideology of the work concept, its many related parallel concepts, and its inherent link to marketing strategies of musical life. In this sense, the idea and practice of "musical interpretation" established a complex system of loyalty, discipline, and control, prescribing not only what can and cannot be played at one moment but alsoand more importantly - what it is possible to play. Anything outside this possible is not exactly forbidden, it is simply unthinkable. To reflect on what is thinkable, and why it is thinkable at any given moment in history, one has to move beyond currently dominant discourses on performance and music ontology, which, in my view, ignore the question of power relations. In the last few years I have been working with discourses that strongly engage with these questions, even if not from a musical perspective, with the goal of learning from them and eventually transposing them to music. In what follows, I will refer to specific writings by Gilles Deleuze, Michel Foucault, Friedrich Nietzsche, and Jacques Rancière, bringing them into dialogue with music performance.

\section{The tacit authorities: Deleuze's "Postscript on the Societies Of Control”}

In May 1990, Gilles Deleuze published the short essay "Postscript on the Societies of Control" (see Deleuze 1992, in which he discusses the way in which societies were moving from what Michel Foucault $[1977,193]$ described as a disciplinary society toward something new, namely, towards a society of control). Foucault's analysis of various systems of surveillance and punishment from the eighteenth and nineteenth centuries led him to articulate precise descriptions of two kinds of societies: a former one, feudal, based upon the principle of sovereignty, and another one, modern, formed and sustained by discipline. Foucault's theory was the crucial starting point for Deleuze's theorisations of societies of control-a term he coined inspired by William S. Burroughs's The Electronic Revolution (1970). As Deleuze $(1992,3)$ summarised: 
Foucault located the disciplinary societies in the eighteenth and nineteenth centuries... They initiate the organization of vast spaces of enclosure. The individual never ceases passing from one closed environment to another, each having its own laws: first, the family; then the school ("you are no longer in your family"); then the barracks ("you are no longer at school"); then the factory; from time to time the hospital; possibly the prison, the preeminent instance of the enclosed environment.... But ... Foucault recognized as well ... the transience of this model: it succeeded that of the societies of sovereignty, the goal and functions of which were something quite different.

To put it succinctly: Societies of sovereignty follow feudal ways of organisation, relaying on the central notions of sovereignty, loyalty, punishment, and tradition. Disciplinary societies, which appeared with and after the Industrial Revolution, are based upon complex systems of training, surveillance, and punishment, using strict methods of control, diverse modes of confinement (prison, hospital, classroom, technical schools), and severe regulations (training, textbooks, codes). Finally, societies of control-whose appearance coincided with the emergence of neo-liberalism in the late 1970s-operate in open systems and networks, using floating forms of control: people are totally free, but totally surveilled, and complex mechanisms of micro-powers replace the once dominant central power display.

If, on an economic level, the movement was from the handicrafts workshop (feudal) to the factory (modern), and to the company (neo-liberal), its mechanisms of control changed from the principle of loyalty (sovereignty) to the principles of training and discipline, and finally to a generalised obedience to the markets focusing on diverse financial strategies. Foucault's and Deleuze's purpose is not so much to provide a historical description or appreciation of these different societies and their respective times, but rather to investigate and expose the different ways by which power was exerted, imposed, and distributed. Their analysis is always centred upon power relations and their implications.

It is not my intention to analyse here Deleuze's "Postscript on the Societies of Control," nor to enter a philosophical explanation of these three forms of society. What I plan is simply to think about some of the characteristics of such societies in relation to the tacit authorities that exert their powers on music performance, especially on the performer. Such an exercise makes sense not just because it is urgently needed-otherwise performers risk being marginalised and degraded to the role of simple reproducers, losing any creative or intellectual power altogether.

The first, and probably strongest hierarchy begins with the relation between composer and executant, the latter traditionally obeying the former, in a master-slave relationship. The composer acts as the sovereign power, which must be entirely respected under threat of a break of loyalty - to the composer or to his or her supposed intentions. The widespread idea that a performer must be "humble" before and respectful to the score and the composer has been an efficient repressor of any critical thinking from the performer's side. Another kind of sovereign-like power relation is recognisable in the instrumental master-pupil relation. The master (the teacher) supposedly has the key, the secret 
to understanding the composer's intentions and the stylistic nuances of a given score; the pupil has to obey and repeat what the master tells him or her. The masters, be they composers or teachers, of course, always suggest that there is much freedom in what one can do, engendering "happy slaves," performers who do not even notice their almost complete absence of creative freedom. In addition to these major sovereign authorities, several instances of discipline and surveillance are to be found in conservatoires, Hochschulen, or universities (which resemble Foucault's institutions of confinement), or in the coded forms of specific music editions, particularly those resulting from the ideology of the urtext. They all follow the forms of admission (recruitment), training, surveillance, and exclusion typical of disciplinary societies. The vast majority of young music students do not enter these institutions in order to learn how to think critically or how to act creatively or spontaneously. On the contrary, they come to learn all the codes and rules, all the prescriptions and opinions that will enable them to occupy a predetermined role in society-well behaved and tamed. Those who dare to question what is being transmitted and how it is being transmitted are frequently ostracised, being recognised as bright spirits but ones who do not conform to the house rules.

More recently, other forms of organising music education and music consumption have appeared with astonishing power: on the one hand, summer courses, masterclasses, and ad hoc workshops, and, on the other hand, all types of seasonal festivals, dominated by (mostly) popularising (if not directly "populist") programmes and marketing strategies. These are the spots where music students, performers, young composers, and audiences feel extremely freewithout noticing that they are totally controlled and alienated by the most simple and evident forms of marketing. When a festival offers the complete piano works of Schumann performed in a single day, who is listening to Schumann's music? Who is articulating the aesthetic, intellectual, and epistemic power of these compositions? No one; people are buying tickets just to be part of a mass event-one that (again) they are totally free to attend, and where they are totally controlled in their behaviour, expectations, and consumption of goods.

In the face of all these systems of domination, the question is, How can they be overcome? How can a new modus operandi be created that will allow performers to be truly creative within the many constraints? How can control over historical inherited materials be shared? In order to propose answers to these questions, it is necessary to briefly reflect on ways of relating to history and to historical materials. I shall do this taking Nietzsche's view of history and historicity as my starting point.

\section{NiETZSCHE'S THREE MODES OF RELATION TO HISTORY: MONUMENTAL, ANTIQUARIAN, CRITICAL}

In the second of the four Untimely Meditations Nietzsche thoroughly explored different modes of relating to history, historicity, and historical materials. Written in 1873/74, the second Untimely Meditation carries the title "On the Uses and Disadvantages of History for Life." In it, Nietzsche describes three modes 


\section{Chapter 7}

of relating to history and the historical: the monumental, the antiquarian, and the critical.

Monumental history is used by those who need great moments from the past in order to admire them, idolatrising them and generating an identity out of them. The antiquarian mode is used by those who like to stick to the familiar and are afraid of seeing their past being "ruined overnight," to use Nietzsche's expression $(1997,73)$. Finally, the critical mode is used by those who look for new habits and combat humanity's most inborn heritage (see ibid., 68-77). Behind Nietzsche's notion of a monumental history there is a "fundamental idea of the faith in humanity" (ibid., 68), a faith that contains some important dangers: the confusion between a monumentalised past and a mythical fiction, which easily tends towards idolatry, the cult of oeuvres and personalities, pointing to proto-religious processes, to mystifications, and to a generalised and uncritical consumption of "classics" of our culture. With the antiquarian mode of relating to history, Nietzsche means a particular type of veneration of the past, a fetishised relationship to past objects, goods, and achievements. This fetishism of past things equalises them and might blur the perfect image of monuments presented by monumental history. "The antiquarian sense of a man, a community, a whole people, always possesses an extremely restricted field of vision; most of what exists it does not perceive at all, and the little it does see it sees much too close up and isolated; it cannot relate what it sees to anything else and it therefore accords everything it sees equal importance and therefore to each individual thing too great importance" (Nietzsche 1997, 74). Antiquarians are so scared of the possibility of losing overnight everything they possess that they become obsessed with conserving anything and everything with equal care. There, where their ancestors lived, exactly there, do antiquarians wish to live forever. Any extra attention given to particularly salient moments (monuments), or any critical remarks on their goods would be seen as profanations of the past, which must be banned at all costs.

Critical history appears at first sight as the most productive in terms of making possible some kind of future. Its fundamental trait is the openness to "from time to time employ the strength to break up and dissolve a part of the past" (Nietzsche 1997, 75). But Nietzsche invests it with a basic negative quality, defining critical history as "a history that judges and condemns" (72). Moreover, the process of judging and condemning is presented as "bringing [the past] before the tribunal, scrupulously examining it and finally condemning it" (76). The difficult task for us, today, is to think with Nietzsche while focusing on the present, asking ourselves whether we can identify in the present (crucially, in our global present) those same modes that Nietzsche identified in nineteenth-century German culture, when history had just been invented.

Transposing to music performance Nietzsche's three modes of relating to history not only is thinkable but also illuminates some of the positions currently observable. Monumentalism is clearly traceable in a particular way of making music history that is essentially composer-based and focused on compositions. It enhances a mythical function, where musical works from the past appear as totems, in relation to which any critical or deconstructive operation 
is unwelcome, and preferably forbidden (taboo function). Musical works are seen, in practical terms, as eternal, as basically stabilised entities that share a coherence and continuity throughout different epochs and times. The idolatry associated with this vision of things leads to the cult of the work, of the composer, and of the "star" interpreter. Everything must be monumentalisedtherefore, we also get larger concert halls, larger festivals, larger collections of "complete works," and so on. Mainstream performers gladly adopt this vision, and claim to be humble servants of the composer's superior intentions, strictly obeying a particular score, a specific playing tradition, or orally transmitted knowledge, all of which are taken as absolute and unquestionable.

The antiquarian is obviously recognisable in all the philological and historiographical attempts to bring us back to a lost paradise, to a time when things were supposedly in order. Such reconstructions are critical of monumentalism; but, at the same time, they also struggle with critically dismantling their objects of work, most of which are treated as enduring fetishes, often artificially constructed in the sense of invented traditions (see Hobsbawm and Ranger 1983). Significantly, this antiquarian position is not confined to a specific historical period-it embraces more and more times, including our own. It is the critical moment that is most lacking in current performance practices; only a few people take the risk to dare to propose some form of serious criticality of past musical works within the performance itself. How can performance practices be created that go beyond monumentalist and antiquarian modes of representation? How can criticality be included inside the performative situation?

A crucial point is that if one remains within the traditional image of work and aims for conventional musical interpretations, nothing new is really possible. The only way to break through, to dissolve parts of the past, and to suggest productive futures, is to fundamentally rethink our image of work, and propose alternative ways of thinking what musical works are and how they operate and function throughout time.

\section{A NEW IMAGE OF WORK}

The conception of what an artwork is and of what artistic practices mean are thoroughly historical, in the sense that they change over time. Different epochs see different things as art; they also see artworks (the "same" artworks) in different ways at different times. There is a fundamental historical nature to ideas of art and to images of work. Every epoch constructs and obeys its own particular modes of conceiving images of work. As explained in Chapters 1 and 2, by image of work, I mean a complex assemblage of things and parameters, a diagram that enables us to think about a given work from a specific point of view. It includes all the things that we acknowledge as belonging to the work, as "making the work," what we recognise as being part of the work. It also includes all the mental categories through which a given epoch and a given community make sense of these works and their possible uses. Very broadly speaking, there are two fundamental, polarising positions: images of work that consider works as solved problems, as systems that were stabilised by the composer (in the case of music), that evolved from 
original chaos into final order (negentropy); and, on the other hand, images of work that see works as acts of problematisation, as systems that remain open for future encounters with the future (entropy). The first position establishes vertical relations between an idealised summit (the Work) and its low-order preparatory materials (sketches, diagrams, plans); the second implies connections that are more horizontal, flattening those same materials, which are considered on a principle of equality, and therefore open to further problematisations. The first position implies some mode of transcendence (with its thesis of the end of history, the end of art, etc.); while the second relies on immanent processes, inventing new configurations that might produce unexpected futures of the past.

As already discussed in Chapter 1, the concept of the musical work has for the last three decades been the object of controversial debates between different positions, ranging from those who critically reflect upon its historically situated construction, to those who affirm its strong ontological (and eternal) character; from those who place it in a chimeric transcendental universe, to those who only accept its immanent audible mode of appearance. Concurrently, recent developments in editorial practices, research on sketches, innovative modes of performing music, and the overarching progressive digitisation of musical materials contributed to a fully renewed horizon of possibilities. Between idealised visions of musical works as fully autonomous entities and materialist approaches centred on the specific conditions of music creation and performance, a new space for reflection and future practices opens up precisely in the process of constituting. Critical to these new modes of conceiving musical entities is taking into consideration the innumerable material objects and things that enable the construction of any possible image of work in the first place. Before gaining their "identity, their unmistakable modes of appearance, their enduring character, or their "aura," musical works are constituted as complex conglomerates of things, such as sketches, drafts, manuscripts, first and later editions, recordings, analytical charts, reflexive texts, performances, and installations. All these things are the basic elements of a multiplicity - a complex articulated set of documents and objects, which are open to including materials beyond the specific horizon of the composition - that is, future or even extra-disciplinary materials. A renewed gaze upon all the innumerable things that actually construe a musical work opens up wider horizons of thought and potentiates innovative performance practices. More than what musical works are or what music practitioners $d o$, material objects define musical works that come under closer scrutiny, enabling a complete new image of work to emerge, and a complete renewed horizon of practices evolving from that image.

According to my notion of musical strata and of stratifications of knowledge, all these material objects can be mapped as belonging to different types of strata, such as substrata (socio-historical and technological contexts), parastrata (documentary sources produced by the composer or close collaborators), epistrata (editions, writings, theoretical discourses), metastrata (future performances), and allostrata (extra-disciplinary or not-directly-related materials). It is from these strata that different times, different traditions, and different disciplines extract the constitutive components of their specific assemblages of 
things, defining varying images of work. Conversely, every given image of work can be de-stratified and reduced to its basic components, revealing (again) specific forms of organising knowledge, establishing hierarchies, and power relations. This is important, and one has to stress that every single discipline constructs its own specific image of $a$ work. Thus, music philology, music sociology, music history, or music analysis build different images of work of one and the same object of study. There is not one work, but a set of materials, which are arranged differently and are seen as being "the work" - thus, my insistence on the notion of image of work. "Works" do not exist once and for all-they are always materially rooted and psychologically driven assemblages of things and functions. Whereas musical works have traditionally been seen from authoritative perspectives that prescribed "this score," "this performance," "this recording," "this analysis," or "this essay," I propose a fundamental redistribution of the available materials, exposing them to their historical, aesthetic, and epistemic situatedness.

Beyond transcendental typologies, beyond extreme or qualified versions of Platonism, beyond functional theories of operative concepts, and beyond aesthetic considerations coming from certain ivory towers of scholarship and academia, I suggest a new image of work, crucially devised in a post-aesthetic regime of the arts, where works are no longer seen as static entities, but rather as highly elaborated manifolds with potentially infinite constitutive parts. In place of a reiteration of uncritically inherited performance practices, this perspective offers a methodology for unconventional, critical renderings that expose the variety and complexity of the musical materials available today. More than repeating what one already knows about a given work, it claims the unknown as the most productive field for artistic practices. Rather than accepting a reproductive tradition, it argues for an experimental, creative attitude. This attitude requires two fundamental elements: an emancipated listener (or spectator) and an emancipated performer.

\section{THE EMANCIPATED PERFORMER}

The notion of an emancipated spectator is crucial to several contemporary theatre and dance performances, and it has been philosophically investigated in the last decades by Jacques Rancière, whose book The Emancipated Spectator (2009) suggested the title of this chapter. Rancière developed a complex discourse on how things become visible and shareable, and on how they are brought together by individuals and groups on the basis of an initial community between words, gestures, signs, and things. For Rancière, the creation of such assemblages is the work of fiction, "which consists not in telling stories but in establishing new relations between words and visible forms, speech and writing, a here and an elsewhere, a then and a now" (ibid., 102, my emphasis). According to Rancière (2009, 13): "Emancipation begins when we challenge the opposition between viewing and acting; when we understand that the self-evident facts that structure the relations between saying, seeing and doing themselves belong to the structure of domination and subjection." Rancière insists on the perspective of spectators, who must 
gain their freedom through emancipating themselves from those structures of domination. Spectators don't receive a ready-to-digest, self-contained "work" in front of their eyes, but must construct for themselves some kind of meaning from all the materials offered to them during a performance. Obviously, this is only possible if the performance and the performers are offering such wider materials. If the performers present a "finished" product with a clearly digestible content, the spectators would be totally satisfied (or positively overwhelmed) and have no need for emancipation whatsoever. Therefore, Rancière's emancipated spectator obviously first requires an emancipated performer - a performer who exposes the materials of his or her practice in their inconsistencies and in their potential to overcome good and common sense, by means of fostering a profound sense of dissensus (Rancière 2009, 48-49):

\begin{abstract}
What there is are simply scenes of dissensus, capable of surfacing in any place and at any time. What "dissensus" means is an organisation of the sensible where there is neither a reality concealed behind appearances nor a single regime of presentation and interpretation of the given imposing its obviousness on all. It means that every situation can be cracked open from the inside, reconfigured in a different regime of perception and signification. To reconfigure the landscape of what can be seen and what can be thought is to alter the field of the possible and the distribution of capacities and incapacities.
\end{abstract}

Film, video art, photography, installation, music, and all other forms of art can rework the frame of our perceptions and the dynamism of our affects. As such, they can open up new passages towards new forms of political subjectivation. Pamphlet art or aesthetically loaded manifestos will not change society: the political power of art doesn't reside in its explicit content (mots d'ordre), but rather in its active redistribution of the sensible, in the suggestion that things can be arranged differently, that our senses can be stimulated differently, that our relations to the world and between ourselves can be organised differently. This is the power of art; to apply it to music performance one needs performers who are emancipated from the tacit authorities and disciplinary regimes described above. Performance should not be a decorative ornament of our knowledge society. Performance is the place par excellence to problematise things and works. It is the ideal place to construct and to expose problems; to develop new practices, and new techniques of thought; to instigate new modes of apprehending historical materials; and to operate new distributions of the sensible. Instead of reifying works again and again, it is the place to ask questions: How are works constructed? How do they function? What interferes with them?

Works are not totally stable entities (as performative "tradition" normally assumes), nor totally unstable (as the proponents of deconstruction claimed); they are metastable and carry a transformational power. As metastable multiplicities, they have potentialities, tensions, inconsistencies, movement, undecided parts, and changeable components. Performance is the place to explore these inconsistencies, and to make them operate productively. Beyond interpretation, performance is the place to embrace experimentation, to establish, on the basis of productive contradictions, the possibility of free, creative action for 
music performers. Interpretation becomes one parameter, not the end goal of a performance. And the performer becomes an operator, what Carmelo Bene (see Giacchè 1997) called an actorial machine, machining new assemblages of things against the grain of their historically inherited constitutive parts. The fundamental step, then, is the passage from a passive reproduction of scores to an adventurous experimentation with all the available materials, taking real decisions, redistributing relations, changing how a given work is perceived, distributed, communicated.

Music performers risk becoming progressively isolated from aesthetic, intellectual, and critical debates of our day. Their uncritical submission to a musical market with simple and clear expectations turns them into a luxurious kind of "happy slave," a condition of which most are unaware. As Roland Barthes observed in relation to textual interpretation, one is master and slave at the same time: "Je suis a la fois maitre et esclave" (Barthes 1979, 5; I am both master and slave). Performers must be much more aware of and responsible for their actions and acts. My claim for an emancipated performer is an offer to change the current state of affairs in music performance of past musical works. I hope to contribute to this movement, suggesting modes of operating that make music performers a bit less like slaves and a bit more like masters, moving from passive modes of musical reproduction to productive, active, and clearly creative modes of operating. This is important not only for the performers themselves, but also for society in general, because it is vital to have the voice and the critical stance of the music practitioner. It is crucial to have performers who think, who intellectually engage with the problems and delusions of their own time, who creatively suggest new modes of organising knowledge, and that effectively operate transformations in society. These performers, as artists in general might think in a different register, but that register is urgently needed as it embraces both rationality and sensibility, logos and pathos. It is time to take performers seriously as engaged co-designers of our aesthetic, intellectual, and epistemic world; but, of course, only if the performer strives for emancipation, which depends on the willingness to creatively engage with the potentials inherent to my proposed new image of work.

\section{REFERENCES}

Barthes, Roland. 1979. "Lecture in Inauguration of the Chair of Literary Semiology, Collège de France, January 7, 1977." Translated by Richard Howard. October 8 (Spring): $3^{-16}$.

Burroughs, William S. 197o. The Electronic Revolution. [West Germany]: Expanded Media Editions.

Danuser, Hermann. 1994-2007.

"Interpretation." In Musik in der Geschichte und Gegenwart: Allgemeine Enzyklopädie der Musik, edited by Friedrich Blume and Ludwig Finscher, 2nd ed., 21 vols.,
3:1053-69. Kassel: Bärenreiter; Stuttgart: Metzler.

- 2016. "Execution-InterpretationPerformance: The History of a Terminological Conflict.” In Experimental Affinities in Music, edited by Paulo de Assis, 177-96. Orpheus Institute Series. Leuven: Leuven University Press.

Deleuze, Gilles. 1992. "Postscript on the Societies of Control." October 59 (Winter): 3-7. Essay first published 1990 as "Postscriptum sur les sociétés de contrôle” (L'autre journal 1 [May]) and republished 


\section{Chapter 7}

in Pourparlers 1972-1990 (Paris: Minuit). Translation republished in revised form in Negotiations: 1972-1990, translated by Martin Joughin (New York: Columbia University Press), 177-82.

Dreyfus, Laurence. 2007. "Beyond the Interpretation of Music." Dutch Journal of Music Theory 12 (3): 253-72.

Foucault, Michel. 1977. Discipline and Punish: The Birth of the Prison. Translated by Alan Sheridan. London: Penguin. First published 1975 as Surveiller et punir: Naissance de la prison (Paris: Gallimard). Giacchè, Piergiorgio. 1997. Carmelo Bene: Antropologia di una macchina attoriale. Milan: Bompiani.

Hobsbawm, Eric, and Terence Ranger, eds. 1983. The Invention of Tradition. Cambridge: Cambridge University Press. Nietzsche, Friedrich. 1997. "On the Uses and Disadvantages of History for Life." In Untimely Meditations, edited by Daniel Breazeale, translated by R. J. Hollingdale, 60-123. Cambridge: Cambridge

University Press. Essay first published 1874 as "Vom Nutzen und Nachteil der Historie für das Leben," 2nd part of Unzeitgemässe Betrachtungen (Leipzig: Fritzsch, 1873-76).

Rancière, Jacques. 2009. The Emancipated Spectator. Translated by Gregory Elliot. London: Verso. First published 2008 as $L e$ Spectateur émancipé (Paris: La Fabrique). 


\section{... at the borders of time that surround our presence ..."}

\section{WHAT IS THE CONTEMPORARY?}

When thinking about the contemporary I cannot avoid initially thinking about it through my own personal acquaintance with the term, an acquaintance that is profoundly and biographically related to music, that is to say to contemporary music. More than contemporary art or contemporary philosophy, it was in music and through the making of music that the question of the contemporary became relevant to me: first as a listener, then as a performer, later as a music analyst, and sporadically as a composer. Saying "contemporary music" automatically triggers in my brain several memories and associations: as a teenager, attending the Gulbenkian Contemporary Music Encounters in Lisbon; as a music student in Germany, attending the Donaueschinger Tage für Neue Musik; and as an advanced student and early-career pianist, in the early 1990 os travelling to Venice for several concerts at the Biennale Musica. For me, biographically speaking, the contemporary is inextricably associated with a rather specific mode of conceiving and making art, which I associated first with a particular set of works and authors. In general, these are authors who strongly challenge common views on their specific art forms and their media, authors who are "difficult" to grasp, whose works seem to resist quick judgements and understandings. In this sense, (for me) the contemporary was always more concerned with a critical attitude towards conventional or common-sense understandings of art than it was with a specific historical period, style, or mode of marketing art products.

The term contemporary music gained wider use in the second half (maybe, even more precisely, in the last quarter) of the twentieth century. Music composed in the first half of the century was not labelled "contemporary" but "new" (in German "Neue Musik") or as "modern." So-called modernity in music usually refers to diverse new orientations in music composition observable between 1900 and 1933 (though the crucial events happened in a shorter period, probably between 1908 and 1913), including impressionism (Debussy, Ravel,

* This text was first written for my lecture at the Fourteenth International Orpheus Academy for Music and Theory 2017, dedicated to the topic of "Futures of the Contemporary," held at the Orpheus Institute on 12 May 2017.

1 As the music philosopher Gunnar Hindrichs (2004, 133) observed: "Generally, for music there are two options of interpretation [of the term "modern"]: used as an overall term, the 'modern' age is taken as the period beginning around the end of the 18 th century, while in more specific usage it refers to the time since the start of the 2 oth century." 
Dukas), expressionism (Schoenberg, Berg, Webern, Scriabin, certain works by Stravinsky), atonality (Schoenberg, Scriabin), and dodecaphony (Schoenberg, Webern, Berg). All these different perspectives, with their different techniques and aesthetic approaches to composition, shared a common trait: the manifestation of the limits (actually, "the end") of "tonality, of music understood in terms of functional harmony. They all critically reflected upon the exhaustion of the Classical-Romantic set of forms, harmonic material, and instrumental choices, and they all proposed alternative paths. These composers operated what Jean-François Lyotard (1984) - in relation to knowledge in generaldescribed as processes of "deligitimation" of previous modes of knowledge production and consumption. In the case of music, these included the dominant structures of functional tonality, standard forms, instrumental set-ups, concert rules, and so on. A "second modernity" in music is usually associated with post-1950 developments, particularly related to the Darmstadt Summer Courses and their consequences. Especially between 1946 and 1961, under the direction of Wolfgang Steinecke, the Darmstadt Summer Courses for New Music (Internationale Ferienkurse für Neue Musik) became the main point of reference for theorising, discussing, and presenting what was then called the avant-garde. It included lectures by music philosophers (Theodor W. Adorno, Heinz-Klaus Metzger), musicologists (Carl Dahlhaus, Rudolf Stephan), older-generation composers (Edgard Varèse, Olivier Messiaen, Ernst Krenek), and young composers (Karlheinz Stockhausen, Pierre Boulez and Luigi Nono, and later also John Cage, Helmut Lachenmann, and Brian Ferneyhough). The courses functioned as the international forum for new music, the place where compositional strategies and concrete modes of doing were openly presented and analysed in detail.

In Paris, the Domaine Musical (1954-73), founded by Pierre Boulez, had a different scope, mainly that of producing performances, but shared the idea of presenting avant-garde, cutting-edge musical works in dialogue with and alongside older pieces. Works by Stockhausen, Boulez, Pousseur, Berio, Kagel, or Boucourechliev were performed, but so too were pieces by Guillaume de Machaut, Dufay, Bach, Debussy, Schoenberg, Stravinsky, and Messiaen. According to Boulez's foundational statement, the Domaine Musical was meant to "produce concerts that would enable the re-establishment of communication between composers of our time and an audience interested in the promotion of its own epoch" (quoted in Steinegger 2012, 107, my translation, my emphasis). ${ }^{2}$ This statement seems to indicate that contemporary music requires not only a special kind of composition but also a special kind of audience, one that is "interested" in "promoting" its own time. It seems to indicate that, in the period in which Boulez made the statement (the 1950s), people were more inclined to appreciate older epochs of music history than they were the contemporary. Therefore, an effort was deemed necessary to "promote" the present, to support a whole new mode of making, thinking, and apprehending music. The

\footnotetext{
2 “créer des concerts pour qu'une communication se rétablisse entre les compositeurs de notre temps et le public intéressé à la promotion de son époque."
} 
composers named above, as well as the concert series discussed, include the composers and festivals that from the late 1960s on widely became labelled "contemporary." These composers lived in periods, in historical epochs, where in general there was little interest in their work-they thus needed a special kind of audience. From then on, music festivals featuring this type of music were known as festivals of contemporary music, and they attracted a specific kind of public.

It is important to draw a distinction here between the coeval-the contemporaneous of a given historically situated time-and the contemporary, which has a fundamental critical function (on the identity of the present) and that enables a clinical glance (symptomatology) at one's own time. The notion of contemporary music does not apply to all music that is composed "today," which in fact in the vast majority of cases is not contemporary at all. Music of today is certainly contemporaneous, it is coeval to us, but nobody would say that, for example, a composer composing a Classical symphony in the style of Haydn today is making "contemporary music." As Jean-Luc Nancy writes, "it can be said that some works of art produced today somewhere in the world do not belong to contemporary art. If today a painter makes a figurative painting with classical techniques, it will not be contemporary art; it will lack the cachet, the distinctive criterion of what we call 'contemporary" (Nancy 2010, 91). Thus, contemporary music, like contemporary art, implies a critical dimension, a distance from the everyday world, a detachment from habitus, conventions, and stratifications of forms and media. But what, then, is the contemporary?

A first, very simple definition is the one offered by Alain Badiou in 2014actually not one, but two definitions of contemporary art: (1) contemporary art is a critical art that it is critical of Classical, Romantic, or even modern forms of artistic creation; and (2) contemporary art is an art that is separated from the real, and which aims at creating a new real by the mediation of new forms (Badiou 2014, 6'12"-6'53"). These apparently simple definitions require the acknowledgement of two distances: distance from art itself, and distance from the world. Both distances imply the presence, and importantly the simultaneous presence, of diverse planes of "reality," that is, of diverse times and spaces in spatio-temporal overlaying. This multiple temporality, the gap between the present and the present, between different planes of the present, is the main topic of this chapter, and I will address it in what follows from a variety of perspectives: first through Giorgio Agamben's attempt to define the contemporary, which is indebted to Roland Barthes's theories of writing and to Friedrich Nietzsche's central notion of Unzeitgemäss (and its problematic translations into other languages); then through Foucault's distinction between the present and the actual, Charles Péguy's fringes of time and his notion of the aternal, Deleuze and Guattari's central concept of haecceity, and my own micro-haecceity. All these notions and concepts share, in my view, a similar constitutive principle, namely the gap between the present and our presence within it, and they define different zones of indeterminacy situated at the borders of time; finally, I will conclude with a plea for artistic research as the contemporaneous carrier of the spirit of the contemporary. 


\section{Chapter 8}

\section{AgAMBEN'S CONTEMPORARY: BARTHES READING NietzsChe}

In October 2005, Giorgio Agamben opened his seminar at the faculty of architecture in Venice with a presentation entitled "What Is the Contemporary?" Agamben's "problem" in "What Is the Contemporary?" (2009), or, better, the question he poses, is, "Of whom and of what are we contemporaries?" This question could also be given as, How can past artists, philosophers, and artworks be considered as being contemporary to us? In this sense, Agamben's major concern is the relation of the present to the past, how this present is defined by its own past, and how some moments of the past remain active in the present. Agamben's questioning remains implicitly hermeneutic and interpretative, not addressing the experimental production of newness outside the actuality of our present. According to Agamben, the contemporary relates to the present through mechanisms of recognition of the present ("actuality") as something fundamentally archaic. Only those able to perceive and identify "the clues and signals of the archaic in the most modern and recent" things and events (Agamben 2009, 50) can really be considered one's contemporaries.

Beginning with a discussion of Friedrich Nietzsche's notion of the untimely, read through the eyes of Roland Barthes, Agamben's essay explores the concept of the contemporary in relation to a poem by Osip Mandelstam, to the interactions of light and darkness in astrophysics, to fashion, to the notion of $a r k h \bar{e}$, and to the fundamental heterogeneity of different (Pauline) times. Strongly inspired by Barthes's Nietzschean statement that "the contemporary is the untimely," Agamben defines the contemporary as "that relationship with time that adheres to it through a disjunction and an anachronism" (Agamben 2009, 41, emphasis removed). For Agamben, contemporariness is a paradoxical structure: those who are contemporary see and grasp their own time more clearly than others, by virtue of their very disjunction with it. This idea derives from Nietzsche's introduction to his second Untimely Meditation, where he posits that the untimely is that which "act[s] counter to our time and thereby act[s] on our time and, let us hope, for the benefit of a time to come" (Nietzsche 1997, 6o). On our time, counter to our time, for a time to come. But how is it possible to be in our time and to act against it? Only through a disconnection and a positive anachronism. As Agamben (2009, 40) puts it: "precisely because of this condition, precisely through this disconnection and this anachronism, they [the untimely] are more capable than others of perceiving and grasping their own time." "Contemporariness," Agamben (ibid, 41) continues, "is, then, a singular relationship with one's own time, which adheres to it and, at the same time, keeps a distance from it.” Through Nietzsche and Barthes, Agamben stresses the fundamental, both existential and experienceable, gap between the present and the present: between the present as "what arrives to us," our presence in it,

3 Agamben doesn't provide a specific reference for this quotation, which seems to have been pronounced by Barthes during his seminars at the Collège de France in 1978-8o, in which he communicated this idea several times. However, and despite my efforts, I couldn't find this precise quotation in the published volume La préparation du roman I et II: Cours au collège de France, 1978-1980 (Barthes 2003). 
and our potential departure from it. It is this gap that makes possible criticality, problematisation, and the invention of a new world. This gap is the untimely. To explore this gap creatively is to become contemporary. That's how, for Barthes (as quoted by Agamben 2009, 40), "the contemporary is the untimely."4

Barthes introduced the idea that the contemporary is the untimely in the last series of his seminars at the Collège de France, in 1979-8o, under the general title of "The Preparation of the Novel." He presented a conception of the act of writing as an act of resistance against the writer's own time. In this frame, Barthes referred to the untimely character (what he called l'inactualite') of the writer as a form of marginalisation, a discrepancy between his interior time and the time of the world around him. In the seminar of 16 February 1980, he specified this relationship in detail and observed that "actuality constantly blackmails whoever intends to forget it" (Barthes 2003, 352, my translation). The writer's responsibility is to counter this blackmail, to offer it a resistance, enabling the affirmation of alternative, infinite possible worlds. As Jean-Luc Nancy (2010) writes, criticising forms of art with explicit political or timely content: "Yes, there is form in these works, but a message precedes it and dominates it" (95). Art that directly reacts to the actuality of its day is "not at all art, precisely because [it is] pure signification" (96). Actuality must be challenged, and that is one of the powers of art. The untimely then would be the result of such resistance against actuality. To make contemporary art would be to generate art objects that operate in an untimely manner, that create or enhance the gap between the world and the world, between the present and the present, between the I and the I.

Barthes's choice of words (inactuel), leaves no doubt that he is referring to Nietzsche's second Untimely Meditation, "On the Utility and Liability of History for Life," dated February 1874. As is well known, Nietzsche expresses in this text his annoyance at many of the most prominent features of the political, philosophical, and intellectual landscape of the European culture of his time. Central to his critique is the "cultivation of history," which makes people live in a state of suffering, consumed by the "fever of history" (Nietzsche 1997, 60). Nietzsche translator and commentator Daniel Breazeale notes:

It was in the Untimely Meditations that Nietzsche first found the courage to "say No" to his age and to his fellow scholars, and, hence, to significant parts of his own self. (Breazeale 1997, xxv-xxvi)

A perhaps more important feature of the second Meditation is precisely the way in which [Nietzsche] seeks simultaneously to concede the inescapable historicity of human existence and to affirm the creative capacity of human beings to overcome themselves and their past.... [Nietzsche's] project is to show how human life requires us to adopt both a "historical" and an "ahistorical" perspective upon ourselves. (Breazeale 1997, xv)

4 On the source of this quotation, see footnote 3 above. 
The specific use of the term "untimely" (Unzeitgemäss)—with which Nietzsche even signed his postcards in that period-deserves a brief commentary. He used it for the first time in a letter to Erwin Rhode dated 17 August 1869. In that letter, the subject of which is Wagner's music, which at that time Nietzsche still admired unconditionally, Nietzsche looks for an explanation for Wagner's inability to gain public acknowledgement. Contrary to those artists that obtain immediate praise from the public, Wagner is described by Nietzsche as someone clinging firmly to his own power, with his glance strongly fixed beyond the transient and ephemeral-" "untimely' in the best sense of the word" (Nietzsche quoted in Breazeale 1997, xlv). According to Breazeale: "Any doubt about how Nietzsche understood the term 'untimely' is removed by a careful reading of Strauss [the First Meditation], which is very largely an attack upon the sovereignty of 'public opinion' as an arbiter of taste, values and truth itself. (Ours, he reminds us in section 2 of Schopenhauer as Educator [the 3 rd Meditation], is 'the age of public opinion.') Whereas the slave of public opinion strives always to be 'timely', a declared critic of the same will instead flaunt his deliberate "untimeliness"' (Breazeale 1997, xlv-xlvi).

The untimely in Nietzsche is opposed to the actual, to everything that in a given time contributes to strengthen the archaic structures of timeliness itself. It is a way to escape the enormous burden of inherited or dictated values, of habits and of all sorts of gregarious practices. What Nietzsche had in mind and what he was most powerfully attacking was his time, which was "consumed by the fever of history." Of course, today things have changed significantly, and I think our age is even more problematically consumed by the fever not of the past but of the present, by the overwhelming dictatorship of the quotidian. But, whether we are consumed by history or the present, Nietzsche's core message is how to escape this consumption, how to create a line of flight, how to act in our time, counter to our time.

\section{NietzSChE's UNTIMELY: LOST In TRANSLATION}

The translation of Nietzsche's word untimely has been problematic in many ways, and one of these problems affects the translation of Agamben's essay "What is the Contemporary?," making obscure for English-speaking readers a very important point of his argumentation. In an early discussion of Agamben's essay with my colleague Michael Schwab, I referred to the untimely as the "inactual," as something distinct from the actual, from dominant, prevailing, and common-sense modes of thought. Michael listened to me and went home. Soon, he called me to say that what I was saying, specifically the word inactual, was not to be found in Agamben's essay. Fearing I had misunderstood Agamben, I read the essay once more, and there it was, at the beginning of its second paragraph: "Le contemporain est l'inactuel [intempestivo]" (Agamben 2008b, 8); and, further down, "le vrai contemporain ... se définit comme inactuel [inattuale]" (ibid., 10). I suddenly realised that I was reading it in French and that Michael was reading it in English. Thus, I checked the English translation, where to my puzzlement I discovered the following: "the contemporary is the untimely [intempestivo]" (Agamben 2009, 40), 
and "those who are truly contemporary ... are irrelevant [inattuale]" (ibid.). I went then to the Italian version, where it reads: "il contemporaneo è l'intempestivo," and "è veramente contemporaneo colui che non coincide perfettamente con (il suo tempo) né si adegua alle sue pretese ed è perciò, in questo senso, inattuale" (Agamben 2008a). The English translator seems not to be aware of the origin of the word, not to know that Agamben is referring back to Nietzsche's Unzeitgemäss, thus eliminating from the whole text the dual dimension of actual versus inactual that is so crucial to the argument. Instead of a gap between the present and our presence in it, one is misled by the assumption that the untimely is something simply of the order of the irrelevant. 5

\section{4. ... AT THE BORDER OF TIME THAT SURROUNDS OUR PRESENCE ...}

Before being investigated by Giorgio Agamben, Nietzsche's untimely had been the object of important reflections by Gilles Deleuze and Félix Guattari, who developed it from Nietzsche, Foucault, and from the French poet and essayist Charles Péguy. In 1980, in the section "Memories and Becomings, Points and Blocks" of $A$ Thousand Plateaus (Deleuze and Guattari 1987, 291-98), just after describing how every musician, painter, writer, or philosopher fabricates a punctual system "in order to oppose it, like a springboard to jump from," Deleuze and Guattari $(1987,295)$ make the Nietzschean claim that "history is made only by those who oppose history (not by those who insert themselves into it, or even reshape it)." They continue: "This is not done for provocation but happens because the punctual system they found ready-made, or themselves invented, must have allowed this operation: free the line and the diagonal, draw the line instead of plotting a point, produce an imperceptible diagonal.... When this is done it always goes down in History but never comes from it" (ibid, 295-96). Insisting on the centrality of drawing a cutting plane that cuts across chaos to produce a plane of composition, Deleuze and Guattari stress the importance of "multilinear assemblages, which are in no way eternal: they have to do with becoming; they are a bit of becoming in the pure state; they are transhistorical" (ibid., 296). In this sense, they continue, "there is no act of creation that is not transhistorical and does not come up from behind or proceed by way of a liberated line. Nietzsche opposes history not to the eternal but to the subhistorical or superhistorical: the Untimely, which is another name for haecceity" (ibid., my emphasis).

With the notion of haecceity, we find yet another way of conceiving the untimely. As already mentioned in Chapter 5, haecceity is a concept developed by Deleuze and Guattari ${ }^{6}$ that describes the emergence of a singularity at any given scale and field. Crucially, a haecceity does not refer to a fully qualified

5 Beyond the translation of Agamben's essay, the difficulty of translating Nietzsche's title Unzeitgemässe Betrachtungen into other languages is manifest in the various attempts officially made in English: Thoughts Out of Season, Untimely Considerations, Unmodern Observations, Unfashionable Observations, Unconventional Observations, and Inopportune Speculations (with the subtitle "Essays in Sham-Smashing”). In Neo-Latin languages, there is always the option of going for intempestivo (Italian, Portuguese, and Spanish), inactual or inatuale (Portuguese and Italian), or extemporaneo (sometimes in Brazilian Portuguese).

6 See Chapter 5 , section 7 for further details on the concept of haecceity. 
space-time, but to a spatio-temporal dynamism. A haecceity is a passage, a singular point in space-time that dramatises it, curving it, folding it, giving it transient form and temporal structure. In this sense, haecceities can be seen as the piercing points, the geometric place of a perforation in a given space-time surface (chronos) that opens a passage, a tunnel towards an empty form of time (aîn). If so, a haecceity would have strong links to the notion of kairos, the inescapable here-and-now of the event.

In the last five years, I have appropriated this notion for the performing arts, applying it to music, dance, theatre, and performance. As described in Chapter 5, particularly focusing on intense and fast moving haecceities, I introduced the notion of micro-haecceity, a temporal radicalisation of the concept, collapsing it into an infinitesimal fraction of a second, into the radical here-and-now of the evolving performance. Such micro-haecceities are characterised by intensive negentropic properties, unfolding at very high speed. These special kinds of haecceities do not suggest (stable) contemplation, but rather rash (metastable) actions. Deleuze's characteristic example of haecceity-Lorca's "at five in the afternoon" (see Lorca 1997, 263, 265) - has a scenic quality: it evokes a particular landscape, time of day, temperature, sunlight, inner memories, and so on. The performers acting onstage navigate high-speed successions of prolonged singularities. There is no time for contemplation; things must happen in the unavoidable urgency and imperative sequentially of the here-and-now. Microhaecceities are high-energy-loaded and high-speed-moving singularities that carry a force of potential from one position to the next. They make up the visible or audible part of artistic transductive processes. In their functioning as radical becoming they never appear as stable beings, remaining an impulse of virtuality from one actualisation to the next. If one thinks, or does, or experiences artistic performances with these operations in mind, the Deleuzian notion of capture of forces becomes more graspable than ever: the virtual becomes actual in order to be instantly dissolved into the virtual again. A performer onstage exemplifies such a capture: he or she is not merely reproducing a stratified pre-existing entity, but operating a capture of forces (from the virtual) that produces a new individuation (actual) as a highly intensive becoming, which immediately-as soon as it is generated-points forward to other virtual pre- and after-individualities. Micro-haecceities reveal, therefore, the non-deterministic pasts of their individuated constitutive forces and energies, as much as their unpredictable futures. By doing so, micro-haecceities reveal that the making of art is a fundamentally problematic field - generating and enhancing heterogeneous tensions that produce the conditions of their own (transient) resolutions. If we understand the untimely also as the production of micro-haecceities we access the now of our becoming, a radical machine capable of piercing the surface of our epoch, the strata of our habits, the skin of our self.

In 1991 Deleuze and Guattari once again returned to Nietzsche's notion of the untimely, in What Is Philosophy?, in the context of theorising the present as an agencement, not as a stable entity but as an arrangement of complex relations, interactions, and psychological processes. For them, there is not one present but a simultaneous multiplicity of temporalities. In a dense page devoted to 
the French writer and novelist Charles Péguy and his definition of an event, Deleuze and Guattari $(1994,112)$ briefly introduce Péguy's concept of the aternal, Plato's nun, and Foucault's actual. Interestingly, these concepts are presented in relation to Nietzsche's untimely, on which they seem to be variations.

Péguy's explanation of the event in his novel Clio led him to create a neologism, the aternal (in French l'internel), a term that describes something that "is no longer the historical, and ... is not the eternal" (Deleuze and Guattari 1994, 111). Deleuze and Guattari write: "Péguy had to create this noun to designate a new concept. Is this not something similar to that which a thinker far from Péguy designated Untimely [Intempestif] or Inactual [Inactuel]—the unhistorical vapor that has nothing to do with the eternal, the becoming without which nothing would come about in history but that does not merge with history?" (ibid., 111-12). Quoting from Nietzsche's second Untimely Meditation, Deleuze and Guattari then discuss the temporal relations between past, present, and future, in a passage that recalls similar paragraphs from Deleuze's Logic of Sense, in which a Stoic conception of time had been presented. What is new in the section on Péguy in What Is Philosophy? is the link to Foucault's notion of the actual, which Deleuze and Guattari derive from Plato's nun. Nietzsche's "acting counter to the past, and therefore on the present, for the benefit ... of a future" points to a future that "is not a historical future, not even a utopian history, it is the infinite Now, the Nun that Plato already distinguished from every present: the Intensive or Untimely, not an instant but a becoming" (Deleuze and Guattari 1994, 112, my emphasis). To complicate things a bit more, Deleuze and Guattari ask whether Péguy's aternal [internal], Nieztsche's untimely [inactuel], and Foucault's actual are not the same thing:

\begin{abstract}
But how could the concept now be called the actual when Nietzsche called it the inactual? Because, for Foucault, what matters is the difference between the present and the actual. The actual is not what we are but, rather, what we become, what we are in the process of becoming... The present, on the contrary, is what we are and, thereby, what already we are ceasing to be. We must distinguish not only the share that belongs to the past and the one that belongs to the present but, more profoundly, the share that belongs to the present and that belonging to the actual. It is not that the actual is the utopian prefiguration of a future that is still part of our history. Rather, it is the now of our becoming. (Deleuze and Guattari 1994, 112)
\end{abstract}

Deleuze and Guattari's very specific reference here is to chapter 5 of part 3 of Michel Foucault's The Archaeology of Knowledge, significantly entitled "The Historical a priori and the Archive" (see Foucault [1972] 2002, 142-48). Theorising the archive, Foucault claims that the "the proper task of a history of thought, as against a history of behaviors or representations ... [is] to define the conditions in which human beings 'problematize' what they are, what they do, and the world in which they live" (Foucault [1985] 1992, 10). As part of this effort, Foucault identified a particular zone in which problematisation occurs, a zone where different temporalities come into contact, friction, and eventually destruction.

The analysis of the archive, then, involves a privileged region: at once close to us, 
and different from our present existence, it is the border of time that surrounds our presence, which overhangs it, and which indicates it in its otherness; it is that which, outside ourselves, delimits us. The description of the archive deploys its possibilities ... on the basis of the very discourses that have just ceased to be ours; its threshold of existence is established by the discontinuity that separates us from what we can no longer say, and from that which fails outside our discursive practice; it begins with the outside of our own language ...; its locus is the gap between our own discursive practices. (Foucault [1972] 2002, 147, my emphasis)

It is this gap-the gap between the present and the present, between the present and our presence within it (which is another way of conceiving the Lacanian gap between the I and the I) - that creates the conditions for a diagnosis. Not a positivist diagnosis that would lead to a clear prescription and cure, but a diagnosis that (paradoxically) creates its own problems, without which our existence would be infinitely less interesting and less fruitful. It is a diagnosis that "deprives us of our continuities; it dissipates that temporal identity in which we are pleased to look at ourselves when we wish to exorcise the discontinuities of history... In this sense, the diagnosis does not establish the fact of our identity by the play of distinctions. It establishes that we are difference, that our reason is the difference of discourses, our history the difference of times, our selves the difference of masks. That difference, far from being the forgotten and recovered origin, is this dispersion that we are and make" (Foucault [1972] 2002, 147-48, my emphasis).

This dispersion occurs in our lives, our activities, and our artistic practices. It happens as a complex arrangement of different temporalities, discourses, and masks-all moving at different paces (fast and slow), with different accelerations (stratifications and ruptures), and with different temperatures (hot and cold). This means that no present is ever One, no present can ever be a stable entity, no simultaneity can be fully grasped. As in the inner eye of a hurricane, we find ourselves in a dispersive and explosive column of air rotating at high speed, a violent storm that doesn't blow forward towards the future (Benjamin's progress) but that revolves around itself, throwing objects, things, ideas, and feelings towards innumerable other compossible futures, which exist now. If there is progress (in Benjamin's terms), it is convoluted rather than linear progress, incoherent, not unifiable, not deductible in its succession, and in centripetal rotation around an empty centre.

\section{Artistic research as the Carrier of the CONTEMPORARY}

Barthes, Agamben, and even Foucault relate to the past. Agamben's strongest examples in What is the Contemporary? are the notion of arkhe and Saint Paul. In relation to arkhe, Agamben (2009) writes, "only he who perceives the indices and signatures of the archaic in the most modern and recent can be contemporary" (50). And he adds, "the key to the modern [in art and literature] is hidden in the immemorial and the prehistoric" $(51)$. He concludes, "to be contemporary means in this sense to return to a present where we have never been" $\left(5^{1-52}\right)$. In this respect, my perspective is totally different: it is not about a return, but about the 
invention of a present to which we have never been - an invention that can only be accomplished by what Paul Klee suggested was a people to come 7 - not a people from the future but people from today looking at our own time in a completely renewed way. However, Agamben does not refer to Paul Klee, nor to any kind of futurity, but to Saint Paul and his "being-contemporary with the Messiah, which he calls ... the "time of the now" $\left(5^{2}\right)$. For Agamben, the new present is to be built after insightful understanding of subtle signs from the remote past, a perspective that implies some sort of primordial lost paradise and some kind of lost sense that ought to be recuperated.

Foucault doesn't believe that history is a product of (modern) sense. But his continued obsession was the archive, and its many different modes of formation, stratification, and modulation. Foucault's archive is highly heterogeneous, articulating a multiplicity of historical dimensions without any clear-cut dialectics that would define its limits and borders. Foucault's historical methodology looks at the past not for the past's sake, but to understand how we became what we are today. Even if not historiographical in conventional terms, his approach remains that of a historian, of someone investigating past facts, documents, and events. This explains his numerous histories: of madness, of the hospital, of the prison, of knowledge, of infamous people, of sexuality. Selfironically, Foucault said about himself, "I am a historian of ideas after all. But an ashamed, or, if you prefer, a presumptuous historian of ideas. ... I cannot be satisfied until I have cut myself off from 'the history of ideas,' until I have shown in what way archaeological analysis differs from the descriptions of 'the history of ideas"' (Foucault 2010, 152).

Thus, moving beyond Agamben's, Barthes's, and Foucault's relation to history and historicity, my view and my proposal are different - they point towards the futures of the contemporary and its manifold possibilities of constitution, formation, and reinvention of connectors. More so than other modes of research, artistic research has the power to reverse the arrow of research: where interpreters investigate the archive, looking into the past, into the arkhe, or into the global present, artistic researchers can look into the abysses of the present in order to grasp its futures, exploring the diagnostic function of art, contributing to a symptomatology of one's own epoch.

Artistic research can also be conceived as performing historical or historiographical research as a means to reactualise older forms, technical objects, or modes of expression. But my position is that artistic research's most interesting perspectives are those that more explicitly relate to the future. My quest is never to try to find out how things really were in the past, nor is it the Foucauldian

7 Paul Klee's famous claim that modern art hadn't yet found its "people" can be found at the end of his short treatise On Modern Art, which he prepared as the basis for a lecture that he delivered in Jena in 1924 (see Read 1948, 7). More than "a people to come," he insists on the notion of a still "missing people." The passage is as follows: "Sometimes I dream of a work of really great breadth, ranging through the whole region of element, object, meaning and style. This, I fear, will remain a dream, but it is a good thing even now to bear the possibility occasionally in mind. Nothing can be rushed. It must grow, it should grow of itself, and if the time ever comes for that work-then so much the better! We must go on seeking it! We have found parts, but not the whole! We still lack the ultimate power, for: the people are not with us. But we seek a people" (Klee 1948, 54-55, my emphasis). 
analysis of how we became what we are today; rather, I want to discover how we can become today what today we aim to be. Or, how we can depart from today, even without a clear destination in mind or safe ports to reach. The future is contained in the present but remains concealed to itself. I am close to Agamben, but with a significant turn: my point is that to be contemporary doesn't mean to return (Agamben) but to invent a present where we have never been. At the borders of time and space defined by the violent hurricane of the present, we need to build the future rather than rescue the past. This future will not solve the storm, but it will generate new tensions and new inconsistencies, as well as new points of reference, new singularities in the ever-expanding manifold of art, life, and society. In this sense, I believe that artistic research has a very important role in the art world of today, especially in its capacity to generate new forms and modes of expression that are rigorous rather than accidental and at the same time indeterminate. Artistic research asks how we can create in the midst of complex arrangements of different temporalities, how we can artistically and creatively operate inside the furious inner eye of the multiple hurricanes we are living in-how we can live at the border of time that surrounds our presence and find the courage to jump into the core of the hurricane, from where we return "breathless and with bloodshot eyes" (Deleuze and Guattari 1994, 172).

\section{REFERENCES}

Agamben, Giorgio. 2008a. Che cos'è il contemporaneo? Rome: Nottetempo. Kindle. Translated by Maxime Rovere as Agamben $2008 \mathrm{~b}$ and by David Kishik and Stefan Pedatella as Agamben 2009. . 2008b. Qu'est que le contemporain? Translated by Maxime Rovere. Paris: Payot \& Rivages. First published as Agamben 2008a.

. 2009. "What Is the Contemporary?" In What Is an Apparatus? And Other Essays, translated by David Kishik and Stefan Pedatella, 39-54. Stanford, CA: Stanford University Press. Essay first published as Agamben 2008a.

Badiou, Alain. 2014. "Alain Badiou and Judith Balso: Contemporary Art: Considered Philosophically and Poetologically." YouTube video, $38: 06$, posted by "European Graduate School Video Lectures," 30 September. Accessed 24 January 2018. https://www.youtube.com/ watch?v=g83QnigalYM.

Barthes, Roland. 2003. La préparation du roman I et II: Cours au collège de France, 1978-1980. Edited by Nathalie Léger. Paris, Seuil. Translated by Kate Briggs as The Preparation of the Novel: Lecture
Courses and Seminars at the Collège de France (1978-1979 and 1979-1980) (New York: Columbia University Press, 2011).

Breazeale, Daniel. 1997. Introduction to Friedrich Nietzsche, Untimely Meditations, edited by Daniel Breazeale, translated by R. J. Hollingdale, vii-xxxiii. Cambridge: Cambridge University Press.

Deleuze, Gilles, and Félix Guattari. 1987. A Thousand Plateaus: Capitalism and Schizophrenia. Translated by Brian Massumi. Minneapolis: University of Minnesota Press. First published 1980 as Mille plateaux (Paris: Minuit). . 1994. What Is Philosophy? Translated by Hugh Tomlinson and Graham Burchell. New York: Columbia University Press. First published 1991 as Qu'est-ce que la philosophie? (Paris: Minuit).

Deleuze, Gilles, and Claire Parnet. 1987. Dialogues. Translated by Hugh Tomlinson and Barbara Habberjam. New York: Columbia University Press. First published 1977 as Dialogues (Paris: Flammarion).

Foucault, Michel. (1972) 2002. The Archaeology of Knowledge. Translated by A. M. Sheridan Smith. Abingdon, UK: 
Routledge. First published 1969 as L'archéologie du savoir (Paris: Gallimard). This translation first published 1972 (London: Tavistock).

. (1985) 1992. The Use of Pleasure: The History of Sexuality: Volume Two. Translated by Robert Hurley. London: Penguin. First published 1984 as Histoire de la sexualité: 2. L'usage des plaisirs (Paris: Gallimard). This translation first published 1985 (New York: Pantheon).

Hindrichs, Gunnar. 2004. "Musical Modernity: What Does it Mean Today?" In The Foundations of Contemporary Composition, edited by Claus-Steffen Mahnkopf, 133-51. Hofheim: Wolke.

Klee, Paul. 1948. On Modern Art. Translated by Paul Findlay. London: Faber and Faber. First published 1945 as Über die moderne Kunst (Bern: Bentelli), including an English translation by Douglas Cooper.

Lorca, Federico García. 1997. Lament for Ignacio Sánchez Mejias. Translated by Alan S. Trueblood. In Federico García Lorca: Selected Poems, edited by Christopher Maurer, 260-73. London: Penguin.
Lyotard, Jean-François. 1984. The Postmodern Condition: A Report on Knowledge. Translated by Geoff Bennington and Brian Massumi. Manchester: Manchester University Press. First published 1979 as $L$ a condition postmoderne: Rapport sur le savoir (Paris: Minuit).

Nancy, Jean-Luc. 2010. "Art Today." Translated by Charlotte Mandell. Journal of Visual Culture 9 (1): 91-99. First delivered as a lecture, Milan, 2006.

Nietzsche, Friedrich. 1997. "On the Uses and Disadvantages of History for Life." In Untimely Meditations, edited by Daniel Breazeale, translated by R. J. Hollingdale, 60-123. Cambridge: Cambridge University Press. Essay first published 1874 as "Vom Nutzen und Nachteil der Historie für das Leben," 2nd part of Unzeitgemässe Betrachtungen (Leipzig: Fritzsch, 1873-76).

Read, Herbert. 1948. Introduction to Klee 1948, [7]-[8].

Steinegger, Catherine. 2012. Pierre Boulez et le théâtre: De la Compagnie Renaud-Barrault à Patrice Chéreau. Wavre: Mardaga. 

Appendices 



\section{Beyond Urtext: A Dynamic Conception of Musical Editing}

\section{On Notation AND time}

When considering the musician's relation to notation in the Western music tradition, a fundamental distinction between two strongly connected but indeed different approaches should be made. On the one hand, there is the composer, who engenders a structure, which he or she encodes according to the codes of his or her own time and space; on the other hand, there is the performer, who decodes the message of the composer, rendering the structure that was given to him or her. The first approach deals mainly with writing, the second with reading. The first creates the bases for future performances; the second-while keeping the piece alive through different time/spaces—refers to and relies upon past compositions. The composer lives and works in a given historical time; the performer (and the listener) lives in a different environment, being surrounded by different rules and codes, which include specific performing codes as well as changeable listening expectations.

The time-space of the composition (time A) is historically fixed; the timespace of the performance/reception (time B) is movable. Consequently, time continuously expands between the two points. "Time B" tries to hold "time $\mathrm{A}$ " in its hands, but the relentless wind of history pushes it forward, creating a steady growing gap between them. "Time A" and "Time B" are connected by two chains. One is not notated; it is called "tradition" and aspires to guarantee a correct transmission of performance codes through dozens of generations, pretending to ignore not only that different times have different codes but also that any form of oral transmission unavoidably infects the original information with codes and perspectives inherent to its current time. The other chain is based on the composer's notation, and it is (arguably) supposed to be more independent of tradition. This chain tries to make the original signs and symbols comprehensible to the notational system of the performer, and it is called an "edition." It constitutes the element where both times (A and B) converge, which results in the most decisive communication between composer and performer happening via the score. Time $\mathrm{A}$ is fixed and Time $\mathrm{B}$ is movable; thus, to adequately fulfil the demands of Time $\mathrm{B}$, the score must also be movable (i.e., changeable), thus surpassing the once dominating illusion of a musical text that is definitive, perennial, exempt from doubts, and unquestionable. 
The present essay aims to bring to the foreground the complex issue of music editing, emphasising and deconstructing its historically rooted essence and placing it in the realm of history. Before considering such immaterial and/or subjective elements as "tradition," "analysis," "intuition," "mimesis," or even "performance," a thorough discussion of music "editions" is of primary importance for a deeper understanding of our musical heritage. In arguing that no edition - existing, projected, or future - can pretend to be definitive, this essay points toward a dynamic conception of musical editing. Inspired by the writings of James Grier (1996) and Peter Gülke (2006), this conception is based upon the idea that the editor and the performer are invested with an unavoidable authority over musical texts of the past, an authority they share with the composer. "Editing ... consists of series of choices, educated, critically informed choices; in short, the act of interpretation. Editing, moreover, consists of the interaction between the authority of the composer and the authority of the editor" (Grier 1996, 2). The significance of each musical sign depends on context and convention. When the historical moment of writing has passed, the specific context and ensemble of conventions at work at that time will change; new observers (editors, performers, and listeners) will use their own conventions to interpret signs and symbols. Moreover, as Adorno $(2006,4)$ suggests, the score needs "to be derived as a memorial trace of the ephemeral sound, not as a fixing of its lasting meaning." Beyond the urtext concept-meanwhile simply transformed into a commercial hallmark-another model is increasingly imposing itself: that of transitory historical-critical editions, where the editor and, moreover, the performer him- or herself have to make choices and take decisions. Such editions are simultaneously witnesses and makers of a new attitude towards music from the past, an attitude that creatively considers the historical relationship between composer and performer and that encourages performers and philologists to converge and work together. In this perspective, the innumerable editions of past music_originating in different times and spaces - might now be seen as a fascinating pile of debris: historical documents that are no longer in use, and are obviously dated, but that contain precious information on the entangled history of a given piece. Creatively wandering through different sources, sketches, autographs, and first prints, as well as through diverse pre-existing editions, might beneficially lead to new editions and new, challenging interpretations of "old" works. At this point, the surpassed but still active urtext concept should be briefly addressed.

\section{THE URTEXT ERA}

The first musical editions labelled urtexts date back to 1895 , when the Königliche Akademie der Künste Berlin published its Urtext-Ausgaben Classischer Musikwerke. These editions-inspired by nineteenth-century editions of literary, philosophical, or biblical texts-claimed to present a musical text free from editorial intervention, a "clean" text, with no performance instructions added by editors (as opposed to former musical editions, particularly of the second half of that century). Their original aim was praiseworthy, since they intended to present 
the composer's notation in "crude" state, letting it speak for itself, and allowing performers, especially students, to build up their own interpretations, free from predetermined aesthetical directions. However, two basic objections soon troubled this idyllic vision, indicating that urtext editions could not achieve what they purported to do. Günter Henle himself noted in 1954-on his statement on the term urtext - that sometimes an autograph and a first edition differ considerably, in which case the editor must decide what to print (Henle 1954, 379); in such cases, the text ceases to be an urtext and becomes the editor's interpretation of the available sources. On the other hand, Georg Feder stated in 1959 that urtext editions must be critical editions (Feder and Unverricht 1959), thus underlining the necessity of source studies and broader research and opening the door to future developments. But when an urtext edition is superseded by subsequent scholarship it is no longer an urtext. All these observations, among many others, underline the conclusion that urtext editions are not what they claim to be. They do not present "the composer's written text, but the editor's reconstruction of it" (Grier 1996, 11). The urtext concept also struggles with music prior to the late eighteenth century (there is no evidence that composers before this time were concerned whether autograph scores should be followed exactly or only in one specific way) and with the theory of the "Fassung letzter Hand" (which involves complex questions about when composers consider works to be complete). Moreover, few sources - even from the nineteenth century — can be transcribed into a modern notational system without editorial intervention. Therefore, the use of the word urtext in the context of musical editions is highly problematic, and its widespread usage during the twentieth century should be seen primarily as a time-bound editorial response to the abuses of several "interpretative editions" from the late nineteenth century.

\section{URtext editions: An epistemological obstacle}

Although urtext editions have been widely criticised by scholars for decades, they have kept an aura of authenticity and legitimacy among music pedagogues and performers that goes far beyond a mere phenomenon of marketing. Not always aware of the aesthetic or philosophical implications of their choices and decisions, many performers are victims of the mimetic illusion of an "intuitive" understanding of the score-ignoring that intuition is historically (and educationally) moulded. By considering urtext editions to be a valid counterweight to the interpretative editions of late Romanticism, music pedagogues and performing artists persist in ignoring the possibilities more recently offered by critical and digital editions. Therefore, urtext editions became de facto-and using Gaston Bachelard's famous notion - an epistemological obstacle: a thoughtless, unconscious, or simply comfortable structure, through which a community recognises important elements of identity, without noticing that such a structure no longer applies to the environment around them. According to Bachelard the history of science consisted in the formation and establishment of such epistemological obstacles, and then the subsequent tearing down of those obstacles. This latter stage is an epistemological rupture - where an unconscious obstacle to scientific thought is 
thoroughly ruptured or broken away from. Although such a rupture with the idea of an urtext is widespread among scholars (see Grier 1996; Fellerer 1980; Feder 1987; et al.), it is much less so among practitioners. The majority of musicians accept, uncritically, what they believe to be a "scientifically" thoroughly worked edition. Urtext editions supposedly responded both to a utilitarian conception (for performers, who wanted an easily readable text) and to scientific demands (where musicologists imposed high standards on critical apparatus and comments). These critical tools were useful and trustworthy, ensuring performers had a reliable text where "everything" was notated. The double task of, on the one hand, making the unavoidable provisional character of any given edition appear reasonable (apparently contradicting the scientific tenet of the whole critical project) and, on the other hand, stimulating performers to think and make decisions on their own is a difficult endeavour. In many different ways, urtext editions create a "commodity" for the user: if the written musical text is "scientifically" correct, the performer does not need to consider it in any depth; if the fingerings are, at least to a certain extent, the composer's originals (or suggested by an experienced editor), the reader trusts them, without exploring diverse fingerings; if there are conflicting readings, but the editor has decided which to print in the main text, there is no reason to read the critical notes and enter a world of doubt. In a nutshell: the survival of urtext editions might be understood to relate to convenience, to the aesthetical and technical security of traditional performers who don't want to revisit their aesthetical categories or reconsider their "universal" instrumental technique. Interest in new forms of editions and the acceptance of those editions by performers, therefore, relate to curiosity and a mental disposition that welcomes newness, which not all practitioners have. Finally, the process of getting rid of the urtext concept implies critical thinking, something that not all musicians consider a positive quality.

\section{Critical editing of MUSic And Different types of EDITIONS}

The present editorial landscape offers both scholars and performers a wide range of editions, from facsimile prints to complex and exhaustive critical editions. In modern practice, some basic assumptions have become fundamental to any serious edition. The first such assumption is that editing is a critical activity. Therefore, editions constitute interpretative endeavours and cannot claim to be definitive. Accordingly, no edition-existing, projected, or still to come-can pretend to be definitive. Different editors working on the same basic materials will unavoidably produce different editions; the same editor, working at different times, will also achieve different texts. As Philip Brett observed $(1988,111)$, "editing is principally a critical act; moreover it is one (like musical analysis) that begins from critically based assumptions and perceptions that usually go unacknowledged. If these assumptions were to be openly stated, if we began to recognize and allow for legitimate differences in editorial orientation, and if we ceased to use the word 'definitive' in relation to any edited text, then much of the polemics surrounding editing might subside.” 
Moreover, different repertories require different editorial methods, which shows that no universal method is applicable to every piece of music. Given that an edition always reproduces the historical relationship between composer, editor, and performer, an editor should immerse him- or herself in the stylistic, technical, and performing features of the composer's time-space, including the piece's rendering as a performance.

Currently, four basic types of editions are to be found: (1) photographic facsimiles; (2) printed editions that replicate the original notation; (3) interpretative editions; (4) critical editions (including the so-called Commented New Urtext Edition).

The photographic facsimile, strictly speaking, is not an "edition." It depicts one of the major sources of a given piece, providing immediate visual information and, therefore, strengthening the link to the composer's gesture of writing. Many nuances of the manual graphical representation that an edited text cannot represent become directly visible. In addition, facsimiles are generally easier to use than a composer's manuscripts and autographs. On the other hand, facsimiles are very often unsuitable for general reading since the handwriting may be legible only to a few specialists, as is the case with Beethoven, to give one example.

Printed replicas of original notation are a form of facsimile, using printed fonts instead of photographic images. Keeping Beethoven's case in mind, such editions turn a composer's sketches and autographs into legible sheets of music. Moreover, editors have the opportunity to incorporate some of their critical findings, including revisions and corrections to the text, making such editions a step towards critical editions. Therefore, editors include some kind of critical apparatus, explaining and giving insight into the decisions made.

Interpretative editions record aspects of important performer's performing styles. They transmit a kind of oral tradition and have an inevitable selfreferential (and self-legitimating) character-the editor (normally a famous performer) prints his or her own interpretative options and establishes them as canon. Such interpretative editions, particularly those of the late nineteenth century, motivated, in reaction, urtext editions. During the twentieth century (especially in the second half), the production of interpretative editions dwindled to a small number; however, recent developments in the urtext concept are reviving the tradition, even if these developments are limited to fingerings, bowings, and explicitly assumed personal opinions. This type of edition will probably always exist, since it records in written form significant aspects of the performing style of a given era. In doing so, it produces a complex artefact where inherited "tradition" and critical "editions" somehow melt together: "Great performers study with great teachers, who pass on insights into the meaning of the work from previous generations" (Grier 1996, 151). Given that increasingly more performers have a solid academic training (enabling them to become artist-researchers, who understand how to critically tackle different kinds of sources), such interpretative editions could very well regain a certain importance. 
Critical editions are defined by their basic intention of transmitting a text that more closely represents the historical evidence of their sources. This evidence is, however, open to interpretation and discussion, leading to different editions based upon the same sources. This aspect should not be understood as a problem, but rather as an enriching element in the fabric of music editing, which is an activity that, finally, remains in the field of human sciences. Such editions should aim for clarity of presentation, allowing immediate comprehension and coordination of the many disparate elements that are being communicated through the score. If too much information is given in the main printed text (the score to be more immediately read) the performer will be confused and, eventually, limited in his or her mimetic response to the score. Therefore, a balance between fidelity to what the editor retains as being essential to the music and ease of comprehension is of the utmost relevance. Furthermore, a detailed critical apparatus and individual readings or commentaries are highly desirable, for only they allow the performer to make informed choices. Finally, such editions should open a window to the performer's faculty of judgement, rather than exempting users from thinking and taking decisions for themselves. This aspect, once again, highlights that performers ought to be adventurous and open to novelty: "Critical editions should generate critical users" (Grier 1996, 181).

\section{Music EDITING AND PERFORMANCE PRACTICE: A DYNAMIC CONCEPTION}

The ideas on music editing exposed so far suggest a process by which the score is transformed from a static and fixed state to a state of permanent changeability. This conceptual shift leads to a new understanding of the roles of both editors and performers. According to Jerome McGann's (1983) theory of the work of art as a social phenomenon, every work is a social and historical artefact; this would include every edition of music. If it is difficult (if not impossible) to assert a final authorial intention, the process of editing changes from a psychological activity (where the editor ought to establish "the author's intentions") to a historical endeavour. At this point, the composer's authority comes face to face with two other forms of authority: that of the editor and that of the performer.

The editor's authority has traditionally been underestimated, neglected, or even considered illegitimate. "Music editors are often reluctant to assume authority over the texts they print, wishing to give the appearance that they present only the text of the composer. And so they rely, or appear to rely, on the sources themselves instead of acknowledging their own critical initiative. Nowhere is this tendency more transparent than in the Urtext industry, whose products purport to reproduce the 'original' text" (Grier 1996, 4). Different from the composer's text, the final edited text inevitably reflects the editor's conception of the piece as it existed in its ecological (historical and social) environment. The performer's authority involves more complex issues, particularly related to the concept of style, a category that directly influences the effect (and the judgement) of a given performance. Style, however, is not com- 
pletely extractable from the score, as it depends much more on the diversity of performing options that each work generates. "It is essential to incorporate the intermediary stage of performance into the concept of style because of the semiotic nature of musical notation" (Grier 1996, 29). But the authority of the performer does not only reside here; by placing the concept of music editing in the realm of history, the performer's role becomes that of a meta-reader of a musical text, facing and studying continuously changing visions of one single work.

An image taken from Walter Benjamin's “Theses on the Philosophy of History" might help us clarify this point. In his ninth thesis, Walter Benjamin uses imagery to express his concept of history. An angel-from Paul Klee's Angelus Novus - stares into the past, while a strong wind pushes him irremediably towards the future, which nevertheless he cannot see. He gazes into the past, terrified: "Where we perceive a chain of events, he sees one single catastrophe which keeps piling wreckage upon wreckage and hurls it in front of his feet" (Benjamin [1968] 1999, 249, my emphasis). He longs to piece together what has been smashed, but the storm blowing from Paradise is so strong that the angel can no longer close his wings. This Angelus Novus can be seen as the contemporary performer. The angel is the meta-reader of infinite musical texts. He looks into the "past" from where uncountable musical objects and things look back at him, hoping to be saved from oblivion. In addition to sketches and manuscripts, he sees another unending pile of debris: the innumerable musical editions originating in different times and spaces. The impossibility of looking at (predicting) the future or of returning to (incarnating) the past gives him no other choice than to creatively wander through all the ruins of the past, studying autographs and first edition prints, consulting other sources, comparing editions, playing period instruments, and, finally, confronting them all with his own contemporary condition, making decisions and moving beyond history and historicity. Inevitably, such decisions in one way or another will depict the historical relationship between the time of the performer and the time of the composer as it is understood in the time of the performer. That some of these decisions may contribute to new editions of a given piece is one possible consequence of this model of thought. "This succession of events demonstrates that editing music, far from being an exact science, presents, in fact, a moving target. As our knowledge of repertories and their sources deepens, and our critical appraisal of that knowledge continues, new editions are needed to keep pace with, and reflect, the latest developments" (Grier 1996, 9). Instead of rigidly insisting on the reification of a particular state of a work, this dynamic conception emphasises the process through which a musical work comes into being and thus requires creative performers whose intelligence and sensibility can contribute to a permanent renewal of the editorial landscape. Editions represent, therefore, nodal points on the continually changing path of musical scholarship and performance. Historically observed variations and differences in the written and performing traditions of a given piece make visible the limits of indeterminacy, without fixing them. Such limits will never be fixed because new performers will continue to challenge and redefine them. In this sense, the 


\section{Appendix 1}

act of communicating a piece to an audience becomes a fully relevant part of the creative process, entering a dialogue in which the context impinges on the final form and sense-making of a work.

\section{REFERENCES}

Adorno, Theodor W. 2006. Towards a Theory of Musical Reproduction: Notes, a Draft and Two Schemata. Edited by Henri Lonitz. Translated by Wieland Hoban. Cambridge: Polity. First published 2001 as $Z u$ einer Theorie der musikalischen Reproduktion: Aufzeichnungen, ein Entwurf und zwei Schemata (Frankfurt am Main: Suhrkamp).

Benjamin, Walter. (1968) 1999. “Theses on the Philosophy of History." In

Illuminations: Essays and Reflections, edited by Hannah Arendt, translated by Harry Zohn, 245-55. London: Pimlico. Essay first published 1950 as "Über den Begriff der Geschichte" (Neue Rundschau 61 [3]: 560-70). Book first published 1955 as Illuminationen: Ausgewählte Schriften (Frankfurt am Main: Suhrkamp). Translation first published 1968 (New York: Harcourt Brace Jovanovich).

Brett, Philip. 1988. "Text, Context, and the Early Music Editor." In Authenticity and Early Music: A Symposium, edited by Nicholas Kenyon, 83-114. Oxford: Oxford
University Press.

Feder, Georg. 1987. Musikphilologie: Eine Einführung in die musikalische Textkritik, Hermeneutik und Editionstechnik. Darmstadt: Wissenschaftliche Buchgesellschaft.

Feder, Georg, and Hubert Unverricht. 1959. "Urtext und Urtextausgaben." Die Musikforschung 12: 432-54.

Fellerer, Karl Gustav. 1980. "WerkEdition-Interpretation.” In Musik, Edition, Interpretation: Gedenkschrift Günter Henle, edited by Martin Bente, 180-92. Munich: Henle.

Grier, James. 1996. The Critical Editing of Music: History, Method, and Practice. Cambridge: Cambridge University Press.

Gülke, Peter. 2006. Auftakte-Nachspiele: Studien zur musikalischen Interpretation. Stuttgart: Metzler.

Henle, Günter. 1954. "Über die Herausgabe von Urtexten.” Musica 8: 377-8o.

McGann, Jerome J. 1983. The Romantic Ideology: A Critical Investigation. Chicago: University of Chicago Press. 


\title{
The Conditions of Creation and the Haecceity of Musical Material:
}

\author{
Philosophical-Aesthetic \\ Convergences between Helmut \\ Lachenmann and Gilles Deleuze
}

\begin{abstract}
Empiricism is by no means a reaction against concepts, nor a simple appeal to lived experience. On the contrary, it undertakes the most insane creation of concepts ever seen or heard. Empiricism is a mysticism and a mathematicism of concepts, but precisely one which treats the concept as object of an encounter, as a here-andnow, or rather as an Erewhon from which emerge inexhaustibly ever new, different distributed "heres" and "nows." (Deleuze 1994, xix)
\end{abstract}

Sound as something real and palpable, as a "natural phenomenon" taking place here and now, evokes a mode of listening previously excluded from the musical medium, or at least neglected in reflections upon it, which treats sound as a phenomenon of nature. (Lachenmann 2004, 64)

\section{Helmut lachenmann and Gilles Deleuze: AN UNCONNECTED CONNECTION}

Starting in 1966-67 with the radio conference "Klangtypen der Neuen Musik" on typology of sounds (see Lachenmann [1967] 1996), ${ }^{1}$ Helmut Lachenmann developed a complex set of concepts about art in general and music in particular that gave shape to an aesthetic methodology grounded in structural thinking (see Lachenmann 2004). Reflecting upon questions such as What is art?, What is composing?, What are the conditions of the musical material?, What are the political implications of art?, and How does art relate to society?, Lachenmann was able to build a theoretical framework based on three "theses on composing," four "conditions of the musical material," and five "types of sound." Such a framework is intended to be not a closed system of contemporary aesthetics

1 The radio conference was broadcast in spring 1967 (Westdeutscher Rundfunk, Cologne), but Lachenmann started working on the manuscript in 1966 (see Lachenmann 1996, 429). 
but a fundamental referential tool for the concrete practice of composingdefining Lachenmann's own route, and giving insight into his musique concrète instrumentale, a music that aims to liberate the energetic potential of concrete (immanent) sound bodies and processes.

Several aspects of Lachenmann's theories point to a unique understanding of the conditions of creation, and to an idea of the radical immanence of musical material that can be productively brought into dialogue with several of Gilles Deleuze's key concepts. Although references to Deleuze do not appear in Helmut Lachenmann's writings (see Lachenmann 1996), and although Lachenmann's name is not to be found in Deleuze's books, it is my aim to enable an encounter between Deleuze's extended ideas on the art, creation, and haecceity of material and elements of Lachenmann's aesthetic/compositional methodology. Thus, this text is not a hermeneutic essay on Deleuze's reflections on music, nor is it a mere exposition of Lachenmann's theoretical framework: it is an attempt to bring together, to produce an encounter between two thinkers who generated thoughts in an unnoticed neighbourhoodto realise an unconnected connection. To do this, I first emphasise the origins of Lachenmann's "aesthetic methodology," before entering into a dialogue between specific elements of such methodology and specific Deleuzian concepts. Through its discussion of philosophical and aesthetic convergences between a philosopher who wrote extensively on art and a composer with strong philosophical interests, this essay aims to contribute new understandings of art as philosophical practice.

\section{Helmut Lachenmann: toward an aesthetico- STRUCTURAL METHODOLOGY}

During the second half of the 196os, after studies with Luigi Nono in Venice (1958-60) and Karlheinz Stockhausen in Cologne (1963-65), Helmut Lachenmann became increasingly aware of $(1)$ the social implications and function of music and (2) the centrality of the processes of concrete listening. These focal points of thought led to a thorough and critical reflection on the conditions of the musical material. Instead of embracing an existing critical theory, Lachenmann thought for himself, even if he took some existing philosophies and aesthetic positions as starting reference points (such as those of Lukács, Marcuse, Benjamin, and Adorno); nevertheless, he developed them into a personal construction founded upon structural thinking: "I personally do not believe that one can do without structural thinking. However, structural thinking and its techniques must constantly be proved by confronting them with reality. They must lose themselves, find themselves, and define themselves anew. Music only has meaning when it points beyond its own structure to other structures and relationships-that is, to realities and possibilities around us and within us" (Lachenmann [1979] 1996, 62, my translation).

Crucially, Lachenmann was able to identify "tonal" categories in the experience and perception of music composed by the most extreme avant-garde composers of the post-Second World War generation. In 1970 he noticed that 
"the break with tonality-be it in the works of the Viennese atonal school, or in more recent serialist works-never really overthrew the tonal categories of perception, and the aesthetic consciousness attached to them [which functions as] as a last refuge for bourgeois thinking" (Lachenmann [1971] 1996a, 145, my translation). ${ }^{2}$ The avant-garde was suffering the consequences of the previous (tonal) use of musical materials and was incapable of liberating itself from these uses and materials. The composer's first task, thus, needed to be a thorough, critical, and uncompromising reflection on the basic materials of composition. From this perspective, radical reflection becomes the condition sine qua non for composing and art-making in general. In Lachenmann's formula: "Art [understood] as the result of a radical reflection on its own aesthetic means and categories of experience.... Art as the product and witness of thought; as the carrier of insecurity" ([1971] 1996b, 95, my translation).

For Lachenmann, art must be grounded in a clinical analysis of the material, an investigation that addresses both pre-existing layers (what he would call tonality and aura) and two more self-oriented ones (corporeity and structure). The proximity to Deleuze's clinical function of art ${ }^{3}$ is the first sign of a more profound vicinity of thought. For Lachenmann, purely constructive, additive ways of composing ("putting things together"), while they might generate coherent sound objects, do not convey any "existential experience"; on the other hand, a compositional strategy based on taking things apart, on an emancipated (and Deleuzian) becoming-minor, allows for the appearance of new connections and necessities: "If the act of composing is meant to go beyond the tautological use of pre-existing expressive forms and-as a creative act - to recall that human potential which grants man the dignity of a cognisant being, able to act on the basis of this cognition, then composition is by no means a 'putting together,' but rather a 'taking apart' and more: a confrontation with the interconnections and necessities of the musical substance" (Lachenmann [1979] 1996, 55).

It should be noted that, in using the word substance, Lachenmann doesn't propose any kind of transcendence, or a teleological purpose for artworks. On the contrary, he points to a radical immanence of sonic events, an immanence that becomes more and more significant as it increasingly breaks the sphere of the magic (which is understood as a summation of collective "irresistible" experiences).

Lachenmann's further development of his extended reflection on the magical or ritualistic origins of artworks and the conditions of creativity (starting in $1979^{4}$ ) culminated in his central claim that "art is a form of magic, broken in and with spirit" (Lachenmann 2004, 56), a formula that encapsulates and implies important conceptual elements related to the philosophies of Herbert Marcuse

2 "Der Bruch mit der Tonalität, sei es in den Werken der Wiener atonalen Schule, in den Werken der seriellen Epoche oder in jüngster Zeit, hat die tonalen Erfahrungskategorien und das daran gebundene ästhetische Bewusstsein als potentiellen Schlupfwinkel bürgerlichen Denkens nie wirklich außer Kraft setzen können."

3 For an extensive discussion on Deleuze's notion of the clinical function of art, see Sauvagnargues (2005, 39-58 [French]; 2013, 23-36 [English]).

4 On Lachenmann's notion of Magie (the magical), see Mosch (2009). 
(with his notion of beauty as the denial of habits), Georg Lukács (the complete man), Walter Benjamin (aura, magic), and Theodor W. Adorno (material, broken magic). Even if not a professional philosopher, Lachenmann's interest in philosophy has always been compelling, and his definitions, concepts, and theoretical tools reveal deep philosophical knowledge and an understanding of interconnections. To localise and clarify Lachenmann's references in detail would exceed the purposes of this article. Nevertheless, and before entering into a dialogue with the philosophy of Gilles Deleuze, five genetic elements of Lachenmann's approach must be clarified:

(1) Lachenmann's use of the term magic seems to derive from Walter Benjamin's definition in The Work of Art in the Age of Mechanical Reproduction, especially when Benjamin $(2008,13)$ postulates: "In primeval times, because of the absolute weight placed on its cultic value, the work of art became primarily an instrument of magic that was only subsequently, one might say, acknowledged to be a work of art." Moreover, this concept is developed and further differentiated in Theodor W. Adorno's Aesthetic Theory (1970 [see Adorno 1997]) and Georg Lukác's fragmentary Ästhetik (1972), books that Lachenmann read thoroughly (Mosch 2009, 86).

(2) The notion of "broken magic" (gebrochene Zauber) is indebted to Theodor W. Adorno, particularly his essay In Search of Wagner, in which Adorno writes: "Music, the most magical of all the arts, learns how to break the spell it casts over the characters" (Adorno [1981] 2005, 144).5

(3) As Lachenmann stated in 1987 ([1987] 1996, 346), the idea of "Beauty as the 'denial of habit"' (Lachenmann 2004, 56) is inspired by Herbert Marcuse's concept of Verweigerung (denial), extensively expressed in his books One-Dimensional Man (1964) and The Aesthetic Dimension: Toward a Critique of Marxist Aesthetics (1978).

(4) Lachenmann's reflection on the aural charge of the material follows Adorno's definition of material, in addition to Benjamin's and Lukács's concepts of aura.

(5) Finally, Lachenmann's foundational understanding of art as a place where the immanent potentiality of a general aesthetic means encounters an objective, concrete, and palpable reality is rooted in Georg Lukács's aesthetics-particularly in his concept of art as a message from the "complete man" ["Der ganze Mensch," "Der Mensch ganz"]. ${ }^{6}$ Reflecting upon the cultural and social conditions of the production of art, while keeping in mind its concrete practice, Helmut Lachenmann's aesthetic-structural

5 "Musik, die zauberischste aller Künste, lernt den Zauber brechen, den sie selber um alle ihre Gestalten legt" (Adorno [1952] 1971, 145).

6 Lachenmann is explicit about Lukács's impact on his own thought: "I have yet to find anywhere else a more comprehensive description of the relations between the immanent rules of the aesthetic medium and the objective reality ... as in the Aesthetics of Georg Lukács” (Lachenmann [1976] 1996b, 109, my translation; Eine umfassendere Beschreibung der Wechselwirkung von immanenten Gesetzen des ästhetischen Mediums und objektiver Wirklichkeit (der "Mensch ganz" im homogenen Medium ästhetischer Disziplinen gegenüber dem "ganzen Menschen" im vielseitig gefächerten existentiellen Alltag) habe ich bisher nirgendwo anders als in der Ästhetik von Georg Lukács gefunden). 
methodology constitutes a complex system of references that derive from the tension between cultural environment and inner experience. Such a tension shouldn't simply be perceived through listening; more importantly, it should be confronted and critically surmounted. On the one hand, one has to resist the numerous temptations of mass culture and, on the other hand, one must develop compositional tools, which-while referring to that culture-allow for a transformation of perception (see Hüppe 1996, 3). This transformation of perception is the fundamental goal of Lachenmann's music. His philosophical thoughts and considerations work solely as clarifiers, as lighthouses signalling dangerous cliffs on the way to new harbours. They also help break through the mystified (and petrified) cultural landscape around us, opening a horizon for change and the possibility of (cultural) liberation. Consonant with Herbert Marcuse, it seems that Lachenmann's programme aims to subvert dominant consciousness, ordinary experience. This programme latently involves a political dimension, since it stimulates the "emergence of another reason, another sensibility, which defy the rationality and sensibility incorporated in the dominant social institutions" (Marcuse 1978, 7). In the place of political pamphleteer activism or radical praxis (as Lachenmann saw in his teacher Luigi Nono), Lachenmann concentrates on the work of art as an autonomous work - converging again with Marcuse in that "the political potential of art lies only in its own aesthetic dimension" (ibid., xii).

Lachenmann's aesthetic-structural methodology is, therefore, more than a critical philosophical-aesthetic discourse; it is a way of escaping music in order to allow music to come into being. Far from being an abstract system, it contains extremely concrete and sound-related categories. It enabled Lachenmann to develop his musique concrète instrumentale, a music in which sound events are chosen and organised so that the manner in which they are generated is at least as important as the resultant acoustic qualities. In such a music, those qualities, such as timbre, volume, dynamics, and duration, do not produce sounds for their own sake but describe or denote the concrete situation: listening, you hear the conditions under which a sound- or noise-action is carried out, you hear what materials and energies are involved and what resistance is encountered. To understand better and to have some kind of control over those energies and resistances, Helmut Lachenmann devised three "theses" on composing, and four more analytical "conditions" of musical material. This essay will now concentrate on these elements, briefly describing each of them and entering a virtual dialogue with concomitant concepts by Gilles Deleuze.

\section{Helmut Lachenmann's three “theses” on composing}

In 1986, in an essay dedicated to Wolfgang Rihm with the title Über das Komponieren (About composing), Lachenmann ([1986] 1996, 73-82) presented three "fundamental observations" about the act of composing. These three observations, full of metaphorical qualities, were presented anew, in condensed form, during Lachenmann's lecture at the Orpheus Institute in Ghent, published as "Philosophy of Composition: Is There Such a Thing?" (2004). 
The first thesis $(\mathrm{T} 1)$ states that composing requires a thorough reflection upon music and its materials: "Composing means: reflecting upon music" (Lachenmann 2004, 56)." Such reflection is intended in the sense of searching, experimenting, and sensitising oneself to the preformations of listening and compositional resources, whether intellectually or intuitively controlled (ibid., 57). It concerns critical and structural thinking, since the material's potentiality is to be scrutinised and its historically charged preformations (aura) are to be investigated. Only when this reflection is made as part of concrete daily work does it allow a creative estrangement of the "familiar."

The second thesis $\left(\mathrm{T}_{2}\right)$ concerns immediate creative practice, following on from the previous understanding of sound as the "experience" of structures. T2 affirms that "composing means: building an instrument" (ibid., ${ }_{56}^{6}$ ). This thesis, which constitutes the central focus of Helmut Lachenmann's investigations, argues that it is necessary to establish a new system of categories in every single new work (ibid., 57). Lachenmann conceives the very essence of composing as the scanning or mapping of diverse possibilities that are drawn together by structural similarity or functional convergences. To compose is to find, discover, or invent such similarities and convergences. In so doing, the composer is "building" a new instrument. Moreover, it is crucial to remember T1: that every sound carries its specific "history," its "expressive" predeterminations and context. To overlook this aspect is to blindly ignore and violate the material.

Finally, Lachenmann insists that music-making is carried out not "to say" something but "to do" something. His third thesis $\left(\mathrm{T}_{3}\right)$ is that "composing does not mean 'letting oneself go, but rather 'letting oneself come"” (ibid., ${ }_{5}^{6}$ ). Beyond structural analysis and mechanisms of innovation, the expressive intuition is now addressed. With this third thesis, Lachenmann opens the door to freedom, to personal doubts and joys, to the passion of writing a score with all the risks and fears it might raise. But this also raises the possibility of change, of inner transformation and the realisation of oneself as a "whole man" (Marcuse 1964). Moreover, the idea of "letting oneself come" carries an erotic dimension, which Lachenmann doesn't evade: for him the encounter between creative will and sonic matter is an encounter full of fascination, passion, complementarities, joy, and happiness (Lachenmann [1986] 1996, 82).

\section{Gilles Deleuze's diagnostic function of aRt, CAPTURE OF FORCES, AND BODY WITHOUT ORGANS: FIRST convergences with Helmut Lachenmann}

Deleuze's references to art and to the phenomena of creation and creativity run through all his periods, but seem to be more intensely and consistently addressed in his last phase, particularly after Francis Bacon: The Logic of Sensation (1981 [see Deleuze 2003]). If his first period is dominated by philosophical and literary interpretation, and the second (marked by his collaboration with Félix Guattari) by discussions on semiotics, psychoanalysis, unconscious processes, and the political implications of thought, the third period is characterised by reflections on art, including a 1981 study on Francis Bacon (Deleuze 2003), two 
books, in 1983 and 1985, respectively, on cinema (Deleuze 1986, 1989), a 1988 study of the Baroque (Deleuze 1993), a 1993 collection of articles on literature (Deleuze 1997), and a final collaboration with Guattari first published in 1991 (Deleuze and Guattari 1994), where art is presented, together with philosophy and science, as one of "three great forms" of thought (ibid., 197). However, Deleuze never wrote a book on music, and even when he did write about music his reflections are more directed toward non-musical concepts (such as territory, refrain, striated space, and smooth space, among others) than to music itself. Nevertheless, many musicians recognise that diverse Deleuzian concepts have a strong potentiality to be articulated in strictly musical terms. Several composers (for example, Brian Ferneyhough and Bernhard Lang) have openly discussed reflecting on and using Deleuzian thoughts and ideas for composing. There seems to be a musical potentiality within Deleuze's philosophy that might be uncovered through setting up unexpected encounters with other domains and systems of thought. An example of one such unexpected encounter follows-an encounter with Helmut Lachenmann's theses on composing.

\subsection{The diagnostic function of art}

Lachenmann's first thesis (T1: "Composing means: reflecting upon music") permits a connection to Deleuze's "diagnostic function of art." For Deleuze, artists and philosophers are symptomatologists, "physicians of culture": "artists are clinicians, not with respect to their own case, nor even with respect to a case in general; rather, they are clinicians of civilization" (Deleuze 1990, 237). Artists are not only the experts who diagnose the pathologies of civilization; they become the operators that enable new constellations of forces to emerge. As Anne Sauvagnargues (2013, 74), referring to Deleuze's clinical understanding of art, observes: "The work of art, in its aesthetic function (the kind of sensation that it reveals), takes on an immediate critical value, because it transforms taste, but above all because it is directly inscribed into customs and modulates a real relation between the work and the social body, which simultaneously transforms the space of its reception and contributes to changing the status and position of the artist."

Inspired by Nietzsche, for whom all phenomena are signs or symptoms that reflect a certain state of forces, and by Spinoza, whose critique of signs revealed that art is not independent of systems of social domination, Deleuze comes to the central question of investigating how it is possible for forces to arrive at producing signs and forms. Without this reflection, it is impossible to study the power of affecting and of being affected by a given material. Here, Deleuze's diagnostic function of art meets Lachenmann's analytical scrutiny of the material. What Lachenmann affirms as the first foundational activity of a composer (reflecting upon the material) is only meaningful if the composer is capable of identifying the forces behind signs and forms. The mapping or active palpating of the sonic resources implies a diagnosis of the sonic resources' own conditions. In addition to identifying weak and strong elements in a given material, the composer's job is to unveil false securities and to reveal new forces, signs, and forms, which bring to light previously unnoticed qualities of the material. If, as Deleuze says, the essence of creation resides in facing and confronting 
chaos and in imposing a cutting plan of immanence, then the first step is to reflect upon, analyse, and diagnose the potential constitutive elements of such a plan. As for music, such an analysis is to be done through "the sense of searching, experimenting, sensitising oneself to the preformations of listening and of compositional resources, whether intellectually or intuitively controlled" (Lachenmann 2004, 57). The next step, the passage from symptomatology to the capture of forces, leads to Lachenmann's second thesis on composing.

\subsection{Capture of forces}

According to Deleuze, the making of art consists of the capture of forces. Many critics of Deleuze overlook the crucial differentiation that such forces do not exist in some kind of transcendental realm, from where they are extracted, but are generated by a radical immanence of the creative process. The idea of the capture of forces originated in Deleuze's extended understanding of Simondon's ecceité, Duns Scottus's haecceité, and Spinoza's theories on affection, before coming to a metaphorical formulation in the image of the Baroque fold. Briefly: the capture of forces is a gradual process through which intensity (latitude, energy) starts generating extension (longitude, matter), a process that occurs in the realms of artistic, philosophical, and scientific activities, in and through the concrete working out of artistic, philosophical, or scientific materials. The fold reveals the (un)folding process behind it. The entire process exists and takes place in terms of matter and of the radical immanence of material unfoldings-and not as the capture of transcendental categories. It concerns structure and the definition of longitudes, extended formulae or objects (percepts), which conversely start liberating sensitive stimuli (affects). Lachenmann's expression "to build an instrument" concerns the invention of such structures. They are not immediately artworks, but they appear after the reflective moment (diagnostic) and before the actual "doing" of the work. "To build an instrument" is to (virtually) organise the material to capture forces, to create a diagrammatic plane of composition that will allow concrete (actual) events to take place.

\subsection{Body without organs}

The term body without organs ( $\mathrm{BwO}$ ) first appeared in Deleuze's The Logic of Sense, in the context of the relation between thought and corporeity, between literature and madness (see Sauvagnargues 2005, 86); with Guattari, Deleuze subsequently refined the term in Anti-Oedipus and A Thousand Plateaus. Deleuze used the term for the last time in Francis Bacon: The Logic of Sensation, after which it became figure. It is important to note that the concept of $\mathrm{BwO}$ is slightly different in the works of Deleuze and of Guattari. While Guattari comes from the psychoanalytical world, considering the $\mathrm{BwO}$ in the light of processes of definition of identity and formation of the subject, Deleuze (coming from the world of literature, in this case, Artaud) considers it as physicality, as an indestructible wholeness capable of affecting and being affected by other bodies-without a central coordinating device commanding diverse organs. Furthermore, Deleuze also invokes German biologist August Weismann's theory of the germplasm in order to propose that the $\mathrm{BwO}$ "is always contemporary with and yet independent of its host organism" 
(see Message 2005, 32). Deleuze's notion of organism is that of a form, which moulds a body inside a predefined organisation.

If Lachenmann's structural organisation implied in T2 is understood as such a predefined organisation, as an organism potentially trying to control all its organs, then his third thesis ( $\mathrm{T}_{3}$ : "letting oneself come") can be connected to Deleuze's BwO. It is the moment where the intense corporeity of the composer comes into action, being contemporary with the structure, yet independent (and even contradictory) of it. One of Lachenmann's fundamental critiques of the classical period of integral serialism (the early 1950s) concerns a certain negation of this liberating element. Serialism's confidence in the given structures was so high that the body, the immanent corporeity of the writing process itself, was disregarded as subjective redundancy.

For Lachenmann, the definition of complex local situations has priority in relation to a hyper-structure (which he doesn't refuse)-a position opposed to those who carry a definition of details imposed by a superstructure located somewhere above. The difference is exactly the same as the difference between a body without organs (defined by an under-determined organ) and an organism determined by clearly defined organs. "In fact, the body without organs does not lack organs, it simply lacks the organism, that is, this particular organization of organs. The body without organs is thus defined by an indeterminate organ, whereas the organism is defined by determinate organs" (Deleuze 2003, 47 ). Thus, the $\mathrm{BwO}$ assumes two functions: (1) dealing with modes of bodily individuation before a centred organisation takes control, and (2) reflecting on the junction between art and body (taking the case of Artaud as a paradigmatic example). Both functions can be retraced in Lachenmann's music and writings. On the one hand, Lachenmann's third thesis functions as a liberator from and as a corrector of the (potentially) centralising second thesis; on the other hand, the metaphor of "letting oneself come" positively affirms the total connection between artistic structures, ideas, and materials and the idiosyncratic body of the composer. The satisfaction or the feeling of fulfilment that Lachenmann explicitly articulates in relation to his third thesis goes even further, pointing to a sexual connotation that opens the horizon for Guattari's post-Freudian concept of desiring machines.

Desire is one of the central terms in Deleuze and Guattari's Anti-Oedipus, where it has a positive, productive, and creative meaning. Instead of desire being a lack of something (as it is understood in classical psychoanalysis), Deleuze and Guattari propose a definition based on processes of experimentation on a plane of immanence. Desire is productive. Desire is projection into the future, not repressed unconscious analysis of the past. In the same terms, writing down a score is a moment of joy, of fascination, passion, and total commitment to oneself. Only such a fusion of reason, passion, and bodily, tactile experience can lead to a music full of energy and the radical immanence of sonic events. After the deterritorialisation operated within $\mathrm{T}_{1}$ and $\mathrm{T}_{2}, \mathrm{~T}_{3}$ offers a renewed and necessarily original reterritorialisation. That such a reterritorialisation establishes a critical tension with the territory (the aesthetic apparatus) is the condition for newness and futurity. 


\section{Helmut Lachenmann's four Conditions of the MUSICAL MATERIAL}

Lachenmann's fundamental concerns are perception and the conditions of perception; they are even more relevant to him than listening: "The concept of perception is more adventurous and more existential than that of listening" (Lachenmann 1995, 102). As a starting point, Lachenmann believes there is no such a thing as free, neutral, and unconditioned perception. On the contrary: every perception, every sounding event is charged with qualities before the composer even starts to use it. The idea of a completely free and independent work structure (as many composers proposed during the 1950s) is for Lachenmann utopian and unrealistic. As a result of his reflection on perception, in 1966 Lachenmann arrived at a first definition of four aspects that participate in the complex process of music perception.

Four aspects that participate in every sounding object come to the foreground. These aspects may be ignored by the composer (who sometimes must even ignore them), but their presence a priori and their inevitable affecting intensity might very well work against the composer's intentions-in which case, it is better to decide how and to what extent he or she wishes to integrate them in the work's final form (Lachenmann [1990] 1996b, 87-88).

These four aspects, which Lachenmann later called conditions of the material, build up a typology of conditions and were further systematised by him in several essays written between 1966 and 1990. They are understood as a synthesis of diverse socio-psychological aspects of the composer's activity, relating both to society and to the individual, revealing deeper relations between them. To Lachenmann, the degree to which a composer is individuated depends on his or her capacity to diagnose and reflect upon the material - even if that capacity appears at first as something intuitive that must later be analytically scrutinised. The four conditions establish a structural tool for such diagnosis and reflection. These four conditions of the musical material (CMM) are as follows (see Lachenmann 2004, 58):

(a) Tonality-almost a synonym of tradition and all its related categories and dialectics of consonance/dissonance, tonal/atonal, familiar/ unfamiliar, domestic/exotic, and so on

(b) Corporeity-the acoustical and physical experience of sound, its bodily expression, its energetic and immediately perceptible anatomy

(c) Structure-not to be confused with ordering or organising procedures, but rather the complex set of newly individuated systems, rules, laws, and temporally-articulated constellations; the experience of organisation and of disorganisation, construction and deconstruction

(d) Aura - the history of the material in wider, musical and extra-musical contexts, in all spheres of our social and cultural reality, of our conscious and unconscious awareness, our archetypal memory, both collective and individual 


\section{Gilles Deleuze's opinion, Corporeity, Fold, AND LATITUDE: FURTHER CONVERGENCES WITH HELMUT LACHENMANN}

\subsection{Against opinion}

Strikingly, Lachenmann's definition of his first condition of musical material (tonality) comes close to Pierre Bourdieu's habitus, a set of acquired schemata, sensibilities, dispositions, and tastes that are dependent on history and human memory. Tonality, understood as the whole complex of experiences related to inherited aesthetic conventions, has an emphatic character, because the experience of the tonal is associated with the idea of individual and social identity. In the same way that Bourdieu criticises those social theories that ignore such elements of structural dependency, Lachenmann objects to anybody who claims that he or she can work with music elements independently of their context, history, and memory. However, Lachenmann also criticises everyone who adheres, defends, and reinforces the acritical notion of a completely pre-determined structuration of elements, a notion that is implicit in the concept of habitus. That is, Lachenmann acknowledges the existence of an extended habitus (that he sometimes calls the monstrum of the aesthetic apparatus), but he conceives the role of the composer as a deconstructer, as a permanent challenger of that habitus. Claiming that there is no such a thing as an aesthetic habitus, or, on the contrary, blindly worshiping it, for Lachenmann are both limited ways of dealing with the responsibility inherent in art-making. According to Lachenmann, the relation to tradition, to the habitus, must be based on a dialectical confrontation, whereby the artwork identifies elements of the habitus in order to subvert them, generating a hiatus of perception-a moment of existential insecurity. Such dialectical confrontation shares some common features with Deleuze and Guattari's idea of lutter contre l'opinion - fighting against opinion. Deleuze and Guattari argue that by making an artwork one extracts something out of chaos: a percept and an affect. An artist's initial fight, therefore, is a struggle against chaos. But "another struggle develops and takes on more importance-the struggle against opinion, which claims to protect us from chaos itself" (Deleuze and Guattari 1994, 203). In a visual metaphor, Deleuze and Guattari quote a passage by D. H. Lawrence in which an umbrella is described (ibid., 203-4). ${ }^{7}$ Under this umbrella, various people are sheltered; they draw a firmament and write their conventions and opinions on its underside. It is the function of poets and artists to make a slit in the umbrella, to open the sight to the firmament-even if for just a short time, since imitators and commentators will soon repair the fissure, restating a state of "familiarity," that is, "tonality." Therefore, the artist's struggle is against the clichés of opinion: "The painter does not paint on an empty canvas, and neither does the writer write on a blank page; but the page or canvas is already so covered with preexisting, preestablished clichés that it is first necessary to erase, to clean,

7 This passage is taken from Lawrence's essay "Chaos in Poetry" (see Lawrence [1928] 1998). 
to flatten, even to shred, so as to let in a breath of air from the chaos that brings us the vision" (Deleuze and Guattari 1994, 204).

Art's struggle with chaos occurs in order to bring forth a vision that illuminates chaos for an instant, what Deleuze calls a sensation, a radical immanence of forces in a specific here-and-now. In a similar way, Lachenmann's dialectical confrontation with tonality aims at enabling a suspension of traditional perception by creating a sound-situation full of energy and bodily expression-a radical immanence of forces in a specific here-and-now.

Another Deleuzo-Guattarian concept that might relate to Lachenmann's tonality is the couple major-minor, expressed in detail in Kafka: Toward a Minor Literature (Deleuze and Guattari 1986). Deleuze and Guattari's notion of major refers to a broader system of imprisonment, domination, and normalisation of creative forces. Minoritarian forces are groupings of ever-changing single events (molecules) that escape the instances of control drawn above them by major systems. ${ }^{8}$ More than a question of quantity, of number, the major is essentially a question of power- the distinction between major and minor art being that between a power (pouvoir) of constants and a power (puissance) of variables. It implies, therefore, a political dimension and the use of a minor language puts the major language into flight. A minor language deterritorialises language and provides an intimate and immediate connection between the individual and the political. Lachenmann's tonality, Bourdieu's habitus, and Deleuze and Guattari's opinion and major systems seem to establish similar categories of power and domination, carrying potential for alienation and misuses. To critically confront power and domination, to fight against them, is Lachenmann's aesthetic position. Similarly to Kafka, who made a minor use of the German language, Lachenmann might be seen as a composer making a minor use of musical elements.

\subsection{Corporeality}

When Helmut Lachenmann focuses his discourse on the acoustical and physical experience of sound, on its bodily expression, its energetic and immediately perceptible anatomy, he addresses the corporeality of the production of music. Every element subjected to compositional treatment can be defined as an immediate stimulus conveyed through physical information: sounds are composed and performed as a result of direct, immediate, and concrete body actions. Such actions create a resistance against the aforementioned first condition of tonality. A glance at the physical, energetic, and immediately perceptible anatomy of sound events implies the exclusion of a mode of listening polished by tradition and habit. Every single body is unique and unpredictable. In terms of music, corporeality and the idiosyncrasy of the body force the material and the tradition to collide.

Corporeality has long been an important element in the conception of music, but it was traditionally understood as a vehicle, as an envelope for the tonal aspects to be conveyed. In Lachenmann's music, the body is no longer a vehicle

8 On the dualism major-minor, see Bouaniche (2007, 186-93). 
for the tonality. It is an energy-in-action that breaks the schemes of thought and perception of the major systems of opinion. The art-making body starts the concrete deconstruction of tonality, opinion, and habitus. Deleuze, following Spinoza, suggests that a body is primarily defined by its speeds and slownesses rather than its functions and forms. The body in its relation to its own internal milieu is capable of producing intensities, which will unfold into infinite affects. But that same body will reduce this infinity to a finite plane of immanence, risking a division in diverse bodies (becoming-schizoid) while allowing body and thought to come together to define the body without organs - a body independent of a centralising instance, an instrument of direct deterritorialisation.

\subsection{Reterritorialisation}

Lachenmann's structurality of sound (expressed in his third condition of the material) as a newly individuated product of systems, rules, laws, and temporally articulated constellations defines a process of reterritorialisation. If the moment of material analysis and the moment of corporeal investigation constitute moments of deterritorialisation, the decisive adventure of giving a structure to a complex set of sensually experienced sounds re-enters the sphere of the finite, of the executable, of a human horizon. Whether it is a new definition of old territories or a construction of fully new ones, in both cases it is a process that reterritorialises forces and energies. Such a process for Lachenmann isn't a mere organisation of acoustic events that would point to transcendence. On the contrary, by emphasising the energetic element carried out through bodily actions Lachenmann affirms the absolute immanence of his music-music as the permanent actualisation of virtual forces. The fundamental difference from transcendental conceptions of music lies in the fact that Lachenmann's conception involves the composer as much as the performer and the listener.

As the result of the unfolding of the structurality of sound, Lachenmann's third condition unveils a form that is defined through complex unfoldings of forces. These new formations of new territories aren't, therefore, based on mimesis or contestation of old musical formulae. They propose completely new ways of reorganising functions and regrouping sensations. Forms appear as conglomerates of relations-probably what Lachenmann calls a polyphony of configurations. They are but forces engendering forms as "becomings of forces."

\subsection{Latitude}

In “Memories of a Spinozist, II," Deleuze and Guattari (1987, 256-60) claim: “To every relation of movement and rest, speed and slowness grouping together an infinity of parts, there corresponds a degree of power. To the relations composing, decomposing, or modifying an individual there correspond intensities that affect it, augmenting or diminishing its power to act; these intensities come from external parts or from the individual's own parts" (ibid., 256). 
The degree of power (or the power to act) of a body is the crucial element of Deleuze's extended reflection on art as the capture of forces. Beyond the diagnostic function of art (against opinion), its corporeality and structured processes of reterritorialisation, art-making comes to its ultimate expression-the haecceity - in the modal aspect of qualitative degrees of power. To explore the movement and relations between material systems of signs and the immaterial ethical implications of art, Deleuze-inspired by Spinoza, and by the late medieval philosopher Nicholas Oresme9-makes use of two terms: latitude and longitude. In geophysics, latitude is an angular measurement ranging from $\mathrm{o}^{\circ}$ at the equator to $90^{\circ}$ at the poles. Longitude is another angular distance, measured east or west from a given meridian (normally Greenwich) to another one. The difference is obvious: where longitude is a pure abstraction concerning the measurement of space, latitude has a natural basis (the distance from the equator) and implies a qualitative change of state-temperature and climate vary dramatically with a change of latitude. Longitude concerns the development of something over time or space (extension), while latitude has to do with intensities, with varying degrees of power. "We call the latitude of a body the affects of which it is capable at a given degree of power, or rather within the limits of that degree. Latitude is made up of intensive parts falling under a capacity, and longitude of extensive parts falling under a relation" (Deleuze and Guattari 1987, 256-57).

On the one hand, longitude deals with extension (relations, speeds, and structures) while latitude deals with intensity (power, potentiality, affects); on the other hand, Deleuze uses these highly elaborated concepts as a means to propose a relation between signs (extension) and ethics (intention), between palpable materiality and ungraspable force. Force is the condition of sensation, and sensation is a relation of forces producing an image: percept and affect. "This is why art is a capture of forces. A force must act upon a body in order for sensation to exist," as Sauvagnargues $(2013,142)$ has formulated. To return to an example we discussed in the introduction: the "extension" horse might have two completely different intensities, according to whether it is a racehorse or a workhorse. As Deleuze stated $(1988,124)$ : “There are greater differences between a plow horse or draft horse and a racehorse than between an ox and a plow horse. This is because the racehorse and the plow horse do not have the same affects nor the same capacity for being affected; the plow horse has affects in common rather with the ox."

The difficulty for art is how to distinguish the racehorse from the workhorse before seeing them in action. Lachenmann's third condition of musical material (structurality, i.e., extension) helps create a basic context for the artwork but it is only through the scrutiny of its inherent auratic potential that the artist has a window to feel its intensity.

9 Nicholas Oresme is mentioned by Deleuze and Guattari in a footnote to the tenth plateau of $A$ Thousand Plateaus $(1987,540$ 29). It is only through this indication that the reader learns that the theologian recalled in the sub-plateau "Memories of a Theologian" (ibid., 252-53) is Nicholas Oresme (1320-82), whose work Deleuze and Guattari knew from Pierre Duhem's encyclopaedic work, Le système du monde (1913-59), especially vols 7-9 (see Deleuze and Guattari 1987, 540n29). 


\title{
7. THE CONDITIONS OF CREATION AND THE HAECCEITY OF MUSICAL MATERIAL: A PHILOSOPHICAL-AESTHETIC EREWHON
}

\begin{abstract}
Life alone creates such zones where living beings whirl around, and only art can reach and penetrate them in its enterprise of co-creation. This is because from the moment that the material passes into sensation, as in a Rodin sculpture, art itself lives on these zones of indetermination. They are blocs. (Deleuze and Guattari 1994, 173)
\end{abstract}

According to Deleuze and Guattari, "philosophy is the art of forming, inventing, and fabricating concepts" (ibid., 2), while science and art are the inventors of functives and images (percepts and affects). The power of invention, of creation, is therefore one of Deleuze's fundamental themes, and in the final sections of What Is Philosophy? the question of the conditions of creation in philosophy, science, and art is openly discussed. Following Deleuze and Guattari (1994, 201-218), these conditions are: (a) a struggle against "opinion" (206); the promotion of a receptor still to be born ("un peuple à venir" ["the people to come"], 218); and (c) the extraction of something out of chaos (see 208).

For Deleuze and Guattari $(1994,197)$, "what defines thought in its three great forms - art, science, and philosophy — is always confronting chaos, laying out a plane, throwing a plane over chaos." However, this confrontation is made difficult by an innumerable amount of clichés and triteness, small truths that give shape to opinion. And it is against opinion that Deleuze and Guattari $(1994,206)$ first speak: "We ... come back to a conclusion to which art led us: the struggle against chaos is only the instrument of a more profound struggle against opinion, for the misfortune of people comes from opinion." Both Deleuze's opinion and Lachenmann's tonality are systems of domination and repression. They not only censure creativity, they also stimulate the proliferation of empty words, of repetitive messages, so that the status quo stays untouched. The struggle against opinion, the critical structural reflection upon the materials of music is, therefore, a first condition of creativity.

As a result of this first condition, the work of philosophers, scientists, or artists will always start by revealing forces, energies, and matter that were not previously known or noticed. Looking beyond recognition, they will write, formulate, or compose works that will only be understood by a receiver still to come: "For the new ... calls forth forces in thought which are not the forces of recognition, today or tomorrow, but the powers of a completely other model, from an unrecognised and unrecognisable terra incognita" (Deleuze 1968, 177, as translated in Deleuze 1994, 136).

The intensity of the newly created object finds its equivalent in the initial incomprehension of the spectator. Artistic creations challenge dominant opinion and do not look for consensus. That's why they steadily address a new audience, and are unconcerned with fulfilling pre-existent expectations of an empirically formed community. "There is no work of art that does not call on a people who does not yet exist," said Deleuze in his famous lecture on the creative act in cinema $(2007,324)$. But this "people still to come" does not belong 
to the future, whether near or far-what is meant are spectators from another temporality, from another perceptual universe, who the artist touches in the precise moment of creation, even if in an unarticulated way: "Through having reached the percept as 'the sacred source,' through having seen Life in the living or the Living in the lived, the novelist or painter returns breathless and with bloodshot eyes" (Deleuze and Guattari 1994, 172).

Lachenmann's critical and structural struggle against a pseudo natural habit ${ }^{10}$ of artistic experiences and perception builds another bridge to Deleuze's philosophy of art. Chaos as the excess of speed and opinion as the excess of redundancy always offer us false security, captious arguments not to abandon them, not to abandon home, not to abandon language, not to abandon tradition, not to abandon "tonality, not to abandon oneself. But without abandoning oneself, without abandoning our world and entering new universes of perception, is there any art at work?

Confronting chaos and opinion is exactly what Lachenmann does when he builds an instrument, defines a structure, critically listens to the preformations, and reflects upon the material-and even more when he "lets himself come" in the form of a score, the place where his philosophy on "composition and the idea of retrieving the concept of art with reference to society, its 'occidentally'-based restrictions, and not least the human need for self-realisation through the creative process" ${ }^{11}$ more deeply reveals itself. To make music is not "to say" something, but rather "to do" something. This "to do" is Deleuze and Guattari's extraction of something out of chaos-a concept in philosophy, a function in science, an image (percept and affect) in the arts.

Beyond all the philosophical-aesthetic arguments presented so far, but as their consequence, Lachenmann's music is existentially energetic, revealing a fundamental corporeality that is present in the moment of composition, as well as in that of the performance and perception. Between a quasitranscendence of elaborated structures (such as time grids, complex pitch sequences, sound families, and polyphony of dispositions) and the extreme physicality of the sound production, it is the energetic concreteness of every single event that carries the attention, revealing an immanent mode of perception. Lachenmann's music is not to be heard sound after sound-it is to be perceived with the whole body ("the whole man") in all its energetically rhythmical power. Much has been written on the rich array of diverse sound production techniques in Lachenmann's music. Much less has been said about the fundamental importance of rhythm and rhythmicality to this music. The sumptuous richness of indications concerning how to produce a given sound leads to a

10 Lachenmann's reflections on habit are situated within his particular definition of beauty, which he defines as "an offer to break free from all security" (Lachenmann 2004, 56). For him, beauty is understood as " 'the denial of habit' . . . insofar as the term 'habit' encompasses the idea of ( . . comfortably? thoughtlessly? safely? unemancipatedly?) 'dwelling'” (ibid., 56).

11 As stated by Lachenmann $(2004,55)$, this quotation was intended as the original title for his seminar at the Orpheus Institute Ghent, later changed to and published as "Philosophy of Composition: Is There Such a Thing?" (Lachenmann 2004). 
certain disdain for its rhythmical qualities. However, these are of the utmost relevance, since without them the entire point is missed: Lachenmann's music happens here-and-now, in an existential Erewhon. It is a combination of forms and matter, giving shape to a becoming of forces, to the emergence of sensations from a radical concreteness of sound and sound production. Establishing relations between movement and rest, between molecules of sound graspable by the body, Lachenmann's music liberates capacities to affect and be affected. Beyond molar elements virtually present in the work's meta-structures, it is the molecular agitation of sonic events that gives life to his music. More than a plane of consistency, it creates a composition of haecceities. "The entire assemblage in its individuated aggregate ... is a haecceity; it is this assemblage that is defined by a longitude and a latitude, by speeds and affects, independently of forms and subjects, which belong to another plane" (Deleuze and Guattari 1987, 262).

With the concept of haecceity, Deleuze and Guattari opened new avenues to the understanding of art. Focusing the discourse on the here-and-now of the effective capture of forces, they relegated hermeneutics, interpretation, and analysis to a second plane. The radical capture of forces in an irreducible Erewhon renders obsolete the quest for the author's intentions (hermeneutics), the imaginary games of interpretation, and the knowledge of the work's internal structure (analysis). With the capture of forces and its implicit relation between form and matter, between sign and potentiality, a completely new mode of perception became possible. More than a classification of experiences, what now gains momentum is the capture of becomings happening in real time. While perceiving the longitude of the artwork (its signs and markings), it is within the latitude that a new ethic of affection is captured. The concrete and radically immanent energy of sound events in Lachenmann's music gives it the quality of an intense existential experience. The effect of this music is not reducible to its structural dimension. It argues for a semiotics of the moment, of the erewhon, of the haecceity - a true logic of sensation.

Helmut Lachenmann and Gilles Deleuze share the idea that thinking is not a natural exercise but always a second power of thought, born under the constraint of experience as a material power, a force. Lachenmann developed a conception of music as existential experience while Deleuze developed a sumptuous philosophy of transcendental empiricism. In this essay, I have brought them together through diverse encounters between concepts and theories, but particularly through the concept of haecceity, a concept derived from Dons Scotus's haec, "this thing." In my view, the radical thingness of Deleuze's philosophy and Lachenmann's music allow for new modes of perception, sensation, and thought. This points towards a radical immanence of things in the world and of the world itself. It is this crucial aspect that makes the encounter between these two thinkers offered in this appendix so rich in potential consequences for artistic research. 


\section{REFERENCES}

Adorno, Theodor W. (1952) 1971. Versuch über Wagner. In Die musikalischen Monographien, edited by Gretel Adorno and Rolf Tiedemann, vol. 13 of Gesammelte Schriften, 7-148. Frankfurt am Main: Suhrkamp. First published $195^{2}$ (Frankfurt am Main: Suhrkamp). - (1981) 2005. In Search of Wagner. Translated by Rodney Livingstone. London: Verso. For further bibliographic information, see Adorno (1952) 1971. This translation first published 1981 (London: Verso).

1997. Aesthetic Theory. Translated by Robert Hullot-Kentor. Minneapolis: University of Minnesota Press. First published 1970 as Ästhetische Theorie: Gesammelte Schriften 7, edited by Gretel Adorno and Rolf Tiedemann (Frankfurt am Main: Suhrkamp).

Benjamin, Walter. 2008. The Work of Art in the Age of Mechanical Reproduction. Translated by J. A. Underwood. London: Penguin Books. First published 1936 as "L'œuvre d'art à l'époque de sa reproduction mécanisée" (Zeitschrift für Sozialforschung 5 [1]: 40-68).

Bouaniche, Arnaud. 2007. Gilles Deleuze, une introduction. Paris: Pocket.

Deleuze, Gilles. 1986. Cinema 1: The Movement Image. Translated by Hugh Tomlinson and Barbara Habberjam. Minneapolis: University of Minnesota Press. First published 1983 as Cinéma 1: L'imagemouvement (Paris: Minuit).

. 1988. Spinoza: Practical Philosophy.

Translated by Robert Hurley. San

Francisco: City Lights. First published 1970 as Spinoza (Paris: Presses universitaires de France), revised 1981 as Spinoza: Philosophie pratique (Paris: Minuit). .1989. Cinema 2: The Time Image. Translated by Hugh Tomlinson and Robert Galeta. Minneapolis: University of Minnesota Press. First published 1985 as Cinéma 2: L'image-temps (Paris: Minuit). . 1990. The Logic of Sense. Translated by Mark Lester with Charles Stivale. Edited by Constantin V. Boundas. New York: Columbia University Press. First published 1969 as Logique du sens (Paris: Minuit).

-1993. The Fold: Leibniz and the Baroque.
Translated by Tom Conley. Minneapolis: University of Minnesota Press. First published 1988 as Le Pli: Leibniz et le Baroque (Paris: Minuit). - 1994. Difference and Repetition. Translated by Paul Patton. New York: Columbia University Press. First published 1968 as Différence et répétition (Paris: Presses universitaires de France). -1997. Essays Critical and Clinical. Translated by Daniel W. Smith and Michael A. Greco. Minneapolis: University of Minnesota Press. First published 1993 as Critique et Clinique (Paris: Minuit). . 2003. Francis Bacon: The Logic of Sensation. Translated by Daniel W. Smith. London: Continuum. First published 1981 as Francis Bacon: Logique de la sensation (Paris: Éditions de la Différence). - 2007. "What Is the Creative Act?" In Two Regimes of Madness: Texts and Interviews 1975-1995, edited by David Lapoujade, translated by Ames Hodges and Mike Taormina, 312-24. New York: Semiotext(e). Chapter first delivered 1987 as a lecture (FEMIS film school), distributed on video as Qu'est-ce que l'acte de création? Book first published 2003 as Deux régimes de fous: Textes et entretiens 1975-1995, edited by David Lapoujade (Paris: Minuit).

Deleuze, Gilles, and Félix Guattari. 1986. Kafka: Toward a Minor Literature. Translated by Dana Polan. Minneapolis: University of Minnesota Press. First published 1975 as Kafka: Pour une littérature mineure (Paris: Minuit). . 1987. A Thousand Plateaus: Capitalism and Schizophrenia. Translated by Brian Massumi. Minneapolis: University of Minnesota Press. First published 1980 as Mille plateaux (Paris: Minuit).

. 1994. What Is Philosophy? Translated by Hugh Tomlinson and Graham Burchell. New York: Columbia University Press. First published 1991 as Qu'est-ce que la philosophie? (Paris: Minuit).

Duhem, Pierre. 1913-59. Le système du monde: Histoire des doctrine cosmologiques de Platon à Copernic. 10 vols. Paris: A. Hermann.

Hüppe, Eberhard. 1996. "Helmut Lachenmann." In Komponisten der 
Gegenwart, Neue Auflage 10 (3). Munich: Edition Text + Kritik.

Lachenmann, Helmut. (1967) 1996. "Klangtypen der Neuen Musik." In Lachenmann 1996, 1-20. First broadcast spring 1967 as "Klangtypen der Neuen Musik” (Westdeutscher Rundfunk Köln). First published 1970 as "Klangtypen der Neuen Musik," Zeitschrift für Musiktheorie, edited by Karl Michael Komma and Peter Rummenhöller (Stuttgart: Ichthys), 20-30.

_. (1971) 1996a. "Werkstatt-Gespräch mit Ursula Stürzbecher.” In Lachenmann 1996, 145-52. First published 1971 in Ursula Stürzbecher, Werkstattgespräche mit Komponisten (Cologne: Gerig), 95-105. - (1971) 1996b. "Zum Verhältnis

Kompositionstechnik-

Gesellschaftlicher Standort." In

Lachenmann 1996, 93-97. First delivered as a speech, November 1971 (First International Symposium for Music Theory, Stuttgart). First published 1972 in Bericht über den 1. Internationalen Kongress für Musiktheorie, Stuttgart, 1971, edited by Peter Rummenhöller, Friedrich Christoph Reininghaus, and Jürgen Habakuk Traber (Cologne: Ichthys), 28-39.

. (1979) 1996. "Vier

Grundbestimmungen des Musikhörens.” In Lachenmann 1996, 54-62. First presented as a speech 20 February 1979 (Musikhochschule Stuttgart). First published 1980 in Neuland: Ansätze zur Musik der Gegenwart, Bd. 1, edited by Herbert Henck (Cologne: Neuland Musikverlag), 66-74. . (1986) 1996. "Über das

Komponieren.” In Lachenmann 1996, 73-82. First delivered as a speech 30 June 1986 (Hochschule der Künste Berlin). First published 1986 (MusikTexte 16: 9-14). - (1987) 1996. "Komponieren

im Schatten von Darmstadt.” In Lachenmann 1996, 342-50. First given as the lecture "La situazione della musica in Germania dopo Darmstadt," 11 June 1987 (San Felice, Italy). First published 1988 (in a reduced version) in Musique pure dans un siècle sale / New Music Darmstadt 1950-1960, edited by Friedrich Hommel and Wilhelm Schlüter (Darmstadt: Internationales Musikinstitut
Darmstadt).

.1995. “On Structuralism.”
Contemporary Music Review 12 (1): 93-102.
Revised and extended version of a lecture
first delivered 17 October 1989 in Oslo
(Nordlyd Festival). First published 1990
as “Über Strukturalismus” (MusikTexte
36 [October]: 18-23). Republished
in German as “Zum Problem des
Strukturalismus" in Lachenmann 1996,
83-92.
Schriften 1966-1995. Edited by Josef
Häusler. Wiesbaden: Breitkopf und
Härtel.
. 2004. "Philosophy of Composition: Is There Such a Thing?” In Identity and Difference: Essays on Music, Language and Time, edited by Frank Agsteribbe, Sylvester Beelaert, Peter Dejans, and Jeroen D'hoe, $55^{-70}$. Collected Writings of the Orpheus Institute. Leuven: Leuven University Press.

Lawrence, D. H. (1928) 1998. "Chaos in Poetry." In D. H. Lawrence: Selected Critical Writing, edited by Michael Herbert, 234-42. Oxford: Oxford University Press. Essay written 1928, first published 1929 (Échanges, December).

Lukács, György. 1972. Ästhetik in vier Teilen: Erster Teil. Neuwied: Luchterhand.

Marcuse, Herbert. 1964. One-Dimensional Man: Studies in the Ideology of Advanced Industrial Society. London: Routledge \& Kegan Paul. . 1978. The Aesthetic Dimension: Toward a Critique of Marxist Aesthetics. English version translated and revised by Herbert Marcuse and Erica Sherover. Boston: Beacon Press. First published 1977 as Die Permanenz der Kunst: Wider eine bestimmte Marxistische Ästhetik (Munich: Hanser).

Message, Kylie. 2005. "Body without Organs." In The Deleuze Dictionary, edited by Adrian Parr, 32-34. New York: Columbia University Press.

Mosch, Ulrich. 2009. "Kunst als vom Geist beherrschte Magie: Zu einem Aspekt von Helmut Lachenmanns Musikbegriff." In Helmut Lachenmann, edited by Ulrich Tadday, 79-96. Musik-Konzepte 146. Munich: Edition Text + Kritik.

Sauvagnargues, Anne. 2005. Deleuze et l'art. Paris: Presses universitaires de France. Translated by Samantha Bankston as 


\section{Appendix 2}

Sauvagnargues 2013 .

. 2013. Deleuze and Art. Translated by Samantha Bankston. London:
Bloomsbury. First published as Sauvagnargues 2005 . 


\section{Acknowledgements}

As an outcome of an international, five-year-long research programme, this book could not have been written without the help of a significant number of people, including team members of MusicExperiment21, colleagues and personnel from the Orpheus Institute, invited artists and scholars, musicians and ensembles that collaborated in the performances of MusicExperiment21, audience members of several performances and lectures of mine throughout Europe, and anonymous reviewers of draft versions of parts of this book, as well as my closest friends and family.

First, I wish to warmly thank all team members, present and past, of MusicExperiment21 for their invaluable contributions to the daily work, brainstorming sessions, writings, rehearsals, and performances done in the last five years. They contributed decisively to the results obtained and have been co-creators of most of them. Michael Schwab has been an extraordinary critical voice, raising pertinent questions while constantly challenging the team to be more precise, specific, and articulated. In addition to the publication of two books (Experimental Systems, 2013; Transpositions, 2018) and several articles, he actively participated as a performer in the project on the music of Friedrich Nietzsche. Lucia D'Errico, who entered the project as a doctoral student (via an extremely competitive international call for a doctoral position), rapidly became a crucial element in all the project's creative developments, including in her roles as guitarist, composer, musical operator, electronic sound expert, graphic designer, and, last but not least, as a profoundly inspired writer of scholarly texts with poetic qualities. She not only completed her PhD trajectory in a record time of three years, but also massively contributed to several publications and performances from the project, offering intelligent feedback and sensitive criticism. With Paolo Giudici the project found the most sophisticated conference organiser, coordinating the highly complex project's conferences with unsurpassable professionalism and dedication. In his double capacity of photographer and philosopher, he contributed to the design of several publications, and co-edited with me a double volume on artistic research and the philosophy of Gilles Deleuze (The Dark Precursor, 2017). Juan Parra Cancino has been the grounding structure of all music technologyrelated projects and outputs; incredibly pragmatic and with a rare sense of the possible and the feasible, he helped us all to keep focus and direction in the staged performances of the project. Additionally, he authored subprojects on the music of Bruno Maderna and Karlheinz Stockhausen. A leading expert in Arnold Schoenberg's music, Jan Michiels designed an ambitious subproject on Schoenberg's music, contributing his encyclopaedic pianistic knowledge to MusicExperiment21. Moreover, he played Luigi Nono's piano pieces for the $\mathrm{CD}$ co-produced by the Viennese record label Kairos and MusicExperiment21, one of the major outputs of the project. I also wish to express my gratitude to former team members, including Darla Crispin, who provided feedback at the proposal stage of the project, the late Bob Gilmore (1961-2015), gone far 
too soon, for his inspirational work on enharmonic composers such as Nicola Vicentino, and Valentin Gloor for his commitment and participation in recordings and performances. Furthermore, I am grateful to the many other artists and scholars who actively collaborated with MusicExperiment21 on particular occasions, including Bobby Mitchell, Gerhard Schabel, Gilles Anquez, Heloisa Amaral, Jan Schacher, João Rafael, Johan Petri, Kai Köpp, Kurt Dreyer, Marlene Monteiro Freitas, Marlies De Munck, Mieko Kanno, Richard Bevan, Tamsin Clark, Thomas Heiber, and Veerle Spronck.

Next, I am deeply indebted to all my colleagues at the Orpheus Institute. They offered me feedback, criticism, and encouragement in a well-tempered balance that situated MusicExperiment21 as a team within a broader team. In the general assemblies of the Orpheus Research Centre we could discuss projects and ideas, while in the institute's dining hall and kitchen we have had excellent lunches and dinners, breaking the formality of a research environment. Without further details, I wish to thank all of them: Anna Scott, Anne Douglas, Bart Vanhecke, Catherine Laws, David Gorton, Einar Torfi Einarsson, Ellie Nimeroski, Hans Roels, Jonathan Impett, Joost Vanmaele, Kathleen Coessens, Luk Vaes, Michael Pecak, Nico Couck, Nicolas Collins, Seth Josel, Stefan Östersjö, Tiziano Manca, Tom Beghin, and William Brooks.

In addition to my colleagues at the Orpheus Institute, I received important support, practical recommendations, and research advice from the Orpheus Institute's Research Advisory Council. I wish to express my gratitude to its members, Jo Bury, Dame Janet Ritterman, Gertrud Sandqvist, and Andreas De Leenheer. Not a direct member of the Orpheus Institute, but a person with the highest commitment to and engagement with the institute's life, Frans de Ruiter has been a continuous supporter of my work, always endorsing it, and providing stimulating input. I am deeply grateful for that and for his personal friendship.

In the course of the project, a dozen study days, four Orpheus Academies, and two international conferences on Deleuze and Artistic Research (DARE 2015 and 2017) have been organised by MusicExperiment21. The invited lecturers and keynote speakers always provided feedback and responses to the team's activities, contributing to the overall discourse in very concrete terms. Lydia Goehr participated in two Academies and two study days, having published two essays in our publications. Given the centrality of her work to the starting assumptions of MusicExperiment21, and with hindsight of her active engagement during its realisation, I feel particularly grateful and intellectually indebted to her. The same is true of Hans-Jörg Rheinberger, whose work was fundamental to us, and whose visits to the Orpheus Institute fostered a strong personal link of admiration and friendship, while with Zsuzsa Baross I discovered a communion of artistic interests and philosophical passions.

From the music and musicological camp, particularly in relation to the Orpheus Academies 2012, 2013, 2016, and 2017, which were organised by MusicExperiment21, I am grateful for the feedback provided by Andreas Dorschel, Babette Babich, Bernhard Lang, Chaya Czernowin, David Davies, Edward Campbell, Felix Diergarten, Frederic Rzewski, Gunnar Hindrichs, 


\section{Acknowledgements}

Heiner Goebbels, Hermann Danuser, Lawrence Kramer, Richard Taruskin, Thomas Christensen, Daniel Leech-Wilkinson, and particularly John Rink, who invited me for public lectures and a masterclass at the Guildhall School of Music \& Drama in London and at the University of Cambridge.

Through the creation of the DARE conferences, I had the opportunity to meet and discuss topics on the relations between art, artistic research, contemporary art, and philosophy with major thinkers from different traditions of thought. I am most grateful to all of them for their time and interest in discussing these matters with me and my team. These thinkers included Anne Sauvagnargues, Barbara Bolt, Bracha L. Ettinger, Éric Alliez, Erin Manning, jan jagodzisnki, Jean-Marc Chouvel, Martin R. Scherzinger, Mick Wilson, Peter Osborne, Peter Stamer, Ronald Bogue, and Simon O'Sullivan. I am particularly thankful to David Savat and Ian Buchanan, for the diverse conversations we had on the notion of "assemblage," for their intellectual generosity, and for their openness to artistic research.

In order to realise the artistic outputs of the project, MusicExperiment 21 created its own ME21 Collective, but there were additional international collaborations with leading ensembles and musicians, such as the WDR Symphony Orchestra Cologne with conductors Peter Rundel and Leo Warinsky, and artistic director Harry Vogt; the Hermes Ensemble Antwerpen, managed by Kevin Voets, with performers Gaetan La Mela, Geert Callaert, Karin De Fleyt, Lena La Mela, Marc Tooten, Peter Merckx, and Stijn Saveniers; and Ensemble Interface (Frankfurt), with Agnieszka Koprowska-Born, Andrea Nagy, Anna D’Errico, Bettina Berger, Christophe Mathias, Marieke Berendsen, Niels Hap, and choreographer Kurt Dreyer. To all of them, I express my deepest gratitude and the certainty of excellent musical realisations.

Finally, for all their institutional support, commitment to the project, and innumerable signs of friendship, I am profoundly grateful to all staff members of the Orpheus Institute, especially to Heike Vermeire, the office manager and production manager, who enormously contributed to the timeliness and perfect shape of our publications; to Kathleen Snyers, the project manager of MusicExperiment21, for her high professionalism and impeccable overview of the innumerable documents and activities of the project; and to Peter Dejans, the director of the institute, a believer in the cause of artistic research, and a brilliant facilitator, for enabling this and many other projects to happen and to productively unravel the processes of making music and conducting research.

In terms of the editing process leading to this book, I am deeply indebted to Lucia D'Errico and Michael Schwab for their insightful comments, to Lydia Goehr, David Davies, and jan jagodzinski for their topic specific remarks, and to Edward Crooks for his sophisticated, precise and meticulous, yet highly creative copy-editing.

On a private level, I am profoundly grateful to Elisabeth and Rafael, for all the reasons they know. 
I would like to thank the following journals and publishers for permission to use parts of previously published material:

"Beyond Urtext: A Dynamic Conception of Musical Editing," in Dynamics of Constraints: Essays on Notation, Editing and Performance, ed. Paulo de Assis (Leuven: Leuven University Press, 2009), 7-18.

"The Conditions of Creation and the Haecceity of Music Material: Philosophical-Aesthetic Convergences between Helmut Lachenmann and Gilles Deleuze," in "Deleuze et la Musique," special issue, Filigrane 13 (2011), 63-86.

"Epistemic Complexity and Experimental Systems in Music Performance," in Experimental Systems: Future Knowledge in Artistic Research, ed. Michael Schwab (Leuven: Leuven University Press, 2013), 151-65.

"GilbertSimondon's ‘Transduction' as Radical Immanence in Performance," Performance Philosophy 3, no. 2 (2017), 1-21; also published in German as "Gilbert Simondons 'Transduktion' als radikale Immanenz der Performanz," Performance Philosophy 3, no. 3 (2017), 1-25.

"Rasch"2: The Somatheme," in Artistic Research in Music: Discipline and Resistance; Artists and Researchers at the Orpheus Institute, ed. Jonathan Impett (Leuven: Leuven University Press, 2017), 15-42.

"Transduction and Ensembles of Transducers: Relaying Flows of Intensities in Performance", in Transpositions: Aesthetico-Epistemic Operators in Artistic Research, ed. Michael Schwab (Leuven: Leuven University Press, 2018), $245^{-66 .}$

"Virtual Works-Actual Things," in Virtual Works-Actual Things: Essays in Music Ontology, ed. Paulo de Assis (Leuven: Leuven University Press, 2018), 19-43. 
A

Abbate, Carolyn, 13, 16

abstract machine, 72, 77, 80, 82-85, 95, 97-99, 100, 101 actor-network theory, 75

actual, 15, 23, 24, 26, 32, 52, 53-57, 59, 61-64, 65, 67,

71-72, 97, 98, 108, 109, 138, 139, 141, 142, 147, 149,

$151,153,155,166,203,206-7,208,209,232$

actuality, 54, 60, 204-5

actualisation, 29, 30, 32, 53-58, 60-61, 63-65, 67, 78,

$97,126,137,138,140,141-44,147,149,152,208$,

211, 237

Adorno, Theodor W., 202, 218, 224, 226, 228, 242

Agamben, Giorgio, 203, 204-7, 210-12

agencement, 27, 73-81, 96, 97, 99, 208

allagmatics, 27

Alliez, Éric, 76, 101

Althusser, Louis, 78

Arbo, Alessandro, 46n11, 47n13, 68

arborescent, 33, 93

archaeology, 86, 90n11, 110, 111, 119, 130-32, 211

Aristotle, 49-51, 55, 56-57, 151

Aristotelianism, 49-52, 56-59, 140

arkhe, 204, 210, 211

Artaud, Antonin, 23, 24, 25, 35, 165, 232, 233

artificial intelligence, 125

artistic research, 12-13, 14-16, 21, 22, 23, 27, 28, 41, 44,

$45,53,68,75,100,107,108,109,111-13,115^{-17}$,

$119,127 \mathrm{n} 3,129,13 \mathrm{O}, 132,159 \mathrm{n}^{*}, 183-84,2 \mathrm{O} 3,21 \mathrm{O}$,

211-12, 241

assemblage, $15,19,20,25^{-26,27,29,52, ~ 63, ~ 67, ~ 71-86, ~}$

92, 94, 96-101, 107, 110, 126, 128, 130, 138, 140, 147,

$150,153,155,195,196-97,199,207,241$

assemblage theory, $73-75,77,99$

collective assemblage of enunciation, $77,82,85,96$ machinic assemblage, $77,82,83,85,96,110$ aternal, 32, 203, 209

Atkinson, Charles M., 164, 184

authenticity, 26, 66, 71, 167, 191, 219

\section{B}

Bach, Johann Sebastian, 42, $2 \mathrm{O} 2$

Bachelard, Gaston, 115, 219

Bacon, Francis, 23, 25, 230

Badiou, Alain, 55n24, 68, 203, 212

Barnard, Suzanne, 182, 184

Barthélémy, Jean-Hughes, 27n4, 35, 144, 145, 156

Barthes, Roland, 30, 32, 35, 41-42, 66, 68, 78, 119, 121, $15^{2}, 156,159^{-64}, 166-84,199,203,204-5,210$, 211, 212

Baugh, Bruce, 25, 35

Baumgarten, Alexander Gottlieb, 161

Beaufils, Marcel, 42n3, 68

becomology, 27

Beethoven, Ludwig van, 42, 43n7, 64, 66, 116, 119, 161,221

being, $27,32,5 \mathrm{O}, 52,53,55^{\mathrm{n} 24}, 64,72,10 \mathrm{O}, 129,14 \mathrm{O}$, $143-44,145,147-49,152,153-54,168,175,205$, 208, 209, 211, 223, 229, 239

Beistegui, Miguel de, 49-5o, 68, 144, 145, 156

Bene, Carmelo, 199

Benjamin, Walter, 210, 223, 224, 226, 228, 242

Benveniste, Émile, 159, 164, 167, 184

Berg, Alban, 202

Bergson, Henri, 24, 53, 54n23, 141n3
Berio, Luciano, $2 \mathrm{O} 2$

biology, 28, 47n12, 58, 89, 113, 116, 121, 124, 129, 140

body without organs, 24, 230, 232-33, 237

Boden, Margaret A., 124n1, 133

Bogue, Ronald, 76, 101

Böhler, Arno, 153n12, 156

Borgdorff, Henk, 108, 109n2, 121, 127n3, 133

Borum, Peter, 145, 154, 156

Bouaniche, Arnaud, 24, 35, 236n8, 242

Boucourechliev, André, $2 \mathrm{O} 2$

Boulez, Pierre, $2 \mathrm{O} 2$

Boundas, Constantin V., 29, 35, 52, 53, 55, 56n27, 59, 68

Bourdieu, Pierre, 235, 236

Bowden, Sean, 146, 156

Breazeale, Daniel, 205, 206, 212

Brett, Philip, 220, 224

Buchanan, Ian, 71n*, 73, 75, 76, 77, 79, 80, 89, 96, 101

Buleu, François-René, 166, 184

Burroughs, William S., 191, 199

Butt, John, 47, 48, 68

C

Cage, John, 202

calculus, 150

Callon, Michel, 75

Cameron, Ross P., 47

Caplan, Ben, 47

Carroll, Lewis, 23, 25

Cavell, Stanley, 47

chaos, 73, 96, 131, 154, 196, 207, 232, 235-36, 239, 240 Chomsky, Noam

Chomskyanism, 93

chora, 160, 167, 176

classical paradigm, the, $25 \mathrm{n}_{3}, 26,35,44,66,71$

Clisby, Dale, 55, 68

coding, 33, 74, 82, 83, 85, 86, 87, 88, 91, 94, 98, 100, 167 cognitive biology, 124

collective assemblage of enunciation, 77, 82, 85, 96 complexity, 19, 27, 28, 48, 68, 73, 107, 120-21, 123-32, $137,181 \mathrm{n} 14,197$

computer science, 28, 121, 125

Conan Doyle, Arthur, 87

condensation, 77, 86, 92, 229

connective synthesis, 80

contemporaneous, 32,203

contemporary, $15,32,112,116,128,132,161,201-7$,

210-12, 223, 232, 233

content, 62, 63, 71, 76, 81-84, 86, 87, 92-98, 100, 107,

$125,163,178,191,198,205$

continuants, 47n12, 51n19, 52, 64

Cook, Nicholas, 13,16

corporeality, 23, 24, 137, 141, 152, 160, 161, 164, 167-68,

$173,179,236,237,238,240$

Cross, Richard, 148 n9, 156

Cull, Laura, $71 \mathrm{n}^{*}$

Cutrofello, Andrew, 179n12, 184

$\mathrm{D}$

Dahlhaus, Carl, 202

Danuser, Hermann, 129n4, 133, 190, 199

dark precursor, 22, 53n22

Darwin, Charles, $5^{8}$

Dasgupta, Subrata, 123, 125-27, 130, 133 
Daverio, John, 168, 184

Davies, David, 25n3, 26, 35, 41n*, 42, 43n7, 44, 45n1o, $47 \mathrm{nn} 13-15,48 \mathrm{n} 16,51 \mathrm{n} 18,68$

Davies, Stephen, 47

De Boever, Arne, 145, 156, 157

Debussy, Claude, 201, $2 \mathrm{O} 2$

deduction, 150

DeLanda, Manuel, 29n $5,35,51,55 \mathrm{n} 24,56-57,58,59$, $61,68,73,74,75,76,82,86,89,101,15$ on1o, 151, 156

Deleuze, Gilles, 12, 14-15, 16, 22, 23-25, 26, 29-30, $31,32,34,35,36,41,46,49^{-} 5^{\circ}, 5^{2-}-57,59^{-62}, 65$ 69, 73-89, 91-100, 101-2, 110, 120, 121, 137, 141, $144,148-5$ O, 151-52, 153, 155, 156, 179n11, 18on13, 191-92, 199, 203, 207-9, 212, 225-27, 228, 229, $230-33,235^{-41,242}$

Deleuzianism, 35, 46, 50, 52, 56n27, 57, 59, 62, 67

$74,75,110,138,143 \mathrm{n} 6,144,147,149,208,226$ 227, 231, 236

post-Deleuzianism, 12, 14, 46, 72

Deleuze, Gilles, and Félix Guattari

Anti-Oedipus, 22, 73, 79-81, 92, 93, 94, 179n11, 232, 233

See also Guattari, Félix

Denkkollektiv, 115

D'Errico, Lucia, 2on1, 36, 41n1, 120, 121, 137n*, 156, 183,184

Derrida, Jacques, 53, 113, $178 \mathrm{n} 10$

Descartes, René

Cartesianism, 15 on10, 15

desire, 22, 29, 30, 32, 79-80, 81, 84, 93, 99, 125, 131, $152,153,159,160,162,163,167 \mathrm{n}_{3}, 169,174,175$, $176,177-78,18 \mathrm{o}-82,183,233$

deterritorialisation, $81,82,83,85,86,88,91-92$, $98-101,163,176,183,233,236,237$

diagram, $15,19,25,27,54,56,60,61,62,64,67,72,73$

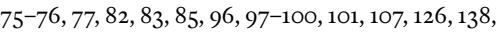
$151,179,181,195,196$

Diderot, Denis, 164

differential geometry, 59

differential repetition, $28,34,67,111,113,114,117,118$, 119,132

disjunctive synthesis, 73,80

dispositif, 81, 97n17

DNA, 57, 58, 145, 147, 154

Dodd, Julian, 44, 47, 51, 52n2o, 65, 69

Domaine Musical, $2 \mathrm{O} 2$

Dorschel, Andreas, 41n*, 44n9, 45n10

Dosse, François, 93, 102, 179n11, 185

double articulation, 87-89, 95, 96, 165

dramatisation, 147, 148, 166, 208

Dreyfus, Laurence, 31, 36, 190, 200

Dufay, Guillaume, 202

Duhem, Pierre, 238, 242

Dukas, Paul, $2 \mathrm{O} 2$

Duns Scotus, John, 148, 157, 232

\section{E}

Eckel, Gerhard, $137 \mathrm{n}^{*}$

Eliade, Mircea, 89, 102

eliminativism, 47n13, 49

emancipation, 31, 197-99

embryogenesis, 139, 141

embryology, $57,5^{8}$ endurantism, 47n13

entropy, $143-46,196$

epistemic complexity, 19, 27, 28, 107, 121, 123-32

epistemic principle, 124,130

epistemic things, 28, 100, 108, 109n2, 113, 114-15, 117,

$118,129,131$

epistemology, 11, 12-13, 15, 27, 28, 33, 61, 72, 78, 107-8, $112,117,119,124,127,219$

Erewhon, 138, 225, 239, 241

essence, 47, 51, 57, 59, 78, 99, 100, 147, 168, 191, 218, 230, 231

ethics, 20, 30, 31, 33, 61, 238, 241

Euclid

Euclidian geometry, 57, 151

European Research Council, 11

executants, 20, 30, 192

execution, $19,31,48,161,189$

experimental, 14, 20, 21, 22, 28, 33, 34, 66, 67, 68, 108,

$111,113,114,116,117,118,119,123,126,129,139$,

197, 204

experimental culture, 117

experimental music, 2O, 21

experimental performance practices, $20,26,31,66$ $118,119,183$

experimental systems, $15,22,28,108-9,111-18$, $120,123,126,129-32$

experimental thought, 12, 14, 21, 24

experimentation, $11,14,15,16,20-25,31,34,79,109$,

112-13, 117-18, 127, 129-30, 132, 153, 180n13.

198-99, 233

expression, $25,29,34,52,63,76,81-87,89,92-98$, $100,127,139,141,142,152,153 \mathrm{n} 12,163,166,175$, 178n1o, 18o, 191, 194, 211, 212, 232, 234, 236, 238 extended performance practices, 13

\section{$\mathrm{F}$}

Feder, Georg, 219, 220, 224

Fellerer, Karl Gustav, 220, 224

Ferneyhough, Brian, 202, 231

fictionalism, 47n13, 48, 49

Fink, Bruce, 16o, 184, 185

Fleck, Ludwik, 115

fluctuatio animi, $153^{-} 54$

Foss, Paul, 76

Foucault, Michel, 22, 32, 36, 53, 73, 76, 78, 81, 84, 85 , $97,102,130-31,133,191-92,193,200,203,207$, 209-11, 212-13

Freitas, Marlene Monteiro, $41 \mathrm{n} 1$

Freud, Sigmund, 22, 77, 164, 168, 176

Freudianism, 76-77, 79, 80, 92n13, 18on13, 181n14 233

function, $13,15,22,26,27,28,29,32,35,42,43 \mathrm{n} 8,47$, $64,65,71,76,78,80,82,84,85,87,89,91-100$, $108,115,116,117,120,127,128,130,146,147,149$, $150,151,155,160,164,166,169,177,182,184,192$, 194-95, 197, 198, 202, 203, 208, 211, 226, 227, $230-31,233,235,237,238,240$

functives, 94, 239

\section{G}

Gallope, Michael, 62, 69

Garelli, Jacques, 27n4, 140, 146, 150, 157

Gauss, Carl Friedrich, 58, 59, 150 n10 genosong, 164 


\section{Index}

genotext, 160, 164-66, 176, 180

geology, 27, 74, 87, 89, 93, 95, 148

Gestalttheorie, 143

Giacché, Piergiorgio, 199, 200

Gieryn, Thomas F., 127n3, 133

Gilmore, Bob, 2on2, 36

Goehr, Lydia, 13, 16, 25n3, 26, 36, 41n*, 44, 45, 47-48, $62,69,127,128,133$

Goffey, Andrew, 76, 101

Goodman, Nelson, 47

Grier, James, 218-23, 224

Griesemer, James, 126, 127n3, 128, 134

group theory, 59

Guattari, Félix, 14, 15, 16, 22, 24, 34, 36, 52, 53, 59, 65

69, 73-77, 79-89, 91-100, 101-2, 110, 121, 148-50,

$151,155,156,162-63,179$ n $11,18 \mathrm{on}_{13}, 184,185,203$,

207, 208-9, 212, 230-33, 235-41, 242

Gülke, Peter, 218, 224

\section{$\mathrm{H}$}

Hacking, Ian, 15, 16, 72n1, 102, 107, 121

haecceity, 15, 32, 137, 141, 148-50, 203, 207-8, 226, $238,239,241$

eccéité, 148,232

haecceitas, 148

micro-haecceity, 15, 137, 141, 148, 149, 203, 208

Hallward, Peter, 55n24, 69

Hasty, Christopher, 44n8, 6o, 69

Hatten, Robert S., 168, 185

Haydn, Joseph, 66n34, 203

Hegel, Georg Wilhelm Friedrich, 151

Henle, Günter, 219, 224

Hindrichs, Gunnar, 41n*, 44n9, 45n10, 50n17, 69, 201n1, 213

historicity, 26, 47, 48n16, 85, 193, 205, 211, 223

Hjelmslev, Louis, 73, 76, 81, 92-96, 102, 178n10

Hobsbawm, Eric, 195, 200

Hoffmeyer, Jesper, 124n2, 133

Horowitz, Vladimir, 42

Hughes, Joe, 56n26, 69

Hume, David, 24

Hüppe, Eberhard, 229, 242

Husserl, Edmund, 124

\section{I}

identity, 22, 32, 47-51, 52, 57-58, 59, 63-64, 72, 8on6, $84,86,99,131,148 \mathrm{ng}, 151,194,196,203,210,219$, 232,235

image of work, 26, 27, 43-44, 46, 52, 62, 64, 66-67. 71-72, 99, 100, 107, 109, 126, 139, 168, 189-90, 195-97, 199

imago, 168

individuation, $30,54,55^{-56}, 57,61,63-64,71-72,73$, $78-79,85,95,137,139-41,144-55,208,233$

induction, 150

information theory, $137,145,146$

inscription, $11,35,51,79,86,111,113,114,115,119,150$, 161,167

intensity, $12,25,27,29,53,54^{-} 56,58,59,80,98,141$, $154,167,232,234,238,239$

interpretation, 11, 14, 19-21, 23-24, 26, 31, 34, 36, $42,48,59 \mathrm{n} 28,66,71,79,93 \mathrm{n} 14,95,111,119,12 \mathrm{O}$, $128-31,153,166,167,170,184,189-91,195,198-99$, 201n1, 218-19, 222, 230, 241 interpreters, 2O, 30-31, 73, 195, 211 Ismaili m'Hamdi, Hafez, 189 n $^{*}$

$\mathrm{I}$

Jacob, François, 108, 121, 127

Jakobson, Roman, 78, 92, 93n14, 159

jouissance, 160, 162, 165, 167, 169, 175-76, 178, 181-82 Jung, Carl Gustav, 168n4

K

Kafka, Franz, 73, 74, 77, 79, 82, 84, 98, 236

Kagel, Mauricio, 202

Kania, Andrew, 44, 47, 69

Kant, Immanuel, 24, 6on31, 151

Kantianism, 6on 31,161

Kéchickian, Anita, 142n 5

Kivy, Peter, 46n11, 47, 48n16, 62

Klee, Paul, 211, 213, 223

Kline, Morris, 15on10, 157

Knorr Cetina, Karin, 129, 133

Kováč, Ladislav, 123-25, 126, 127, 130, 133

Kramer, Lawrence, 127, 128, 133

Krenek, Ernst, 202

Kristeva, Julia, 159, 160, 162, 164-67, 169, 176, 183, 185

Krtolica, Igor, 76, 96, 102

Kubler, George, 16, 109, 121, 127, 130, 133

Kuhn, Hans, 124, 133

Kuhn, Thomas

Kuhnianism, 15, 107, 112

$\mathrm{L}$

Lacan, Jacques, 30, 77, 78, 92, 102, 160, 162, 164 $175^{-79}, 180$ n $13_{3}, 181-84,185$

Lacanianism, 23, 79, 80, 160, 169, 176, 179, 210

Lachenmann, Helmut, 35, 202, 225-41, 243

Lang, Bernhard, 231

Laplanche, Jean, 168n4, 185

Lapoujade, David, 79n2, 102

larval selves, 22, 79

Latour, Bruno, 15, 16, 75, 107, 121

Lautréamont, Comte de (Isidore Lucien Ducasse), 165

Laviosa Zambotti, Pia, 65n33, 69, 73, 76, 89-91, 103

Lebenswelt, 124

Lawrence, D. H., 235, 243

Levinson, Jerrold, 43n7, 46, 47, 48n16, 51, 69

Lévi-Strauss, Claude, 78, 159, 178n10, 179 n11

linguistics, 27, 59, 60, 78, 89, 92-94, 160, 162-63, 165, $178 \mathrm{n} 1 \mathrm{o}, 179-8 \mathrm{o}, 183$

llanguage, 175

Ligeti, György, 66n34

Lorca, Federico García, 149, 157, 208, 213

Lukács, Georg, 226, 228, 243

Lyotard, Jean-François, 202, 213

M

Machaut, Guillaume de, 202

machinic assemblage, $77,82,83,85,96,110$

Mader, Mary Beth, 59n28, 69

Maderna, Bruno, 116, 245

Magnus, P. D., $52 \mathrm{n} 2 \mathrm{O}, 69$

Mag Uidhir, Christy, 46, 47n13, 69

Mahler, Gustav, 98

Maïmon, Salomon, 6on31 
mainstream (performance practice), 20, 26, 42, 167, 190, 195

Mallarmé, Stéphane, 165, 183

Mandelstam, Osip, 204

Marcuse, Herbert, 226, 227, 228, 229, 230, 243

Martianus Minneus Felix Capella, 164

Massumi, Brian, 76, 80, 103, 137, 141, 142, 145, 152m, 157

Matheson, Carl, 47

Mauceri, Frank X., 21, 36

ME21 Collective, 41n1, 43

McGann, Jerome, 222, 224

Message, Kylie, 86, 103, 233, 243

Messiaen, Olivier, 202

metastability, 56, 87, 88, 89, 99, 100, 138, 140, 143-47 149, 150, 152, 154, 198, 208

Metzger, Heinz-Klaus, 202

Michaud, Yves, 140, 157

Milner, Jean-Claude, $178 \mathrm{n} 1 \mathrm{o}, 185$

modulation, $24,56,97,137 \mathrm{n}^{\star}, 139,140,144,152,153$,

$164,174,211,231$

Mosch, Ulrich, 46n11, 227, 228, 243

Moscheles, Ignaz, 42, 66

multiplicity, 22, 25, 31, 32, 53, 57, 59-60, 61-62, 64-67 $73,74,78,79,81,83,100,101,107,109,140,15$, $151,196,198,208,211$

MusicExperiment21, 11-16, 28, 33, 41, 43, 45, 108-10, $112-13,116-20,183$

MusicExperimentX, 11

Murray, Alex, 145, 156, 157

\section{$\mathrm{N}$}

Nail, Thomas, 73, 74, 75, 76, 103

Nancy, Jean-Luc, 203, 205, 213

Nat, Yves, 42, 98, 170

Nietzsche, Friedrich, 15, 17, 24, 31-32, 36, 52, 112, 116 , 153, 191, 193-94, 200, 203, 204-9, 213, 231, 245 nominalism, 47n13, 48, 6o, 61

Nono, Luigi, 116, 202, 226, 229

Noudelmann, François, 16o, 161, 162, 185

\section{$\mathrm{O}$}

O'Farrell, Clare, 130, 133

Ó Maoilearca, John, 71n*

ontogenesis, 64, 72, 139, 154

ontogenetics, 24, 27, 57, 107

ontology, 13, 20, 25-27, 33, 43-64, 66-67, 72, 82, 100,

$107,114,116,127,129,139,147,191,196$

operator, 20, 27, 30-32, 79, 153, 189, 199, 231, 245

Oresme, Nicholas, 238

Orpheus Institute, 11, 12, 15, 16, 34, 411*, 44n9, 71n*, $108 \mathrm{n} 1,112 \mathrm{n} 4,117,201 \mathrm{n}^{\star}, 229,24 \mathrm{On} 11$ overdetermination, $93,129,163,168,169,178,179$

$\mathrm{P}$

paleo-anthropology, 27, 89, 95

Panzéra, Charles, 162

Parnet, Claire, 14, 16, 22, 36, 74, 78, 80, 102, 148, 156, 212

Parra Cancino, Juan, 41n

Patton, Paul, 76

Paul, Saint, 210, 211

Pauline time, 204
Péguy, Charles, 32, 203, 207, 209

perdurantism, 47n13

performance studies, 12, 21, 115

phenomenology, 27, 50, 78, 84, 100, 115, 161-62, 167, $169,176,183$

phenosong, 164, 166, 167

phenotext, 16o, 164-66, 176, 180

Phillips, John, 76, 103

Pierce, Charles Sanders, 162

Pirrò, David, $137 \mathrm{n}^{*}$

Plato, 49-50, 54n23, 55, 209

Platonism, 24, 47n13, 48-52, 54, 57, 6o, 61-62, 63, $64,67,197$

Plotnitsky, Arkady, 56n27, 57-58, 69, 151, 157

Pontalis, Jean-Bertrand, $168 \mathrm{n} 4,185$

post-interpretation, 19

Pousseur, Henri, $2 \mathrm{O} 2$

problematisation, 19-20, 30, 32, 43, 56, 61, 63, 109-11, 130-32, 196, 205, 209

Protevi, John, 55n24, 69

Proust, Marcel, 24

Q

quidditas, 148n9

$\mathrm{R}$

Rancière, Jacques, 31, 36, 191, 197-98, 200

Ranger, Terence, 195, 200

Ravel, Maurice, 201

recitation, 19,189

rendering, $13,19,24,42,43,44,65,68,139,142,153$, 16o, 189, 190, 197, 217, 221

repetition, $28,34,67,111,113,114,117-19,129,132$, 165,180

representation, $11,19-21,28,31,43^{-4} 44 \mathrm{n} 8,4^{8-}{ }^{-} \mathrm{O}, 5^{2}$, 78,8 o, 97, 99n18, 109, 112-14, 118, 131, 159n * ${ }^{*} 166$, 168n4, 176, 179, 180, 182, 195, 209, 221 reproduction, 19, 66, 114, 189, 190, 199, 228 Read, Herbert, 211, 213

Research Catalogue, 11, 41n2, 107n ${ }^{\star}, 116,118$ Rheinberger, Hans-Jörg, 12, 14n1, 15-16, 17, 28, 36, $107-9,111-18,121,123,126,127,129-32,133$

rhizomatic, 33

rhizome, $33,79,81,101$

Rhode, Erwin, 206

Riemann, Bernhard, 58-60 Riemannianism, 137, 151

Rihm, Wolfgang, 229

Rink, John, 41n*, 44n9, 45n1o

Roffe, Jon, 55n24, 69, 145, 156, 157

Rohrbaugh, Guy, 46, 47, 51-52, 64-65, 69

Rodin, Auguste, 239

Rosen, Charles, 43

Rostagno, Antonio, 42, 69

Roudiez, Leon S., 165, 166, 175-76, 185

Ruta, Marcello, 41n*, 46n11, 47n13, 68

Ruwet, Nicolas, 159

Rycroft, Charles, 168nn4-5, 185

\section{S}

Sacher-Masoch, Leopold von, 24

Saint-Hilaire, Geoffroy, $5^{8}$ 
Saussure, Ferdinand de, 92-93, 164, 169 post-Saussureanism, 81 Saussureanism, 80, 81, 92-94, 167

Sauvagnargues, Anne, 24, 36, 53, 56, 69, 71, 76, 79n2, 8 on $6,81,99,103,139,140,148,153,155,157$, 227n3, 231, 232, 238, 243-44

Savat, David, $71 \mathrm{n}^{*}$

Schaffer, Simon, 15, 17, 107, 122

schizoanalysis, 22, 24

Schoenberg, Arnold, 66n34, 116, 202

Schumann, Clara, 42

Schumann, Robert, 30, 41-43, 66-67, 98, 116, 119, 120, $138,149,159-62,167,168,170-74,180,182,193$

Schwab, Michael, 15, 17, 108n1, 112, 117-18, 119, 121, 122, $127 \mathrm{n}_{3}, 137 \mathrm{n}^{*}, 206$

Schwarte, Ludger, 132, 134

science and technology studies, 28

Scott, David, 144, 157

Scriabin, Alexander, 202

semiology, 30, 78, 93, 153, 159-60, 162-64, 166, 167, $168,179,181,183$

semiotics, 30, 83, 89n1o, 93, 94-95, 111, 124n2, 127, 159 $160,162-67,169,181,183,223,230,241$

sensation, 16, 23-25, 62, 74, 152, 155, 160, 231, 236-39, 241

sense, 22, 23-25, 31, 32, 74, 79, 132, 142, 152, 161, 198, 211, 224

Shannon, Claude E., 145

Shapin, Steven, 15, 17, 107, 122

signification, 163, 166, 169, 178n9, 181, 198, 205 signified, 44n8, 93-94, 98, 163, 167, 168 signifier, 81, 92-94, 98, 114, 162, 163, 166, 167 $175-76,178-83$ signifying, 159-6o, 162-63, 165-69, 175, 178n9, $179,180,182$

Simon, Herbert, 125, 134

Simondon, Gilbert, 14, 27, 30, 36, 132, 137, 139-48, 150, $151,153-55,157,232$

simulacrum, 49

singularities, 27, 53, 55-67, 84, 86, 96, 109, 110, 113, $128,138,140,146-47,149,151-52,155,208,212$

somatheme, $15,30,159-60,163,166,168-69,175^{-76}$, $178-83$

Somers-Hall, Henry, 15, 17, 56, 70

Sondag, Gérard, 148,157

space of graphematicity, 28,109

space of representation, 28, 113, 114, 118

Sontag, Susan, 165,185

Soveral, Madalena, $189 n^{*}$

Spinoza, Benedict de [Baruch Spinoza], 25, 29-30, 36, $153^{-}-54,157,231,232,237,238$ split ego, 22

Star, Susan Leigh, 126, 127n3, 128, 134

Starobinski, Jean, 167n2, 169, 185

Steinecke, Wolfgang, 202

Steinegger, Catherine, 202, 213

Stephan, Rudolf, $2 \mathrm{O} 2$

Stiegler, Bernard, 154, 157

Stockhausen, Karlheinz, 116, 202, 226

strata, $15,19,25,27,29,32,62,65-67,72-73,75$,

$76-77,82,83,85^{-93}, 95,97^{-101,107,109,118,126,}$ 196,208

allostrata, 66, 109, 196

epistrata, 65, 66, 89-92, 109, 196

interstrata, 65, 109 metastrata, 65, 66, 91, 109, 196

parastrata, 65, 89-92, 109, 196

substrata, 65, 89-92, 109, 196

stratification, 65, 81, 85, 87, 9on11, 93, 95-96, 101, 109, 140, 155, 196, 203, 210, 211

Stravinsky, Igor, 202

structural germ, 144, 146, 149-47, 149-51, 153-54 structuralism, 27, 73, 77-79, 84, 85, 92, 93, 96, 98, 176 structure, 12, 19, 21, 22, 25, 27, 30, 31, 43, 44n8, 47, $48,51,54,57,58,60-62,64,65$ n $33,67,72,73,76$, $77-81,84,87,92,93,94,95,96,97 \mathrm{n} 17,98,99^{-100}$ $116,119,139-40,143,146,147,148,150,151,159$, $160,163,164,165,166,167,176,177,179,180$ n $13^{3}$, 181, 190, 197-98, 202, 204, 206, 208, 217, 219, 226, 227, 230, 232-34, 237, 238, 240-41

substance, 53, 59, 60, 87-88, 91-96, 143, 146, 153, 227 symptomatology, 32, 203, 211, 231, 232 symptoms, 31, 168n $5,180,231$

$\mathrm{T}$

Tarasti, Eero, 164, 185

Taruskin, Richard, 13, 17, 66, 70

technical objects, 14, 28, 71, 108, 113-15, 118, 129, 140, 153,211

territorialisation, $82-83,85-87,91,92,94,98,100-101$, $233,237-38$

textual fidelity, 26

themodynamics, $55 \mathrm{n} 24,137,143,144,145,146,149$

things, $13,22,23,25,26,28,29,43,44,47,48 \mathrm{n} 16,49$, $51,52,53,55^{-57}, 59,61,63-65,67,72,76-78,83$, $84,86,96,98,100,107^{-11}, 113^{-15}, 117,118,123$, $125^{-32}, 140,143,148,149,151,153,184,194-99$,

204, 206, 208, 209, 210, 211, 223, 227, 234, 235, 241 thought collective, $28,115^{-16}$

Tillman, Chris, 47

Todorov, Tzvetan, 159

tokens, $48,51,57,126,128,130$ topological singularities, $60-64,138,155$

topology, 57, 58, 137, 149, 151, 179

Toscano, Alberto, 54, 70, 147, 157

transcendental empiricism, 63,241

transduction, $15,30,53,54,56,59,61,62,63,100,132$, $137-43,146-47,149-55,208$

transmission, 19, 21, 50, 64, 86, 107, 110, 132, 138, 139,

$142,150,179,189,193,195,217,221,222$

transtextuality, 111

truth, 24, 61, 71, 191, 206, 239

\section{$\mathrm{U}$}

Uexküll, Jakob von, 124n2, 134

Umwelt, 124

universal singularities, $53,55,57-58,60-62,151$

untimely, the, 32, 112, 204-9

Unverricht, Hubert, 219, 224

urtext, 71, 191, 193, 218-22

$\mathrm{V}$

Varèse, Edgard, 202

Vellodi, Kamini, $71 \mathrm{n}^{*}$

Venn, Couze, 73, 76, 78, 103

Verhaeghe, Paul, 175, 182, 185

Vicentino, Nicola, 120 


\section{Index}

virtual, $15,23,24,27,29,52-56,58,59-63,67,71-72$, $97-98,109,118,138,140-44,147,149,152,208$, 229, 232, 237, 241

W

Wagner, Richard, 98, 206

Webern, Anton, 98, 202

Werktreue, 191

Wiener, Norbert, 145

Williams, James, 53, 55, 56n26, 6o, 70

Wise, J. Macgregor, 76, 103

Wollheim, Richard, 47,48

Wolterstorff, Nicholas, 47

Woodward, Ashley, 156
Woolgar, Steve, 15, 16, 107, 12

work concept, 13, 19, 25-26, 44, 45, 47-48, 66, 71, 98-99, 107, 128, 190, 191

Y

Young, Eugene B., 29, 37, 59, 70, 85, 103

Young, James O., 45, 70

Z

Zaw, Susan Khin, 124n1, 133

Zdebik, Jakub, 76, 97, 103

Zischler, Hanns, 113

Zourabichvili, François, 76, 148, 157 

Author

Paulo de Assis

Production manager

Heike Vermeire

Managing editor

Edward Crooks

Series editor

William Brooks

Lay-out

Studio Luc Derycke

Cover design

Lucia D’Errico

Cover image

Gerhard Richter,

Abstract Painting 748-3,

oil on canvas, $112 \times 102 \mathrm{~cm}(1991)$ (c) Gehard Richter Archiv, Dresden.

Typesetting

Friedemann bvba
This project has received funding from the European Union's Seventh Framework Programme for research, technological development and demonstration under ERC grant agreement nr. 313419.
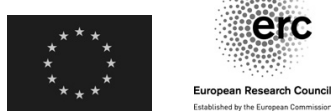

(C) by Paulo de Assis and

Leuven University Press /

Universitaire Pers Leuven /

Presses Universitaires de Louvain.

Minderbroederstraat 4

B-3ooo Leuven (BE)

ISBN 9789562701380

eISBN 9789461662507

$\mathrm{D} / 2018 / 1869 / 36$

NUR: 663

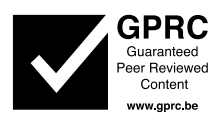

(1) (1) (8)

This book is published in the Orpheus Institute Series

DOI https://doi.org/10.11116/9789461662507 
The Orpheus Institute Series encompasses monographs by fellows and associates of the Orpheus Institute, compilations of lectures and texts from seminars and study days, and edited volumes on topics arising from work at the institute. Research can be presented in digital media as well as printed texts. As a whole, the series is meant to enhance and advance discourse in the field of artistic research in music and to generate future work in this emerging and vital area of study.

\section{RECENT TITLES IN THIS SERIES:}

- Virtual Works-Actual Things: Essays in Music Ontology

Paulo de Assis (ed.)

2018, ISBN 9789462701403

- Transpositions: Aesthetico-Epistemic Operators in Artistic Research

Michael Schwab (ed.)

2018, ISBN 978946270141 o

- Powers of Divergence: An Experimental Approach to Music Performance

Lucia D'Errico

2018, ISBN 9789462701397

- Explosive Compressions, after Bruno Maderna's Hyperion

Juan Parra Cancino

2018, EAN-13.542503540002

- .....sofferte onde serene...

Paulo de Assis

2018, EAN-13.542503540004

- Artistic Research in Music: Discipline and Resistance

Jonathan Impett (ed.)

2017, ISBN 9789462700901

- The Dark Precursor: Deleuze and Artistic Research

Paulo de Assis and Paolo Giudici (eds.)

2017, ISBN 9789462701182

- Experimental Affinities in Music

Paulo de Assis (ed.)

2015, ISBN 9789462700611

O R P H E U S Orpheus Institute

institud $\quad$ Korte Meer 12

B - 9000 Ghent

Belgium

+32 (o) 93304081

www.orpheusinstituut.be 
The Orpheus Institute has been providing postgraduate education for musicians since 1996 and introduced the first doctoral programme for music practitioners in Flanders (2004). Acting as an umbrella institution for Flanders, it is co-governed by the music and dramatic arts departments of all four Flemish colleges, which are strongly involved in its operation.

Throughout the Institute's various activities (seminars, conferences, workshops, and associated events) there is a clear focus on the development of a new research discipline in the arts, one that addresses questions and topics that are at the heart of musical practice, building on the unique expertise and perspectives of musicians and maintaining a constant dialogue with more established research disciplines.

Within this context, the Orpheus Institute launched an international Research Centre in 2007 that acts as a stable constituent within an ever-growing field of enquiry. The Orpheus Research Centre is a place where musical artists can fruitfully conduct individual and collaborative research on issues that are of concern to all involved in artistic practice. Its core mission is the development of a discipline-specific discourse in the field of artistic research in music. 
Logic of Experimentation offers several innovative and groundbreaking perspectives on music performance, music ontology, research methodologies, and ethics of performance. It proposes new modes of thinking and exposing past musical works to contemporary audiences, arguing for a new kind of performer, emancipated from authoritative texts and traditions, whose creativity is propelled by intensive research and inventive imagination. Moving beyond the work concept, this book presents a new image of musical works, based upon the notions of strata, assemblage, and diagram, advancing innovative practice-based methodologies that integrate archival and musicological research into the creative process leading to a performance. This volume appropriates concepts for music performance from post-structural philosophy, psychoanalytical theory, science and technology studies, epistemology, and semiotics, showing how transdisciplinarity is central to artistic research. An indispensable contribution to artistic research in music, Logic of Experimentation is compelling reading for music performers, composers, musicologists, philosophers, and artistic researchers alike.

Paulo de Assis is an experimental performer, pianist, and artistic researcher with transdisciplinary interests in composition, philosophy, psychoanalytical theory, and epistemology. A research fellow at the Orpheus Institute, Ghent, he was the Principal Investigator of the EU project "Experimentation versus Interpretation: Exploring New Paths in Music Performance in the Twenty-first Century," is the Chair of the international conference series Deleuze and Artistic Research (DARE), and is the editor of the book series Artistic Research (Rowman \& Littlefield International).

"This is an outstanding book in every way. It demarcates a new field - that of artistic research as an experimental activity-and then provides an original theoretical framework within which to relate the field to music. All the chapters address issues that transcend music and are of great import for aesthetics, ethics, epistemology, ontology, psychoanalytic theory, and cultural theory."

-Ronald Bogue, University of Georgia, US

"Reading Logic of Experimentation is an intellectual adventure. The reader comes away with a much more flexible and more powerful context for engaging in performance as scholarship, corporeality, and the manifestation of energy."

-Neely Bruce, Wesleyan University, US

O R P H E U S

INSTITUUT 